UNIVERSIDADE DE SÃO PAULO

INSTITUTO DE ASTRONOMIA, GEOFÍSICA E CIÊNCIAS ATMOSFÉRICAS.

MESTRADO PROFISSIONAL EM ENSINO DE ASTRONOMIA

\title{
O SOL: UMA PROPOSTA DE ENSINO
}

\author{
Irineu Gomes Varella
}

São Paulo, Julho de 2017. 
UNIVERSIDADE DE SÃO PAULO

INSTITUTO DE ASTRONOMIA, GEOFÍSICA E CIÊNCIAS ATMOSFÉRICAS.

MESTRADO PROFISSIONAL EM ENSINO DE ASTRONOMIA

\title{
O SOL: UMA PROPOSTA DE ENSINO
}

\author{
Irineu Gomes Varella
}

Orientador: Prof. Dr. Nelson Vani Leister

Dissertação apresentada ao Programa de Mestrado Profissional em Ensino de Astronomia do Instituto de Astronomia, Geofísica e Ciências Atmosféricas da Universidade de São Paulo, como parte dos requisitos para a obtenção do título de Mestre em Ciências.

Versão Corrigida. O original encontra-se disponível na Unidade

São Paulo, Julho de 2017. 
Aos meus pais que sempre me incentivaram a estudar

Irineu Varella (in Memorian)

e Josefina da Conceição Gomes Varella 


\section{Agradecimentos}

Em primeiro lugar, quero agradecer ao Prof. Dr. Nelson Vani Leister pela atenciosa e dedicada orientação, pelo apoio e incentivo e pelas inúmeras discussões que manteve comigo sobre o conteúdo deste trabalho.

Aos professores do programa de Mestrado Profissional em Ensino de Astronomia: Amâncio César Santos Friaça, Claudemir Roque Tossato, Elysandra Figueredo Cypriano, Enos Picazzio, Jorge Ernesto Horvath, José Ademir Sales de Lima, Nelson Vani Leister e Roberto Dell'Aglio Dias Costa, pela dedicação e empenho no desenvolvimento das disciplinas e nas atividades propostas.

Aos meus colegas e amigos do Mestrado Profissional em Ensino de Astronomia pela amizade e solidariedade.

Ao longo dos vários anos que me dediquei ao ensino da Astronomia na Escola Municipal de Astrofísica (EMA), diversas pessoas contribuíram para a minha formação de professor - profissão a qual me dediquei durante toda a minha vida - e que me levou a fazer um mestrado em ensino de Astronomia. Entre elas estão: o Prof. Aristóteles Orsini, com quem trabalhei durante doze anos no Planetário do Ibirapuera e na Escola Municipal de Astrofísica e que me deu a oportunidade de descobrir a carreira docente; o Prof. Acácio Riberi, meu primeiro professor de Astronomia (em 1967) e com quem pude desfrutar de longa amizade e aprendizado; o Prof. Mário Della Nina, a quem devo muito do meu interesse pela Matemática e pela Astronomia Matemática; o Prof. Pedro Serpe, com quem conheci o céu estrelado e os lados cultural e histórico da Astronomia e o Prof. Walter Augusto Sevo que me deu a oportunidade de ministrar minhas primeiras aulas na EMA no curso de Fundamentos de Astrofísica, no primeiro semestre de 1970.

Um agradecimento especial ao meu irmão Paulo Gomes Varella, professor aposentado da EMA, pelo convívio pessoal e profissional, desde quando começamos a observar as estrelas e as constelações nos anos 60 do século passado, até chegarmos ao ensino de Astronomia, produção de material didático, propostas de implantação e 
implementação de cursos destinados ao público em geral e aos professores e na elaboração dos programas levados ao público nas apresentações diárias do Planetário Municipal de São Paulo.

Além de ter convivido com a equipe da Escola Municipal de Astrofísica praticamente todos os dias, pude ainda desfrutar da convivência com o Dr. Alexander Postoiev, do IAG, com quem aprendi a realizar e a reduzir as observações solares efetuadas com o antigo celostato do IAG no período de 1969 a 1972. Também fui seu aprendiz na confecção do Anuário Astronômico do IAG, no período de 1974 até seu lastimável falecimento em 1977.

Não posso deixar de registrar a atenção que recebi inúmeras vezes do Prof. Abrahão de Moraes, que me indicou material para leitura, estudos e pesquisa quando eu, ainda jovem nos finais dos anos 60 do século passado, frequentava a biblioteca do Observatório de São Paulo.

Quero ainda agradecer ao Professor Eder Ricardo Canalle, da Escola Municipal de Astrofísica, pelo acesso aos questionários aplicados aos alunos da EMA sobre o conteúdo dos cursos e a assimilação dos conceitos que tiveram durante as aulas.

Por fim, mas não por último, quero agradecer à Prof ${ }^{\mathrm{a}}$. Melina Bassoli pela paciente e cuidadosa revisão que realizou em todo o texto no tocante à gramática e à ortografia, tanto no português como no inglês. Suas preciosas observações e sugestões melhoraram muito a apresentação. Agradeço também a ela por todo o apoio e incentivo durante estes últimos anos. 


\section{Resumo}

O Sol e a Lua são os astros mais acessíveis à observação quer pelas suas frequentes aparições no céu, quer pelos seus tamanhos aparentes pronunciados. Por essas razões, constituem-se em astros disponíveis ao estudo, atendendo aos cuidados necessários no caso de observações solares.

Apesar disso, pouca ou nenhuma atenção é dada a eles pelos professores dos ensinos fundamental e médio deixando de utilizar observações que podem contribuir muito para o aprendizado e, ainda, despertar o interesse dos alunos pela ciência. Em particular o Sol, permite a exemplificação e a compreensão de diversos fenômenos estudados na física, na biologia, na geografia, na química assim como permite aplicações práticas da matemática - geometria e trigonometria - ministradas em sala de aula.

Escolhemos levar aos professores e aos estudantes universitários um curso sobre astronomia e física solar abordando questões sobre o Sol - algumas pouco discutidas nos livros, mesmo os de Astronomia - com a finalidade de proporcionar material de aprendizado, estudo e discussão de temas da astronomia moderna. Neste curso básico, serão abordados: como se concluiu que o Sol é uma estrela; como foram determinados seus principais parâmetros físicos e astronômicos tais como a sua distância, o seu tamanho, a sua massa, sua temperatura e composição química, e sua estrutura interna; e como o Sol produz energia.

PALAVRAS-CHAVE: Ensino de Astronomia, Astronomia Solar, Física Solar. 


\section{Abstract}

The Moon and the Sun are the easiest celestial bodies to observe because their frequent appearance in the sky and their great apparent size. As a result, they are celestial bodies available to study, attending the essential cares regarding Sun observations.

Nevertheless, teachers from elementary and high schools pay little or no attention to them and miss a great opportunity to use observations that might add a lot to the learning process and also to arouse students' attention to science. The sun, specially, allows to illustrate and to understand several points that students learn in physics, biology, geography, and chemistry, and still can have practical applications in mathematics geometry and trigonometry - taught in the classroom.

We chose to bring to teachers and university students a course about astronomy and solar physics approaching issues of the Sun - some of them very little discussed even in astronomy books - for the purpose of provide learning material about modern astronomy topics. This basic course will develop: how was it concluded that the Sun is a star; how was it determined its main parameters, such as its distance, its size, its mass, its temperature and its chemical composition, and its internal structure; and how does the Sun produce energy.

KEYWORDS: Astronomy Teaching, Solar Astronomy, Solar Physics 


\section{ÍNDICE}

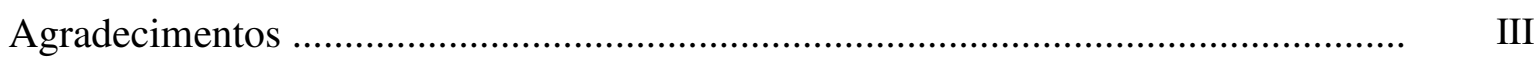

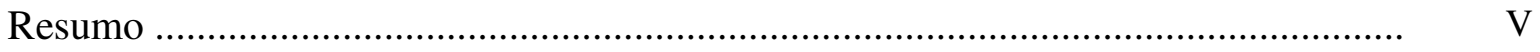

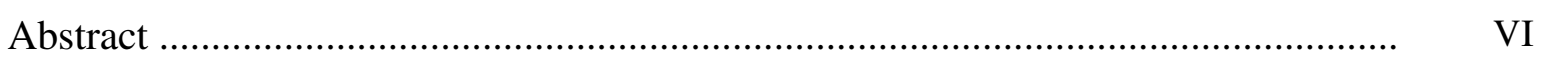

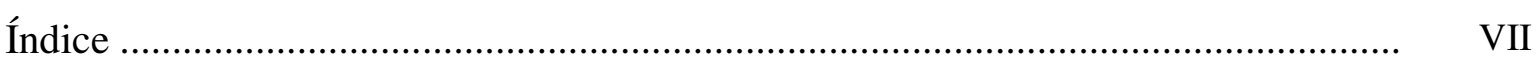

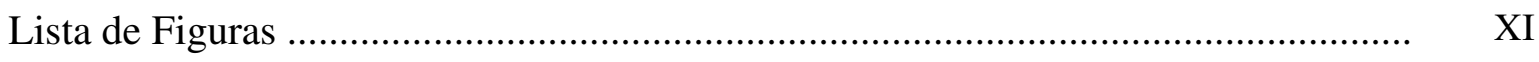

Lista de Tabelas ........................................................................................... XV

Apresentação ......................................................................................... XVI

Sobre o conteúdo desta dissertação .................................................................. XXII

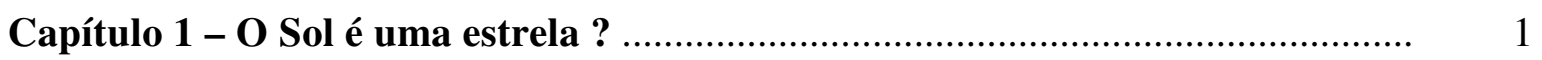

1.1 - Da antiguidade até Copérnico..................................................................... 1

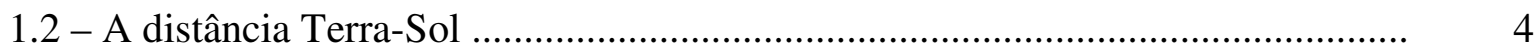

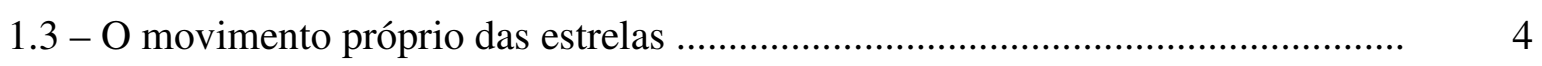

1.4 - As distâncias estelares ............................................................................. 5

1.5 - Medindo a energia emitida pelo Sol e pelas estrelas ...................................... 6

1.6 - Espectros e massas estelares .................................................................... 7

Capítulo 2 - Pequeno Inventário do Sistema Solar .......................................... 8

2.1 - Características gerais do Sistema Solar .......................................................... 9

2.2 - Localização do Sistema Solar na Galáxia ........................................................ 10

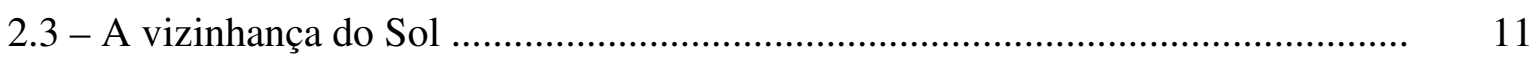

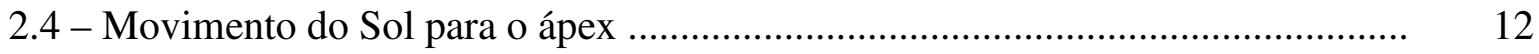

Capítulo 3 - Apresentando o Sol ..................................................................... 14

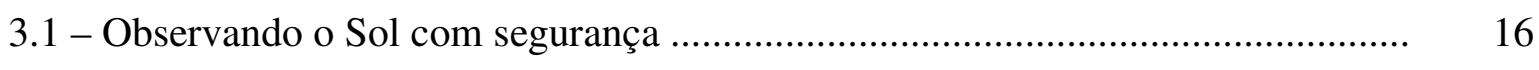

3.2 - Observando o Sol com placas filtrantes (filtros) ........................................... 17 


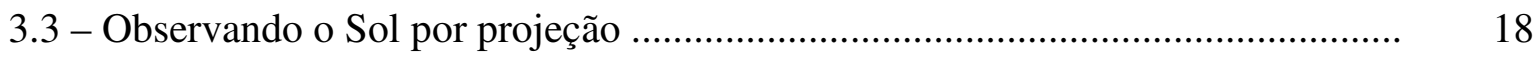

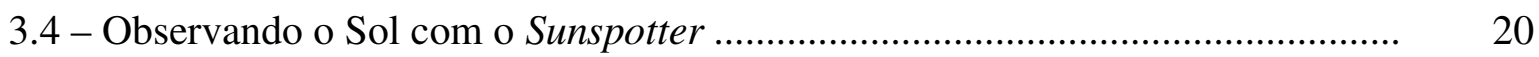

Capítulo 4 - Distância e tamanho do Sol ............................................................. 22

4.1 - Paralaxe para os astros do Sistema Solar............................................................ 22

4.2 - A paralaxe de Marte obtida por Cassini e Richer ........................................... 24

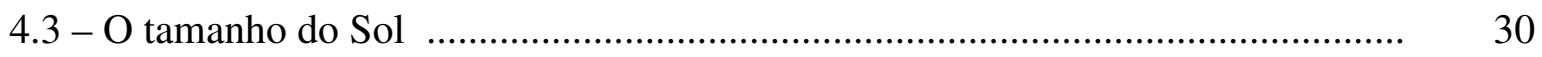

4.4 - As primeiras medidas do diâmetro aparente do Sol ........................................ 31

4.5 - Medidas de precisão do diâmetro aparente do Sol ........................................... 32

4.6 - Medidas do diâmetro aparente do Sol com o heliômetro ................................... 33

4.7 - Medidas do diâmetro aparente do Sol com o astrolábio Danjon ........................ 35

4.8 - Medidas do diâmetro aparente do Sol com o SOHO ........................................ 37

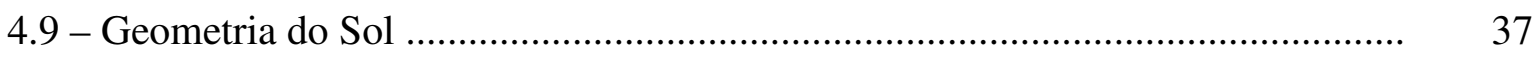

4.10 - Comparando o tamanho do Sol com outras estrelas ...................................... 38

Capítulo 5 - Massa e campo gravitacional do Sol ….......................................... 40

5.1 - Centro de massa do sistema Terra-Sol ......................................................... 41

5.2 - Centro de massa do Sistema Solar ................................................................ 42

5.3 - A extensão do Sistema Solar ............................................................................ 43

5.4 - O campo gravitacional do Sol .............................................................. 45

5.5 - Comparando a massa do Sol com as massas estelares ..................................... 46

Capítulo 6 - Luminosidade e temperatura do Sol .............................................. 47

6.1 - A luminosidade do Sol ............................................................................ 47

6.2 - Fluxo de energia e constante solar ................................................................ 47

6.3 - Determinação de Langley da energia irradiada pelo Sol ................................... 48

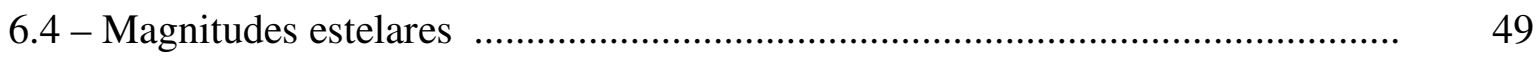

6.5 - Decompondo a luz solar: o espectro do Sol …............................................ 51 
6.6 - A composição química do Sol

6.7 - A temperatura do Sol

Capítulo 7 - A origem da energia solar

7.1 - A Teoria de Mayer

7.2 - A Teoria de Helmholtz

7.3 - Uma mudança de paradigma

7.4 - Origem nuclear da energia solar

7.4.1 - A cadeia P-P II 68

7.4.2 - A cadeia P-P III

Capítulo 8 - A estrutura do Sol

8.1 - A estrutura interna do Sol

8.1.1 - O núcleo solar .

8.1.2 - A zona de radiação

8.1.3 - A tacoclina 76

8.1.4 - A zona de convecção ou zona convectiva 76

8.1.5 - A fotosfera 76

8.1.6 - A atmosfera solar 80

8.1.7 - Sobre as cores das imagens do Sol

Capítulo 9 - A atividade solar.

9.1 - As manchas solares.

9.2 - A rotação solar.

9.3 - Flares

9.4 - Ejeções de massas coronais

$9.5-\mathrm{O}$ vento solar 
9.7 - Avaliando a atividade solar: o índice F10.7 ….............................................. 105

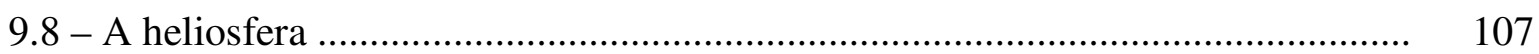

Capítulo 10 - A heliosismologia ................................................................... 112

10.1 - Oscilações estelares ...................................................................................... 112

10.2 - Oscilações solares ........................................................................................... 113

10.3 - Heliosismologia .................................................................................... 114

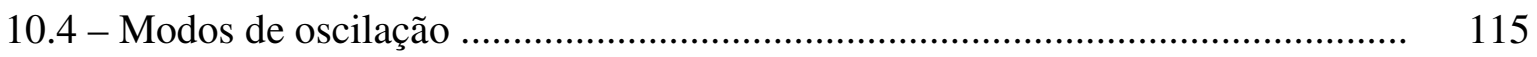

10.5 - Modos de oscilação: como se estudam ...................................................... 117

10.6 - O que nos trouxe a heliosismologia ........................................................... 119

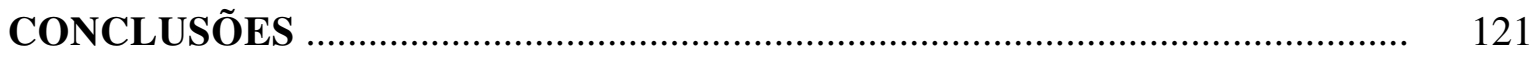

Apêndice 1 - Dados numéricos e abundância de elementos químicos no Sol ............ 122

Apêndice 2 - O teorema do Virial .......................................................................... 124

Apêndice 3 - Centro de massa do Sistema Solar ...................................................... 127

Apêndice 4 - Velocidade de escape .......................................................................... 131

Apêndice 5 - A estrutura interna das estrelas ........................................................ 132

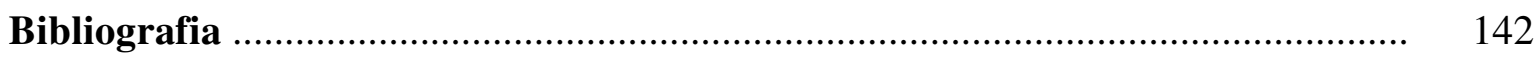

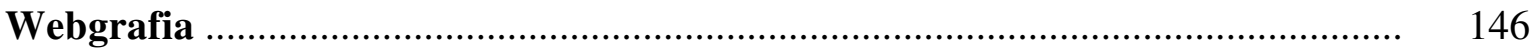




\section{Lista de Figuras e Imagens}

1.1 - Sistema geocêntrico de Ptolomeu ...................................................................... 2

1.2 - Sistema heliocêntrico de Copérnico ..................................................................... 3

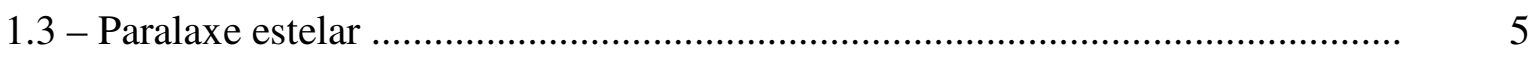

2.1 - Principais componentes do Sistema Solar .................................................... 9

2.2 - Localização do Sistema Solar na Galáxia ........................................................... 11

3.1 - Concentrando a luz do Sol em uma folha de papel ....................................... 14

3.2 - Imagem do Sol produzida por uma placa filtrante ........................................ 16

3.3 - Observando o Sol com uma placa filtrante ................................................. 16

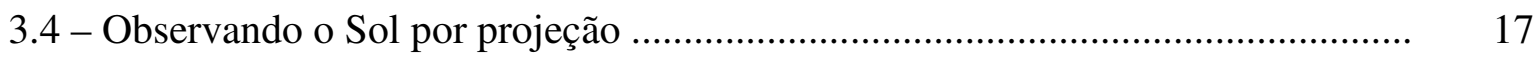

3.5 - Imagem do Sol projetada em um anteparo.................................................... 17

3.6 - Imagem do Sol produzida por um Sunspotter …............................................... 18

3.7 - Esquema óptico de um Sunspotter .................................................................... 19

3.8 - Imagem do Sol em um equipamento do Planetário de Stuttgart ....................... 19

4.1 - Paralaxe dos astros do Sistema Solar ............................................................. 23

4.2 - Observação do planeta Marte em Paris e em Caiena......................................... 24

4.3 - Carta celeste da constelação de Aquarius ........................................................... 25

4.4 - Distância Paris-Caiena, ao longo de um círculo máximo .................................. 26

4.5 - Oposição do planeta Marte ............................................................................. 28

4.6 - O diâmetro aparente de um astro ....................................................................... $\quad 30$

4.7 - Uso do micrômetro na determinação do diâmetro aparente do Sol .................... 32

4.8 - Objetiva do heliômetro do Observatório Kuffner ............................................. 34

4.9 - Princípio de funcionamento do heliômetro ..................................................... 35

4.10 - Esquema óptico da produção de imagens no astrolábio Danjon ...................... 36 
4.11 - Observação do Sol no astrolábio Danjon

4.12 - Comparação do tamanho Sol com algumas estrelas brilhantes ........................ 38

4.13 - Comparação do Sol com algumas estrelas próximas e o planeta Júpiter ......... 39

5.1 - Sistema de dois corpos interagindo gravitacionalmente

5.2 - O centro de massa do sistema Terra-Sol

5.3 - Centro de massa do Sistema Solar para o período de 1944 a 2020

6.1 - Fluxo de energia solar

6.2 - Circuito elétrico simplificado do bolômetro de Langley

6.3 - O espectro solar e as linhas de Fraunhofer

6.4 - Um espectro contínuo 53

6.5 - Espectros de alguns elementos químicos compostos por linhas brilhantes ... 53

6.6 - Um espectro composto por linhas escuras 54

6.7 - O espectro solar ampliado com linhas 55

6.8 - O espectro do Sol comparado aos espectros de alguns elementos químicos .... 55

6.9 - Espectro solar gráfico 56

6.10 - A curva de emissão do Sol nos vários comprimentos de onda

7.1 - Hans Albrecht Bethe e C. F. F. von Weizsäcker

8.1 - A estrutura interna do Sol e alguns fenômenos fotosféricos

8.2 - Trajetórias aleatórias de fótons na zona de radiação

8.3 - Células convectivas e granulações da fotosfera

8.4 - Imagem da fotosfera solar com granulações 
8.6 - Imagem do SOHO mostrando a diferença de brilho da fotosfera .................... 79

8.7 - Obscurecimento da borda do disco solar ........................................................... 79

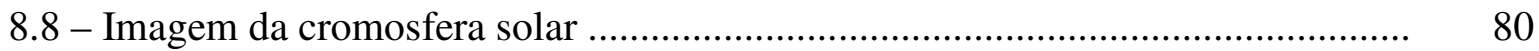

8.9 - Protuberância solar observada e fotografada em 14 de setembro de 1999 ......... $\quad 81$

8.10 - Rede cromosférica observada no violeta .................................................... 82

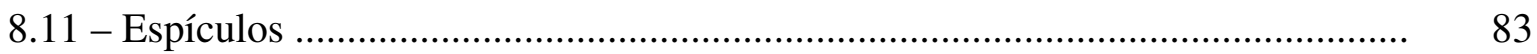

8.12 - Campo magnético na presença de ondas de Alfvén ........................................ 84

8.13 - Coroa solar visível durante o eclipse total do Sol em 01 de agosto de 2008 .... $\quad 85$

8.14 - Loops coronais observados em regiões solares ativas .................................... 86

8.15 - Grande buraco coronal observado no ultravioleta extremo (EUV) .................. 87

9.1 - O Sol e seu complexo campo magnético ......................................................... 89

9.2 - Polaridade das manchas solares ....................................................................... 90

9.3 - Imagem ilustrando uma grande mancha solar e sua estrutura ........................... 91

9.4 - Padre Christoph Scheiner realizando observações do Sol ................................. 92

9.5 - Gráfico do número diário de manchas solares (1750 a 2000) ............................ 93

9.6 - Diagrama de Maunder para o período de 1942 a 2000 ...................................... 94

9.7 - Rotação diferencial do Sol ........................................................................... 95

9.8 - Modelo de Babcock para o campo magnético das manchas solares ................... 96

9.9 - Desenho elaborado por Richard Carrington em 01 de setembro de 1859 .......... 97

9.10 - Flare (explosão) capturada pela NASA ………………................................. $\quad 98$

9.11 - Ejeção de massa coronal ........................................................................... 100

9.12 - A magnetosfera terrestre desviando as partículas do vento solar ..................... 101

9.13 - O cometa Hale-Bopp observado em 1996/1997 .......................................... 102

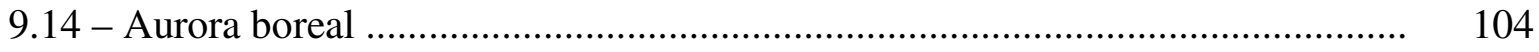

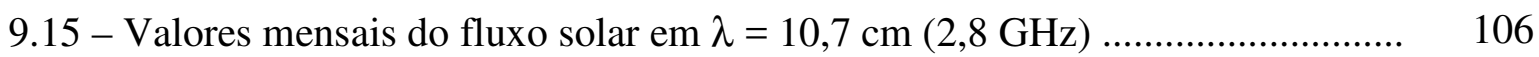

9.16 - Temperaturas e densidades nas diversas camadas da atmosfera solar ............. 107

9.17 - Concepção artística da heliosfera ................................................................ 108

9.18 - Aumento na quantidade de partículas na passagem pelo termination shock ... 109 
9.19 - Diminuição na contagem de partículas registrada pela Voyager 1 .................. 110

9.20 - Aumento na contagem de raios cósmicos registrados pela Voyager1

10.1 - Oscilações observadas com períodos de cerca de 5 minutos no disco solar .....

10.2 - Trajetórias de ondas sonoras (modo-p) e ondas de gravidade (modo-g) ........... 115

10.3 - Oscilações no modo-p observadas no Sol ....................................................... 116

10.4 - Sistema de coordenadas esféricas ................................................................. 118

10.5 - Diversos modos-p de oscilação para diferentes valores de $n, \ell$ e m ................. 119

10.6 - As diferentes velocidades de rotação solar em diferentes camadas ................. 120

A2.1 - Sistema composto por dois corpos ..................................................... 125

A3.1 - Sistema de coordenadas esféricas eclípticas heliocêntricas ............................ 127

A3.2 - Sistema de coordenadas heliocêntricas retangulares ..................................... 128

A4.1 - Velocidade de escape de um corpo .............................................................. 131

A5.1 - Casca esférica situada no interior de uma estrela esférica ............................ 134

A5.2 - Diferença de pressão em um recipiente contendo água .................................. 136

A5.3 - Gradiente de pressão no interior de uma estrela ......................................... 137

A5.4 - Produção de energia a partir da transformação de massa ................................. 139 


\section{Lista de Tabelas}

Tabela 1 - Componentes do Sistema Solar e suas massas ...................................... 10

Tabela 2 - Algumas determinações da paralaxe solar e da unidade astronômica ....... 29

Tabela 3 - Velocidade de escape do campo gravitacional do Sol ............................. 46

Tabela 4 - Estrutura do Sol ............................................................................

Tabela A1.1 - Dados numéricos do Sol …............................................................ 122

Tabela A1.2 - Abundância de elementos químicos no Sol ........................................ 123 


\section{Apresentação}

A Escola Municipal de Astrofísica de São Paulo foi inaugurada em 25 de janeiro de 1961 ampliando o espaço didático do Planetário do Ibirapuera, aberto ao público em 26 de janeiro de 1957. Em sua origem, o Planetário do Ibirapuera estava incluído no projeto inicial do Parque Ibirapuera e deveria ter sido inaugurado em 1954 na abertura do parque durante os festejos do IV Centenário da Cidade de São Paulo. Foi inaugurado somente três anos depois. Para a operação do Planetário foram convocados os membros da Associação de Amadores de Astronomia de São Paulo (AAA), fundada em 18 de novembro de 1949, da qual faziam parte o Dr. Aristóteles Orsini, o Dr. Abrahão de Morais, o Prof. Abraham Szulc, o Dr. Décio Fernandes de Vasconcelos e vários professores de diversas faculdades da Universidade de São Paulo.

A Associação, muito conhecida e conceituada entre os paulistanos, já desde o seu início promovia, em sua modesta sede situada na Rua Mauá, $\mathrm{n}^{\circ}$ 940, cursos sobre Astronomia e ciências correlatas e palestras de divulgação científica destinados ao público em geral e aos amadores e estudiosos da Astronomia. Com a convocação da Associação para operar o Planetário, suas atividades relacionadas aos cursos e palestras foram transferidas para o edifício do Planetário. A grande novidade da cidade - o Planetário aliada ao início das atividades espaciais (o lançamento do Sputnik I ocorreu em 04 de outubro de 1957) fez a procura por conhecimentos atrair milhares de visitantes e a procura pelos cursos de Astronomia tornou-se muito grande.

Esse quadro levou a administração do Planetário, na pessoa do Dr. Aristóteles Orsini, a solicitar e expor à administração superior da Prefeitura, a necessidade da construção de um espaço anexo ao Planetário que permitisse o desenvolvimento das atividades de ensino e divulgação. Somou-se a isso o fato que a Associação havia criado um departamento de Radioastronomia e desde 1959 já possuía equipamentos instalados no Parque Ibirapuera sem ter, no entanto, um local apropriado e seguro para instalar e abrigar os equipamentos eletrônicos destinados aos sistemas de observação radioastronômicas. 


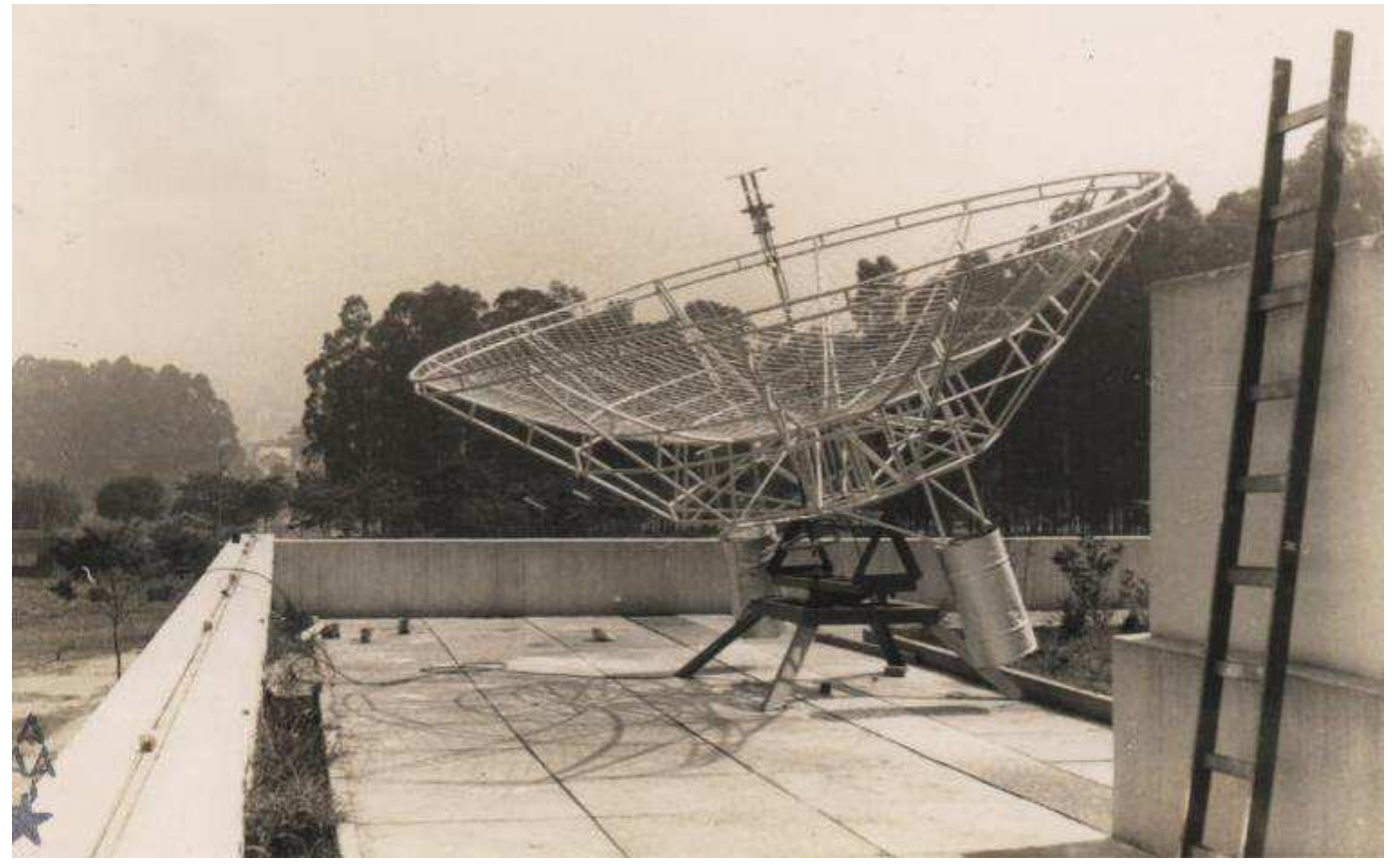

Fig.1.1 - Radiotelescópio da EMA - Crédito: Associação de Amadores de Astronomia de São Paulo.

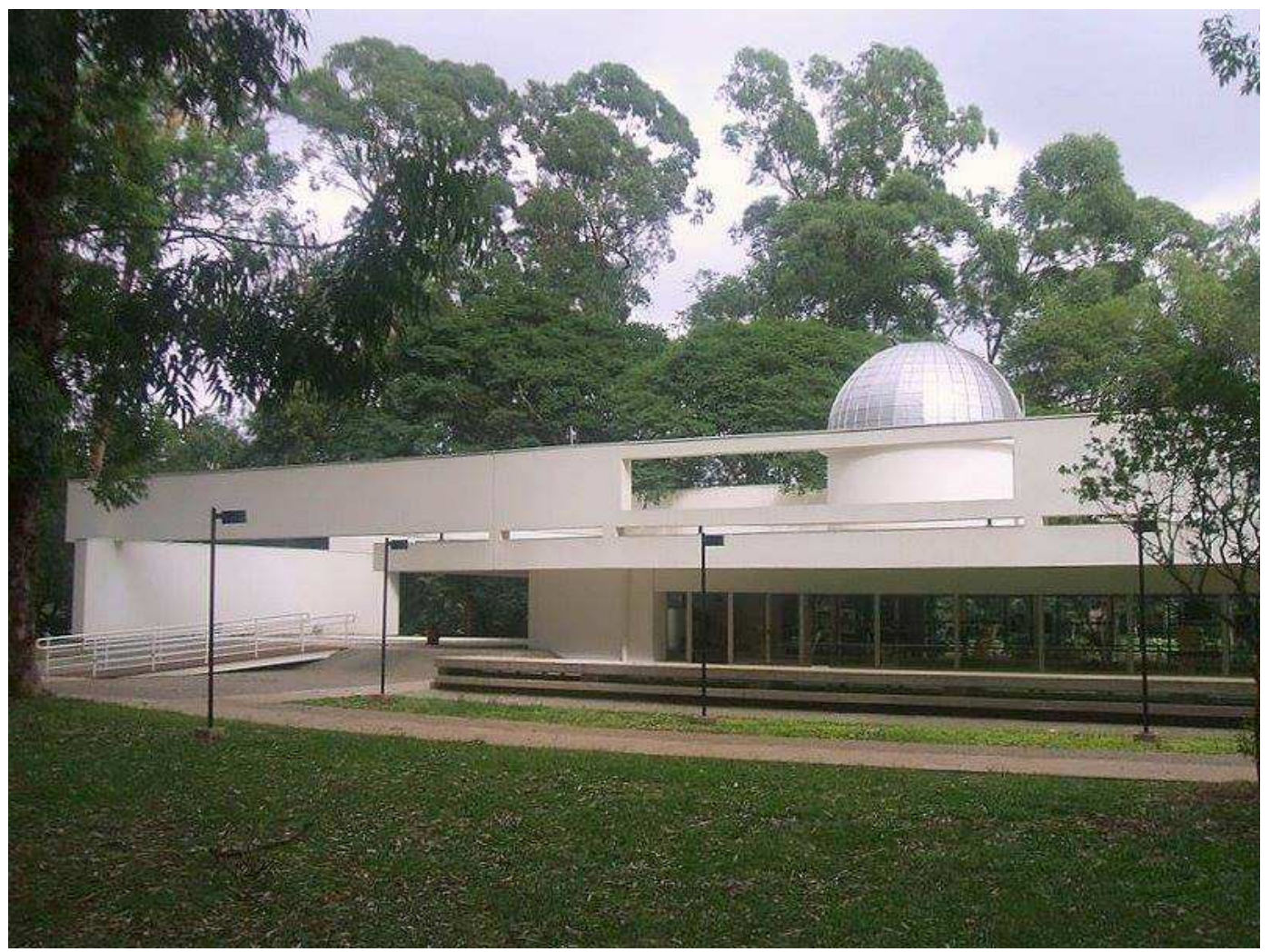

Fig. 1.2 - Visão atual da Escola Municipal de Astrofísica (EMA) inaugurada em 25 de janeiro de 1961, no Parque Ibirapuera. 
Foi assim que, numa iniciativa inédita e pouco comum na administração municipal, a Prefeitura resolveu construir um amplo espaço destinado ao estudo, à pesquisa e ao ensino da Astronomia - a Escola Municipal de Astrofísica (EMA) - instituição pública única aberta ao público em geral interessado em estudar Astronomia.

Ao longo de seus 56 anos de existência, a EMA promoveu mais de 700 cursos de Astronomia (a maioria com a duração de um semestre) atendendo a mais de 22 mil interessados. Incluem-se neles os cursos pioneiros de Radioastronomia dirigidos ao público em geral. Entre os interessados nos cursos da EMA estão: estudantes dos ensinos fundamental e médio, professores, médicos, advogados, engenheiros, dentistas, economistas, jornalistas e vários outros que, posteriormente, procuraram a Universidade para buscar formação profissional na área. Apesar disso, a Instituição não tem sido lembrada nas resenhas que tratam da história da Astronomia e de seu ensino no Brasil. A título de exemplos seguem alguns depoimentos de alunos que frequentaram os cursos:

"Estudar Astronomia na Escola Municipal de Astrofísica é uma possibilidade única. Aprender com quem gosta do que faz - ensinar. Isso me despertou novamente a busca pela Física, Matemática, Mecânica Celeste e outros assuntos relacionados com Astronomia. Agradeço a oportunidade”.

\section{Marcelo de Breyne - Fotógrafo e publicitário - Maio de 2015}

"Sempre tive um interesse muito grande por astronomia, mas não tive acesso durante a infância e a adolescência. Quando me mudei para São Paulo, soube dos cursos da Escola Municipal de Astrofísica por meio da divulgação do calendário em uma rede social. Durante muito tempo estive afastada de qualquer estudo de ciências exatas, mas resolvi tentar fazer um dos cursos que eram para iniciantes e direcionados para a divulgação científica. Gostei muito do curso, tanto que continuei a fazer outros cursos na escola durante anos. A diversidade de cursos com muitos assuntos abordados e a qualidade dos professores são notáveis na escola. Além disso, o preço popular dos cursos garante acessibilidade a qualquer pessoa que se interessar. 
Não há muitas escolas atualmente preocupadas com a divulgação científica, até mesmo as universidades estão cada vez mais centradas nos seus próprios alunos e professores, abrindo pouco ou nenhum espaço para a comunidade externa. Por isso, acredito que a Escola Municipal de Astrofísica é um destaque nessa área e sua importância é enorme”.

Melina Bassoli - Socióloga - Maio de 2015

"Há muito tempo eu ouvia falar numa escola de astronomia que existia no Ibirapuera, em São Paulo, mas apesar de minha grande curiosidade sobre esse tema e vontade de aprender pensava que era algo reservado a pessoas com uma formação específica. Em 2009, ao ver uma matéria no jornal "Estadão" sobre a abertura de inscrições na Escola Municipal de Astrofísica Aristóteles Orsini (EMA) e descobrir que as programações eram abertas ao público, corri para garantir uma vaga no curso que mais me atraiu, Fundamentos de Astrofísica - Evolução Estelar, com o professor Irineu Gomes Varella. Desde o primeiro dia me encantei com o curso. As aulas, de altíssima qualidade, eram ministradas por um professor experiente, que além de apresentar profundo conhecimento teórico e prático é um grande didata, capaz de traduzir em palavras simples e explicar de forma a todos entenderem os temas mais complexos. O curso era muito bem estruturado, enriquecido pelas observações e exemplos retirados de uma prática vivida.

Desde então, todos os anos fiz cursos na EMA, na grande maioria das vezes com esse mesmo professor, sobre temas como mecânica celeste, movimentos da Terra, eclipses, trigonometria e astronomia esférica, etc. Fiz também alguns cursos com outros professores, como Paulo Gomes Varella (sobre reconhecimento do céu) e Priscila Di Cianni F. Oliveira (sobre astronomia galáctica e extragaláctica), também excelentes. Recomendo vivamente a todos os que se interessam por astronomia e também aos professores em geral os cursos da EMA. Na verdade, acredito que cursos como esses que fiz deveriam ser obrigatórios na formação dos professores de ensino fundamental e médio, como um importante item de capacitação. É também uma pena que não sejam divulgados e prestigiados como deveriam, pois com certeza muitas outras pessoas gostariam de freqüentá-los”.

Maria da Anunciação Rodrigues - Professora de Artes e Tradutora - Maio de 2015 
"Meu interesse por Astronomia, Cosmologia, Física e afins vêm desde tenra idade. Na verdade, fiz meu primeiro curso na EMA quando tinha 16 anos, motivado principalmente por várias sessões do Planetário do Ibirapuera que frequentei desde criança. Depois houve um hiato - voltei a frequentar os cursos somente lá pelo início dos 90s e não mais parei de cursá-los desde então. Devo dizer que, além do interesse natural que sempre tive sobre o tema, os motivos que me fazem sempre continuar a fazer os cursos da EMA há tantos anos, são o excelente nível das aulas, dos professores que ali ensinam, e também da turma de amigos que fiz por ali. E ressalto especialmente as aulas dos professores/irmãos Irineu e Paulo Varella que há muito tempo ensinam e "comandam" os cursos da escola com maestria. E isso me faz pensar que, não fosse por eles, talvez a EMA não permanecesse com essa grade anual de excelentes cursos, levando à população o ensino de tão raros temas aqui no Brasil e assim mantendo viva a chama, o ensino dessas matérias tão fascinantes como a Astronomia e correlatas".

Marcos Grillo Junior - Maio de 2015

"A Escola Municipal de Astrofísica (EMA) me foi tão bem recomendada por amigos, que me fez procurar os cursos com grandes expectativas. Que foram plenamente satisfeitas e por muitas vezes, agradavelmente superadas pelo ótimo conteúdo e competência dos professores. $O$ ambiente da escola sempre foi acolhedor, com pessoas de formações diversas que buscam o aprendizado de conceitos que parecem distantes de seus cotidianos atribulados. Penso que em Astronomia, somos todos atraídos inicialmente pelo conhecimento científico, mas acabamos surpreendidos pela beleza inerente à apreensão de visões e reflexões que transcendem o nosso dia-a-dia.

Entre 2009 e 2014, pude fazer 24 cursos variados, desde "Reconhecimento do Céu”, "Trigonometria Esférica" e "Física Estelar”, entre outros tópicos igualmente interessantes. Considero um enorme privilégio ter tido aulas com um dos melhores docentes que já conheci: o professor Irineu Gomes Varella. Assisti às suas aulas com total deleite e atenção, com a certeza que meu microcosmo se enriqueceu com o vislumbre do Universo em expansão e todos os conceitos envolvidos na compreensão dos fenômenos astrofísicos. Foi o efeito da Astronomia em mim: entendimento e encantamento, 
admiração e respeito pela Ciência e pelas pessoas que fazem e ensinam as várias ramificações do conhecimento.

Sou profundamente grata por tudo que aprendi na EMA, especialmente com o professor Irineu, que sendo o professor nato e inspirador que é, conseguiu transmitir além das questões astrofísicas e matemáticas, o amor pelo aprendizado que amplia a nossa visão de mundo. Meu olhar brilha quando eu miro as estrelas. Hoje compreendo melhor os processos de formação, evolução e morte das estrelas e galáxias, e reconheço que o caminho do aprendizado continua indefinidamente. "Parece que o Universo se tornou maior, mais belo e, com certeza, mais instigante”.

\section{Lílian Naomi Shibata Pêra - Artista plástica - Bacharel em Pintura - Maio de 2015}

"Nunca tinha ouvido falar da Escola Municipal de Astrofísica"Professor Aristóteles Orsini" até que minha irmã me chamou para assistir o curso "Reconhecimento do Céu” no Planetário de São Paulo. Aceitei o convite na hora, pois ainda tinha vívida em minha memória o encantamento que experimentei quando tinha estado lá, ainda criança acompanhada de meu pai. Desde pequena tive interesse por astronomia, assistia documentários sobre o tema na televisão e lia a respeito, mas era um interesse disperso e solitário. Depois do curso sobre reconhecimento de céu que fiz em 2008, não parei mais. Fiz e ainda faço todos os cursos oferecidos na escola, na medida da minha disponibilidade. Alguns, inclusive, assisti mais de uma vez.

Graças aos professores da EMA, perdi o medo da matemática e da física. As aulas ministradas são acessíveis ao público leigo, sem deixar o rigor científico de lado. Considero um privilégio poder acompanhar as aulas de professores tão experientes e dedicados. A base sólida que recebi me possibilitou ousar fazer uma pós-graduação lato sensu em astronomia.

Para mim, este interesse veio para ficar. Não como uma atividade profissional, mas nem por isso de menor importância. Hoje me considero uma dedicada astrônoma amadora”.

Maria Eduarda Frabasile - Bacharel e Licenciada em Letras - Maio de 2015 


\section{O conteúdo desta dissertação}

Os cursos da EMA vêm preenchendo uma enorme lacuna que existe entre os conhecimentos apresentados nos livros de divulgação e aqueles apresentados nos textos universitários. Este grande vazio surgiu na década de 40 do século passado quando a disciplina de Cosmografia foi retirada dos currículos escolares. Até então, diversos textos destinados ao ensino da Astronomia - tanto para o antigo curso ginasial, como para o curso colegial - foram publicados, com conteúdos adequados à compreensão dos fenômenos e usando, muitas vezes, linguagem matemática compatível com os conhecimentos dos alunos.

Já faz muito tempo que a Física, a Matemática e a Química são apresentadas no ensino médio com a utilização de linguagem matemática adequada e necessária à compreensão dos conceitos. É bem verdade que isto tem ocorrido, em muitos casos, como necessário ao adestramento dos estudantes para enfrentar o exame vestibular. A Astronomia, felizmente, não corre este risco!

Por outro lado, a maneira como se pratica o ensino da Astronomia em nosso país é bastante insatisfatória. Não se faz uso dos recursos da física, da matemática e da química que muitos alunos adquiriram no ensino médio e que são de capital importância para o estudo, a compreensão e a operacionalização dos conceitos, não permitindo a apreciação mais aprofundada da maravilhosa ciência que é a Astronomia. Fico me perguntando: por que isso?

Tendo trabalhado por 47 anos na Escola Municipal de Astrofísica (de junho de 1968 a junho de 2015) e participado como professor dos cursos desde fevereiro de 1970, sempre achei natural o ensino da Astronomia acompanhado de um tratamento mais formal, indo muito além da simples divulgação científica.

$\mathrm{Na}$ minha apresentação para ingressar no Mestrado Profissional do IAG, discorri sobre isso, enfatizando a necessidade de se elaborar um texto acessível aos alunos do 
ensino médio que não fosse apenas descritivo e com belas imagens. Propus inicialmente a elaboração de um texto que abordasse a Física das Estrelas com o uso dos conhecimentos de física, matemática e química, adquiridos pelos estudantes do ensino médio. É perfeitamente viável e já ministrei inúmeros cursos sobre o tema para estudantes do ensino médio e para um público que só havia tido contato com a física, com a matemática e com a química quando cursaram o ensino médio.

Porém, dada a grande extensão do assunto e mantendo muito das idéias iniciais, reduzimos a abordagem original a um exemplo mais simples que permite, da mesma forma, expor e aplicar os conceitos fundamentais da física estelar a um astro típico: o Sol.

É essa experiência que venho trazer na proposta de um curso sobre Astronomia e Física Solar que apresento nesta dissertação. Dada a grande amplitude do tema inicial, a Física e a Astronomia solar retratam, de maneira mais objetiva, a proposta de se estudar as estrelas com o uso da Física, da Química e da Matemática do ensino médio.

Nos vários cursos ministrados pela EMA exclusivamente para os professores municipais e também nos cursos abertos ao público em geral nos quais professores das redes estadual e particular frequentavam, ficou muito claro que, a despeito da enorme vontade que tinham em apresentar a Astronomia em suas aulas, faltavam conhecimentos. A Professora Ludmila Bolina Costa na apresentação de sua dissertação de Mestrado Profissional relatou essa insegurança dos professores que entrevistou, em abordar temas de Astronomia em suas aulas.

O curso aqui desenvolvido pretende suprir essas inseguranças e apresentar a Astronomia e o uso dos seus conceitos nos temas do cotidiano das ciências ensinadas no ensino médio. Ele foi elaborado para ser ministrado aos alunos de Licenciatura em Física e Licenciatura em Ciências, com duração de um semestre letivo, podendo ser desenvolvido em duas ou quatro aulas semanais, com duração de uma hora cada.

O curso apresenta a maneira como diversos parâmetros e características do Sol foram determinados. Assim, abordaremos: 
- COMO se descobriu que o Sol é uma estrela;

- COMO foram determinados a sua distância e o seu tamanho;

- COMO se determinou a sua massa;

- COMO se obteve a sua temperatura;

- COMO soubemos a sua composição química;

- COMO o Sol produz energia;

- COMO soubemos a sua estrutura interna.

Acreditamos que professores com conhecimentos vão se sentir aptos a transmitir aos seus alunos conceitos que vão além do que é solicitado nos vestibulares. 


\section{1 - O SOL É UMA ESTRELA?}

Uma questão muito interessante e de fundamental importância, negligenciada pela maioria dos autores dos livros e textos de Astronomia, é Como sabemos que o Sol é uma estrela $?{ }^{1} \mathrm{Ou}$, ainda, como sabemos que as demais estrelas são sóis?

O famoso astrofísico ucraniano George A. Gamow (1904-1968) escreveu inúmeros textos de divulgação científica em Astronomia, entre eles o famoso livro Nascimento $\boldsymbol{e}$ Morte do Sol (The Birth and Death of the Sun, 1940) ${ }^{2}$ - um best-seller no Brasil. Alguns anos depois, produziu uma espécie de atualização dele, denominado Uma Estrela Chamada Sol (A Star Called The Sun, 1964) que, no título, encerra o assunto: o Sol é uma estrela!

Assim, quase todos passam pela questão de "Como sabemos que o Sol é uma estrela?" sem apresentar razões para isso, ou mesmo, como o homem construiu a ideia de que o Sol e as estrelas são astros de mesma natureza. Adiante vamos descrever, de maneira sucinta, os fatos históricos e as descobertas que foram feitas nesse sentido desde a antiguidade até que os astrônomos concluíram que o Sol é uma estrela!

\section{1 - Da antiguidade até Copérnico}

$\mathrm{Na}$ antiguidade, e durante os séculos seguintes, os astrônomos ocuparam-se prioritariamente dos movimentos planetários e pouca atenção deram às estrelas. A imutabilidade do céu, decorrente das posições "fixas" das estrelas e os seus fracos brilhos não atraíram a atenção dos astrônomos.

As estrelas foram, em geral, consideradas presas a uma esfera que envolvia as esferas planetárias - tanto no sistema geocêntrico, como no sistema heliocêntrico proposto por Copérnico (figuras 1.1 e 1.2). Essa esfera era chamada de esfera das fixas. Na

\footnotetext{
${ }^{1}$ Essa interessante questão foi proposta pelo Professor Jorge Ernesto Horvath na disciplina "Tópicos Avançados de Física Estelar" pertencente ao Programa de Mestrado Profissional em Ensino de Astronomia, do IAG;

${ }^{2}$ A primeira edição em português, com tradução de Monteiro Lobato, foi publicada em 1944, pela Livraria do Globo, Porto Alegre.
} 
cosmologia copernicana a esfera das estrelas fixas estava situada a grande distância dos planetas de maneira que não havia variação no tamanho aparente das estrelas, variações nos seus brilhos e nem aumento de suas separações angulares devido ao movimento de translação da Terra que fazia com que a Terra ora se aproximasse da esfera das fixas e ora se afastasse dela.

Como estavam todas à mesma distância da Terra, as mais brilhantes eram consideradas maiores que as menos brilhantes. As mais brilhantes foram classificadas, então, como estrelas de primeira grandeza pelo seu suposto grande tamanho, enquanto as mais fracas foram classificadas como de sexta grandeza em razão do seu pequeno tamanho. As demais, em função de seus brilhos intermediários, foram classificadas como de segunda grandeza, terceira grandeza etc.

\section{Schema huius pramiffx diuifionis Sphærarum .}

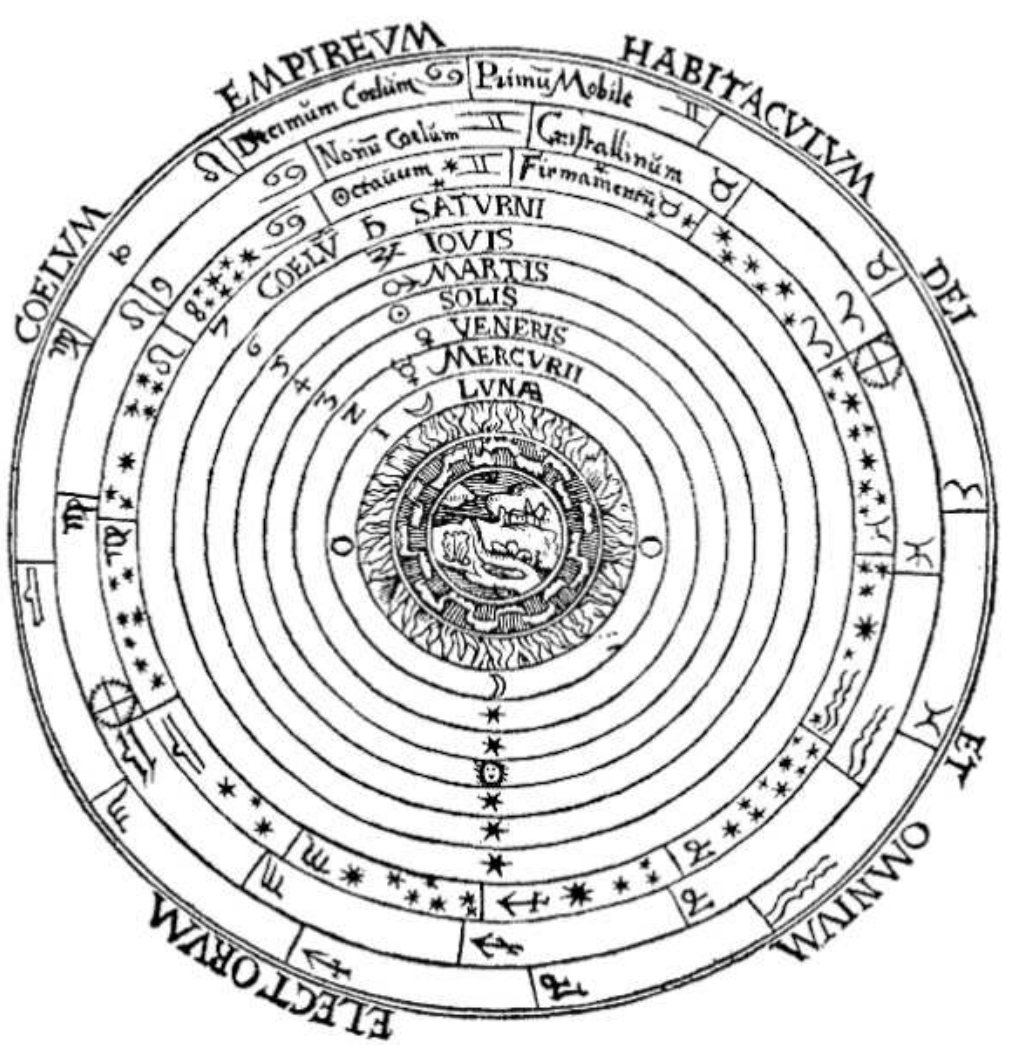

Fig. 1.1 - Sistema geocêntrico de Ptolomeu mostrando a esfera da estrelas fixas. Fonte: http://hypescience.com/12-diagramas-que-mudaram-nossa-compreensao-do-sistema-solar/ 


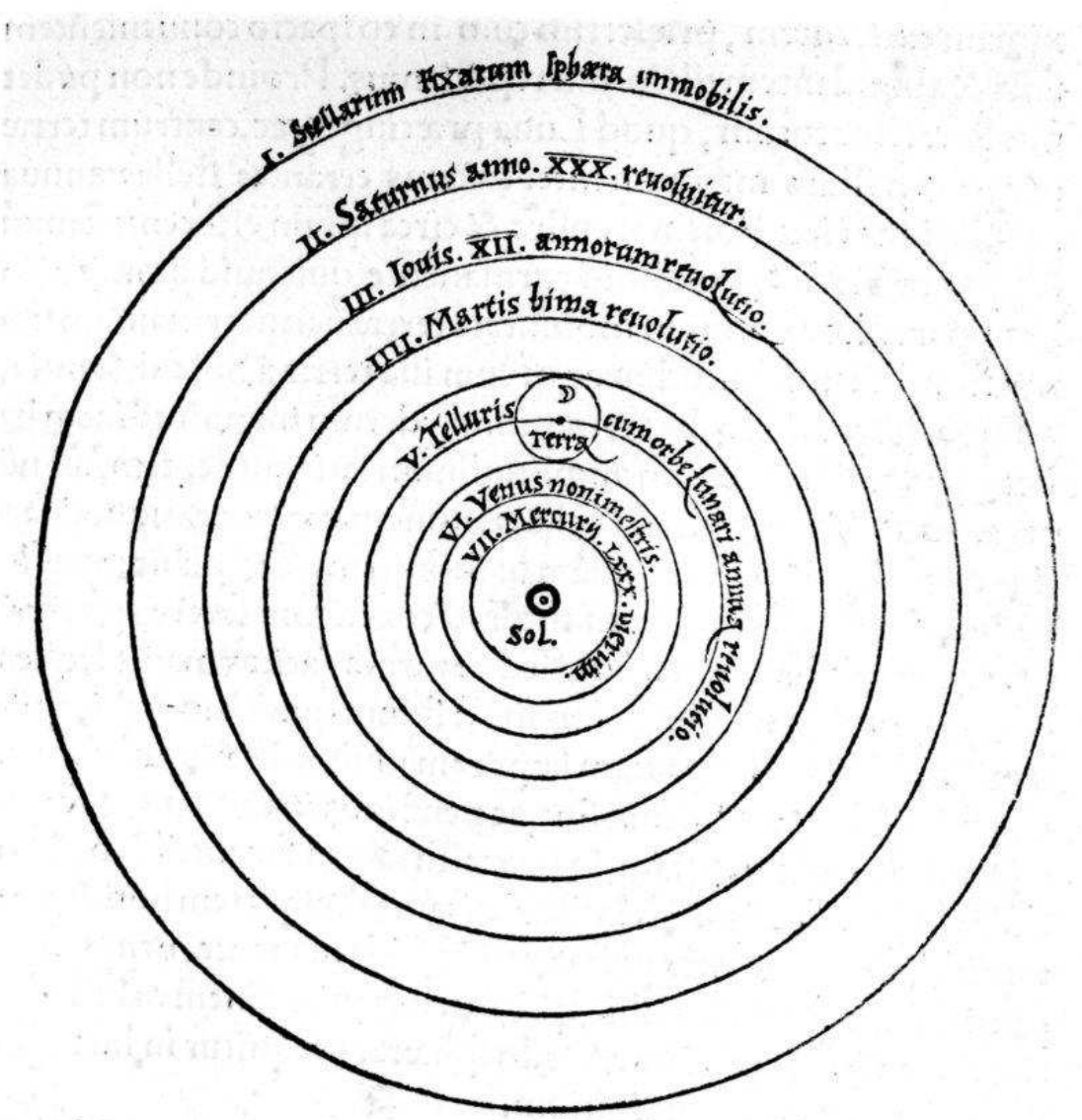

Fig. 1.2 - Sistema heliocêntrico de Copérnico mostrando a esfera da estrelas fixas.

Fonte: http://hypescience.com/12-diagramas-que-mudaram-nossa-compreensao-do-sistema-solar/

Ao mesmo tempo, o Sol era considerado um astro diferente de todos. Tinha uma identidade própria. Embora fosse considerado um planeta pelo fato de se deslocar ao longo do ano por entre as estrelas, sua natureza era, no entanto, bem diversa da dos demais planetas e da Lua. A primeira pessoa a sugerir que o Sol era uma estrela situada próxima da Terra (ou de forma equivalente, que as estrelas eram sóis distantes) foi Anaxágoras ao redor do ano 450 a.C.

Isso foi sugerido também por Aristarco de Samos, mas essa ideia foi rejeitada por outros filósofos. Ao redor do ano 1590 de nossa era, o filósofo italiano Giordano Bruno sugeriu a mesma coisa e acabou, por essa e por outras afirmações, sendo queimado vivo em 1600. 


\section{2 - A distância Terra-Sol}

Os trabalhos de Copérnico, Galileu e Kepler acabaram por colocar o Sol em um novo lugar no Sistema Solar e, embora os astrônomos conhecessem a distância da Lua desde a antiguidade, a distância da Terra ao Sol era ainda desconhecida. Somente em 1672 o valor dessa distância tornou-se conhecido a partir dos trabalhos de observação dos astrônomos Jean Dominique Cassini (1625-1712) e Jean Richer (1630-1696). Eles efetuaram cuidadosas medidas da posição de Marte em relação às estrelas, durante a grande aproximação (oposição) do planeta em setembro de 1672, obtendo a sua distância ao Sol e, partir dela, a distância Terra-Sol. ${ }^{3}$

\section{3 - O movimento próprio das estrelas}

Até o início do século XVIII, as estrelas ainda eram consideradas fixas, isto é, imóveis. A simples observação mostrava que as posições de umas em relação às outras não se alteravam com o passar do tempo. Esse fato já havia sido notado na antiguidade e em razão disso as estrelas, desde há muito tempo, haviam sido agrupadas em constelações regiões contendo uma certa quantidade de estrelas que mantinham suas posições fixas.

Em 1718, no entanto, o astrônomo inglês Edmond Halley, comparando as posições que havia determinado de algumas estrelas com as posições das mesmas estrelas obtidas pelo astrônomo grego Hiparco no século II a.C., notou que as posições de algumas estrelas brilhantes (Sirius, Aldebaran e Arcturus) tinham se alterado consideravelmente (cerca de meio grau ${ }^{4}$ ) desde aqueles tempos. Essas observações levavam à conclusão de que as estrelas não eram objetos fixos no firmamento: elas se moviam lentamente.

\footnotetext{
${ }^{3}$ Veja mais adiante "Distância e Tamanho do Sol".

${ }^{4}$ Meio grau (30') corresponde ao diâmetro aparente da Lua, isto é, o ângulo sob o qual observamos nosso satélite.
} 


\section{4 - As distâncias estelares}

$\mathrm{Na}$ primeira metade do século XIX, as primeiras distâncias estelares foram determinadas por F. W. Bessel (61Cygni), F. G. W. Struve (Vega = Alpha Lyræ) e T. Henderson (Alpha Centauri).

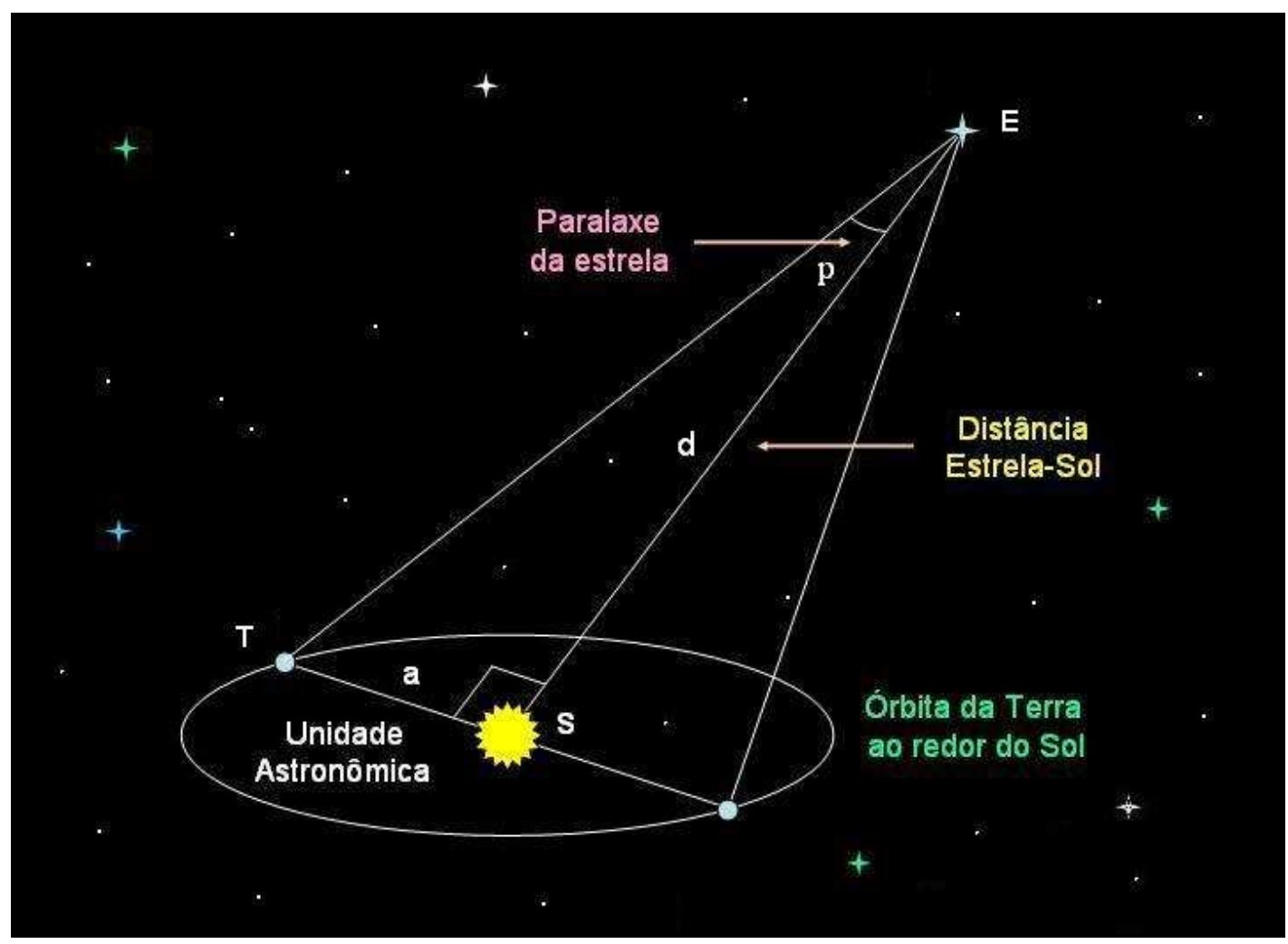

Fig. 1.3 - O ângulo sob o qual de uma estrela se vê a unidade astronômica (distância Terra-Sol) perpendicularmente à direção de visada, chama-se paralaxe estelar.

Essas determinações foram feitas medindo-se a paralaxe dessas estrelas. A paralaxe estelar é o ângulo sob o qual se observa a unidade astronômica (distância Terra-Sol) a partir de uma estrela (figura 1.3).

Para se obter a paralaxe de uma estrela, os astrônomos a observam durante um longo tempo em várias posições da Terra em sua órbita e medindo a posição da estrela em relação às estrelas de fraco brilho que se supõem situadas à grande distância do Sistema Solar. 
$\mathrm{Na}$ mesma época, astrônomos estavam determinando os brilhos das estrelas com mais precisão. Nos anos 30 do século XIX, Sir John F.W. Herschel havia notado, efetuando medidas do brilho de várias estrelas, que as chamadas estrelas de primeira grandeza eram, em média, cem vezes mais brilhantes que as estrelas de sexta grandeza. Isto levou o astrônomo inglês Norman Robert Pogson (1829-1891), alguns anos depois (1856), à construção de uma escala de brilhos para as estrelas cujos fundamentos são utilizados até os nossos dias.

\section{5 - Medindo a energia emitida pelo Sol e pelas estrelas}

Com o conhecimento das distâncias e a partir dos brilhos aparentes, foi possível verificar que as estrelas emitem energia com a mesma ordem de grandeza que o Sol. Em 1878, o astrônomo americano Samuel Pierpont Langley inventou o bolômetro (capítulo 6), instrumento que permitiu que se medisse, com precisão, a quantidade de energia solar que chega à Terra. Com esse valor e conhecendo-se a distância do Sol, foi possível saber quanta energia saía da superfície solar. A lei de Stefan-Boltzmann, formulada na segunda metade do século XIX, possibilitou, posteriormente, determinar a sua temperatura superficial, assumindo-se que o Sol emitia como um corpo negro.

O conhecimento das distâncias estelares permitiu, também, a determinação das suas temperaturas. A mesma hipótese aplicada às estrelas (de que elas irradiam como corpos negros) associada ao conhecimento da energia que delas chegava à Terra, calculada a partir de suas magnitudes, permitiu conhecer as suas temperaturas superficiais. A temperatura superficial do Sol e as temperaturas das superfícies estelares tinham, também, a mesma ordem de grandeza: milhares de graus!

Com essas determinações chegamos à conclusão de que as estrelas não estavam presas a uma esfera - não eram astros fixos -, emitiam energia e tinham temperaturas da mesma ordem de grandeza do Sol. 


\section{6 - Espectros e massas estelares ${ }^{5}$}

O desenvolvimento da análise espectral com os trabalhos de Kirchhoff e Bunsen, em 1861, trouxe mais uma informação importante: permitiu descobrir a composição química do Sol. O mesmo método aplicado às estrelas revelou que elas também apresentavam composições químicas semelhantes.

Finalmente, a determinação das massas estelares em sistemas binários de estrelas, com o uso da terceira lei de Kepler, mostrou, de maneira definitiva, que as massas estelares eram semelhantes à massa solar e, encerrando a questão, as estrelas eram outros sóis...

\footnotetext{
${ }^{5}$ Nos capítulos "Energia Solar" e "Massa e Campo Gravitacional do Sol" esses temas serão vistos com detalhes.
} 


\section{2 - PEQUENO INVENTÁRIO DO SISTEMA SOLAR}

Chamamos de sistema um conjunto de corpos que interagem entre si. O Sistema

Solar ${ }^{6}$ é um sistema constituído de milhares de corpos que interagem, predominantemente, através de ações gravitacionais havendo também interações não gravitacionais originadas nos efeitos da pressão de radiação, nas ações devidas aos campos magnéticos do Sol e dos planetas etc. O Sistema Solar está constituído por:

01 - Uma estrela: o Sol;

02 - Oito planetas: Mercúrio, Vênus, Terra, Marte, Júpiter, Saturno, Urano e Netuno;

03 - Cinco planetas anões: Ceres, Plutão, Haumea, Makemake e Eris;

03 - 173 satélites dos planetas;

04 - 9 satélites dos planetas anões;

$06-488.449$ pequenos $\operatorname{planetas}^{7}$ (asteroides) catalogados até março de 2017;

05 - 330 satélites de pequenos planetas, catalogados até fevereiro de 2017;

07 - 314 cometas periódicos catalogados e 89 cometas não periódicos registrados;

08 - 1.650 objetos transnetunianos catalogados até julho de 2015 (Disco de EdgeworthKuiper);

09 - Uma infinidade de meteoroides;

10 - O meio interplanetário;

11 - A Nuvem de Öpik - Oort.

$\mathrm{Na}$ nova classificação adotada pela União Astronômica Internacional (IAU Internacional Astronomical Union), os componentes do Sistema Solar passam a fazer parte das seguintes categorias: planetas, planetas anões e pequenos corpos do Sistema Solar. Neste último grupo estão os pequenos planetas (asteroides), cometas, objetos transnetunianos, os meteoroides e os componentes da nuvem de Öpik - Oort.

\footnotetext{
6 Por recomendação da União Astronômica Internacional (IAU), deve-se escrever $\underline{\text { Sistema }}$ Solar (com as iniciais maiúsculas);

7 Também por recomendação da União Astronômica Internacional deve-se preferir o termo "pequenos planetas" no lugar de asteroides ou planetoides.
} 
O Sol encontra-se praticamente no centro do Sistema Solar e os planetas, pequenos planetas, cometas, objetos transnetunianos, planetas anões, etc descrevem trajetórias ao seu redor, chamadas órbitas. Os satélites descrevem órbitas ao redor dos planetas. As órbitas descritas pelos planetas, pelos satélites e etc. obedecem às Leis de Kepler.

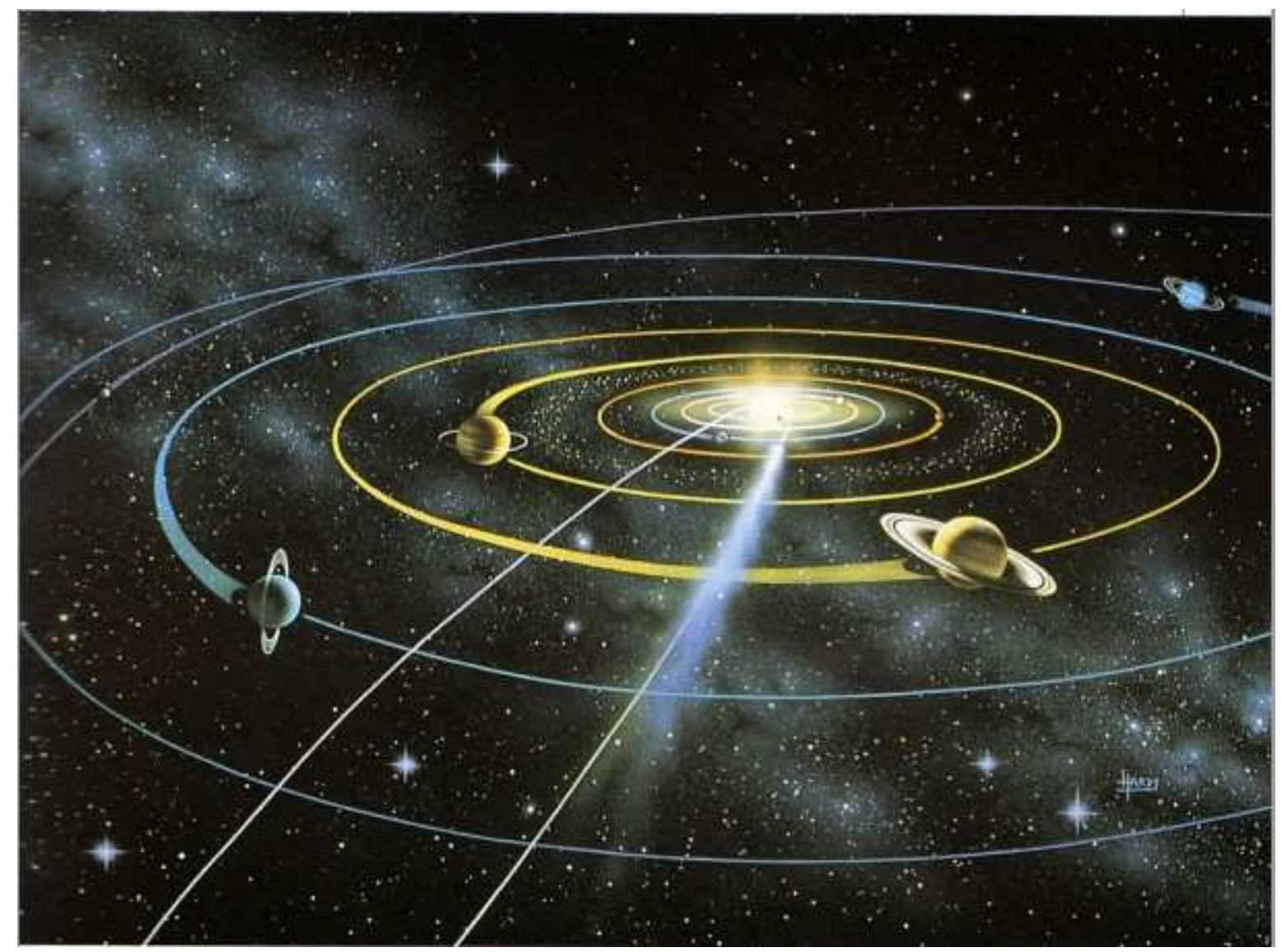

Fig. 2.1 - Principais componentes do Sistema Solar. Diagrama fora de escala no que se refere aos tamanhos e distâncias dos planetas ao Sol. Fonte: http:/www.geoaprendo.com/2016/02/el-universo-y-el-sistema-solarensayo.html

\section{1 - Características gerais do Sistema Solar}

O Sistema Solar é praticamente plano: as órbitas dos planetas são pouco inclinadas em relação ao plano da órbita terrestre. A órbita do planeta Mercúrio possui a maior inclinação: $7^{\circ} 00^{\prime} 17,5^{\prime \prime}$. Os planetas descrevem órbitas ao redor do Sol todos no mesmo sentido que coincide com o sentido da rotação do Sol sobre o seu eixo. 
Cerca de $99,9 \%$ da massa do sistema está concentrada no Sol; a distribuição de massas no sistema planetário está descrita na Tabela 1 , adotando-se a massa da Terra $\left(\mathrm{M}_{\oplus}\right.$ $=5,974 \times 10^{24} \mathrm{~kg}$ ) como unidade.

\section{TABELA 1 - COMPONENTES DO SISTEMA SOLAR E SUAS MASSAS}

Massa do Sol $(\mathrm{M} \odot)$

Massa total dos planetas

Massa total dos satélites

Massa total dos pequenos planetas

Massa meteorítica e matéria cometária

Massa total do sistema planetário interno

Massa provável da Nuvem de Öpik-Oort

Massa total do Sistema Solar
$332.946,0 \mathrm{M}_{\oplus}$

$447,8 \mathrm{M}_{\oplus}$

$0,12 \mathrm{M}_{\oplus}$

$0,0003 \mathrm{M}_{\oplus}$

$10^{-9} \mathrm{M}_{\oplus}$

$448 \mathrm{M}_{\oplus}$

$24 \mathrm{M}_{\oplus}$ (entre $14 \mathrm{M}_{\oplus}$ e $34 \mathrm{M}_{\oplus}$ )

$333.417,9 \mathrm{M}_{\oplus}$

\section{2 - Localização do Sistema Solar na Galáxia}

- O Sistema Solar encontra-se localizado no Braço de Órion da Galáxia ${ }^{8}$, distando 8,5 kpc (cerca de 28.000 anos-luz) do centro galáctico (figura 2.2);

- O movimento do Sistema Solar ao redor do centro da Galáxia processa-se em 220 milhões de anos e em seu movimento orbital o Sistema Solar desloca-se com velocidade de $250 \mathrm{~km} / \mathrm{s}$;

- Em relação a um sistema especial de referência relacionado às estrelas próximas $(\mathrm{LSR})^{9}$, o Sistema Solar desloca-se com velocidade peculiar de $19,7 \mathrm{~km} / \mathrm{s}$, movendo-se em direção a um ponto, chamado ápex solar, situado entre as constelações de Hercules e $\operatorname{Lyra}\left(\mathrm{AR}=18 \mathrm{~h} 04 \mathrm{~m}\right.$ e DECL $\left.=+30^{\circ}\right)$.

\footnotetext{
8 Alguns astrônomos consideram o braço de Órion como uma estrutura menor preferindo considerar que o Sol está localizado entre os braços de Sagittarius (Sagitário) e de Perseus (Perseu) (veja a figura 2.2);

${ }^{9}$ LSR = Local Standard of Rest (Padrão Local de Repouso).
} 


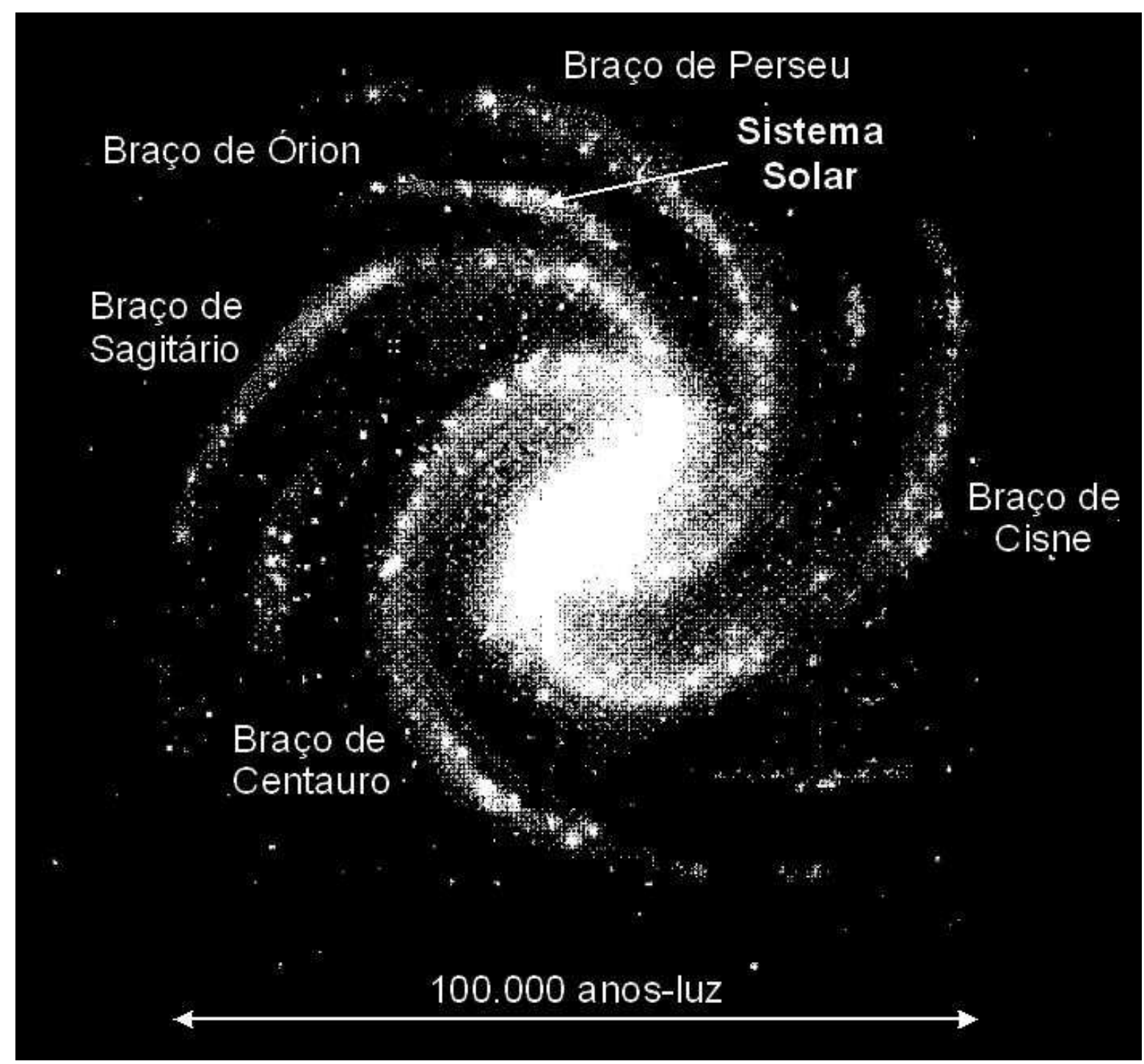

Fig.2.2 - Localização do Sistema Solar na Galáxia. O Sistema Solar encontra-se a cerca de 28.000 anos-luz do centro galáctico.

\section{3 - A vizinhança do Sol}

Até a uma distância de 12,5 anos-luz do Sol há 33 estrelas em suas proximidades. A maioria delas são estrelas anãs vermelhas e apenas três são bem brilhantes: a estrela Sirius ( $\alpha$ Canis Majoris), que se encontra a 8,6 anos-luz do Sistema Solar, o sistema Alpha Centauri - o sistema estelar mais próximo do Sistema Solar (4,3 anos-luz) - e a estrela Procyon ( $\alpha$ Canis Minoris), situada a 11,4 anos-luz. 


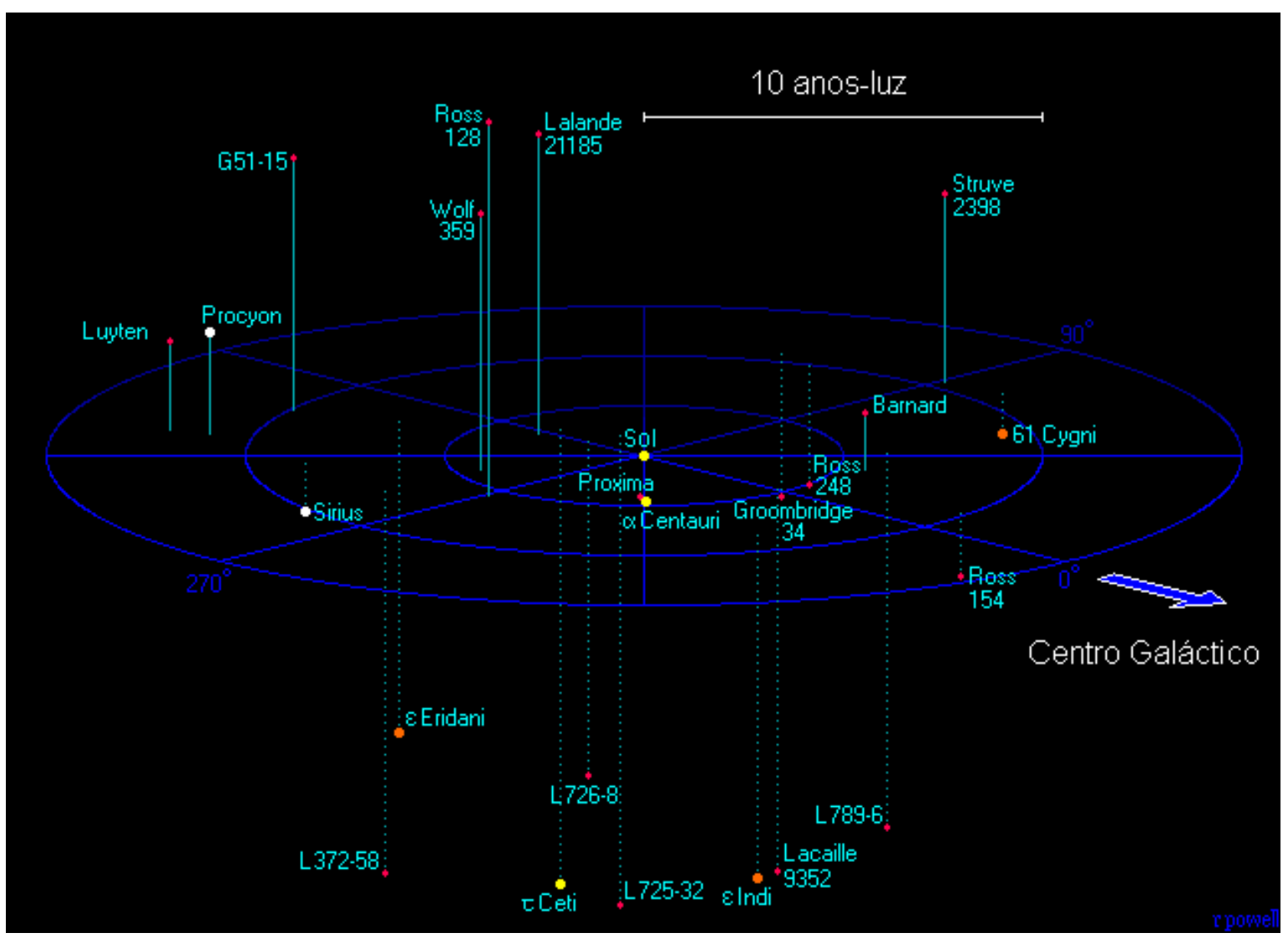

Fig.2.3 - A vizinhança do Sol em um raio de 12,5 anos-luz. Gráfico de R. Powell, extraído de http://www.atlasoftheuniverse.com/12lys.html.

\section{4 - Movimento do Sol para o ápex}

Em relação às estrelas próximas (situadas na vizinhança solar), o Sol, e todo o Sistema Solar, se desloca para um ponto do espaço situado entre as constelações de Lyra e Hercules, denominado ápex solar. O Sol desloca-se para o ápex com velocidade de 19,7 \pm $0,5 \mathrm{~km} / \mathrm{s}$ em relação a um referencial ligado às estrelas vizinhas. Nesse movimento a Terra descreve uma trajetória helicoidal em relação às estrelas, ao passo que, em relação ao Sol, descreve uma órbita elíptica. 


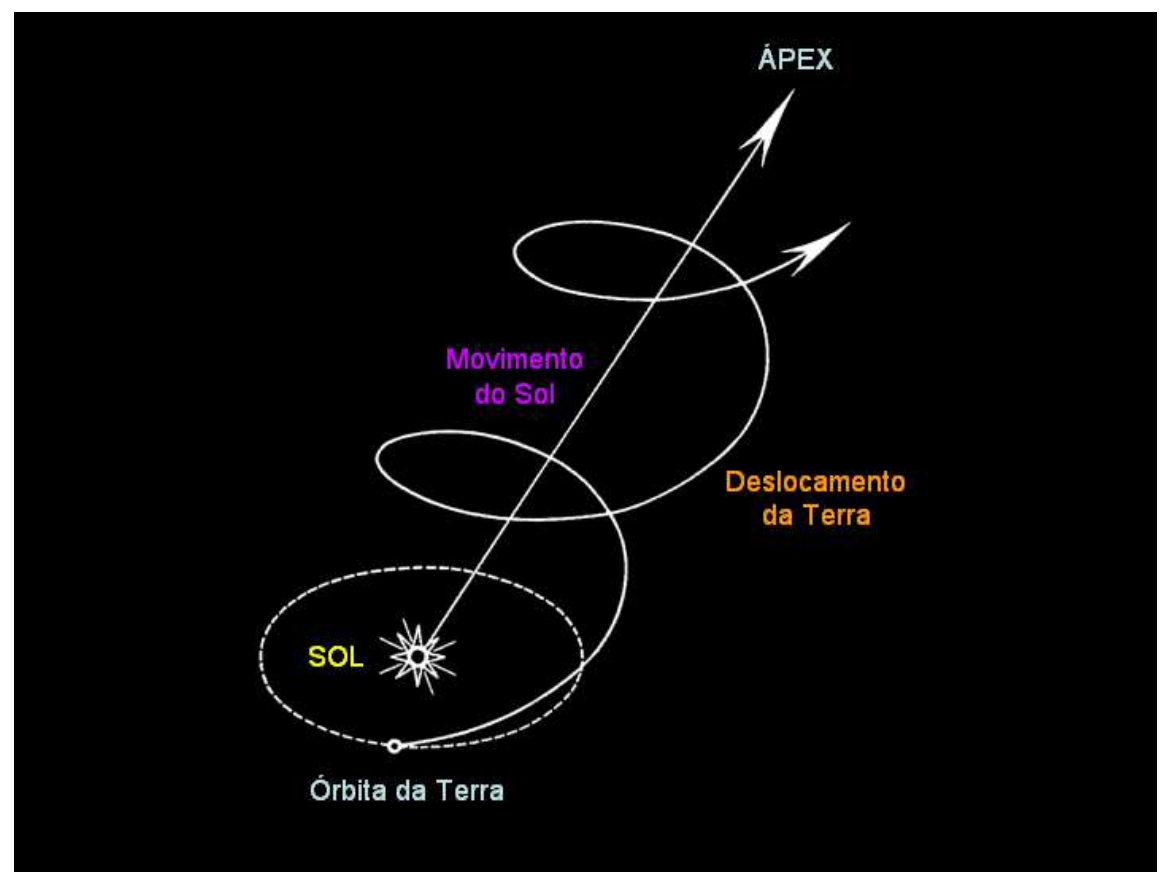

Fig 2.4 - Movimento do Sol (e do Sistema Solar) para o ápex. Ilustração adaptada pelo autor a partir de ilustração do livro Astronomia de Rudaux e Vaucouleur.

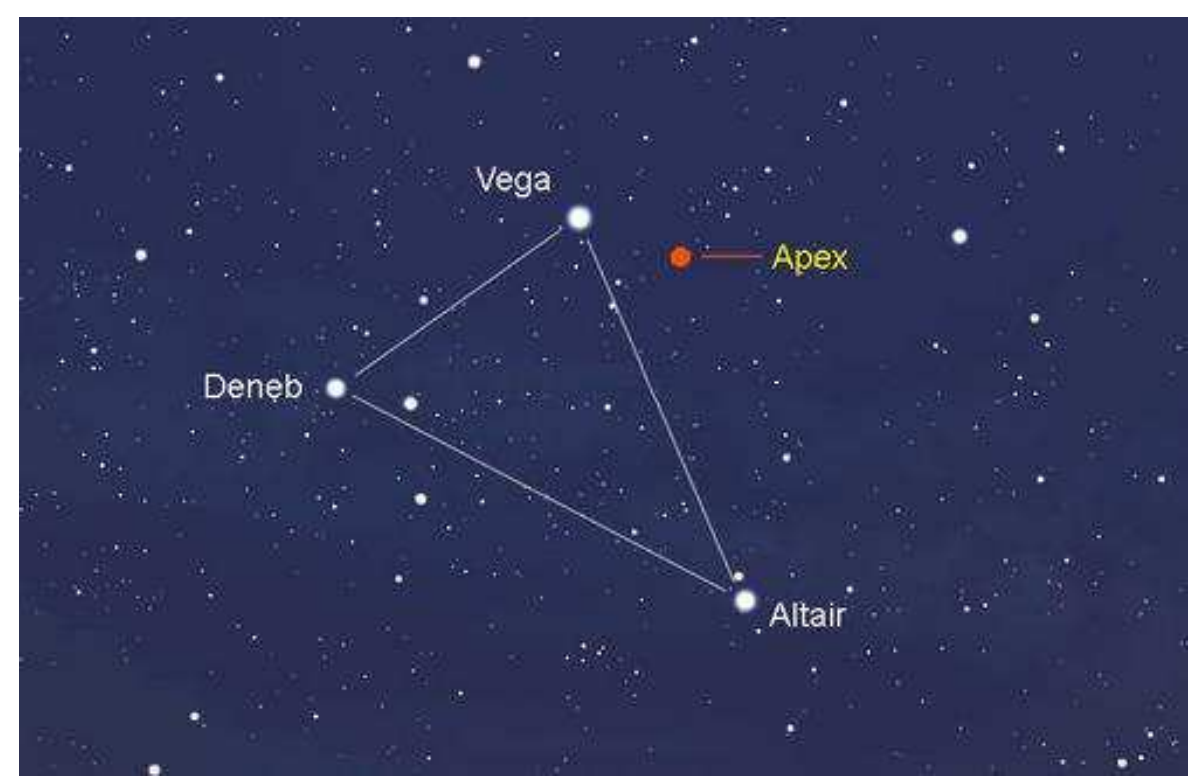

Fig 2.5 - Posição do ápex na esfera celeste. Adaptada https://astrobob.areavoices.com/2009/07/04/headlonginto-the-celestial-abyss/

\section{GLOSSÁRIO}

Ano-luz: unidade de distância que corresponde à distância percorrida pela luz, no vácuo, em um ano. Como a luz se desloca à velocidade de $299.792,458 \mathrm{~km} / \mathrm{s} \mathrm{e}$, em um ano, temos $365,25 \times 24 \times 60 \times 60 \mathrm{~s}=31.557 .600$ segundos, o valor do ano-luz será $\approx 9,461 \times 10^{12} \mathrm{~km}$, isto é, 9 trilhões e 461 bilhões de km, aproximadamente. A luz do Sol demora apenas $8 \mathrm{~min}$ e 19s para vir do Sol até a Terra. 


\section{3 - APRESENTANDO DO SOL}

Distando da Terra cerca de 150 milhões de quilômetros, o Sol é a única estrela do Sistema Solar. É uma estrela amarela com temperatura superficial de 5.770K. Sua massa é cerca de 740 vezes a massa reunida dos demais constituintes do sistema e superior a 330.000 vezes a massa da Terra. É o maior astro do Sistema Solar, com um diâmetro de $1.392 .000 \mathrm{~km}$, sendo, em volume, mais de 1.300 .000 vezes maior do que a Terra.

Embora nos pareça muito grande, quando comparado com outras estrelas, o Sol possui dimensões modestas. Há estrelas, como Antares, na constelação do Escorpião e Betelgeuse, na constelação de Órion, que são milhões de vezes maiores que o Sol em volume. Em compensação há, também, estrelas muito menores do que ele. De um modo geral, os astrônomos consideram o Sol uma estrela anã ${ }^{10}$.

Toda a energia que o Sol produz provém de reações nucleares que ocorrem em seu interior, transformando hidrogênio em hélio. No seu estado atual de evolução, nosso Sol está constituído por $73,2 \%$ de hidrogênio, $25,3 \%$ de hélio e $1,5 \%$ de elementos químicos mais pesados. Os modelos atuais dos astrofísicos permitem concluir que uma estrela como o Sol deva existir por 10 bilhões de anos aproximadamente e a estimativa de sua idade atual nos leva à conclusão que cerca da metade desse tempo já se passou.

A enorme quantidade de energia irradiada pelo Sol para o espaço $\left(3,9 \times 10^{26} \mathrm{~J} / \mathrm{s}\right)$ atinge o nosso planeta na taxa de $1,4 \times 10^{3} \mathrm{~W} / \mathrm{m}^{2}$. Tem sido um desafio para os cientistas o seu aproveitamento de maneira eficiente e de modo economicamente viável.

Por ser um astro de massa muito maior que a da Terra, a aceleração da gravidade em sua superfície é tremendamente mais intensa: cerca de $274 \mathrm{~m} / \mathrm{s}^{2}$. Os corpos nas proximidades de sua superfície teriam, portanto, um peso 27,4 vezes maior do que têm

\footnotetext{
${ }^{10}$ A forma mais correta é denominá-lo de estrela da seqüência principal. O termo "estrela anã" é, muitas vezes, empregado para designar as estrelas da chamada sequiência principal do diagrama de HertzsprungRussell.
} 
aqui na Terra. Uma pessoa com $70 \mathrm{~kg}$, por exemplo, que na Terra pesa ao redor de $700 \mathrm{~N}$, pesaria, na superfície do Sol, quase $19.200 \mathrm{~N}$ !

O Sol apresenta um lento movimento de rotação ao redor de seu eixo, completando uma volta em 25,38 dias na sua região equatorial ${ }^{11}$. Além dele, realiza um movimento de translação ao redor do centro da Galáxia, completando uma volta a cada 220 milhões de anos, aproximadamente. Com uma idade estimada em cerca de cinco bilhões de anos, desde o seu surgimento, o Sol efetuou, portanto, pouco mais de 22 voltas ao redor do núcleo galáctico.

Não só em massa e volume o Sol pode ser considerado uma estrela modesta. Quando se compara o seu brilho com o das demais estrelas também chegamos à conclusão de sua pequena emissão de energia. Por estar muito próximo da Terra, o Sol é o astro mais brilhante do céu. Muitas estrelas que vemos à noite no céu têm, na realidade, um brilho próprio (intrínseco) muito maior que o do Sol. Aparentam ser astros de fraco brilho em virtude das grandes distâncias que as separam da Terra.

Para efetuar uma comparação entre os brilhos intrínsecos (reais) das estrelas, os astrônomos idealizaram um sistema muito interessante. Se todas as estrelas pudessem ser colocadas hipoteticamente à mesma distância da Terra, as diferenças entre os seus brilhos não mais seriam devidas às diferenças de suas distâncias, mas às diferenças reais entre eles.

Convencionou-se a distância padrão de 32,6 anos-luz para estabelecer a comparação. Se o Sol estivesse a essa distância da Terra, o seu brilho seria comparável a uma estrela de magnitude cinco ( $5^{\mathrm{a}}$ grandeza, na linguagem antiga). Nessa distância, o Sol nos pareceria de brilho quase tão fraco quanto as estrelas mais tênues que podemos observar no céu à vista desarmada.

Essa é uma característica do Sol, citada ainda em muitos livros didáticos escritos para uso nas escolas brasileiras: quase todos eles afirmam que o Sol é uma estrela de $5^{\text {a }}$ grandeza, sem apresentar qualquer explicação do seu significado. Neste ponto, apresentase, ainda, uma questão interessante: os mesmos textos costumam afirmar que as estrelas

\footnotetext{
${ }^{11}$ Como veremos mais adiante, o período de rotação do Sol depende da latitude heliográfica considerada, diminuído do equador para os pólos.
} 
mais brilhantes do céu são as de $1^{\mathrm{a}}$ grandeza e as de brilho mais fraco são as de $6^{\mathrm{a}}$ grandeza. Os alunos, certamente, devem ficar muito confusos ao tentarem entender porque o Sol é uma estrela de $5^{a}$ grandeza sendo o astro mais brilhante que se pode observar no céu!

\section{1 - Observando o Sol com segurança}

Observar o Sol requer extremo cuidado. A grande intensidade da radiação solar pode produzir cegueira quase instantânea. Um simples experimento que pode ser realizado com supervisão do professor é concentrar a luz solar com uma lente convergente, em um pedaço de papel. Logo se verá o aparecimento de uma pequena fumaça denunciando a queima do material.

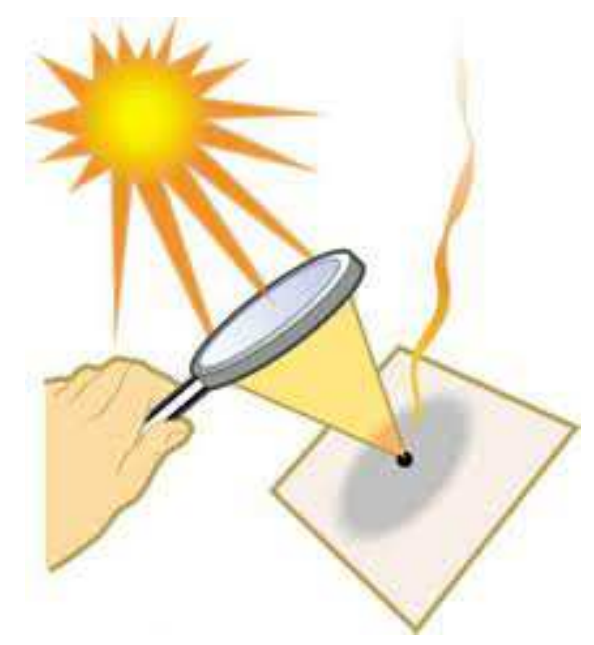

Fig. 3.1 - Concentrando a luz do Sol em uma folha de papel com uma lente convergente. Figura extraída de https://cienciasnoseculoxxi.wordpress.com/tag/lentes-convergentes/

Os telescópios refratores e os binóculos têm objetivas constituídas por lentes convergentes que concentram a luz solar. Os espelhos dos telescópios refletores fazem o mesmo. Por isso, NUNCA SE DEVE APONTAR UM EQUIPAMENTO ÓPTICO PARA O SOL sem a devida proteção. A radiação solar concentrada pelas objetivas dos equipamentos ópticos pode produzir cegueira quase instantânea. Nas atividades práticas de observação do Sol e de eclipses solares que a Escola Municipal de Astrofísica promovia junto ao público, sempre foi enfatizada a necessidade de se utilizar meios seguros na observação. Paralelamente a isso, uma série de métodos inadequados, embora muito 
difundidos, eram de conhecimento de grande parte do público. Por isso, antes de indicar os procedimentos seguros, alertava-se sobre maneiras inadequadas de se observar o Sol.

Devem ser evitadas e amplamente divulgadas entre os estudantes os seguintes procedimentos inadequados, para que não sejam utilizados:

1. "Sanduíches" formados com pedaços de filmes preto e branco velados ou "sanduíches" de pedaços de filmes coloridos velados (este último "método" é ainda pior);

2. Vidros "esfumaçados", vidros coloridos, pedaços de garrafas escuras, vidros "filmados";

3. Olhar para o reflexo do Sol em uma bacia com água;

4. Utilizar óculos escuros, lentes polaróides ou óculos que "filtram" o ultravioleta, mesmo que de acordo com o fabricante, a redução de ultravioleta seja grande;

5. Papéis celofanes de quaisquer cores em folhas simples ou associados em "sanduíches";

6. Pedaços escuros de radiografias (chapas de raios-X);

7. Não utilizar filtros que se acoplem à OCULAR do seu telescópio, mesmo que tenham vindo junto com o telescópio e indicados pelo fabricante. A concentração da radiação solar pode romper o filtro expondo repentinamente os olhos à radiação causando sérios riscos à visão.

\section{2 - Observando o Sol com placas filtrantes (filtros)}

Para a observação direta sem uso de binóculos ou telescópios é recomendada utilização de uma placa filtrante (vidro para máscara de soldador), com numeração mínima 14, como ilustrado na figura 3.2 adiante. Os vidros para máscara de soldador são placas retangulares de vidro escuro com dimensões $5,0 \mathrm{~cm}$ de largura por $10,8 \mathrm{~cm}$ de comprimento e espessura de $0,2 \mathrm{~cm}$.

As placas filtrantes são capazes de transmitir apenas 0,00027\% da radiação incidente. A imagem do Sol observada com este tipo de filtro fica com coloração ligeiramente esverdeada. A observação (figura 3.3) pode ser feita em curtos intervalos de tempo (por 15 segundos) seguido por um período de 2 minutos de descanso, antes de efetuar nova observação. 


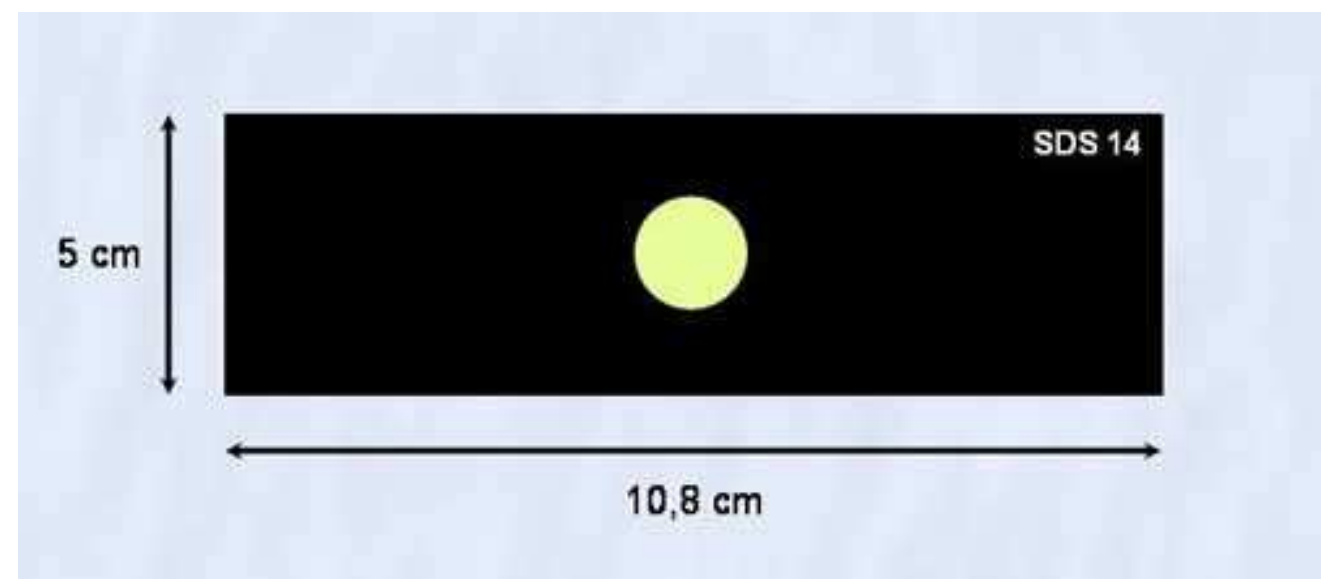

Fig. 3.2 - Imagem do Sol produzida com uma placa filtrante (vidro de soldador) $\mathrm{n}^{\mathrm{o}} 14$ adequada para a observação visual do Sol.

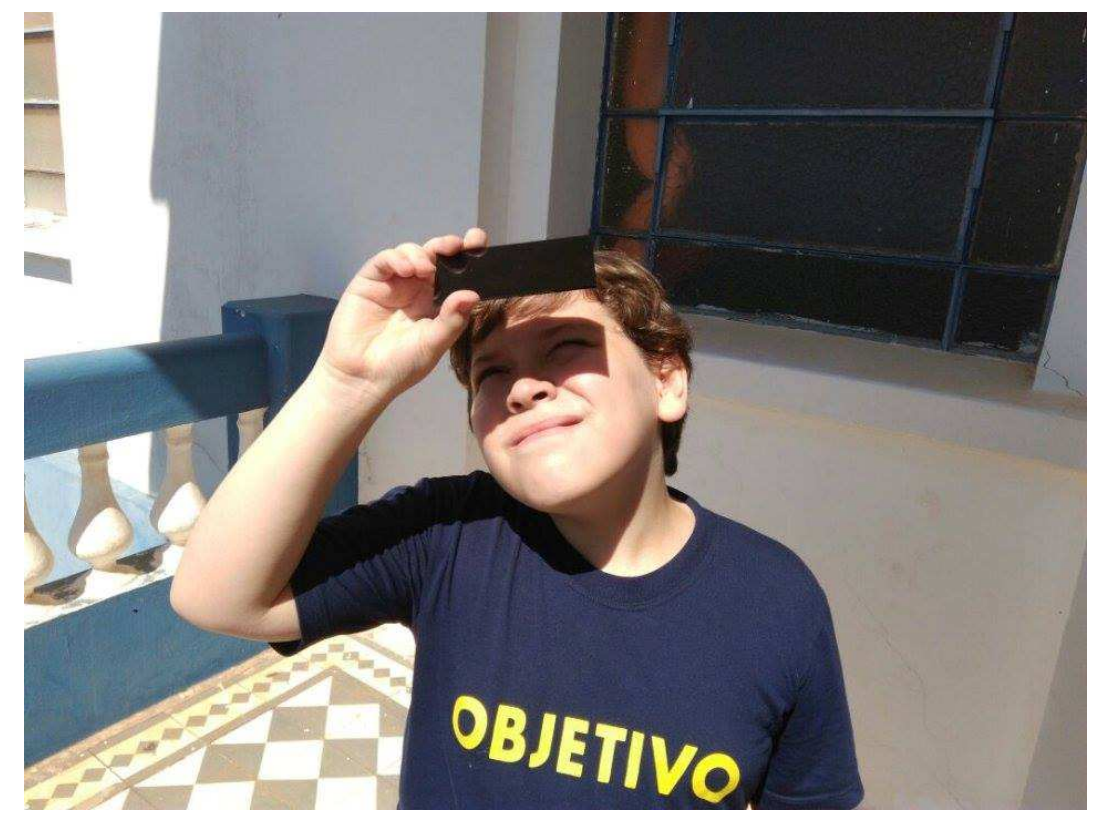

Fig. 3.3 - Observação do Sol com uma placa filtrante (vidro de soldador) $\mathrm{n}^{\circ} 14$ adequada para a observação visual do Sol. (Foto de Munique Bassoli).

\section{3 - Observando o Sol por projeção}

A maneira mais prática e segura de observar o Sol com equipamentos ópticos é pelo método da projeção. A imagem do Sol é projetada em um anteparo branco (uma cartolina, por exemplo) não apresentando qualquer risco aos observadores, além de permitir que 
várias pessoas observem o Sol simultaneamente, com imagem ampliada, e possam acompanhar as eventuais explicações de um professor.

Dispondo de equipamentos adequados é altamente recomendado que os professores efetuem observações do Sol com seus alunos. Além de produzir uma aula agradável ao ar livre, permitirá o ensino de observação segura além de, possivelmente, despertar o interesse de algum aluno para a Astronomia.

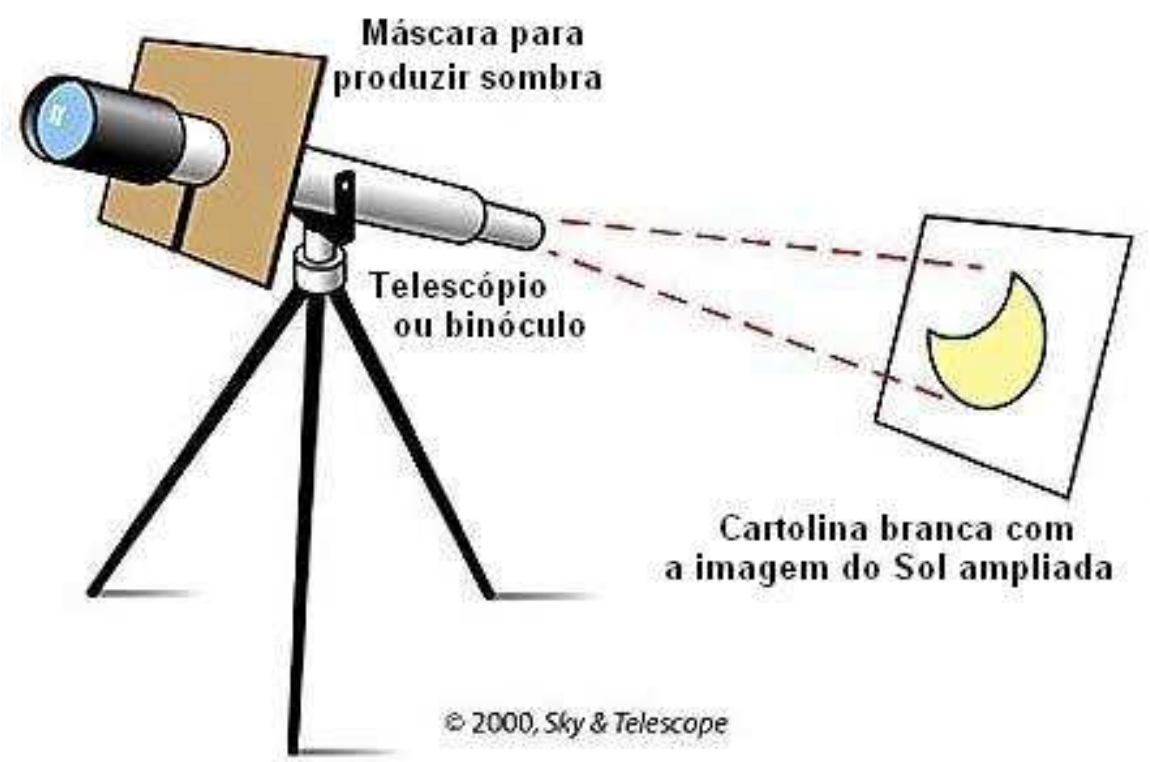

Fig. 3.4 - Método seguro de observar o Sol: imagem solar de um eclipse solar projetada em um anteparo, permitindo que diversas pessoas observem simultaneamente e sem risco de danos à vista. Diagrama reproduzido de Sky and Telescope.

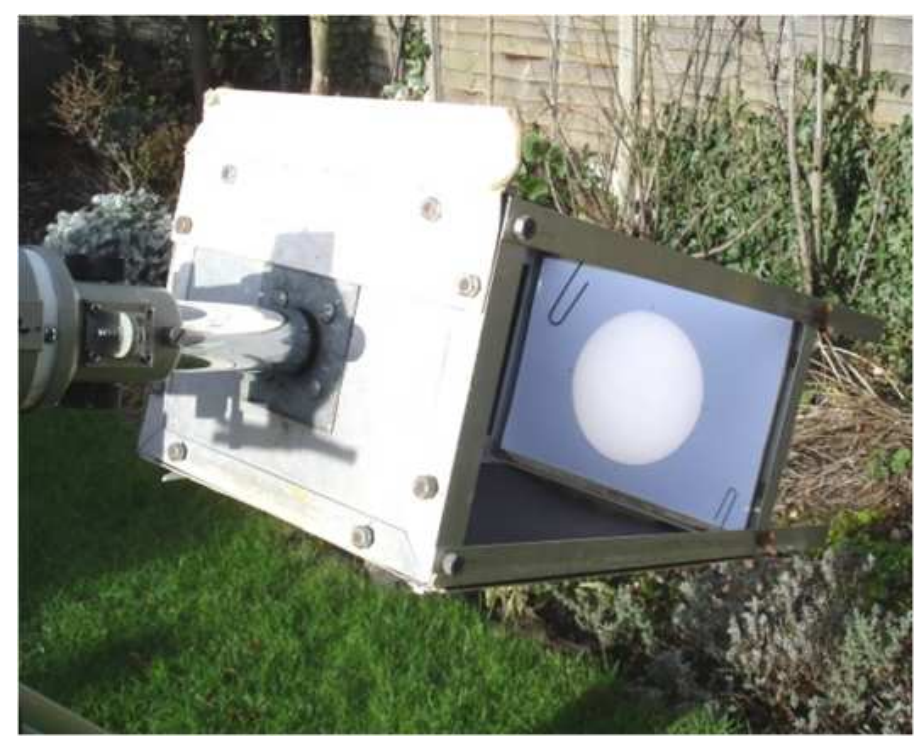

Fig. 3.5 - A imagem solar ampliada e projetada em um anteparo, com o uso de uma luneta (telescópio refrator) de pequeno porte. 


\section{4 - Observando o Sol com o "Sunspotter"}

Um equipamento muito interessante destinado à observação segura do Sol, permitindo a observação simultânea por várias pessoas, é o Sunspotter. O equipamento de custo relativamente elevado para ser adquirido individualmente, apresenta um custo razoável para a aquisição institucional. A Escola Municipal de Astrofísica possui cinco desses equipamentos que são colocados periodicamente à disposição do público nos eventos monitorados de observação do Sol.

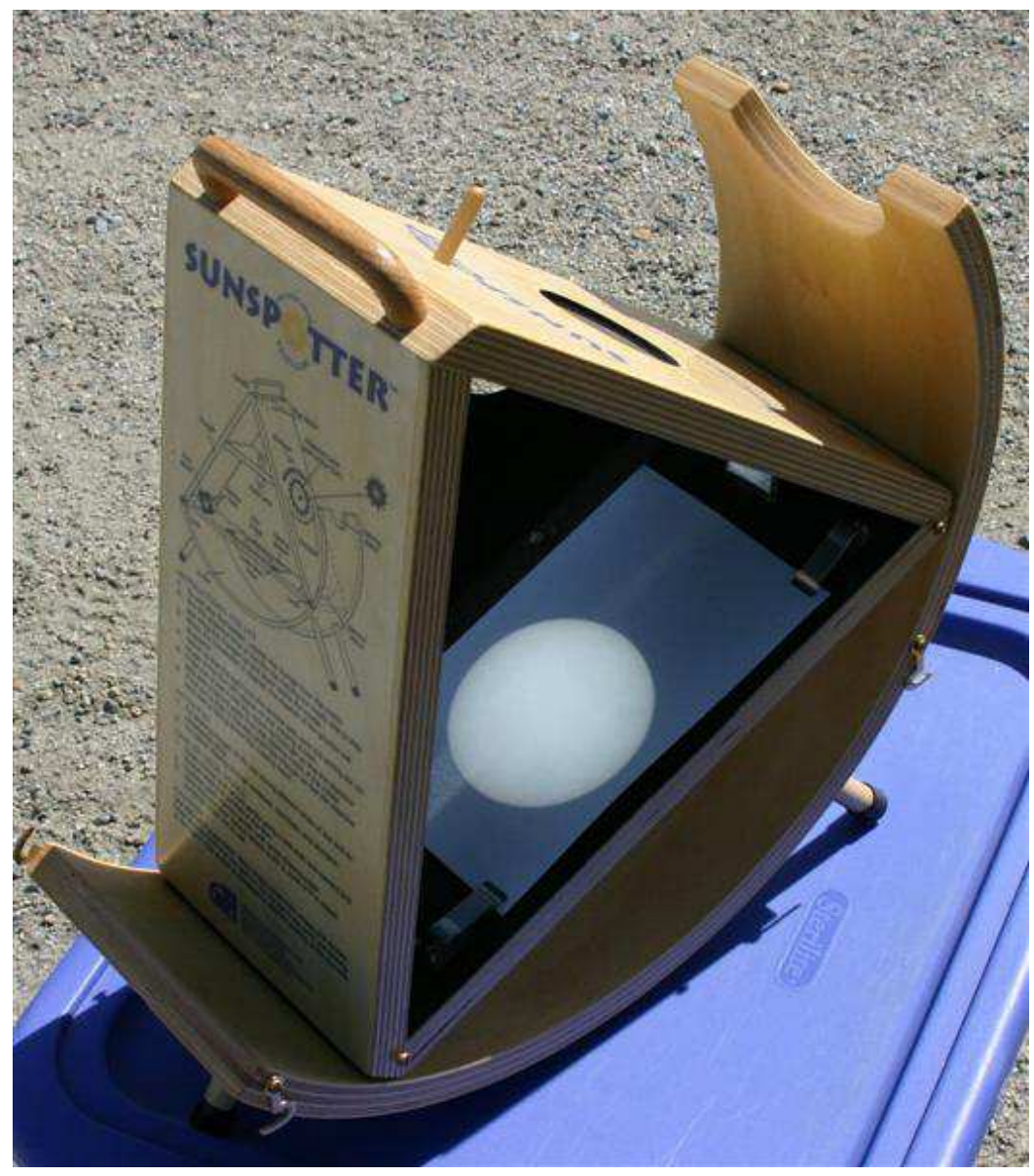

Fig. 3.6 - O Sol observado em um sunspotter. Após várias reflexões a imagem solar é projetada sobre uma cartolina ou um formulário destinado a registrar os fenômenos observados. 


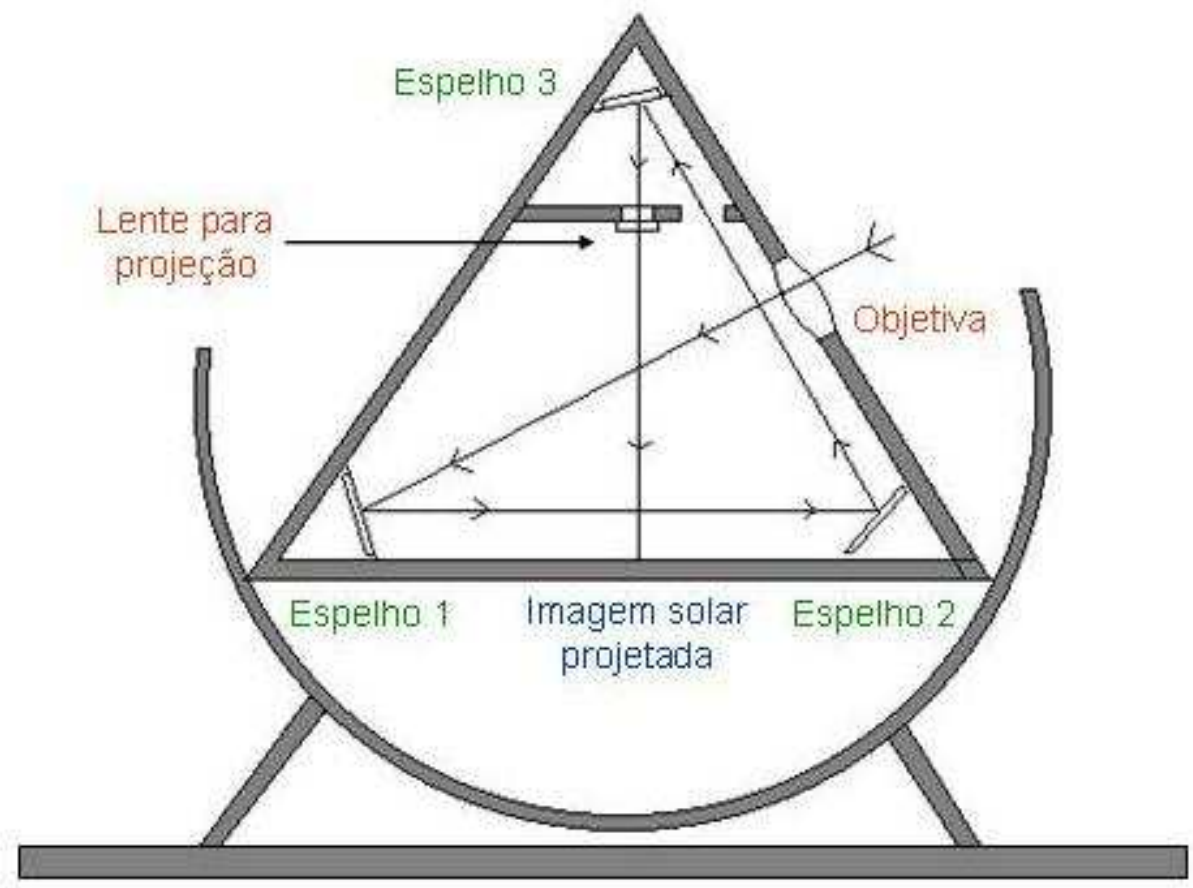

Fig. 3.7 - O esquema óptico de um sunspotter. Diagrama modificado pelo autor a partir de gráfico obtido em http://mariabelgien.blogspot.com.br/2012/06/venus-transit.html

Equipamentos alternativos, construídos com inspiração no sunspotter produzem o mesmo efeito e permitem a confortável observação segura do Sol. A figura 3.8 apresenta o equipamento desenvolvido no Planetário de Stuttgart (Alemanha):

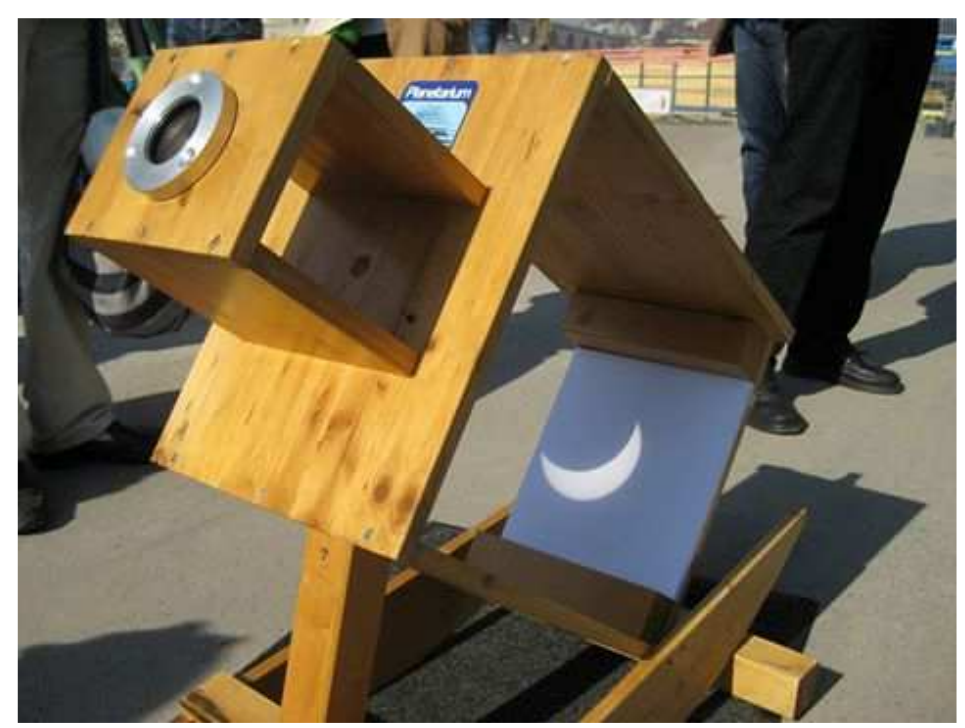

Fig.3.8 - Imagem de um eclipse do Sol projetada em uma cartolina com o uso de um equipamento de projeção produzido no Planetário de Stuttgart (Alemanha). 


\section{4 - DISTÂNCIA E TAMANHO DO SOL}

Em meados do século XVII, os astrônomos sentiam-se ainda desconfortáveis por não conhecer as distâncias dos planetas nas unidades que estavam acostumados a utilizar no dia a dia. O diâmetro da Terra, o da Lua e a distância Terra-Lua já eram conhecidos nestas unidades desde a antiguidade. As dos planetas não, e pelo simples fato da distância Terra-Sol não ser conhecida em valor absoluto. Copérnico já havia determinado o valor das distâncias dos planetas ao Sol tomando-se como unidade, a distância Terra-Sol. Era, então, necessário determinar o valor da distância Terra-Sol para se obter as distâncias dos planetas.

Somente em 1672 esse valor tornou-se conhecido a partir dos cuidadosos trabalhos de observação dos astrônomos Jean Dominique Cassini ${ }^{12}$ (1625-1712) e do francês Jean Richer (1630-1696). Eles efetuaram delicadas medidas da posição de Marte em relação às estrelas, durante a oposição do planeta em setembro de 1672, obtendo a sua paralaxe.

\section{1 - Paralaxe para os astros do Sistema Solar}

O fenômeno da paralaxe pode ser percebido quando observamos um mesmo astro (ou um mesmo objeto) a partir de dois pontos separados por uma certa distância (os pontos não podem estar alinhados com o astro ou com o objeto). Se a distância entre os pontos de observação for suficientemente grande, perceberemos uma mudança na posição de um astro, referida, por exemplo, a outros astros. Algumas estrelas quando observadas a partir de duas posições da Terra separadas pelo intervalo de seis meses (posições separadas pela distância de cerca de $300.000 .000 \mathrm{~km}$ ) apresentam um pequeno deslocamento em relação às estrelas de fundo.

\footnotetext{
${ }^{12}$ Giovanni Domenico Cassini, astrônomo italiano, nascido em 1625, foi convidado em 1668, pelo Rei Luis XIV, para ser um observador na Academia de Ciências de Paris. Com a instalação do Observatório de Paris em 1672, foi convidado a dirigi-lo. Naturalizou-se francês e mudou seu nome para Jean Dominique Cassini. Permaneceu no cargo até a sua morte em 1712, tendo sido sucedido pelo seu filho Jacques Cassini.
} 
Astros do Sistema Solar quando observados a partir de dois pontos na superfície terrestre e separados por uma distância considerável, também apresentam deslocamentos em relação às estrelas de fundo. A medida desse deslocamento nos fornece meios para determinar as distâncias dos planetas à Terra. Para os astros do Sistema Solar, definimos paralaxe planetária ou, simplesmente paralaxe, como o ângulo sob o qual um hipotético observador situado nesse astro veria o raio equatorial da Terra.

Assim, considerando a Terra esférica e um astro do Sistema Solar situado em um ponto $\mathrm{P}$ do espaço, o hipotético observador estará vendo o raio terrestre (OT) sob o ângulo $\mathrm{p}_{\mathrm{o}}$. Ao mesmo tempo, o astro $\mathrm{P}$ estará no horizonte para um observador localizado no ponto $\mathrm{O}$ da superfície terrestre (figura 4.1).

Por isso, a paralaxe planetária é também chamada de paralaxe horizontal. A paralaxe da Lua, por exemplo é de 57,2' em média. Seu valor é variável pois a distância Terra-Lua se altera muito durante o período de revolução da Lua ao redor da Terra.

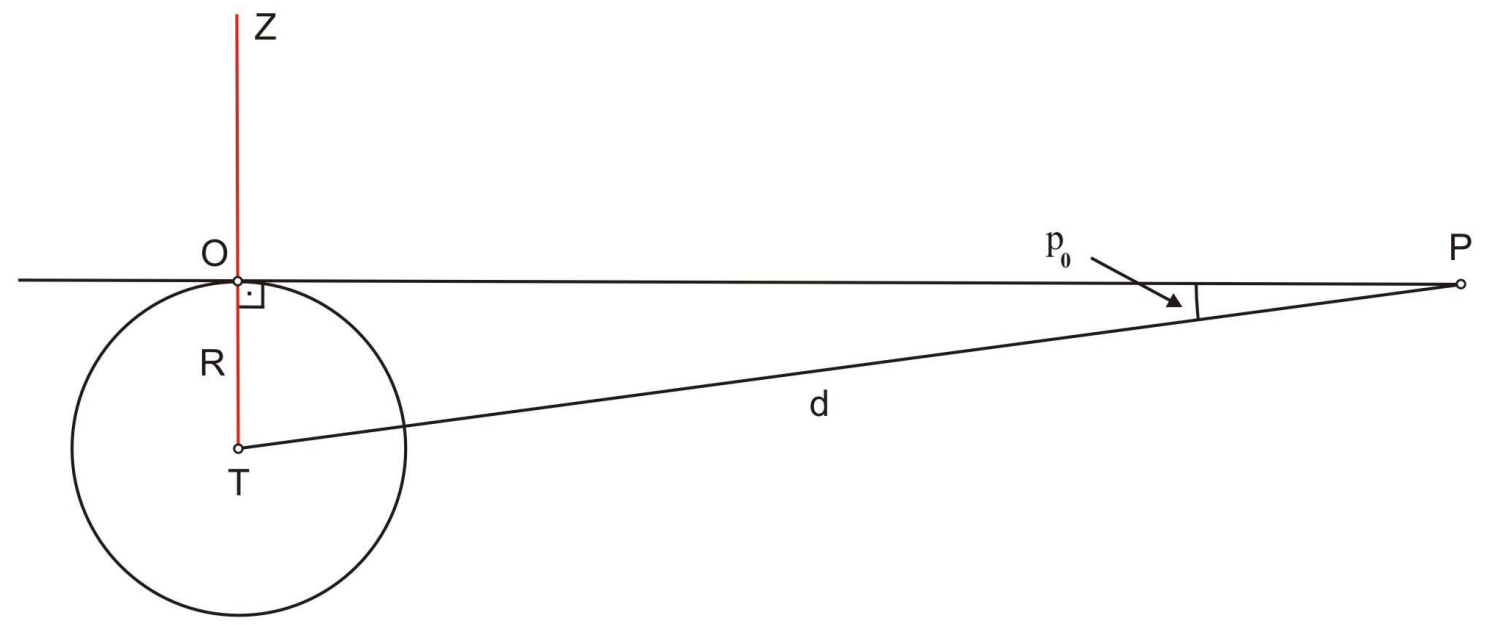

Fig. 4.1 - Paralaxe de um astro do Sistema Solar. O observador encontra-se no ponto O da superfície terrestre e P é um astro que se encontra em seu horizonte.

Como o triângulo PTO é retângulo, sen $\mathrm{p}_{\mathrm{o}}=\mathrm{R}_{\oplus} / \mathrm{d}$. Sendo $\mathrm{p}_{\mathrm{o}}$ um ângulo pequeno, $\sin \mathrm{p}_{\mathrm{o}} \approx \mathrm{p}_{\mathrm{o}}$ (em radianos). $\mathrm{E}$ ainda, como um ângulo expresso em radianos relaciona-se com a sua medida em segundos de arco por: 


$$
\left(p_{o}\right)_{\text {rad }}=\frac{p_{o}{ }^{\prime \prime}}{206.265^{\prime \prime}}
$$

juntando-se as expressões anteriores, obtemos:

$$
p_{o}^{\prime \prime}=\frac{R_{\oplus}}{d} \times 206.265^{\prime \prime}
$$

No modelo do elipsoide de revolução para a Terra, se $\mathrm{R}_{\oplus}$ for o raio equatorial da Terra, $p_{o}$ é denominada paralaxe horizontal equatorial.

\section{2 - A paralaxe de Marte obtida por Cassini e Richer}

As observações de Marte foram efetuadas a partir de dois observatórios astronômicos bem distantes entre si: o Observatório de Paris, onde Cassini efetuou as suas medidas, e uma estação de observação localizada em Caiena, na Guiana Francesa, para onde Richer se dirigiu, em 1671. Na figura 4.2 ilustra-se como essa observação foi realizada.

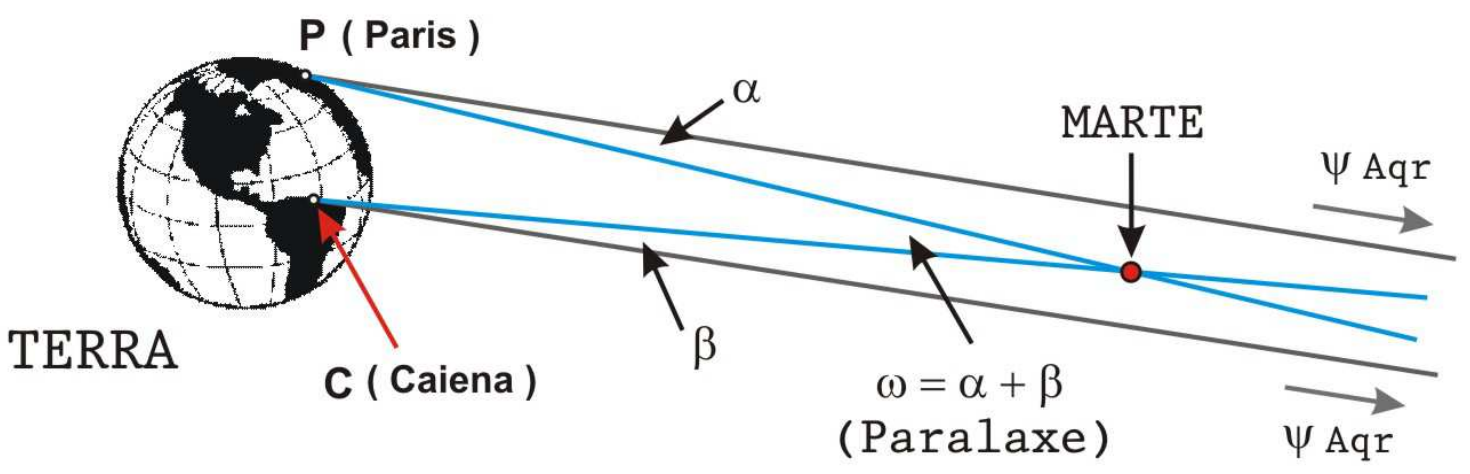

Fig. 4.2 - Observação do planeta Marte a partir dos observatórios situados em Paris e em Caiena. A separação angular entre Marte e a estrela $\psi$ Aquarii (ângulos $\alpha$ e $\beta$ ) foi medida nos dois locais e partir desses valores a paralaxe de Marte foi deduzida. 
Em uma mesma data e horário previamente estabelecidos, efetuaram medidas da separação angular de Marte em relação a uma das três estrelas da constelação de Aquarius, designadas por Bayer, em sua Uranometria ${ }^{13}$, com a letra $\psi(\mathrm{psi})$.

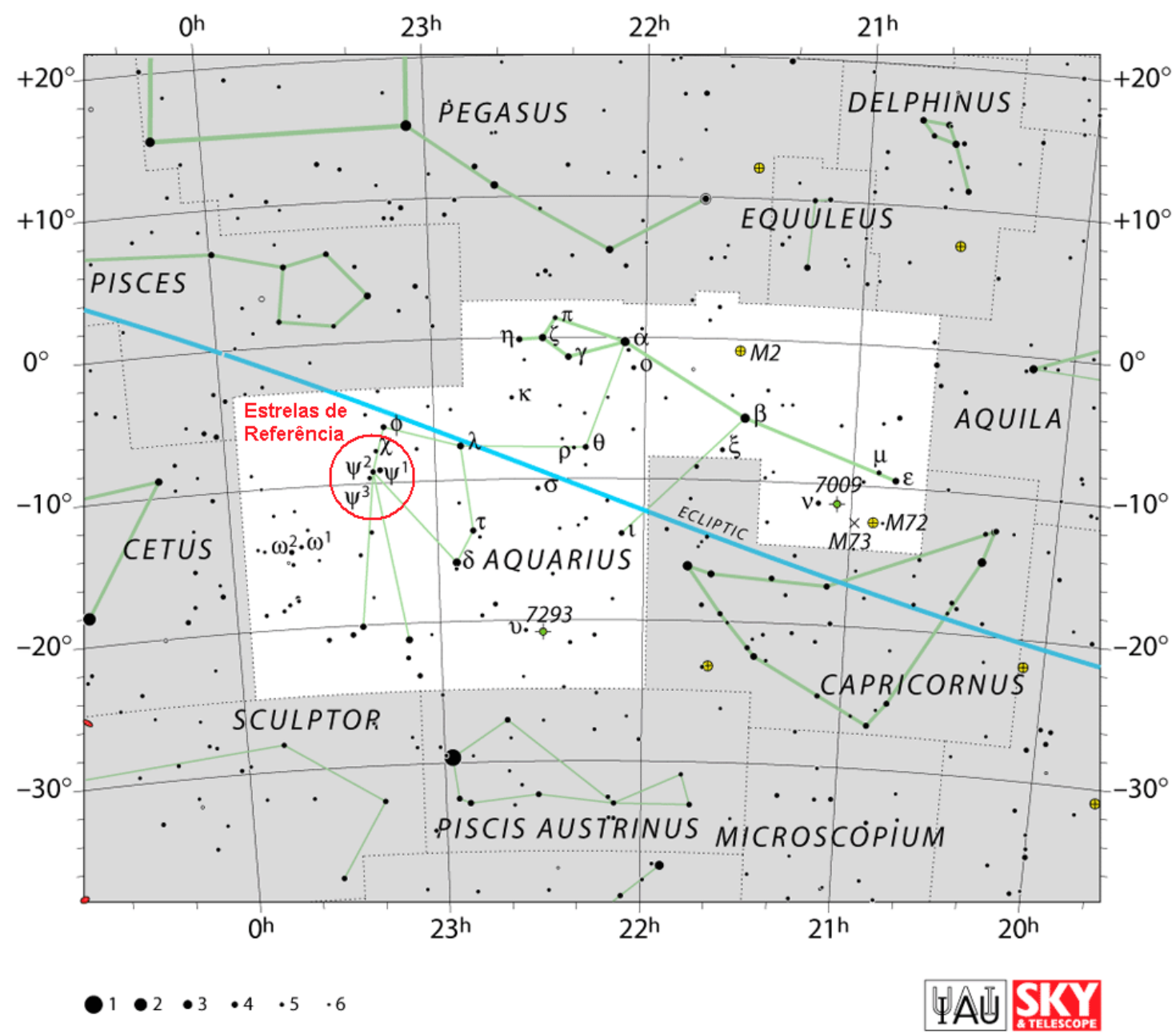

Fig. 4.3 - Carta celeste da constelação de Aquarius onde estão assinaladas as estrelas $\psi^{1}, \psi^{2}$ e $\psi^{3}$ utilizadas como referência por Cassini e Richer para determinar a paralaxe de Marte. Fonte: IAU e Sky and Telescope (https://www.iau.org/static/public/constellations/gif/AQR.gif)

Naquele ano, a oposição de Marte ocorreu em 08 de setembro e os astrônomos, desde os trabalhos de Copérnico, Kepler e Tycho Brahe, já conheciam muito bem o movimento de Marte ao redor do Sol. Sabiam que esta era uma época de máxima

\footnotetext{
${ }^{13}$ Uranometria - Johannes Bayer - 1603. Nessa obra o astrônomo alemão criou a nomenclatura científica das estrelas designando-as com as letras do alfabeto grego. A designação de uma estrela passou a ser composta de uma letra grega seguida pelo genitivo latino da constelação em que se encontrava. A estrela a que nos referimos acima seria designada como $\psi$ (psi) Aquarii.
} 
aproximação de Marte em relação à Terra, pois sua oposição ocorreria próxima ao seu periélio. As medidas foram efetuadas em 05 de setembro de 1672, três dias antes da oposição.

A observação foi feita em melhores condições por Richer que tinha Marte elevado a mais de $70^{\circ}$ em relação ao horizonte, ao passo que, em Paris, sua altura não ultrapassava os $30^{\circ}$ (a declinação de Marte no dia de sua oposição, em 1672, era $\delta=-10^{\circ} 32^{\prime}$ ). Verificaram que, na mesma data e no mesmo instante, o afastamento angular de Marte em relação à estrela $\psi$ Aquarii medido em Paris e em Caiena não era o mesmo, denunciando a existência de uma paralaxe.

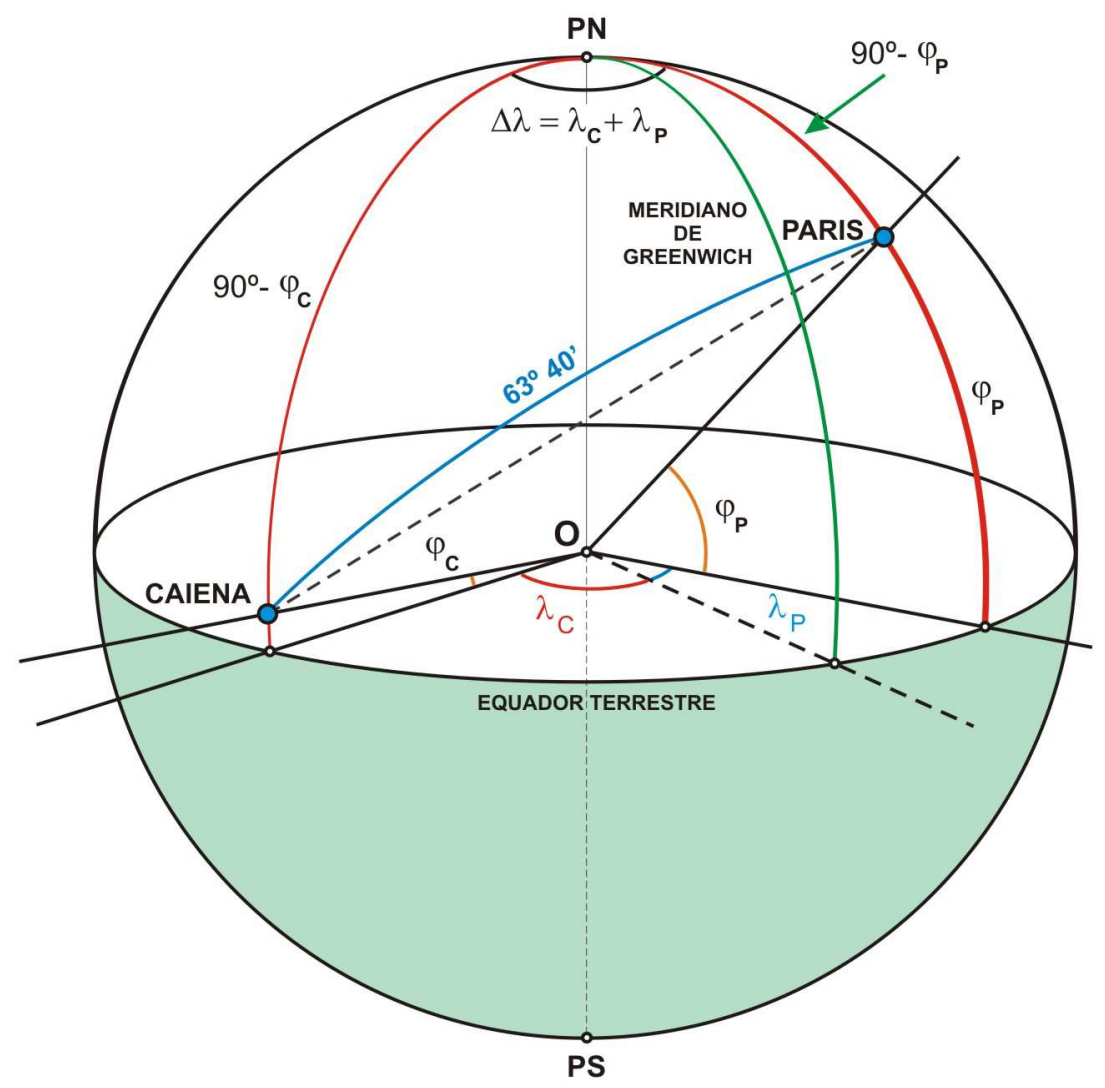

Fig. 4.4 - Distância Paris-Caiena, ao longo do círculo máximo que une as duas cidades. Uma vez conhecido o arco PC (Paris-Caiena) é possível calcular, com a geometria elementar, o comprimento da corda que une as duas cidades (linha tracejada).

A distância entre as duas cidades ao longo da corda que as une era conhecida. Seu valor havia sido determinado previamente a partir do conhecimento das coordenadas geográficas dessas cidades e do raio $\mathrm{R}_{\oplus}$ da Terra. 
Para exemplificar o procedimento que permite obter a distância entre dois pontos da superfície da Terra ao longo da corda que os une e que se repete em diversas outras determinações de distâncias, vamos considerar (figura 4.4) o triângulo esférico com vértices em Paris, Caiena e no pólo norte da Terra $(\mathrm{PN})$. O arco de círculo máximo CP que passa por Caiena e Paris pode ser calculado a partir da lei dos cossenos da Trigonometria Esférica:

$$
\cos C P=\operatorname{sen} \varphi_{C} \operatorname{sen} \varphi_{P}+\cos \varphi_{C} \cos \varphi_{P} \cos \Delta \lambda
$$

onde $\varphi_{\mathrm{C}}$ e $\varphi_{\mathrm{P}}$ são, respectivamente, as latitudes de Caiena e Paris e $\Delta \lambda$ é o módulo da diferença entre as suas longitudes. Substituindo-se os valores para as duas cidades ${ }^{14}$, obtemos $\mathrm{CP}=63^{\circ} 40^{\prime}$. No plano do círculo máximo que contém as duas cidades e o centro da Terra, podemos construir o triângulo isósceles OCP, cujos lados congruentes OC $\equiv \mathrm{OP}$ têm por valor o raio da Terra $\left(\mathrm{R}_{\oplus}\right)$ e base igual à corda $\mathrm{CP}$. Os ângulos da base do triângulo ( $\angle \mathrm{C}$ e $\angle \mathrm{P}$ ) medem $58^{\circ} 10^{\prime}$, determinados a partir do ângulo com vértice em $\mathrm{O}$, cujo valor é $63^{\circ} 40^{\prime}$. A corda PC tem por valor:

$$
\mathrm{CP}=2 \mathrm{R}_{\oplus} \cos \left(58^{\circ} 10^{\prime}\right)=2 \mathrm{R}_{\oplus} \mathrm{x} 0,5274=1,0548 \mathrm{R}_{\oplus}
$$

Da definição de paralaxe e tendo em conta os elementos geométricos da figura 4.2, podemos escrever:

$$
\frac{\omega^{\prime \prime}}{206.265^{\prime \prime}}=\frac{\overline{C P}}{d}=\frac{1,0548 R_{\oplus}}{d}
$$

Dessa relação podemos calcular d (distância Terra-Marte):

$$
d=\frac{1,0548 \times 206.265^{\prime \prime} \times R_{\oplus}}{\omega^{\prime \prime}}=217.568,322^{\prime \prime} \frac{R_{\oplus}}{\omega^{\prime \prime}}
$$

O valor determinado por Cassini e Richer para o ângulo $\omega "=\alpha+\beta$ foi de 25 ".

\footnotetext{
${ }^{14}$ Coordenadas geográficas - Paris: $\varphi_{P}=+48^{\circ} 51^{\prime}$ e $\lambda_{P}=-02^{\circ} 20^{\prime}$. Caiena : $\varphi_{C}=+04^{\circ} 56^{\prime}$ e $\lambda_{C}=+52^{\circ}$ 20 '.
} 
Deve-se ter em conta que as linhas de visada para a estrela $\psi$ Aquarii a partir de Paris e de Caiena são sensivelmente paralelas. Por esse motivo, temos $\omega^{\prime \prime}=\alpha+\beta$. Substituindo-se esse valor e o do raio da Terra $R_{\oplus}(6.400 \mathrm{~km})$ obtemos, em nossas unidades habituais de distância, aproximadamente, $\mathrm{d}=55.700 .000 \mathrm{~km}$, para a distância Terra-Marte. Nas recentes aproximações periélicas de Marte, a sua distância à Terra têm sido da ordem de $56.000 .000 \mathrm{~km}$, evidenciando a grande acuidade do trabalho de Cassini e Richer.

Estando Marte em oposição, como no alinhamento Sol-Terra-Marte - STM ilustrado na figura 4.5, Cassini e Richer determinaram o valor da distância TM. Como era do conhecimento que a distância de Marte ao Sol (SM), nas oposições em que Marte está próximo do seu periélio era de 1,4 vezes a distância da Terra ao Sol ( $\mathrm{SM}=1,4$ x ST ), temos então:

$$
\mathrm{SM}=\mathrm{ST}+\mathrm{TM}
$$

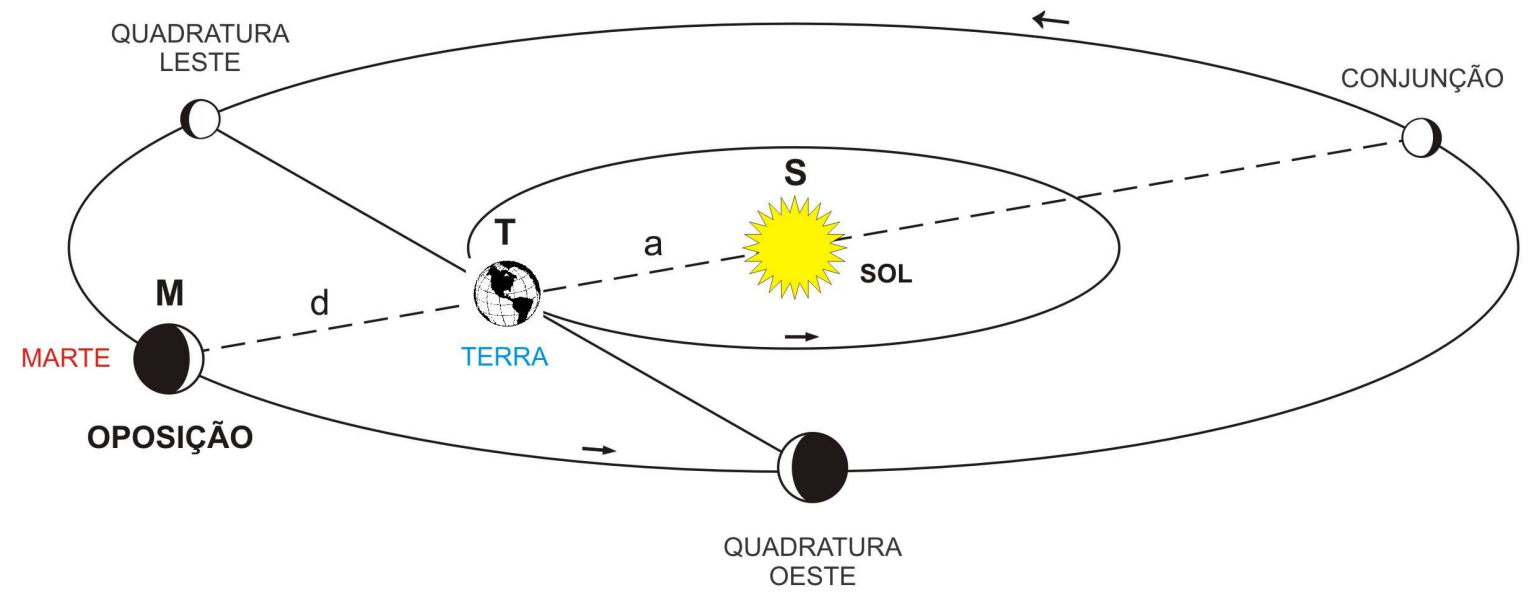

Fig. 4.5 - Oposição do planeta Marte.

Considerando a distância Terra-Sol ST = a e a distância Terra-Marte TM = d, segue-se que

$$
1,4 \mathrm{a}=\mathrm{a}+\mathrm{d} \quad \rightarrow \quad \mathrm{a}=\mathrm{d} / 0,4
$$

Obtemos, então, 


$$
a=\frac{d}{0,4}=\frac{55.700 .000 \mathrm{~km}}{0,4}=139.250 .000 \mathrm{~km}
$$

A partir desse valor para a distância Terra-Sol, Cassini e Richer apresentaram o seguinte valor para a paralaxe solar, como era o costume na época:

$$
p^{\prime \prime}=\frac{R_{\oplus}}{d} \times 206.265^{\prime \prime}=\frac{6.400 \times 206.265^{\prime \prime}}{139.250 .000}=9,5^{\prime \prime}
$$

O valor por eles obtido para a paralaxe solar difere muito pouco ( $\left.0,7^{\prime \prime}\right)$ do valor atualmente aceito de 8,8 " e permitiu que todas as distâncias dos planetas ao Sol se tornassem conhecidas em valores absolutos e, sua determinação, foi um grande passo para a Astronomia.

\begin{tabular}{|c|c|c|c|c|}
\hline Ano & Autor & Método & Paralaxe (") & Distância (km) \\
\hline 1672 & Cassini \& Richer & Paralaxe de Marte & 9,5 & 138.370 .000 \\
\hline 1672 & J. Flamsteed & Paralaxe de Marte & 10 & 130.000 .000 \\
\hline 1770 & L. Euler & Trânsito de Vênus 1769 & 8,82 & 151.225 .000 \\
\hline 1771 & J. de Lalande & Trânsito de Vênus 1769 & 8,5 & 154.198 .000 \\
\hline 1814 & J. Delambre & Trânsito de Vênus 1769 & 8,6 & 153.841 .000 \\
\hline 1823 & J.F. Encke & Trânsitos de Vênus 1761 e 1769 & 8,5776 & 153.375 .000 \\
\hline 1867 & S. Newcomb & Paralaxe de Marte & 8,855 & 145.570 .000 \\
\hline 1877 & G.B. Airy & Trânsito de Vênus 1874 & 8,754 & 150.280 .000 \\
\hline 1877 & E.T. Stone & Trânsito de Vênus 1874 & 8,884 & 148.080 .000 \\
\hline 1878 & J.G. Gale & Paralaxe dos asteróides Phocæa e Flora & 8,87 & 148.290 .000 \\
\hline 1884 & M. Houzeau & Trânsito de Vênus 1882 & 8,907 & 147.700 .000 \\
\hline 1896 & D. Gill & Paralaxe do asteróide Victória & 8,801 & 149.480 .000 \\
\hline 1911 & J. Hinks & Paralaxe do asteróide Eros & 8,807 & 149.380 .000 \\
\hline 1925 & H. Spencer Jones & Paralaxe de Marte & 8,809 & 149.350 .000 \\
\hline 1939 & H. Spencer Jones & Paralaxe do asteróide Eros & 8,790 & 149.670 .000 \\
\hline 1950 & E. Rabe & Movimento do asteróide Eros & 8,798 & 149.526 .000 \\
\hline 1962 & G. Pettengill & Radar para Vênus & 8,7940976 & 149.598 .728 \\
\hline 1992 & Vários & Radar para Vênus & 8,794148 & 149.597 .871 \\
\hline
\end{tabular}

Tabela 2 - Algumas determinações da paralaxe solar e da Unidade Astronômica 
Ao longo dos séculos que se seguiram à determinação de Cassini e Richer, inúmeras determinações da distância Terra-Sol foram efetuadas por diversos processos. $\mathrm{Na}$ Tabela 2 encontram-se relacionados diversos valores para essa distância, o ano de obtenção e os autores que as obtiveram.

\section{3 - O tamanho do Sol}

Após ter sido determinada a distância Terra-Sol os astrônomos passaram a determinar o tamanho do Sol a partir da medida do seu diâmetro aparente. Chamamos de diâmetro aparente de um astro o ângulo $(\alpha)$ sob o qual vemos o seu diâmetro real.

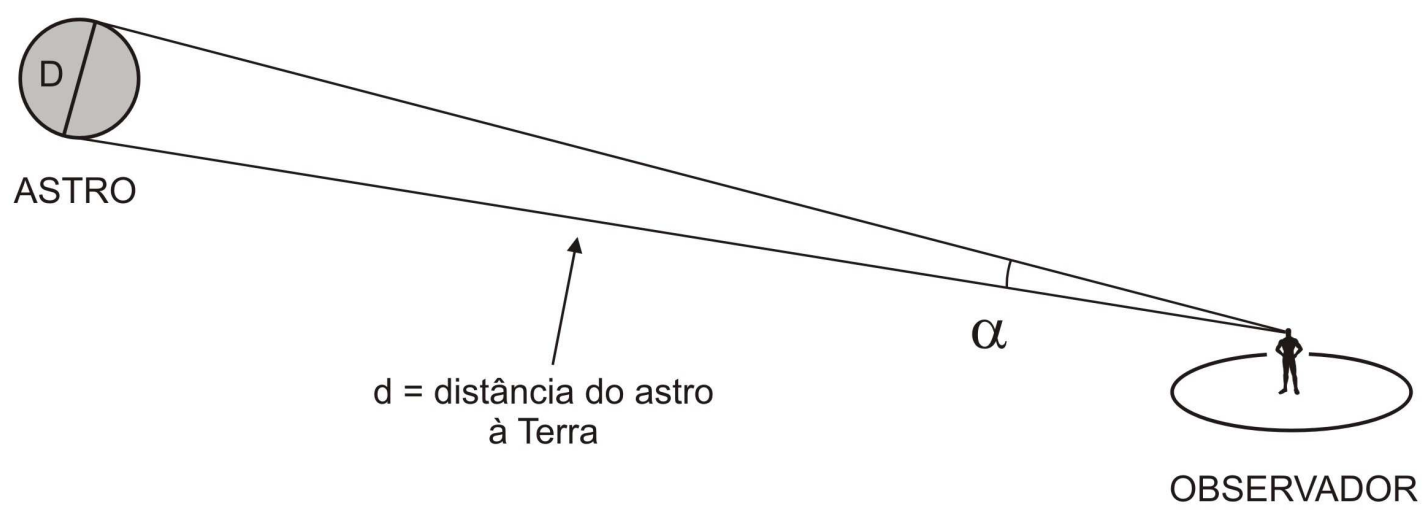

Fig.4.6 - O diâmetro aparente de um astro.

O valor do diâmetro aparente, expresso em radianos, pode ser obtido (figura 4.6) por:

$$
\alpha_{\text {rad }}=\frac{D}{d}
$$

O diâmetro aparente de um astro é, em geral, expresso em segundos de grau, e pode ser calculado pela expressão:

$$
\alpha^{\prime \prime}=206.265^{\prime \prime} \times \frac{D}{d}
$$


Como se vê, o diâmetro aparente de um astro depende, portanto, diretamente do seu diâmetro real (geométrico) e inversamente de sua distância ao observador. Os diâmetros aparentes do Sol e da Lua são da ordem de 1.800" (30').

\section{4 - As primeiras medidas do diâmetro aparente do Sol}

Desde a antiguidade os astrônomos estiveram interessados em medir o tamanho dos corpos celestes. A medida do tamanho do Sol estava entre as principais determinações. Costuma-se citar que Aristarco de Samos (c.310-230 a.C.) utilizando um procedimento geométrico concluiu que o diâmetro do Sol era 1/720 do círculo do Zodíaco, ou seja, $1.800^{\prime \prime}\left(360^{\circ} / 720=30^{\prime}\right)$. No entanto, parece que não foi a esse valor acurado que ele chegou. Sir Thomas Heath ${ }^{15}$ relata que Aristarco concluiu que o diâmetro aparente do Sol era $1 / 15$ de um signo do Zodíaco ${ }^{16}$, o que corresponde a $2^{\circ}$. Antes dele, astrônomos da Babilônia medindo o tempo que demorava o nascer do Sol já haviam concluído que o seu diâmetro aparente era de cerca de $1^{\circ}$. Alguns anos depois, Arquimedes (c.287-212 a.C.) encontrou que o diâmetro solar aparente situava-se entre 1/164 e 1/200 do ângulo reto e, assim, o diâmetro aparente do Sol deveria estar entre 1.620" e 1.976" (ou entre 27'00"e $\left.32^{\prime} 56^{\prime \prime}\right)$. Os valores por ele encontrado, embora incorretos, não estavam muito distantes dos valores que conhecemos atualmente.

Durante vários séculos, esses valores não foram questionados. Somente no século XIV, quando o astrônomo árabe Ibn-al-Shatir (1304-1375) escreveu um livro intitulado Kitab Nihayat al-Sul fi Tashih al-Usul (A Pesquisa Final sobre a Retificação dos Princípios) no qual afirma que o diâmetro solar variava de 29' 50" a 32' 32". A relação encontrada por Ibn-al-Shatir entre o mínimo e o máximo diâmetros aparentes (0.913) está ainda distante do melhor valor atual (0.967) mas com um erro de apenas $6 \%$.

Em 1656, o astrônomo italiano Giovanni Battista Riccioli (1598-1671), revendo as medidas efetuadas do diâmetro aparente do Sol, notou que elas mostravam a existência de

\footnotetext{
${ }^{15}$ Thomas Heath - Aristarchus of Samos, The Ancient Copernicus - Pag. 311.

${ }^{16}$ O Zodíaco era dividido em 12 partes iguais, cada uma tendo $30^{\circ}$ de extensão.
} 
um limite inferior de 30' 30" (fornecido por Kepler) e de um limite superior de 32' 44" (dado por Copérnico). Foram os astrônomos franceses Gabriel Mouton (1618-1694) e Jean Picard (1620-1682), considerados os pioneiros nesse campo, que realizaram as primeiras medidas sistemáticas e com uma precisão de $0,8 \%$. Resultados das medidas do diâmetro solar até 2011, podem ser encontradas em Rozelot et al. (vide bibliografia ao final).

\section{5 - Medidas de precisão do diâmetro aparente do Sol}

O diâmetro aparente do Sol pode ser medido de várias maneiras. Ao longo do tempo, diversos métodos foram utilizados para a medida do diâmetro aparente do Sol: com o uso do micrômetro de fios, com o heliômetro, a partir de observações dos trânsitos de Vênus, com observações de eclipses solares, com o astrolábio e CCD e, por fim, com os satélites artificiais. As medidas apresentam precisões diferentes em função dos equipamentos utilizados. Vamos descrever apenas alguns processos que ilustram o procedimento, começando com o uso de micrômetros de fios largamente utilizado durante muito tempo.

As primeiras determinações precisas foram feitas com o uso de quadrantes equipados com telescópios que possuíam oculares com micrômetros de fios que podiam ser movidos com parafusos. As figuras 4.7(a) e 4.7(b) ilustram o campo de visão através de oculares que dispõe de micrômetros filares.

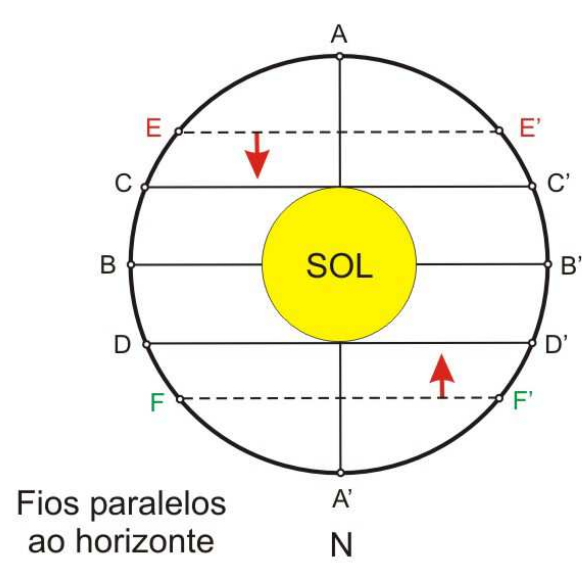

(a)

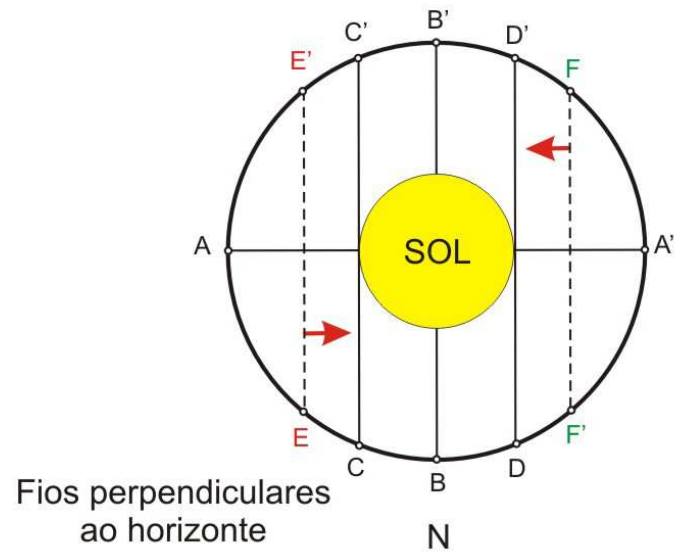

(b)

Fig. 4.7 - Uso do micrômetro na determinação do diâmetro aparente vertical e horizontal do Sol. 
O micrômetro é colocado no plano focal de um telescópio. Quando observamos através de um telescópio provido de um micrômetro vemos, além das imagens dos astros que estamos estudando, um conjunto de linhas retas cortando o campo: são os fios do micrômetro (fig. 4.7).

Um conjunto de fios mantém suas posições fixas. Na figura 4.7(a) estão representados os fios AA' e BB' (diâmetros perpendiculares) e dois fios EE' e FF' paralelos ao fio BB' e são móveis e podem ser deslocados, por meio de parafusos micrométricos até as posições $\mathrm{CC}^{\prime}$ e DD'.

Utilizando-se de quadrantes meridianos equipados com lunetas (precursores dos círculos meridianos) e oculares com micrômetros, a observação era feita nas imediações da passagem meridiana quando o movimento aparente do Sol se dá paralelamente ao horizonte (figura 4.7(a)). Os fios do micrômetro, que podiam ser movidos por meio de parafusos, eram dispostos paralelamente ao movimento diurno e o observador notava que o Sol estava se deslocando paralelamente aos fios. A distâncias entre os fios paralelos que tangenciavam as bordas superior e inferior do Sol permitiam medir o diâmetro aparente vertical.

Para medir o diâmetro horizontal da imagem solar, os fios eram posicionados perpendicularmente ao horizonte (figura 4.7(b)). Dessa forma, os diâmetros horizontal e vertical podiam ser medidos. O diâmetro vertical era afetado pela refração atmosférica e o horizontal requeria extremo cuidado na determinação pois era afetado pelo movimento de rotação da Terra. Mesmo assim, o diâmetro aparente do Sol chegou a ser medido com a precisão de $1^{\prime \prime}$, limite dos micrômetros que foram utilizados. Uma leitura interessante sobre os problemas que afetam as medidas do diâmetro aparente do Sol é o livro The Sun in Time de C.P. Sonett et al. (veja a bibliografia ao final)

\section{6 - Medidas do diâmetro aparente do Sol com o heliômetro}

O heliômetro é um telescópio muito especial, atualmente não mais fabricado e nem utilizado nos grandes observatórios, por ser de difícil construção e por haver outros instrumentos que realizam de modo mais eficiente as suas funções. Sua finalidade era determinar a separação angular entre dois astros e foi muito empregado para a 
determinação das variações do diâmetro aparente do Sol com bastante precisão (daí a sua denominação).

Consistia em um telescópio refrator ${ }^{17}$ (figura 4.8) que possuía a objetiva dividida ao meio, ao longo de um de seus diâmetros. Uma das metades da objetiva é fixa e a outra móvel. Um dispositivo mecânico (parafuso micrométrico de passo conhecido) permite fazer com que uma das metades deslize ao longo do corte.

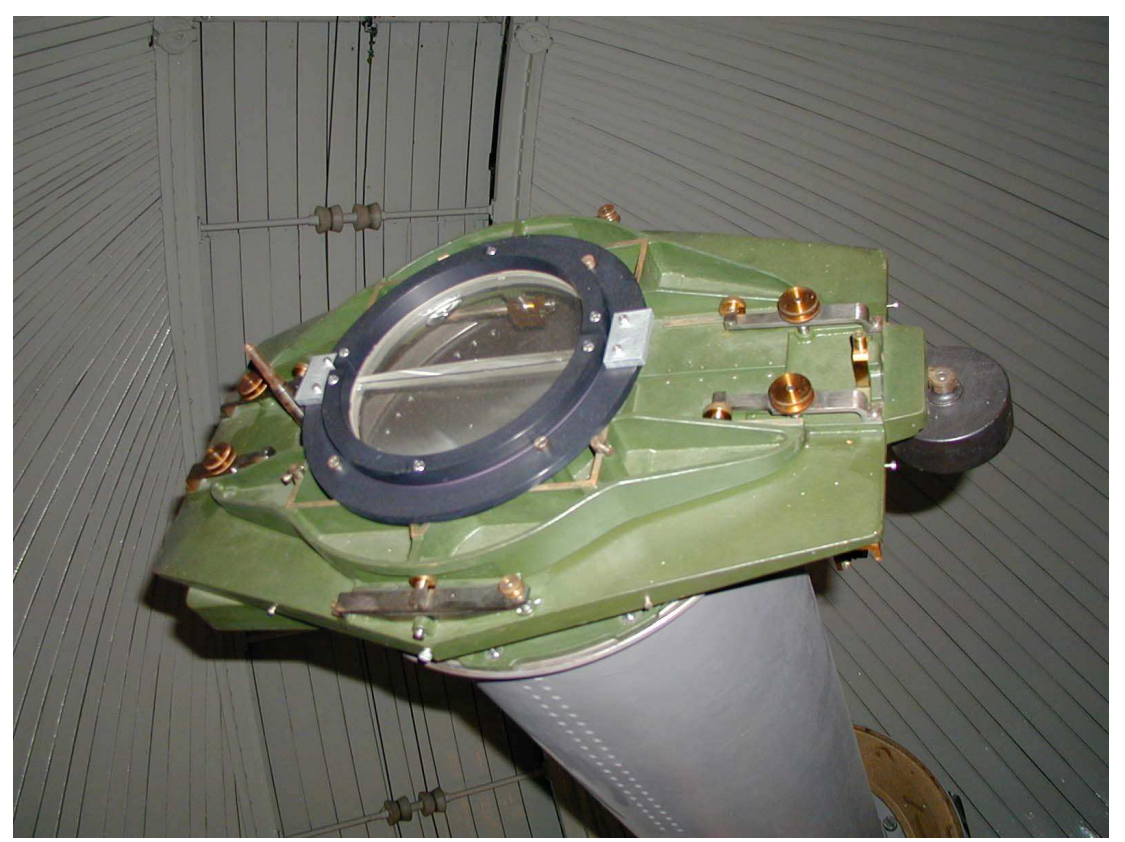

Fig. 4.8 - Objetiva do heliômetro do Observatório Kuffner (Áustria). Foto: Martin Sloboda - Kuffner-

Sternwarte. http://kuffner-sternwarte.at/sternwarte/vks_ksw_instr1.php

Ao se fazer deslizar a metade móvel da objetiva acionando-se um parafuso micrométrico, surgiam duas imagens do Sol: uma dada por uma das metades e outra fornecidas pela outra (figura 4.9). Nos primeiros heliômetros as imagens ficavam afastadas. Um micrômetro permitia medir a separação entre elas. Um conjunto de medidas das separações angulares feitas durante um grande intervalo de tempo permitia determinar as variações do diâmetro aparente do Sol, uma vez que diferentes valores das separações indicavam diferentes medidas dos diâmetros aparentes do Sol. Posteriormente foram desenvolvidos outros tipos de heliômetros, com duas objetivas ao invés de uma dividida ao meio e, nesta nova configuração, era possível colocar as imagens em contato.

\footnotetext{
${ }^{17} \mathrm{O}$ astrônomo Eugênio Reis Jr., do Museu de Astronomia e Ciências Afins (MAST), em sua tese de doutorado realizada no Observatório Nacional, descreve como construiu um heliômetro cuja objetiva era um espelho dividido em duas partes.
} 
Quando isso ocorria, o número de voltas dadas pelo parafuso micrométrico permitia determinar o deslocamento relativo entre as duas metades e o diâmetro aparente do Sol.

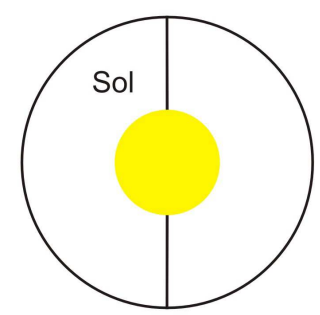

Campo de visão Ocular do heliômetro

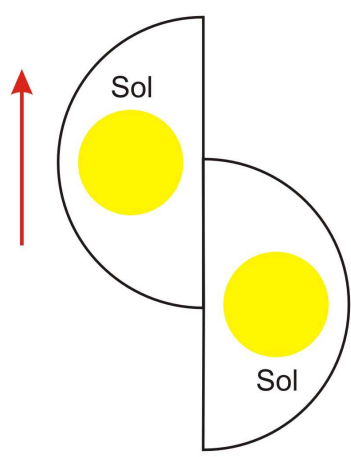

Movendo-se as duas metades da objetiva

Fig. 4.9 - Princípio de funcionamento do heliômetro

\section{7 - Medidas do diâmetro aparente do Sol com o astrolábio}

O astrônomo Dr. Nelson Vani Leister, foi o pioneiro no Brasil na utilização do Astrolábio Danjon nas observações solares. Na forma tradicional do astrolábio Danjon, observam-se os astros (estrelas, Sol e Lua) em distância zenital fixa $\left(30^{\circ}\right)$. O equipamento é constituído basicamente por um prisma equilateral refrator e por um horizonte artificial de mercúrio.

$\mathrm{Na}$ observação, duas imagens de um mesmo astro são produzidas pelo equipamento: uma pelo prisma a partir da incidência direta da luz de um astro sobre uma de suas faces e outra produzida pela outra face, a partir da luz refletida por um horizonte artificial de mercúrio. As imagens produzidas movimentam-se no campo de observação da ocular, uma delas deslocando-se de cima para baixo, enquanto a outra, de baixo para cima, superpondo-se quando o astro atinge a distância zenital de $30^{\circ}$. 


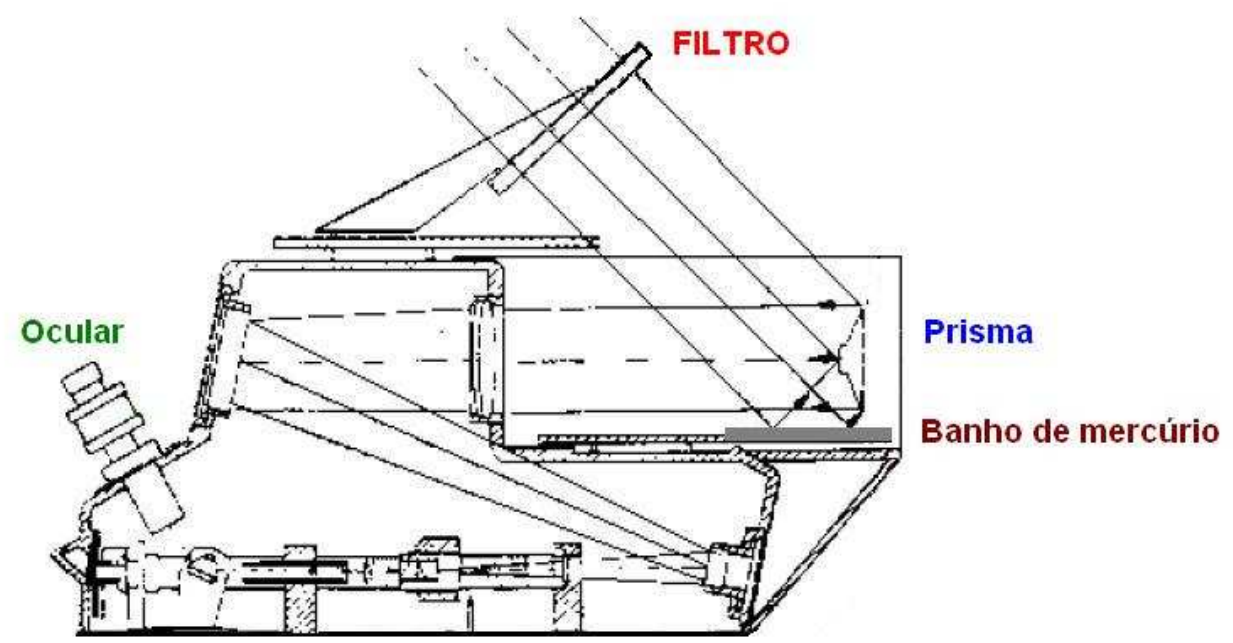

Fig. 4.10 - Esquema óptico da produção de imagens no astrolábio Danjon do Observatório Abrahão de Morais adaptado para observações solares com prisma de reflexão. Diagrama adaptado pelo autor a partir do constante na tese de doutorado de Marcelo Emilio.

Para a observação do Sol, modificações foram efetuadas para torná-lo mais estável devido às condições extremas de variação de temperaturas durante o dia. A modificação, para o caso da observação solar, constitui-se na substituição do prisma equilateral por um conjunto de prismas que viabilizaram a observação do Sol em várias distâncias zenitais. Na figura 4.10 mostra-se como são formadas as duas imagens no plano focal do astrolábio Danjon adaptado à observação solar: a primeira é formada pela reflexão no prisma e a segunda pela luz refletida no banho de mercúrio. Na observação do Sol, aguarda-se a tangência das duas imagens produzidas e determina-se o diâmetro aparente do Sol a partir do tempo gasto para que as imagens transpassem uma pela outra e voltem a se tangenciar (figura 4.11(c)):

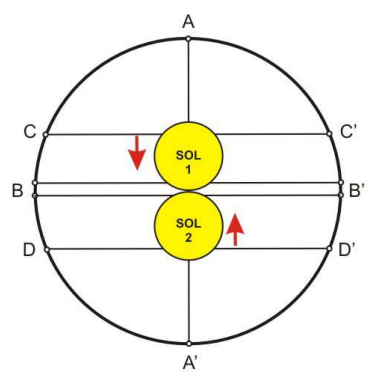

(a)

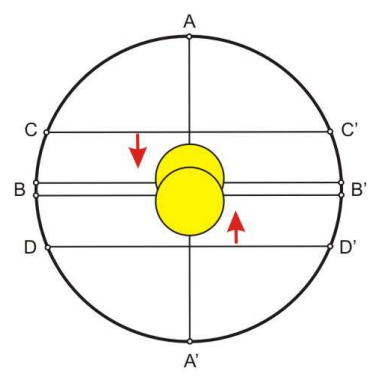

(b)

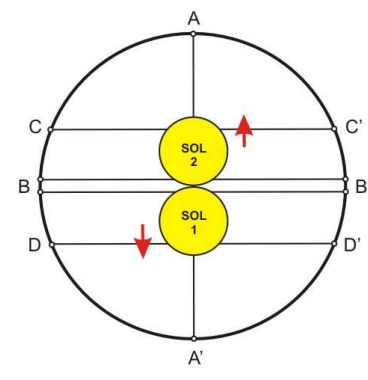

(c)

Fig. 4.11 - Observação do Sol no astrolábio Danjon: mede-se o instante da primeira tangência entre as imagens do Sol (a) e o instante da nova tangência (c). Com isso, calcula-se o tempo para que uma imagem transpasse a outra (b). 


\section{8 - Medidas do diâmetro aparente do Sol com o SOHO}

O SOHO (Solar and Heliospheric Observatory), sonda espacial da ESA e da NASA, possui diversos equipamentos que podem monitorar diversos parâmetros físicos do Sol. Um desses equipamentos é o Michelson Doppler Imager (MDI). O MDI produz uma quantidade enorme de imagens do Sol que são tratadas levando em conta a posição do satélite além das condições geométricas do telescópio que gera a imagem do Sol. As imagens tratadas fornecem as variações, ao longo do tempo, das correções ao diâmetro solar que mostrarão um limite superior da variação do diâmetro do Sol quando comparadas às medidas de solo.

Aproveitando a ocorrência de trânsitos de Mercúrio em 07 de maio de 2003 e em 08 de novembro de 2006, o dispositivo foi utilizado para medir os tempos de contato entre Mercúrio e o limbo solar. Embora esse procedimento tenha sido utilizado desde o século XVII para determinar o diâmetro solar, estando o satélite acima da atmosfera terrestre, conseguiu-se imagens de alta qualidade nesses dois eventos.

Com as medidas obtidas pelo MDI obteve-se, recentemente, o valor de 960,12" \pm 0,09" para o semi-diâmetro solar, o que corresponde a $(696.342 \pm 65) \mathrm{km}$ para o raio solar.

\section{9 - Geometria do Sol}

Adotando-se o valor de $695.700 \mathrm{~km}$ para o raio do Sol podemos obter o seu volume:

$$
V_{\odot}=\frac{4}{3} \times \pi R_{\odot}^{3}=1,410 \times 10^{18} \mathrm{~km}^{3}
$$

Considerando o raio médio da Terra $\mathrm{R}_{\oplus}=6.371 \mathrm{~km}$, obtemos:

$$
\frac{R_{\odot}}{R_{\oplus}}=109,2 \quad \rightarrow \quad \frac{V_{\odot}}{V_{\oplus}}=(109,2)^{3}=1,302 \times 10^{6}
$$


Para a área da superfície solar $\left(A_{\odot}\right)$, teremos:

$$
A_{\odot}=4 \pi R_{\odot}^{2}=6,082 \times 10^{12} \mathrm{~km}^{2}
$$

Comparada à área da superfície terrestre, teremos:

$$
\frac{A_{\odot}}{A_{\oplus}}=(109,2)^{2}=11.925
$$

\subsection{0 - Comparando o tamanho do Sol com outras estrelas}

Embora o Sol nos pareça muito grande, quando comparado às demais estrelas, seu tamanho é modesto. Há, em nossa galáxia, estrelas que são milhares, milhões e até bilhões de vezes mais volumosas que o Sol. A figura 4.12 apresenta uma comparação entre o tamanhos do Sol, de Júpiter e os de algumas estrelas brilhantes:

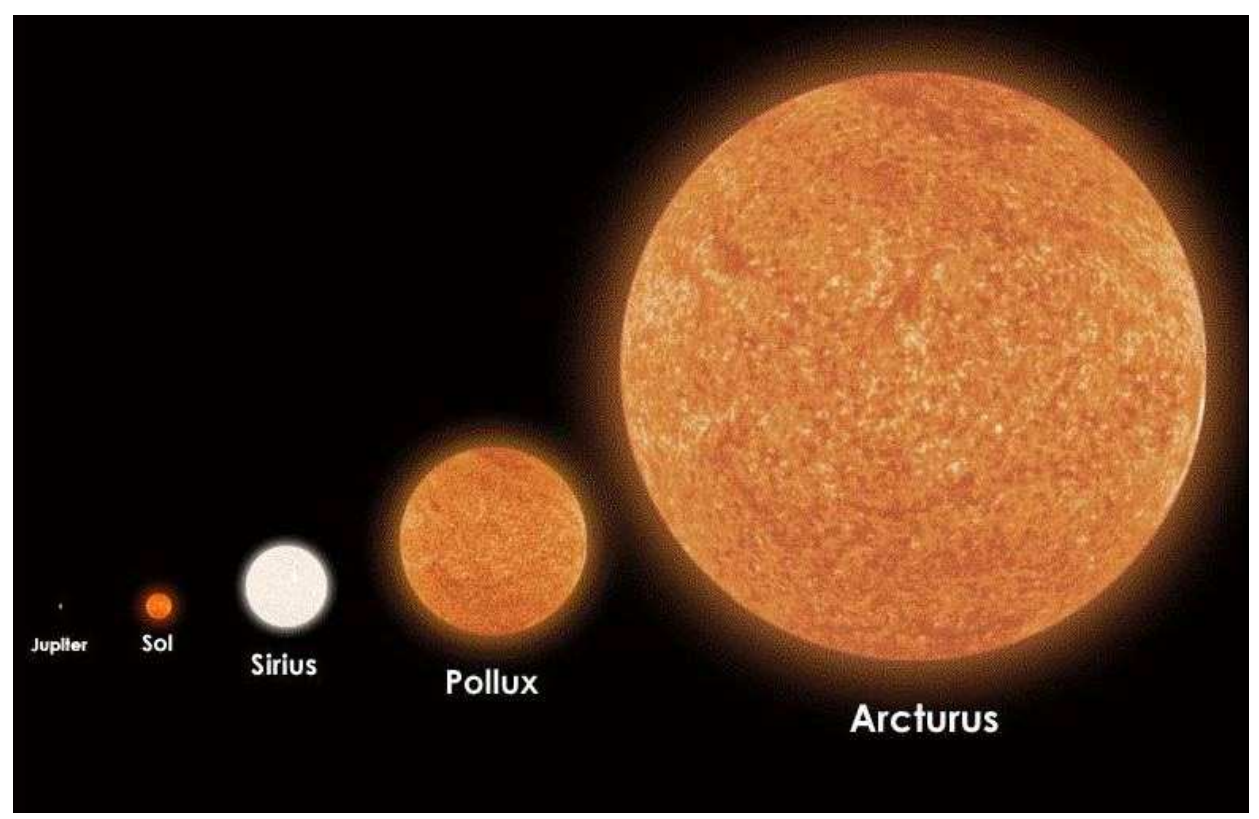

Fig. 4.12 - Comparação do tamanho Sol com algumas estrelas brilhantes (observáveis à vista desarmada) e o planeta Júpiter. Fonte: ESO

Em relação a algumas estrelas que se situam nas proximidades do Sol, o seu tamanho é da mesma ordem de grandeza. E é muito superior em relação às chamadas anãs 
vermelhas como Proxima Centauri ( $\alpha$ Cen $C$ ), por exemplo, que é a estrela mais próxima do Sistema Solar.

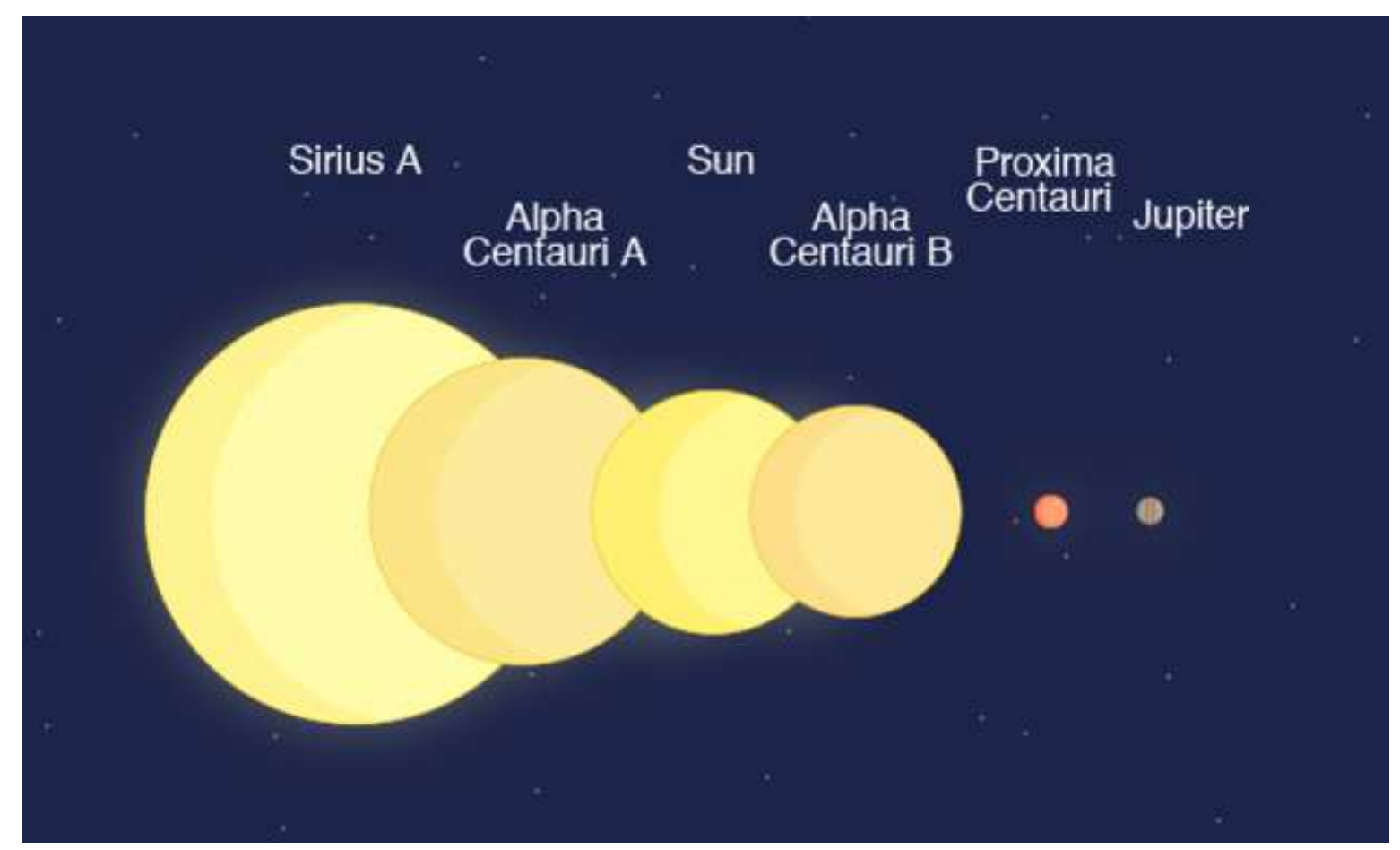

Fig. 4.13 - Comparação do Sol com algumas estrelas próximas e o planeta Júpiter. Fonte: ESO. 


\section{5 - MASSA E CAMPO GRAVITACIONAL DO SOL}

A massa do Sol pode ser obtida a partir do conhecimento da distância Terra-Sol, do período de translação da Terra ao redor do Sol e do valor da constante de Gravitação Universal. Considere um sistema constituído por dois corpos de massas respectivamente iguais a $\mathbb{m}_{A}$ e $\mathbb{m}_{B}$, interagindo gravitacionalmente e descrevendo órbitas ao redor do centro de massa do sistema, como ilustrado na figura 5.1. O período de translação de cada corpo ao redor do centro de massa é $\mathrm{P}$.

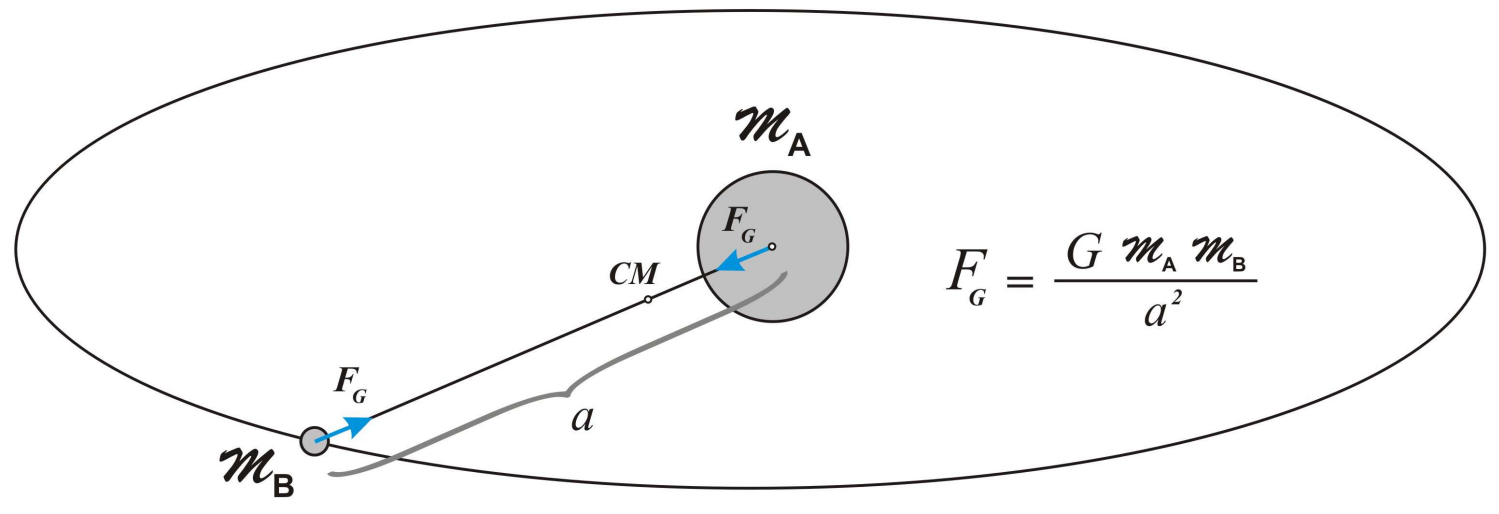

Fig. 5.1 - Sistema de dois corpos interagindo gravitacionalmente.

A terceira lei de Kepler, expressa matematicamente a partir da lei da gravitação de Newton, permite escrever para o sistema considerado:

$$
\frac{a^{3}}{P^{2}}=\frac{G}{4 \pi^{2}}\left(m_{A}+m_{B}\right)
$$

onde a é o semi-eixo da órbita relativa de B ao redor de A, $\mathbf{P}$ o período de translação e $\mathbf{G}$ a constante de Gravitação Universal.

Para o sistema Terra-Sol, introduzindo-se os valores conhecidos para o semi-eixo maior da órbita terrestre e do seu período: $\mathrm{a}=149.597 .870,696 \mathrm{~km}, \mathrm{P}=365^{\mathrm{d}} 06^{\mathrm{h}} 09^{\mathrm{m}} 10^{\mathrm{s}}=$ $31.558 .150 \mathrm{~s}$ e $\mathrm{G}=6,672 \times 10^{-11} \mathrm{~m}^{3} \cdot \mathrm{kg}^{-1} \cdot \mathrm{s}^{-2}$, e considerando que a massa terrestre ${ }^{18}$, pode ser conhecida por processos desenvolvidos aqui mesmo na Terra, obtemos:

\footnotetext{
${ }^{18}$ A massa terrestre é igual a $m_{\oplus}=(5,9722 \pm 0,0006) \times 10^{24} \mathrm{~kg}$ e corresponde a $3,003 \times 10^{-6}$ da massa do Sol.
} 


$$
\frac{a^{3}}{P^{2}}=\frac{G}{4 \pi^{2}}\left(m_{\odot}+m_{\oplus}\right)
$$

e daí calculamos ${ }^{19} M \odot=1,989 \times 10^{30} \mathrm{~kg}$.

A massa do Sol, comparada à massa de alguns astros do Sistema Solar, nos mostra as seguintes relações: a massa solar é 27.068.510 massas lunares, 332.946 massas terrestres e 1.047,56 massas do planeta Júpiter.

Uma vez conhecido o volume do Sol (capítulo 4) e a sua massa, obtemos para a sua densidade média, o valor:

$$
\rho_{m}=\frac{m_{\odot}}{V_{\odot}}=\frac{1,989 \times 10^{33}}{1,410 \times 10^{33}} \frac{\mathrm{g}}{\mathrm{cm}^{3}}=1,41 \mathrm{~g} / \mathrm{cm}^{3}
$$

A densidade média do Sol é, portanto, pouco superior à densidade da água. Como veremos nos capítulos seguintes, a densidade no interior solar é muito diferente desse valor, chegando a $160 \mathrm{~g} / \mathrm{cm}^{3}$ no núcleo solar.

\section{1 - Centro de massa do sistema Terra-Sol}

Com uma relação de massas tão grande, o centro de massa do sistema Terra-Sol encontra-se mais próximo do centro geométrico do Sol. Para determinar a sua posição, vamos considerar apenas o Sol e a Terra, como ilustrado na figura 5.2, e admitir que a Terra esteja a uma unidade astronômica do Sol:

\footnotetext{
${ }^{19} \mathrm{Um}$ valor mais acurado para a massa solar é: $\mathcal{M}_{\odot}=(1,98855 \pm 0,00025) \times 10^{30} \mathrm{~kg}$.
} 


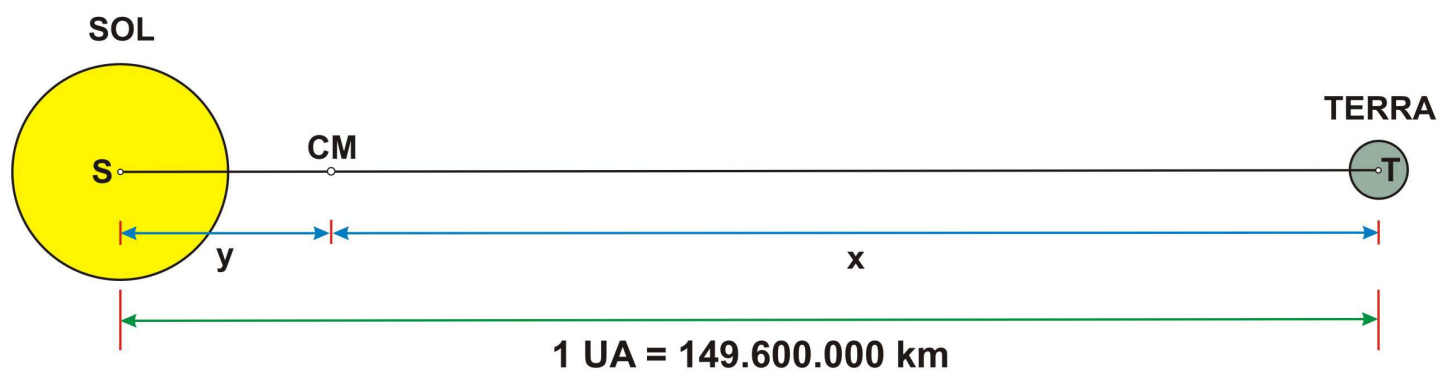

Fig. 5.2 - O centro de massa do sistema Terra-Sol. Para facilitar a apresentação dos elementos geométricos, o centro de massa do sistema Terra-Sol (CM) foi propositalmente colocado no exterior do globo solar.

Para determinar a posição do centro de massa do sistema Terra-Sol, vamos considerar S o centro do Sol, T o centro da Terra, y a distância do centro do Sol ao centro de massa e $x$ a distância do centro da Terra ao centro de massa do sistema. Considerandose $\mathbb{M}_{\odot}$ e $\mathbb{M}_{\oplus}$, respectivamente massa do Sol e a massa da Terra, devemos ter:

$$
\frac{x}{y}=\frac{m_{\odot}}{m_{\oplus}} \rightarrow \frac{y+x}{y}=\frac{m_{\odot}+m_{\oplus}}{m_{\oplus}} \rightarrow y=\frac{m_{\oplus}}{m_{\odot}+m_{\oplus}} \times(y+x)
$$

sendo $y+x=149.600 .000 \mathrm{~km}$, substituindo-se os valores para as massas do Sol e da Terra, chegamos ao valor de $y=4,5 \times 10^{2} \mathrm{~km}$, isto é, o centro de massa do sistema TerraSol está a apenas $450 \mathrm{~km}$ do centro do Sol (pouco superior à distância de São Paulo ao Rio de Janeiro). Em termos do raio solar, isto significa apenas 0,00064 R $\odot$.

\section{2 - Centro de massa do Sistema Solar}

Embora as massas dos planetas em muitos casos possam ser consideradas desprezíveis em relação à massa do Sol, o centro de massa do Sistema Solar não coincide com o centro geométrico do Sol. Por incrível que possa parecer, em muitas situações ele encontra-se localizado externamente ao globo solar podendo estar afastado até mais de 2 R $\odot$ do centro do Sol. A posição do centro de massa do Sistema Solar depende das posições dos planetas, isto é, como estão distribuídas as massas ao redor do Sol. O procedimento 
para se determinar a posição do centro de massa do Sistema Solar encontra-se descrito no Apêndice 3.

O diagrama adiante ilustra as posições do centro de massa do Sistema Solar, em relação ao centro do Sol, para o período de 1944 a 2020:

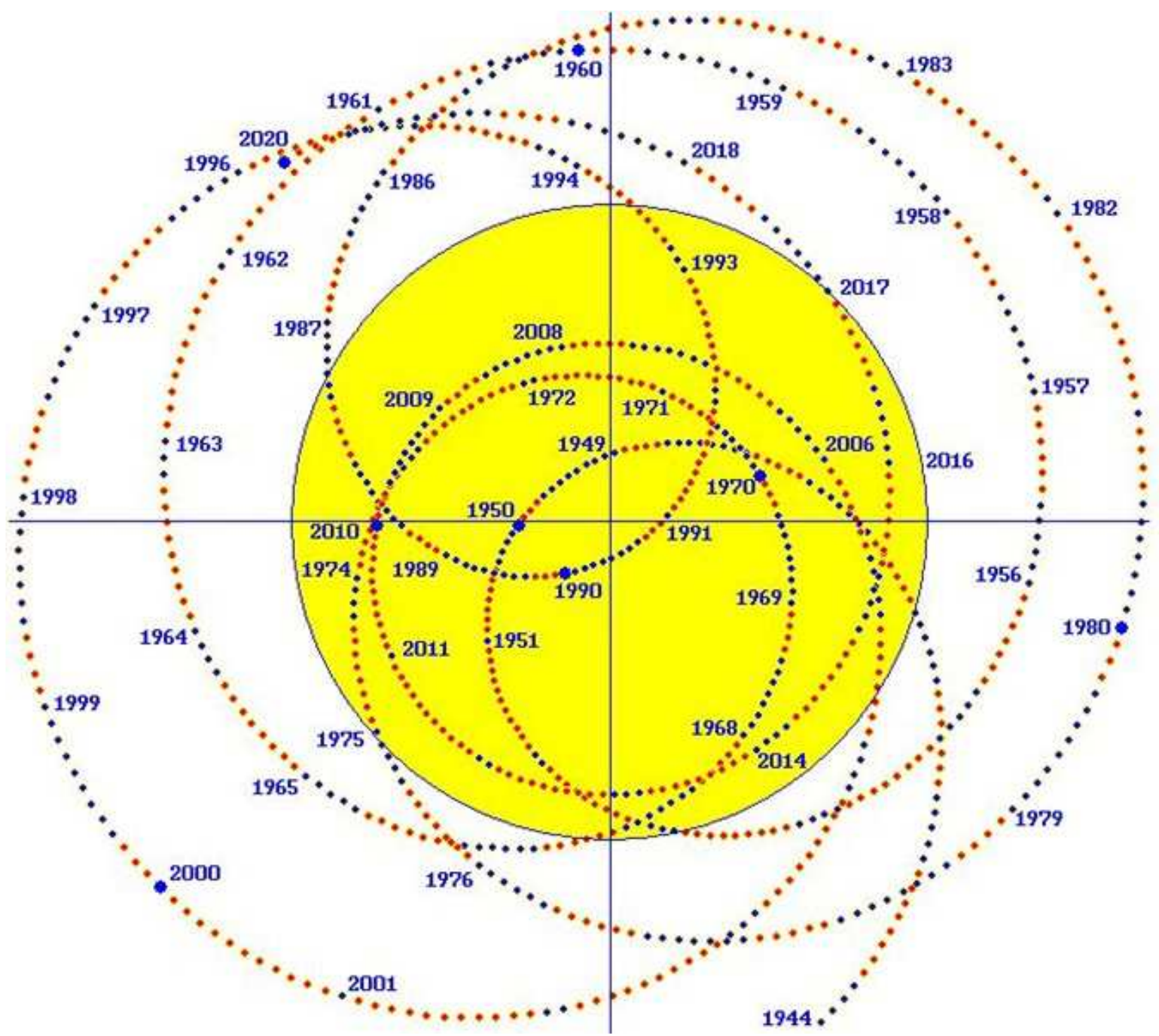

Fig. 5.3 - Posições do centro de massa do Sistema Solar para o período de 1944 a 2020, projetadas no plano da eclíptica. As posições correspondem ao dia 1 de janeiro de cada ano. O círculo amarelo representa o disco solar.

\section{3 - A extensão do Sistema Solar}

Do ponto de vista teórico, a ação gravitacional do Sol estende-se até o infinito. Entretanto, nas proximidades do Sistema Solar, há outras estrelas e estas, por sua vez, também exercem atrações gravitacionais. 
A 4,3 anos-luz do Sol encontra-se o sistema estelar Alpha Centauri, constituído por três estrelas e cuja massa total é aproximadamente 2 M $\odot$. Considerando-se apenas o Sol e o sistema em questão, na reta que os une, as atrações gravitacionais sobre um corpo de prova de massa $\underline{\mathbf{m}}$ se igualam à distância $\mathrm{r}=1,8$ ano-luz do Sol. Isto significa que até 1,8 ano-luz e na direção de $\alpha$ Centauri, a atração gravitacional solar sobre algum corpo celeste predomina sobre a atração gravitacional exercida pelo sistema $\alpha$ Centauri. Para distâncias superiores, a atração solar é sobrepujada (figura 5.4).

$$
F_{\odot}=F_{\alpha C e n} \rightarrow \frac{G \times m_{\odot} \times m}{r^{2}}=\frac{G \times 2 m_{\odot} \times m}{(4,3-r)^{2}} \rightarrow r=1,8 \text { anos }- \text { luz }
$$

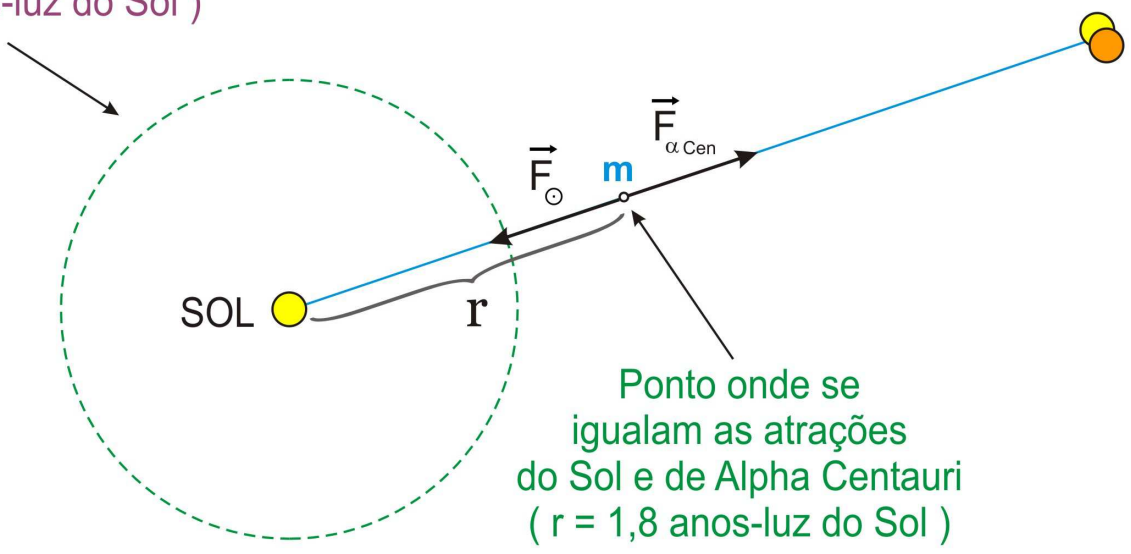

Fig. 5.4 - Até onde o Sistema Solar se estende? Um critério prático para o limite do Sistema Solar é considerar a distância onde se igualam as atrações do Sol e do sistema Alpha Centauri.

Repetindo-se as considerações anteriores e tomando-se agora o sistema Alpha Canis Majoris AB (Sirius), com massa total 2,4 $M_{\odot}$ e situado a 8,6 anos-luz do Sol, verificaremos que a ação gravitacional do Sol predomina sobre a atração de Sirius até 3,4 anos-luz de distância. Se levarmos em conta a ação combinada de outras estrelas, que se encontram a diferentes distâncias e em outras direções, o problema torna-se muito mais complexo. Com o objetivo de estabelecer um limite prático de trabalho, podemos considerar que o nosso sistema planetário pode se estender até cerca de 1,8 ano-luz a partir 
do centro solar, distância essa em que a atração gravitacional solar é predominante sobre as atrações das demais estrelas situadas em suas imediações.

\section{4 - O campo gravitacional do Sol}

O campo gravitacional mantém todos os corpos do Sistema Solar transladando ao seu redor. Muito recorrente entre os alunos dos vários cursos que ministrei em diversas instituições era a seguinte questão: por que a Terra ou outro corpo não escapa do Sistema Solar? Uma resposta muito mais convincente do que simplesmente apresentar a resposta padrão sobre a atração solar é utilizar o conceito de velocidade de escape.

Chama-se velocidade de escape à velocidade mínima que um corpo deve ter para ser lançado a partir da superfície ou de um ponto do espaço situado no campo gravitacional de um astro e, sem ser acelerado, escapar do seu campo gravitacional. Considerando um astro esférico de massa $\mathrm{M}$ e raio $\mathrm{R}$, a velocidade mínima $\mathrm{V}_{\text {esc }}$ que um corpo deve ter para, se lançado de sua superfície, não mais retornar a ela, é dada por (Veja apêndice 4):

$$
V_{e s c}=\sqrt{\frac{2 G M}{R}} \rightarrow V_{\odot}=\sqrt{\frac{2 G M_{\odot}}{R_{\odot}}}
$$

A velocidade de escape na superfície do Sol é de 617,6 km/s. Quando nos afastamos da superfície de um astro e nos situamos a uma distância $r=R+d$ dela, a velocidade de escape diminuirá e será calculada por:

$$
V_{e s c}=\sqrt{\frac{2 G M}{R+d}}=\sqrt{\frac{2 G M}{r}} \rightarrow V_{\odot}=\sqrt{\frac{2 G M_{\odot}}{r_{\odot}}}
$$

À distância de uma unidade astronômica do centro do Sol $\left(\mathrm{r}=\mathrm{a}=1,496 \times 10^{8} \mathrm{~km}\right)$ a velocidade de escape do campo gravitacional do Sol será $\mathrm{V}_{\mathrm{esc}}=42,1 \mathrm{~km} / \mathrm{s}$. Sendo a velocidade orbital média da Terra igual a $29,8 \mathrm{~km} / \mathrm{s}$, vemos que não há como a Terra "escapar" do Sistema Solar! Em relação aos demais planetas, a velocidade de escape do campo gravitacional do Sol, na distância correspondente às suas distâncias médias, é superior às suas velocidades orbitais, de modo que os planetas permanecem ligados ao Sol. 
Para os principais corpos do Sistema Solar (Sol e planetas), os valores para $\mathrm{V}_{\text {esc }}$ do campo gravitacional do Sol, na distância média que eles se encontram, estão dados na tabela 3. Nela está incluído o planeta-anão Plutão apenas por razões históricas:

TABELA 3 - Velocidade de Escape do campo gravitacional do Sol

\begin{tabular}{|l|c|c|l|l|c|c|}
\hline ASTRO & $\mathrm{V}_{\text {orb }}(\mathrm{km} / \mathrm{s})$ & $\mathrm{V}_{\text {esc }}(\mathrm{km} / \mathrm{s})$ & ASTRO & $\mathrm{V}_{\text {orb }}(\mathrm{km} / \mathrm{s})$ & $\mathrm{V}_{\text {esc }}(\mathrm{km} / \mathrm{s})$ \\
\hline \hline Sol Superfície & ----- & 617,6 & Júpiter & 13,1 & 18,5 \\
\hline Mercúrio & 47,4 & 67,7 & Saturno & 9,7 & 13,6 \\
\hline Vênus & 35,0 & 49,5 & Urano & 6,8 & 9,6 \\
\hline Terra & 29,8 & 42,1 & Netuno & 5,4 & 7,7 \\
\hline Marte & 24,1 & 34,1 & Plutão & 4,7 & 6,6 \\
\hline
\end{tabular}

Notamos que as velocidades médias orbitais dos planetas são todas inferiores à velocidade de escape do campo gravitacional do Sol na distância média em que eles se encontram.

Quando consideramos os corpos situados no cinturão de Kuiper ou, ainda, na nuvem de Oort, teremos velocidades orbitais pequenas acompanhadas de velocidades de escape do campo gravitacional do Sol também reduzidas, o que pode acarretar no desligamento desses corpos do Sistema Solar, se suas velocidades orbitais aumentarem, por exemplo, por algum processo colisional.

\section{5 - Comparando a massa do Sol com as massas estelares}

Quando comparamos a massa do Sol com as massas de outras estrelas vemos que a massa do Sol não difere grandemente das demais massas. A grande maioria das estrelas tem massas que se encontram entre $0,1 M_{\odot}$ e $10 M_{\odot}$. Há estrelas com grande massa como, por exemplo, a Eta Carinae, cuja massa é estimada entre 100 e $150 \mathrm{M} \odot$. Outras possuem massa muito reduzida. Um exemplo é a estrela $\mathrm{AB}$ Doradus $\mathrm{C}$, companheira de $\mathrm{AB}$ Doradus A, com massa de apenas $0,09 \mathrm{~m} \odot$, correspondendo a apenas 93 massas do planeta Júpiter. 


\section{6 - LUMINOSIDADE E TEMPERATURA DO SOL}

\section{1 - A luminosidade do Sol}

A quantidade de energia irradiada pelo Sol, por unidade de tempo, em todas as direções e em todas as frequências é chamada de luminosidade bolométrica $\left(L_{b o l}^{\odot}\right)$. O Sol irradia não só luz mas também radiação infravermelha, ondas de rádio, raios gama, raios $\mathrm{X}$ e ultravioleta. A quantidade total de energia por segundo que o Sol envia para o espaço é:

$$
L_{b o l}^{\odot}=3,846 \times 10^{26} \mathrm{~J} / \mathrm{s}=3,846 \times 10^{26} \mathrm{~W}
$$

\section{2 - Fluxo de energia e constante solar}

Essa quantidade de energia, em um dado instante, deixa a superfície do Sol e vai se distribuindo em esferas de raios cada vez maiores e, admitindo que não haja perdas no trajeto, após cerca de 8 minutos está distribuída em uma esfera cujo raio é a distância Terra-Sol. Chamamos de fluxo de energia a quantidade de energia, por unidade de tempo, que atravessa uma unidade de área perpendicular à direção de propagação.

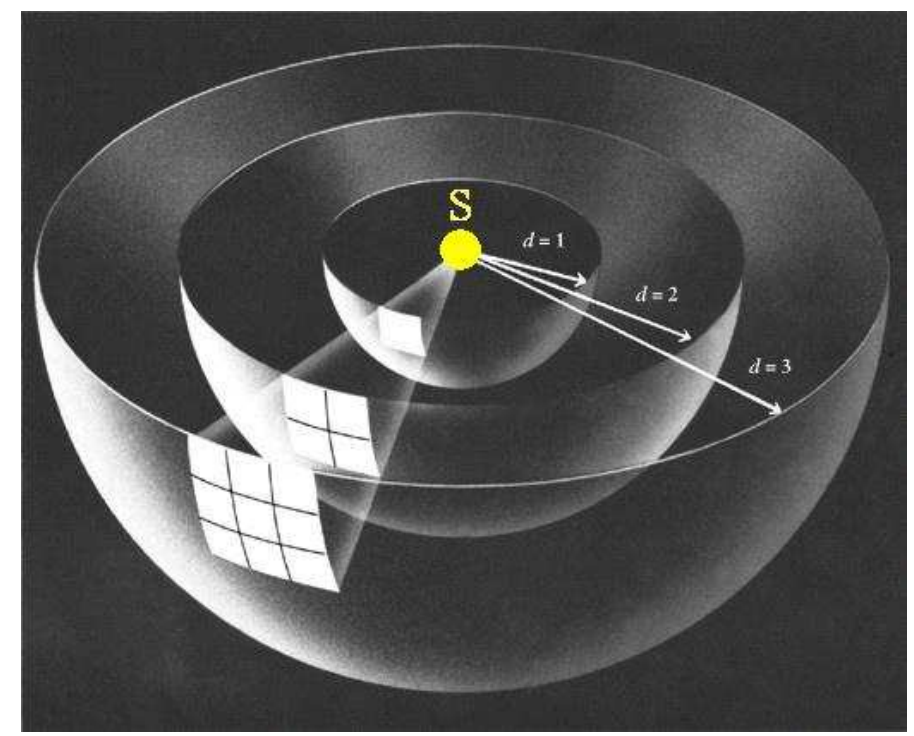

Fig. 6.1 - Fluxo de energia solar. A energia que deixa a superfície solar vai se distribuído em esferas de raios cada vez maiores. Fonte: http://www.splung.com/content/sid/7/page/magnitude. 
Cada unidade de área da superfície solar irradia, por unidade de tempo, a quantidade:

$$
F_{\text {sup }}^{\odot}=\frac{L_{b o l}^{\odot}}{4 \pi R_{\odot}^{2}}=6,34 \times 10^{7} \mathrm{~W} / \mathrm{m}^{2}
$$

A quantidade $F_{\text {sup }}^{\odot}$ é denominada fluxo superficial, pois se refere à energia por unidade de tempo que atravessa uma unidade de área da superfície solar.

No topo da atmosfera terrestre recebemos um fluxo de energia bem menor, pois a energia que deixou a superfície do Sol está, agora, distribuída em uma esfera de raio igual à distância Terra-Sol. A uma Unidade Astronômica do Sol, o fluxo de energia será $F_{d=1 U A}^{\odot}:$

$$
F_{d=1 U A}^{\odot}=\frac{L_{b o l}^{\odot}}{4 \pi a^{2}}=1,3676 \times 10^{3} \mathrm{~W} / \mathrm{m}^{2}
$$

onde a é a Unidade Astronômica cujo valor é 1,496 x $10^{11} \mathrm{~m}$. A quantidade de energia, por unidade de área e por unidade de tempo que atinge o topo da atmosfera terrestre, proveniente do Sol, chama-se constante solar. Seu valor pode ser determinado, com muita precisão ao longo do ano, pelos satélites que estão em órbita ao redor da Terra.

\section{3 - Determinação de Langley da energia irradiada pelo Sol}

A quantidade de energia que o Sol emite foi calculada e conhecida a partir dos trabalhos do astrônomo americano Samuel Pierpont Langley (1834-1906), diretor do Allegheny Observatory (Pensilvânia, Estados Unidos), que inventou, em 1878, o bolômetro, instrumento que permitiu que se medisse, com precisão, a quantidade de energia solar que chega à Terra.

Basicamente o bolômetro de Langley era uma ponte de Wheatstone, na qual um de seus ramos era constituído por uma lâmina de platina de resistência $R_{B}$ (figura 6.2). 
Quando exposta à radiação, a lâmina se aquecia e tinha, portanto, o valor de sua resistência elétrica alterada desequilibrando a ponte que havia sido previamente colocada em equilíbrio. A partir do valor da corrente registrada em um galvanômetro, era possível determinar a quantidade de energia que incidiu na lâmina de platina.

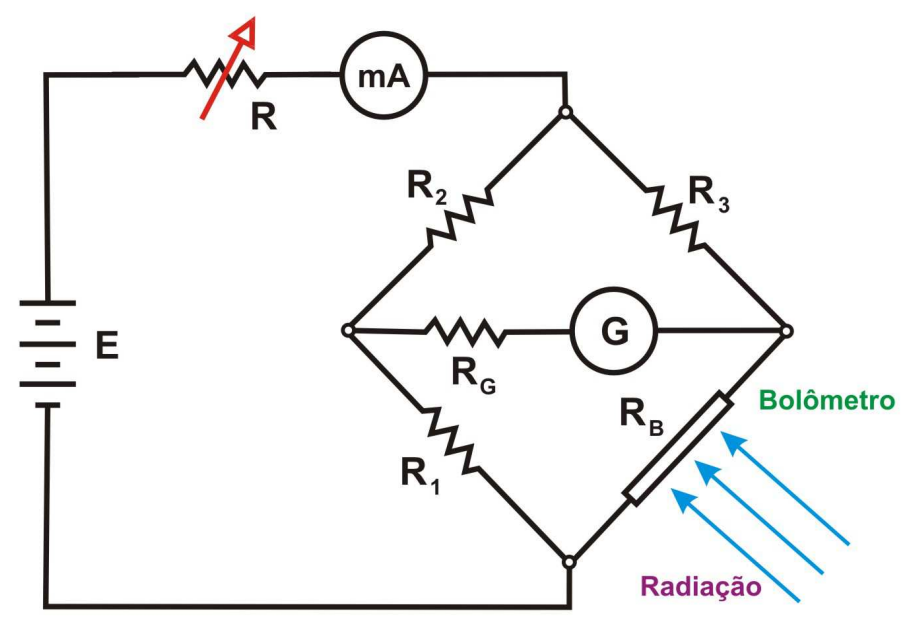

Fig. 6.2 - Circuito elétrico simplificado do bolômetro de Langley. A radiação incide na lâmina de platina de resistência $R_{B}$. $G$ é um galvanômetro de resistência $R_{G}$ e $\mathbf{E}$ uma bateria. Na condição de equilíbrio da ponte, devemos ter: $R_{1} \cdot R_{3}=R_{2} \cdot R_{B}$. Diagrama do autor.

O procedimento de Langley para obter a quantidade total de energia irradiada pelo Sol consistiu em medir a quantidade de energia por unidade de tempo que atingia uma área determinada aqui na Terra e, em seguida, multiplicou esse valor pela área de uma esfera de raio igual à distância Terra-Sol. Obteve, assim, a quantidade de energia que saiu da superfície solar, admitindo que não tenha havido perdas de energia nesse trajeto.

\section{4 - Magnitudes estelares}

Em Astronomia estelar utiliza-se uma escala para os brilhos das estrelas relacionada à quantidade de energia que elas emitem. A primeira escala de brilho teve origem na antiguidade e é atribuída ao astrônomo grego Hiparco de Nicéia que viveu no século II antes da era Cristã (entre 190 a.C. e 120 a.C.). A escala de Hiparco agrupava as estrelas em seis grandezas de acordo com os seus brilhos aparentes, sendo as mais brilhantes classificadas como de primeira grandeza e as de brilho mais fraco, no limite da visibilidade 
humana, de sexta grandeza. Ao que parece, Hiparco elaborou um catálogo com mais de mil estrelas registrando suas posições e seus brilhos, após ter observado o aparecimento de uma estrela nova (ou de uma estrela supernova) ${ }^{20}$ em 134 a.C..

A escala de Hiparco, utilizada e ampliada por Ptolomeu, permaneceu durante quase 1.500 anos em uso, até a invenção da luneta. Houve, então, a necessidade de sua ampliação para permitir a classificação de estrelas até então invisíveis. Somente em 1856 a escala adquiriu bases científicas com o trabalho do astrônomo inglês Norman Robert Pogson (1829 - 1891). Na versão atual da escala, os brilhos das estrelas são expressos em magnitudes e estão determinados a partir de seus fluxos de radiação, de acordo com a relação:

$$
m=-2,5 \log F(d)+C
$$

onde $\underline{\mathrm{m}}$ é denominada magnitude aparente, $F(d)$ é o fluxo de energia à distância $\underline{\mathrm{d}}$ do observador e $\mathrm{C}$ é uma constante de ajuste de escala. O fluxo de energia à distância d é calculado por:

$$
F(d)=\frac{L}{4 \pi d^{2}}
$$

de maneira que a magnitude aparente bolométrica fica expressa por:

$$
m_{b o l}=-2,5 \log \frac{L_{b o l}}{4 \pi d^{2}}+C
$$

Nessa escala, a magnitude aparente bolométrica do Sol é $m_{b o l}^{\odot}=-26,82$, pois o fluxo de energia do Sol é muito grande.

A escala de magnitudes aparentes para as estrelas não permite comparar os seus brilhos intrínsecos pois a magnitude aparente depende de suas luminosidades $\left(L_{b o l}\right)$ e, também, da distância em que se encontram.

\footnotetext{
${ }^{20}$ Estrelas novas e supernovas são estrelas que surgem repentinamente no céu com forte brilho originado em processos explosivos que ocorrem na estrela. Apesar no nome, são estrelas "velhas" que estão em estágios avançados de sua evolução.
} 
Para permitir a comparação dos brilhos intrínsecos das estrelas, os astrônomos criaram o conceito de magnitude absoluta $(\mathrm{M})$ que representa o brilho que uma estrela (ou outro astro) teria, se sua distância fosse 32,6 anos-luz (10 parsecs $)^{21}$. Supondo que todas as estrelas estivessem à mesma distância do observador, as diferenças de brilho observadas seriam devidas às diferenças de luminosidades entre elas.

Para uma dada estrela, de luminosidade $L_{b o l}$, teremos, se sua distância fosse 10 parsecs, a magnitude,

$$
M_{b o l}=-2,5 \log \frac{L_{b o l}}{4 \pi 10^{2}}+C
$$

Se o Sol estivesse a 10 parsecs de distância da Terra, a sua magnitude absoluta bolométrica seria: $M_{b o l}^{\odot}=+4,75$. Seu brilho seria, então, bastante reduzido e comparável à uma estrela de magnitude aparente igual a 5, próximo ao limite da visibilidade humana. Antigamente, nos livros de cosmografia e de geografia os autores, quando elencavam as principais características do Sol, afirmavam que ele era uma estrela de $5^{\text {a }}$ grandeza. Referiam-se, embora não explicando, que esse seria o brilho do Sol se sua distância à Terra fosse 32,6 anos-luz. Mas, para que citar isso sem explicar?

\section{5 - Decompondo a luz solar: o espectro do Sol}

Embora seja comum atribuir-se a Isaac Newton (1642-1727) a descoberta da decomposição da luz solar em outras cores, tal fato já era conhecido muito antes dele. Em seu livro Opticks ${ }^{22}$, publicado em 1704, narra a decomposição da luz solar por um prisma e mostra que as componentes coloridas podem ser recombinadas para gerar a luz branca (disco de Newton). Ele apresenta explicações para vários fenômenos, baseadas em sua teoria corpuscular para a luz. Foi Newton que introduziu o termo espectro para o resultado da decomposição da luz solar.

\footnotetext{
${ }^{21}$ Veja o GLOSSÁRIO ao final deste capítulo.

${ }^{22}$ Opticks:or a treatise of the Reflexions, Refractions, Inflections an Colours of Light. Londres, 1704.
} 
Muito tempo se passou antes que astrônomos e físicos dessem a devida atenção ao fenômeno da decomposição da luz em outras cores. Em 1802, o físico e químico inglês William Hyde Wollaston (1766-1828) construiu um espectroscópio ${ }^{23}$, melhorando o modelo construído por Newton, introduzindo uma lente que permitia projetar o espectro solar em um anteparo. Na observação do espectro solar, Wollaston notou a presença de quatro linhas escuras que supôs serem marcas divisórias entre as cores.

Alguns anos mais tarde (1814), o físico alemão Joseph Ritter von Fraunhofer (1787-1826), mostrou que no espectro solar havia uma grande quantidade de linhas escuras (figura 6.3) que depois passaram a ser chamadas de linhas (ou raias) de Fraunhofer.

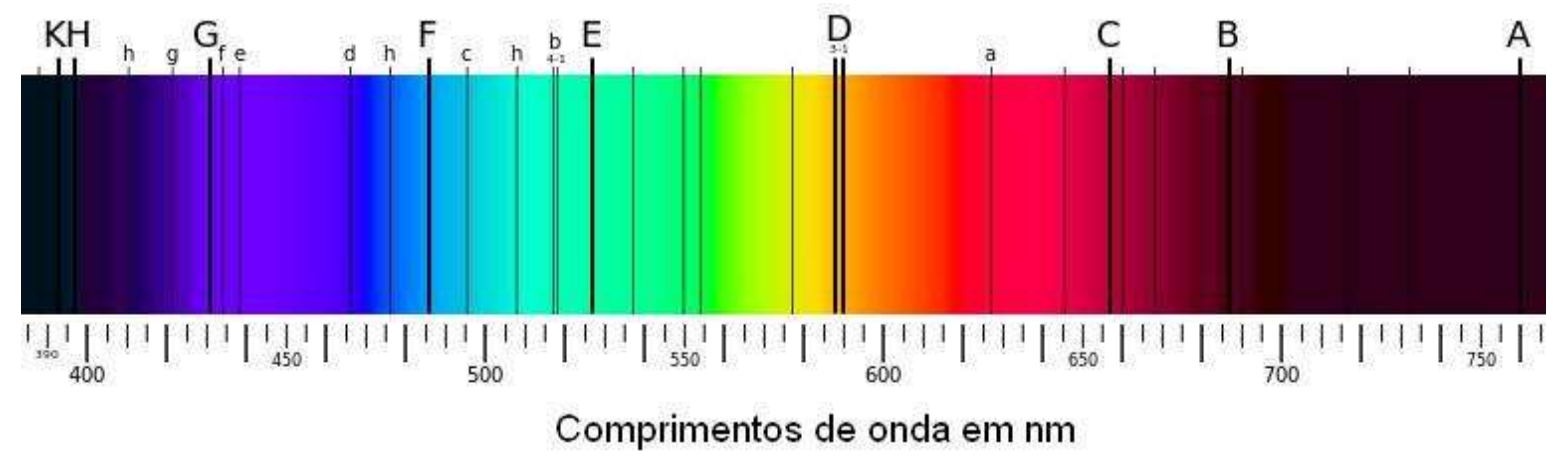

Fig. 6.3 - O espectro solar e as linhas de Fraunhofer. (https://en.wikipedia.org/wiki/History_of_spectroscopy) Editada pelo autor.

Para identificá-las, ele utilizou a nomenclatura de letras maiúsculas, para nomear as linhas mais fortes e letras minúsculas para as mais fracas. Ainda hoje, nos referimos a algumas linhas utilizando a nomenclatura de Fraunhofer, como por exemplo, as linhas $\mathrm{D}_{1} \mathrm{e}$ $\mathrm{D}_{2}$ do sódio, as linhas $\mathrm{H}$ e $\mathrm{K}$ do cálcio neutro e a linha $\mathrm{E}$ do magnésio.

\section{6 - A composição química do Sol}

Em 1860, o físico alemão Gustav Robert Kirchhoff(1824-1887) e o químico alemão Robert Wilhelm Eberhard Bunsen (1811-1899) publicaram os resultados ${ }^{24}$ de suas análises sobre os espectros de diversos elementos químicos. Eles obtiveram os espectros

\footnotetext{
23 Há três termos relacionados aos equipamentos que servem para a análise de um espectro: a) o espectroscópio que permite observar o espectro; b) o espectrógrafo que permite fotografar o espectro e c) o espectrômetro que serve para a medir comprimentos de onda nos espectros.

${ }^{24}$ Chemische Analyse durch Spectralbeobachtungen. Annalen der Physik und Chemie. Band CX, nº 6, 1860.
} 
colocando elementos químicos em chamas, produzindo descargas elétricas em gases e analisando o espectro da luz por eles emitida.

Entre as conclusões que eles obtiveram estava a que cada elemento químico apresentava um espectro característico: um conjunto de linhas que não se repetia em nenhum outro elemento. É como se cada elemento químico tivesse uma "impressão digital". Outras conclusões importantes que eles obtiveram, e que passaram a ser chamadas de leis da espectroscopia, foram:

1) Os sólidos, líquidos ou gases a altas temperaturas e sob altas pressões produzem um espectro contínuo. Os espectros contínuos são aqueles em que temos todas as cores (do vermelho ao violeta) sem a presença de linhas escuras (figura 6.4):

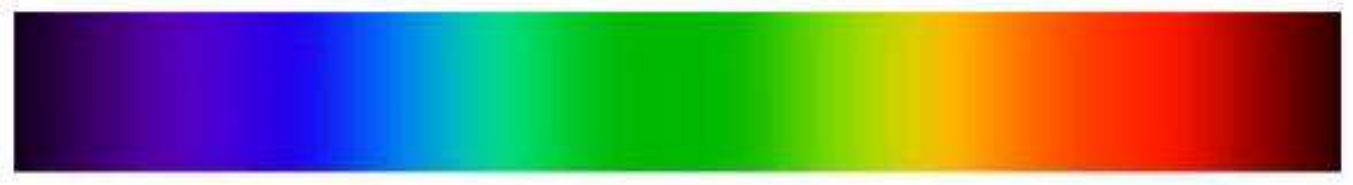

Fig. 6.4 - Um espectro contínuo.

2) Um gás a alta temperatura e sob baixa pressão produz um conjunto de linhas brilhantes, chamado de espectro de emissão (figura 6.5):

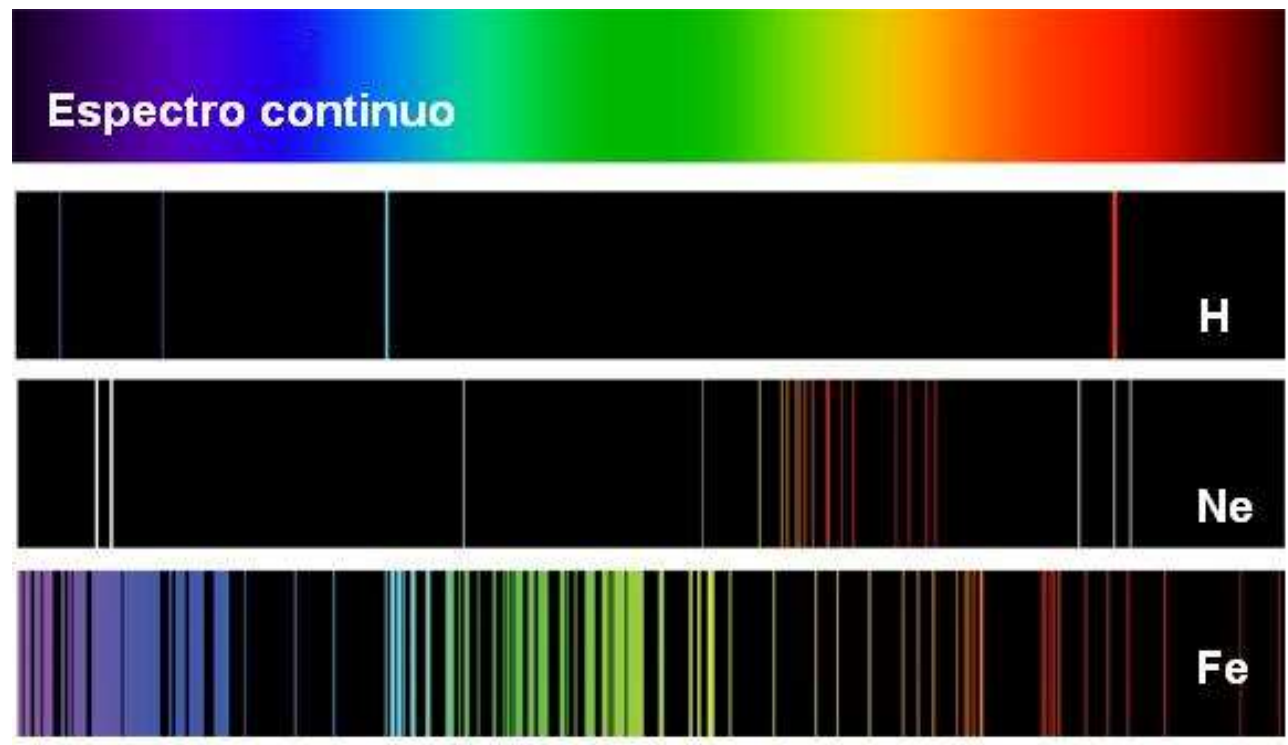

Fig. 6.5 - Espectros de alguns elementos químicos compostos por linhas brilhantes e o espectro contínuo para comparação. Adaptado pelo autor de: http://ianhfrancis.blogspot.com.br/ 
3) Linhas escuras, também chamadas de linhas de absorção, são produzidas quando a luz proveniente de uma fonte de espectro contínuo atravessa um gás frio sob pressão (figura 6.6):

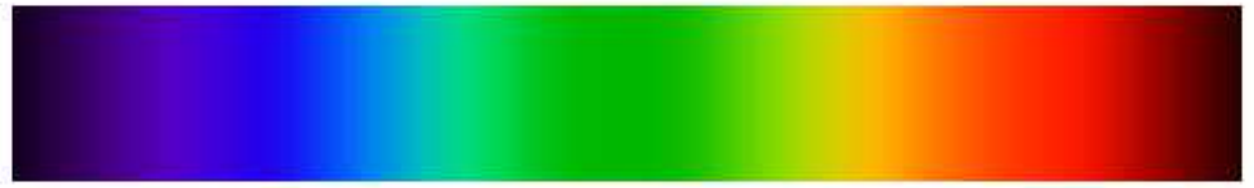

\section{Espectro contínuo}

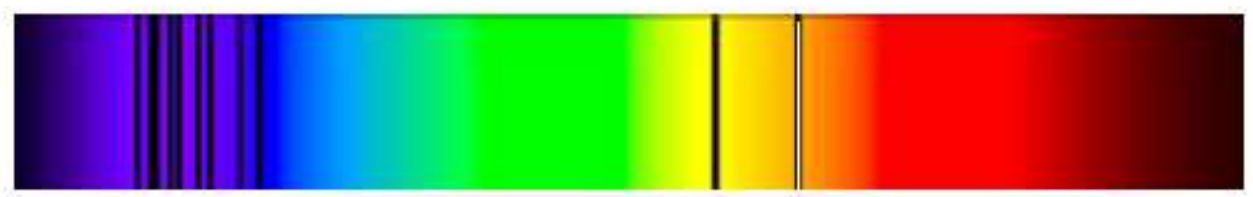

Espectro de absorção do Sódio

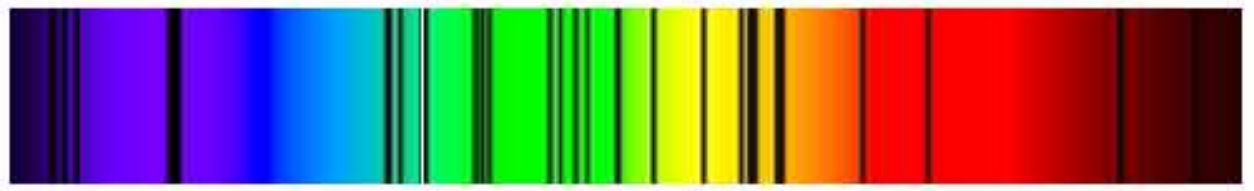

Espectro de absorção do Mercúrio

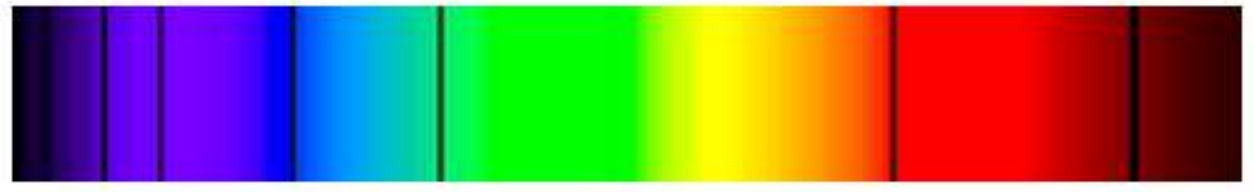

\section{Espectro de absorção do Lítio}

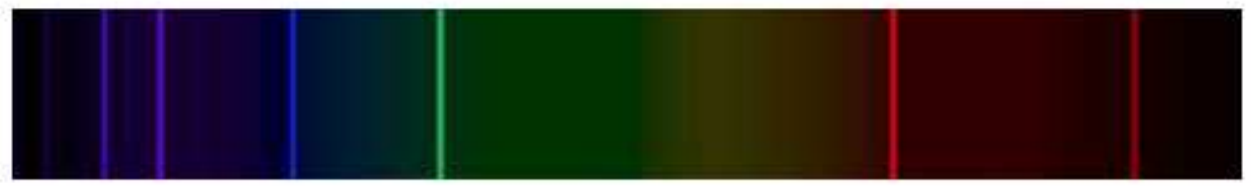

\section{Espectro de emissão do Lítio}

Fig. 6.6 - Um espectro composto por linhas escuras (linhas de absorção) e o espectro contínuo para comparação. Adaptado de um gráfico de http://www.astronoo.com/en/articles/spectroscopy.html

Comparando-se o espectro solar com os espectros dos diversos elementos químicos foi possível determinar a composição química do Sol. O mesmo procedimento permitiu obter, também, a composição química das estrelas. 


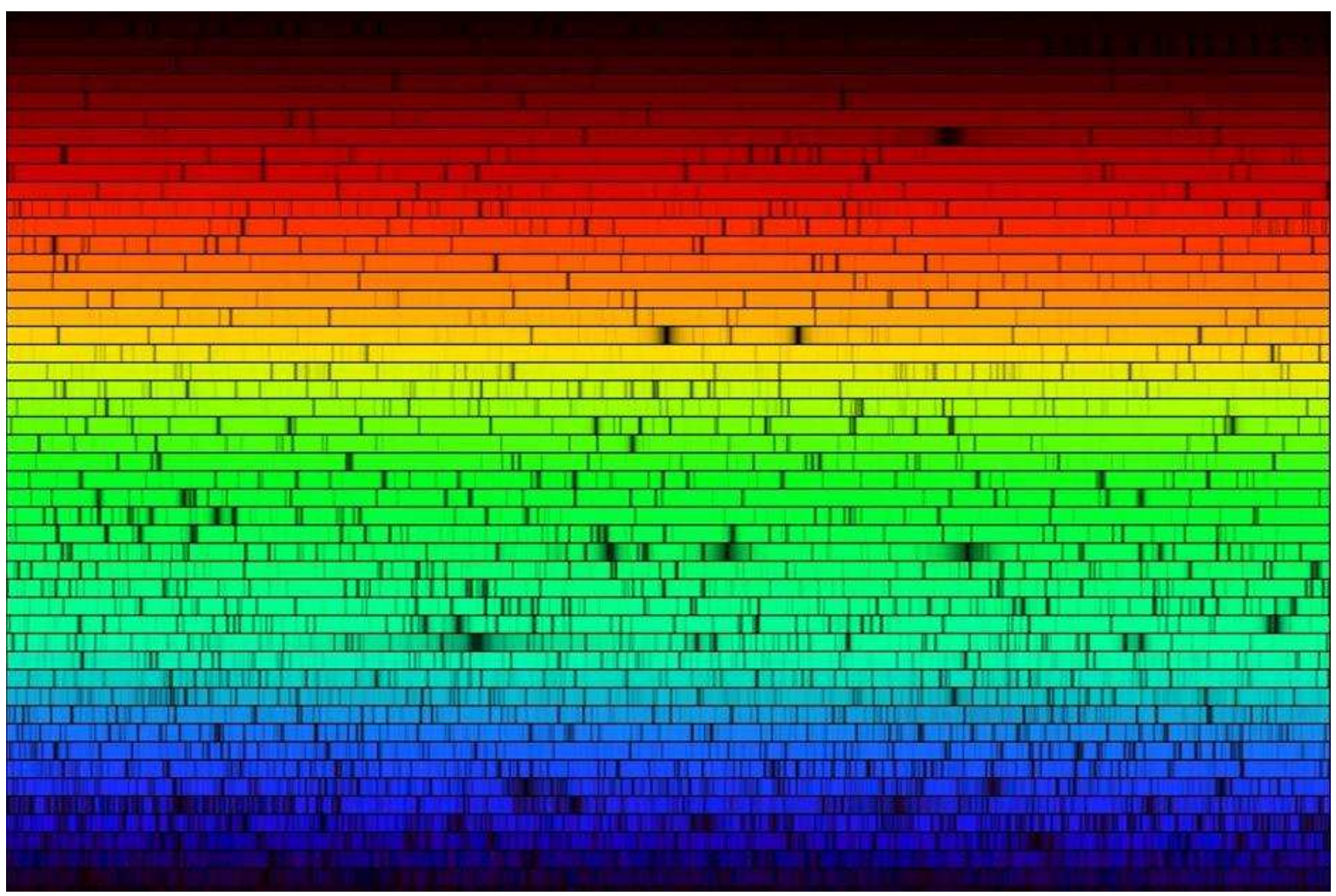

Fig. 6.7 - O espectro do Sol com linhas de absorção

Fonte: https://annasunmoonstars.wordpress.com/2016/02/17/the-suns-absorption-spectrum/

\section{Espectro Solar}
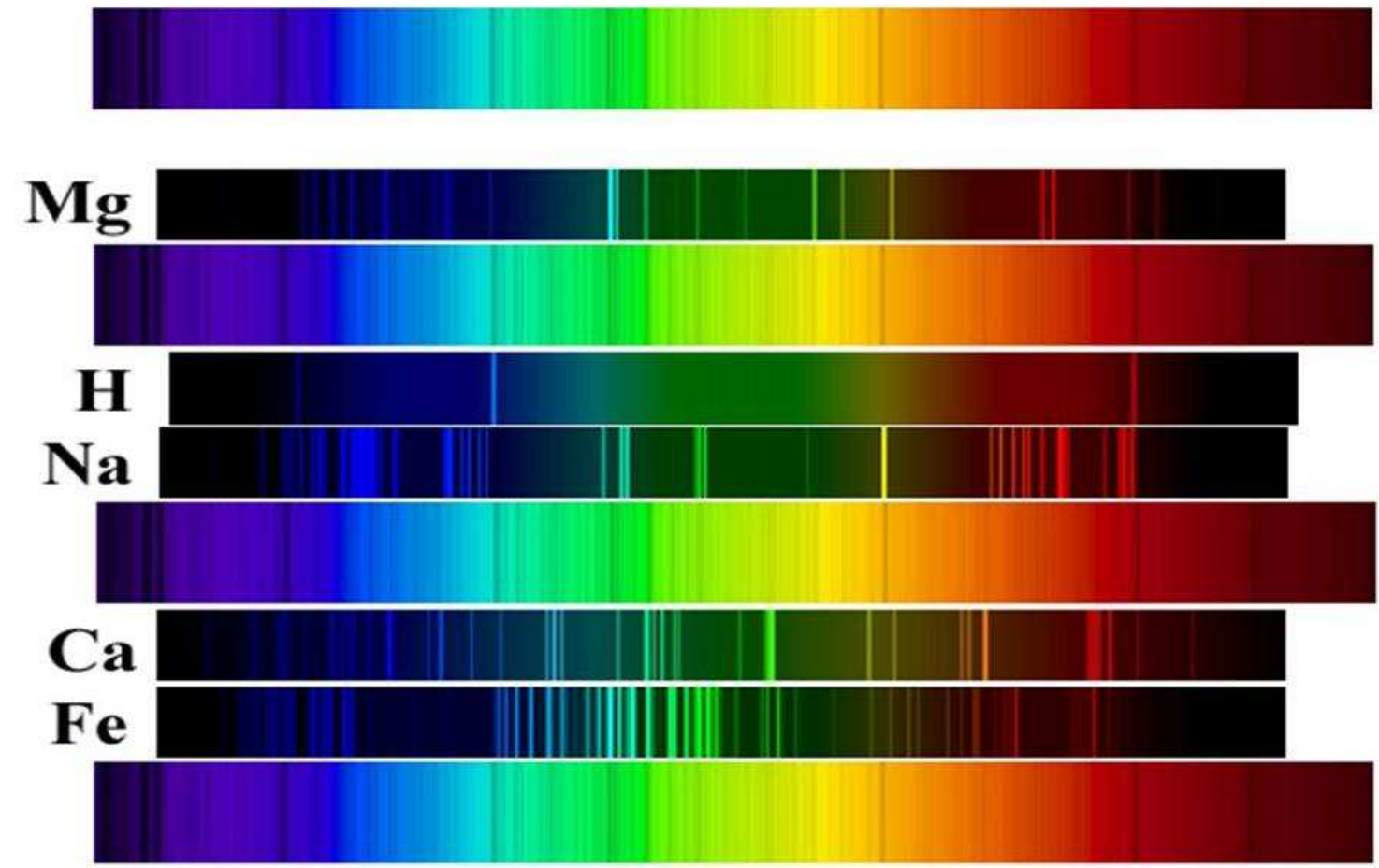

Fig. 6.8 - O espectro do Sol comparado aos espectros de alguns elementos químicos. A partir da comparação podemos determinar a composição química do Sol. 
Nos trabalhos de espectroscopia que os astrônomos realizam no dia a dia, não são observados espectros como ilustrados nas figuras anteriores. Na figura 6.9, temos um exemplo mostrando o espectro solar gráfico, com o qual os astrônomos trabalham e o espectro colorido, como vimos acima, para comparação. As posições das linhas no espectro estão assinaladas pelos seus comprimentos de onda.

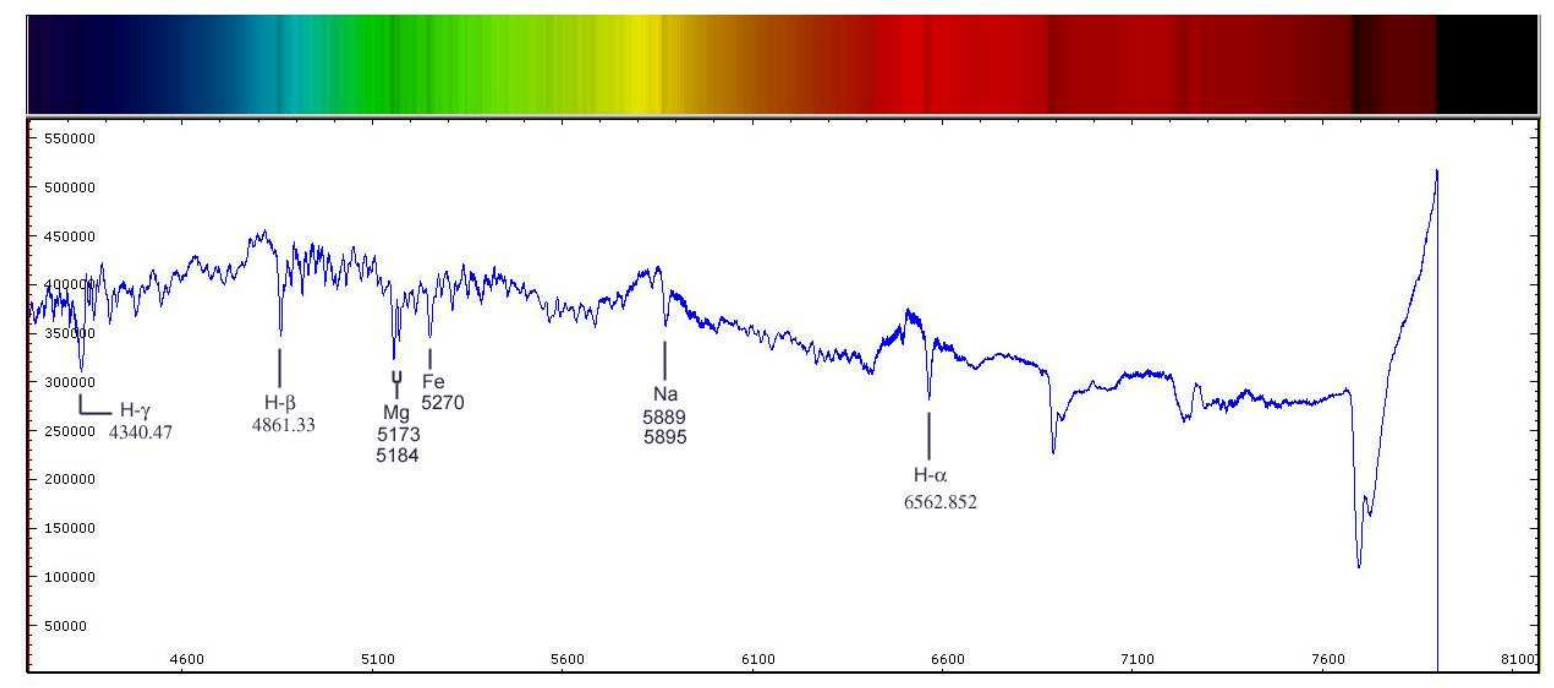

Fig. 6.9 - Espectro solar gráfico. No eixo das abscissas estão os comprimentos de onda em Angstrons e no eixo das ordenadas as intensidades em uma escala arbitrária. Fonte: http://igss.wikidot.com/the-sun-scontinuous-spectrum.

Nota-se com clareza que nos comprimentos de onda correspondentes às linhas de absorção há uma queda na intensidade. Embora em desuso (recomenda-se o uso de unidades do sistema internacional), muitos astrônomos ainda utilizam o Ångström como unidade de comprimento para exprimir os comprimentos de onda. O Ångström equivale a $10^{-10} \mathrm{~m}$ ou $10^{-1} \mathrm{~nm}$.

\section{7 - A temperatura do Sol}

A curva de intensidade do espectro solar segue muito de perto a curva de Planck que descreve a emissão de radiação por um corpo negro. Um corpo negro é um corpo físico ideal que é capaz de absorver toda a radiação eletromagnética que incide sobre ele, independente da frequência ou do ângulo de incidência. 


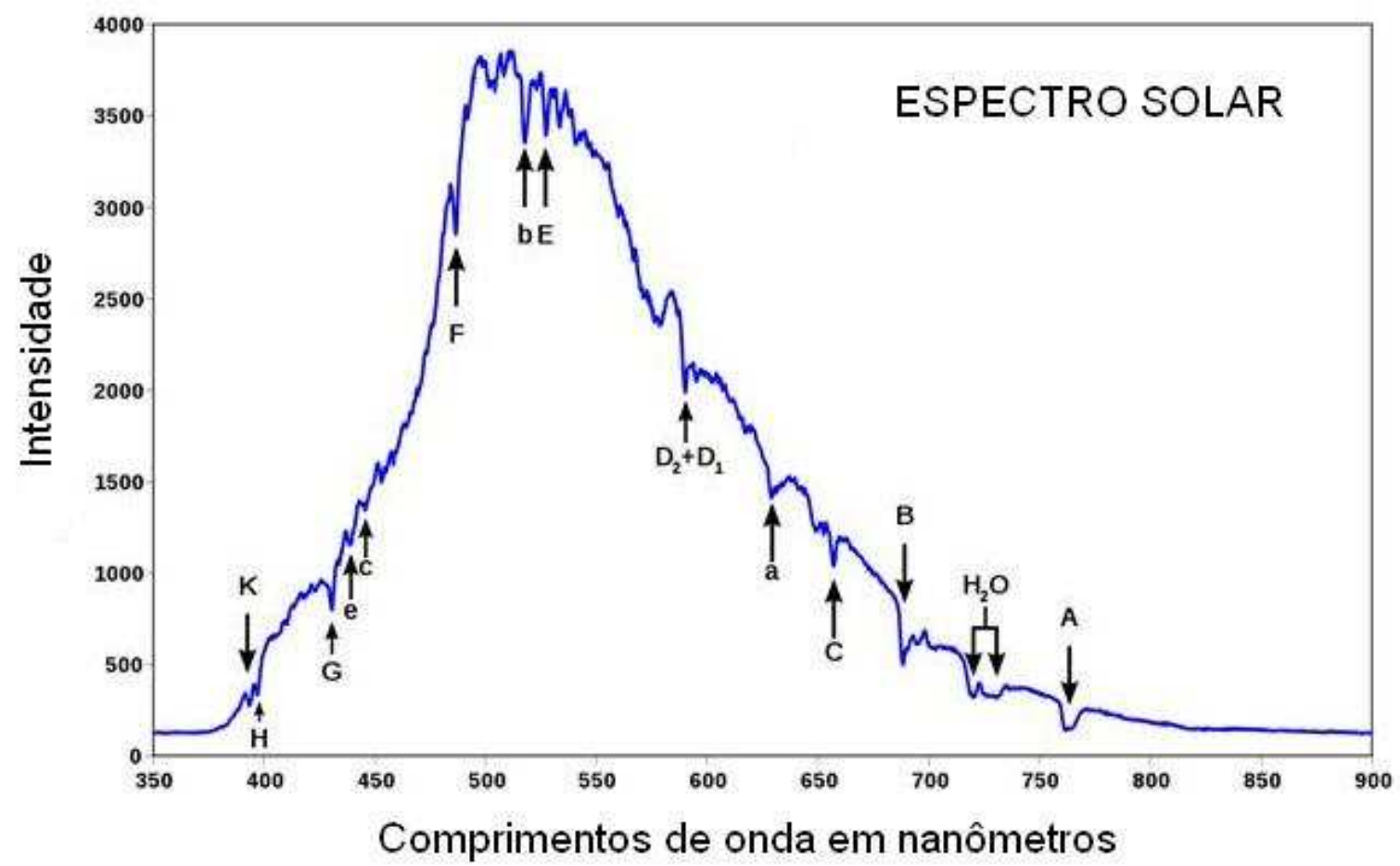

Fig. 6.10 - O espectro solar e as linhas de Fraunhofer. A curva de emissão do Sol nos vários comprimentos de onda assemelha-se à curva de Planck para a radiação de um corpo negro. Adaptado pelo autor de gráfico de https://en.wikipedia.org/wiki/Spectral_line

Um corpo negro em equilíbrio térmico (em temperatura constante) emite radiação chamada radiação de corpo negro. O fluxo irradiado por um corpo negro em equilíbrio térmico, isto é, a energia irradiada por unidade de área e por unidade de tempo em todas as frequências e em todas as direções, obedece à chamada Lei de Stefan-Boltzmann:

$$
F=\sigma \cdot T^{4}
$$

onde F é o fluxo, T a temperatura absoluta e $\sigma=5,67051 \times 10^{-8} \mathrm{~W} \cdot \mathrm{m}^{-2} \cdot \mathrm{K}^{-4}$ é chamada de constante de Stefan-Boltzmann.

Supondo que o Sol irradie como um corpo negro, podemos obter a chamada temperatura efetiva do Sol $\left(\mathrm{T}_{\text {eff }}\right)$, isto é, a temperatura de um corpo negro que irradia na mesma taxa que o Sol: 


$$
\begin{gathered}
F_{\text {sup }}^{\odot}=F_{C N} \rightarrow \frac{L_{b o l}^{\odot}}{4 \pi R_{\odot}^{2}}=\sigma T^{4} \\
\frac{L_{b o l}^{\odot}}{4 \sigma \pi R_{\odot}^{2}}=\left(T_{e f f}^{\odot}\right)^{4}
\end{gathered}
$$

Sendo $\quad F_{d=1 U A}^{\odot}=\frac{L_{b o l}^{\odot}}{4 \pi a^{2}} \quad \rightarrow \quad L_{b o l}^{\odot}=4 \pi a^{2} \times F_{d=1 U A}^{\odot} \quad$ e daí, tiramos:

$$
T_{e f f}^{\odot}=\sqrt[4]{\frac{L_{b o l}^{\odot}}{4 \sigma \pi R_{\odot}^{2}}}=\sqrt[4]{\frac{a^{2} \times F_{d=1 U A}^{\odot}}{\sigma R_{\odot}^{2}}}=5.770 K
$$

\section{GLOSSÁRIO}

O parsec é uma unidade de distância amplamente utilizada na Astrofísica. Corresponde à distância de um ponto cuja paralaxe é de 1". Seu valor é de $3,086 \times 10^{13} \mathrm{~km}$. Equivale a 32,6 anos-luz ou 206.265 unidades astronômicas. Abreviatura: pc 


\section{7 - A ORIGEM DA ENERGIA SOLAR}

A questão da origem da energia solar intrigou diversos astrônomos e físicos ao longo do tempo. Um dos primeiros a tocar nessa questão foi o filósofo, matemático e astrônomo grego Filolau de Crotona (século V a.C.) que, ao propor o seu modelo cosmológico, colocava no centro do mundo o fogo central. O Sol seria apenas um "espelho" que refletia a luz e o calor do fogo central. O fogo central não podia, no entanto, ser observado da Terra pela presença da Anti-Terra. Esta orbitava o fogo central entre ele e a Terra, com o mesmo período de nosso planeta. Depois dele, outros filósofos, como Aristarco de Samos, chegaram a propor um sistema heliocêntrico sem, no entanto, se preocupar com a natureza do Sol.

Posteriormente, outras hipóteses foram analisadas e descartadas. Uma delas supunha que a energia solar tivesse origem na combustão (reação química). Logo se verificou que isso não daria conta da enorme energia emitida pelo Sol ao longo de milênios, mesmo que ele fosse constituído de carvão queimando em oxigênio. Um cálculo simples evidencia isso. A combustão completa do carvão ocorre quando existe oxigênio suficiente para consumi-lo totalmente:

$$
\mathrm{C}(\mathrm{s})+\mathrm{O}_{2}(\mathrm{~g}) \rightarrow \mathrm{CO}_{2}(\mathrm{~g})
$$

Ou seja, 1 mol de carvão sólido, que corresponde a $12 \mathrm{~g}$ de $\mathrm{C}$, deve reagir com 1 mol de $\mathrm{O}_{2}$ gasoso, que corresponde a 32g. A massa total do Sol deveria ser constituída dessas duas substâncias, nas seguintes proporções em massa, para que a combustão se desse de forma completa:

a) quantidade de carvão sólido em massa $=5,45 \times 10^{29} \mathrm{~kg}$;

b) quantidade de oxigênio gasoso em massa $=14,54 \times 10^{29} \mathrm{~kg}$;

Se o Sol fosse uma esfera de carvão e oxigênio, com massa total $\mathbb{M}_{\odot}=1,989 \times 10^{30}$ $\mathrm{kg}$, emitiria, com a combustão completa do carvão, uma quantidade de energia igual a: 


$$
\mathrm{E}=5,45 \times 10^{32} \mathrm{~g} \times 32,8 \times 10^{3} \mathrm{~J} / \mathrm{g}=17,876 \times 10^{36} \mathrm{~J}
$$

onde a quantidade $32,8 \times 10^{3} \mathrm{~J} / \mathrm{g}$ é o calor de combustão do carvão. Dividindo-se a quantidade emitida na combustão pela taxa de energia irradiada pelo $\mathrm{Sol}\left(\mathrm{L}_{\odot}=3,9 \times 10^{26}\right.$ $\mathrm{J} / \mathrm{s}$ ), obteríamos o tempo de vida do Sol:

$$
\mathrm{T}_{\odot}=17,876 \times 10^{36} \mathrm{~J} / 3,9 \times 10^{26} \mathrm{~J} / \mathrm{s}=4,58 \times 10^{10} \mathrm{~s}=1.450 \text { anos }
$$

o que, evidentemente, é muitíssimo inferior ao próprio período da história da humanidade! Se considerássemos ainda que toda a massa do Sol $\left(1,989 \times 10^{30} \mathrm{~kg}\right)$ fosse constituída de carvão e uma nuvem externa de oxigênio produzisse a sua combustão, ainda assim o Sol irradiaria:

$$
\mathrm{E}=1,989 \times 10^{33} \mathrm{~g} \times 32,8 \times 10^{3} \mathrm{~J} / \mathrm{g}=65,24 \times 10^{36} \mathrm{~J}
$$

o que lhe daria um tempo de vida igual a:

$$
\mathrm{T}_{\odot}=65,24 \times 10^{36} \mathrm{~J} / 3,9 \times 10^{26} \mathrm{~J} / \mathrm{s}=16,73 \times 10^{10} \mathrm{~s}=5.300 \text { anos }
$$

\section{1 - A Teoria de Mayer}

Em 1848, o médico e físico alemão Julius Robert Von Mayer (1814-1878) sugeriu que o calor solar talvez fosse mantido pela queda de meteoroides no Sol. Ele argumentou que na ausência de uma fonte de energia, o Sol não poderia irradiar por mais de 5.000 anos. Estudando a entrada de meteoroides na atmosfera da Terra, explicou o aparecimento dos meteoros como resultado da fricção entre eles e os gases da atmosfera. Essa ideia lhe sugeriu que a energia cinética de grandes meteoroides caindo no Sol poderia gerar uma quantidade de energia que permitiria repor a energia que o Sol perde por irradiação.

Os cálculos do autor da teoria mostraram que um corpo com massa de $1 \mathrm{~kg}$ caindo no Sol, com velocidade da ordem de $600 \mathrm{~km} / \mathrm{s}$, forneceria cerca de 43.000.000.000 de calorias, quantidade muito superior àquela que seria gerada na combustão desse corpo se ele fosse constituído de carvão. 
Meteoroides estão continuamente caindo na Terra produzindo meteoros e, em muitos casos, atingindo a superfície da Terra (meteoritos). Mayer imaginou que continuamente estariam caindo no Sol em grandes quantidades. Se uma quantidade equivalente a 1/100 da massa da Terra caísse anualmente no Sol, com velocidades superiores a $600 \mathrm{~km} / \mathrm{s}$, poderia se dar conta da quantidade de energia irradiada pelo Sol.

Não há dúvida de que uma certa quantidade de meteoróides cai anualmente no Sol. No entanto, a energia gerada nas quedas não dá conta da energia emitida pelo Sol. A queda anual de tal quantidade de meteoroides implicaria na presença, nas proximidades do Sol, de uma enorme quantidade de matéria. Como sabemos, poucos meteoroides que se aproximam do Sol procedentes do espaço distante, atingem a sua superfície. Os cometas rasantes (sungrazing comets) aproximam-se muito do Sol sem tocá-lo. Além disso, se houvesse matéria na quantidade citada, nas proximidades do Sol, ela provocaria perturbações gravitacionais nos movimentos de Mercúrio e Vênus. As observações, no entanto, não revelam isso.

\section{2 - A Teoria de Helmholtz}

Em 1854, o físico e médico alemão Hermann Ludwig Ferdinand Von Helmholtz (1821-1894) propôs que a própria gravidade solar poderia suprir a enorme quantidade de energia do Sol. Se o Sol estivesse lentamente se contraindo, a energia gerada nesse processo poderia dar conta da radiação emitida. No entanto, a geração de energia, nesse processo, não permitiria que o Sol irradiasse por mais de 20 milhões de anos, como adiante verificamos.

A energia resultante da contração gravitacional é muito importante não só para o Sol como para outras estrelas que estão se contraindo. Considerando uma estrela esférica com massa $\mathrm{M}$ se contraindo, pelo princípio da conservação da energia temos, para a energia total (E) da estrela:

$$
\mathrm{E}=\mathrm{E}_{\mathrm{T}}+\mathrm{E}_{\mathrm{G}}
$$


onde $\mathrm{E}_{\mathrm{T}}$ é energia térmica e $\mathrm{E}_{\mathrm{G}}$ é energia gravitacional. Quando a energia potencial gravitacional $\left(\mathrm{E}_{\mathrm{G}}\right)$ diminui, devido à contração, a energia cinética das partículas no interior da estrela aumenta, isto é, há um aumento da energia térmica $\left(\mathrm{E}_{\mathrm{T}}\right)$.

O teorema do virial permite afirmar que a energia total $(\mathrm{E})$ é igual à metade da energia potencial gravitacional, ou seja:

$$
\frac{1}{2} E_{G}=E_{T}+E_{G}
$$

Desta forma, quando uma estrela se contrai, apenas metade da sua energia total é utilizada para aumentar a sua temperatura. A outra metade é liberada como radiação. Sendo a energia potencial gravitacional de uma esfera de massa $\mathrm{M}$ e raio $\mathrm{R}$ é dada por:

$$
E_{G}=-\frac{G M^{2}}{R}
$$

segue-se que a energia gerada na contração e que está disponível para ser irradiada é:

$$
\frac{1}{2} E_{G} \cong \frac{1}{2} \frac{G M^{2}}{R}
$$

No caso do Sol, o tempo durante o qual a contração gravitacional poderia sustentar a luminosidade do Sol, em seu valor atual, é chamado de tempo de contração de Kelvin ( $\left.\mathrm{T}_{\mathrm{K}}\right)$ ou tempo térmico e seu valor é:

$$
T_{K}=\frac{1}{2} \frac{G M^{2}}{R L}
$$

Substituindo-se os valores de G, M, L e R, obteremos para o Sol, cerca de 20 milhões de anos para o tempo de contração de Kelvin. 


\section{3 - Uma mudança de paradigma}

Durante muitos anos, a teoria da contração foi a mais considerada pelos astrônomos para explicar a origem da energia solar. No final do século XIX, a radioatividade foi descoberta. Elementos químicos pesados decaiam em elementos mais leves com emissão de partículas contendo altas energias. Era essa a energia emitida pelos elementos radioativos contidos nas rochas que produziam o calor interno da Terra. A radioatividade proporcionou meios novos de se estimar a idade da Terra. As quantidades acumuladas dos produtos oriundos dos decaimentos indicavam o tempo envolvido no processo de decaimento. Os resultados indicavam que a Terra era muito mais velha que o valor calculado por Helmholtz para a idade do Sol. Havia a necessidade de se encontrar outra fonte interna que suprisse a enorme energia irradiada pelo Sol. Houve, também, quem propusesse que o calor do Sol tinha origem na desintegração de elementos radioativos em seu interior.

Em 1925, Cecília Helena Payne ${ }^{25}$ (1900-1979), astrônoma inglesa que imigrou para os Estados Unidos em 1923, defendeu sua tese de doutorado no Radcliffe College, da Universidade de Harvard, sob a orientação do famoso astrônomo Harlow Shapley (18851972). Na tese, intitulada "Stellar Atmospheres, A Contribution to the Observational Study of High Temperature in the Reversing Layers of Stars" (Atmosferas estelares: Uma contribuição para o estudo observacional de altas temperaturas nas camadas inversoras das estrelas), ela mostra que no Sol (e nas estrelas) o elemento químico preponderante é o hidrogênio. Em relação a esse trabalho, os astrônomos Otto Struve e Velta Zebergs chegaram a afirmar que era "indubitavelmente a tese de doutoramento mais brilhante jamais escrita em astronomia"26.

No entanto, quando a tese foi avaliada, o astrônomo Henry Norris Russell desencorajou a astrônoma a apresentar as suas conclusões (de que a composição do Sol era de hidrogênio predominantemente). Essa conclusão diferia muito do conhecimento

\footnotetext{
${ }^{25}$ Casou-se em 1934 com o astrônomo russo Sergei I. Gaposchkin e passou a chamar-se Cecília Helena Payne Gaposchkin.

${ }^{26}$ Astronomy on The 20th Century - Otto Struve e Velta Zebergs- pag.220.
} 
vigente na época, pois mostrava que a composição do Sol era bastante distinta da composição química da Terra.

Cerca de quatro anos depois, Russell mudou de opinião tendo chegado aos mesmos resultados que Cecília, embora por um caminho diferente. Ao publicar seus resultados, fez uma breve menção à tese de Cecília Gaposchkin. Os créditos dessa descoberta são frequentemente atribuídos a Russell, embora seja amplamente sabido quem descobriu.

\section{4 - Origem nuclear da energia solar}

Entre 1937-1939, os físicos alemães Hans Albrecht Bethe ${ }^{27}$ (1906-2005) e Carl Friedrich Freiherr Von Weizsäcker ${ }^{28,29}$ (1912-2007) propuseram um mecanismo nuclear para a produção de energia no Sol e nas estrelas. O processo consistia em sequências cíclicas de reações de fusão nuclear, que levavam à transformação do hidrogênio em hélio.
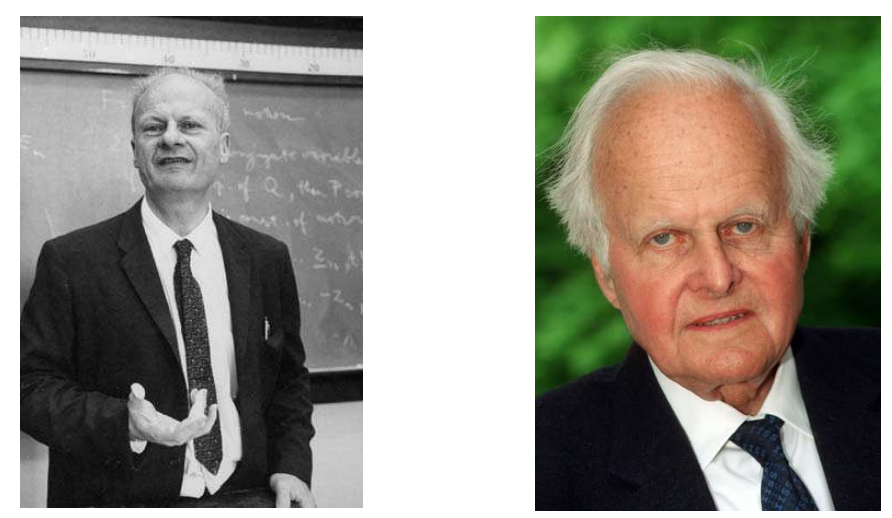

Fig. 7.1 - À esquerda, Hans Albrecht Bethe (1906-2005) e à direita, C. F. F. von Weizsäcker (1912-2007).

\footnotetext{
${ }^{27}$ Bethe, H. A. (1939). "Energy Production in Stars". Physical Review. 55 (5): 434-56.

${ }^{28}$ C.F. von Weizsäcker (1937) "Über Elementumwandlungen im Innern der Sterne. I" (On transformations of elements in the interiors of stars. I), Physikalische Zeitschrift (Physics Journal), vol. 38, p. 176-191;

${ }^{29}$ C.F. von Weizsäcker (1938) "Über Elementumwandlungen im Innern der Sterne. II" (On transformations of elements in the interiors of stars. II), Physikalische Zeitschrift, vol. 39, p. 633-646;
} 
O principal conjunto de reações nucleares responsáveis pela produção da energia solar é o chamado CICLO P-P (ciclo próton-próton) ou CADEIA P-P (cadeia prótonpróton). Esse conjunto de reações leva à transformação do hidrogênio em hélio.

No primeiro passo da cadeia $\mathrm{p}$-p, dois prótons se unem para formar um deuteron que é o núcleo do deutério ou hidrogênio pesado ${ }_{1}^{2} \mathrm{H}$ :

$$
{ }_{1}^{1} \mathrm{H}+{ }_{1}^{1} \mathrm{H} \rightarrow{ }_{1}^{2} \mathrm{H}+e^{+}+\mathrm{v}_{e}+0,42 \mathrm{MeV}
$$

onde ${ }_{1}^{1} H$ é o próton (núcleo do átomo de hidrogênio), e é o pósitron, $v_{\mathrm{e}}$ é o neutrino do elétron e 0,42 MeV é a quantidade de energia carregada pelo neutrino, expressa em Mega $\left(10^{6}\right)$ elétron-Volts. Lembramos que 1 elétron-Volt é a energia cinética que um elétron adquire sob a diferença de potencial de 1 Volt. Seu valor, no Sistema Internacional de Unidades é $1,602177 \times 10^{-19} \mathrm{~J}\left(1 \mathrm{MeV}=10^{6} \mathrm{eV}=1,602177 \times 10^{-13} \mathrm{~J}\right)$.

Como o deuteron é constituído de um próton e de um nêutron, um dos prótons que participou da reação transformou-se em um nêutron, emitindo um pósitron (que carregou a carga do próton) e um neutrino de baixa energia. Cada próton no interior solar envolve-se em colisões com outros prótons milhões de vezes por segundo. No entanto, somente aqueles mais energéticos são capazes de vencer a barreira de potencial (de repulsão com outros) e se juntar com outro próton. Apenas uma colisão em cada $10^{25}$ colisões dá origem à reação de início na cadeia p-p.

Os pósitrons produzidos pela reação anterior colidindo com elétrons existentes no núcleo solar são aniquilados (reação de matéria com antimatéria):

$$
e^{+}+e^{-} \rightarrow 2 \gamma+1,02 \mathrm{MeV}
$$

O passo seguinte na cadeia p-p ocorre quando o deuteron colide com outro próton produzindo um núcleo leve de hélio $\left({ }_{2}^{3} \mathrm{He}\right)$ :

$$
{ }_{1}^{2} \mathrm{H}+{ }_{1}^{1} \mathrm{H} \rightarrow{ }_{2}^{3} \mathrm{He}+\gamma+5,49 \mathrm{MeV}
$$


Esta reação ocorre rapidamente. Assim que o deuteron é formado na reação anterior, em menos de um segundo ele colide com um próton e forma o núcleo leve do hélio. Pela rapidez que essa reação ocorre, o deutério acaba por não ser sintetizado no interior das estrelas, sendo consumido na formação de elementos mais pesados.

Finalmente, dois núcleos leves de hélio se fundem e produzem um núcleo comum de hélio $\left({ }_{2}^{4} \mathrm{He}\right)$ :

$$
{ }_{2}^{3} \mathrm{He}+{ }_{2}^{3} \mathrm{H} \rightarrow{ }_{2}^{4} \mathrm{He}+2{ }_{1}^{1} \mathrm{H}+12,86 \mathrm{MeV}
$$

Resumindo o processo, temos:

$$
\begin{gathered}
{ }_{1}^{1} \mathrm{H}+{ }_{1}^{1} \mathrm{H} \rightarrow{ }_{1}^{2} \mathrm{H}+e^{+}+v_{e}+0,42 \mathrm{MeV} \\
{ }_{1}^{1} \mathrm{H}+{ }_{1}^{1} \mathrm{H} \rightarrow{ }_{1}^{2} \mathrm{H}+e^{+}+v_{e}+0,42 \mathrm{MeV} \\
{ }_{1}^{2} \mathrm{H}+{ }_{1}^{1} \mathrm{H} \rightarrow{ }_{2}^{3} \mathrm{He}+\gamma+5,49 \mathrm{MeV} \\
{ }_{1}^{2} \mathrm{H}+{ }_{1}^{1} \mathrm{H} \rightarrow{ }_{2}^{3} \mathrm{He}+\gamma+5,49 \mathrm{MeV} \\
{ }_{2}^{3} \mathrm{He}+{ }_{2}^{3} \mathrm{He} \rightarrow{ }_{2}^{4} \mathrm{He}+2{ }_{1}^{1} \mathrm{H}+12,86 \mathrm{MeV}
\end{gathered}
$$

$$
4{ }_{1}^{1} H \rightarrow{ }_{2}^{4} \mathrm{He}+2 e^{+}+2 \gamma+v_{e}
$$

Considerando que os dois pósitrons se aniquilam gerando 2,04 MeV, verificamos que a cadeia p-p completa produz $26,72 \mathrm{MeV}$. Dois porcento dessa energia é carregada pelos neutrinos produzidos no processo. Esse conjunto de reações, denominado também de p-p I, é dominante em temperaturas que vão da ordem de 10 a 14 milhões de kelvins. Abaixo de 10 milhões de kelvins, a cadeia p-p não produz muito hélio.

A quantidade de $26,7 \mathrm{MeV}$ corresponde à cerca de 4,3 x $10^{-12} \mathrm{~J}$ de energia. Um valor extremamente pequeno. Isso resulta do fato da massa de um núcleo de hélio ser ao redor de $0,007(0,7 \%)$ da soma das massas de quatro prótons (quatro núcleos de átomos de 
hidrogênio). A massa de um núcleo de hélio é $\mathrm{m}_{\mathrm{He}}=6,64 \times 10^{-27} \mathrm{~kg}$. Cada próton tem massa $\mathrm{m}_{\mathrm{H}}=1,67 \times 10^{-27} \mathrm{~kg}$. Temos então:

$$
4 m_{\mathrm{H}}-\mathrm{m}_{\mathrm{He}}=4 \times 1,67 \times 10^{-27}-6,64 \times 10^{-27}=6,6810^{-27}-6,64 \times 10^{-27}=0,04 \times 10^{-27} \mathrm{~kg}
$$

Utilizando a equação $\mathrm{E}=\mathrm{mc}^{2}$ da Teoria da Relatividade, que permite calcular a quantidade de energia (E) que se obtém numa transformação de massa em energia, poderemos obter a quantidade de energia:

$$
\mathrm{E}=\mathrm{mc}^{2}=0,04 \times 10^{-27} \mathrm{~kg} \times\left(3 \times 10^{8} \mathrm{~m} / \mathrm{s}\right)^{2}=3,6 \times 10^{-12} \mathrm{~J}
$$

valor muito próximo do obtido pela soma das energias liberadas nas reações nucleares. Esse valor deve ser multiplicado pela enorme quantidade de reações que ocorrem no interior do Sol em cada segundo, e teremos a quantidade de energia produzida por segundo.

Como a quantidade de energia produzida no núcleo solar é a mesma que sai em sua superfície (o Sol não está se aquecendo) e, sendo a luminosidade do Sol $\mathrm{L}_{\odot}=3,9 \times 10^{26}$ $\mathrm{J} / \mathrm{s}$, teremos:

$$
m=\frac{L_{\odot}}{c^{2}}=\frac{3,9 \times 10^{26} \mathrm{~J} / \mathrm{s}}{\left(3 \times 10^{8} \mathrm{~m} / \mathrm{s}\right)^{2}}=4,3 \times 10^{9} \mathrm{~kg}=4,3 \times 10^{6} \mathrm{ton}
$$

o que nos permite obter que cerca de 4,3 milhões de toneladas de massa do Sol são convertidas em energia a cada segundo.

A produção de hélio no Sol, através da cadeia p-p I, representa 83,30 \%. Outras duas ramificações, chamadas p-p II e p-p III respondem, respectivamente, por 16,68 \% e $0,02 \%$. Esses dois ramos estão adiante esquematizados. 


\subsection{1 - A CADEIA P-P II:}

Cerca de 69\% do hélio-3, produzido na reação: ${ }_{1}^{2} \mathrm{H}+{ }_{1}^{1} \mathrm{H} \rightarrow{ }_{2}^{3} \mathrm{He}+\gamma$ gera o hélio 4 comum, como vimos:

$$
{ }_{2}^{3} \mathrm{He}+{ }_{2}^{3} \mathrm{He} \rightarrow{ }_{2}^{4} \mathrm{He}+2{ }_{1}^{1} \mathrm{H}
$$

No entanto, $31 \%$ do hélio-3 formado se funde com hélio-4 já formado, dando origem ao elemento químico berílio:

$$
{ }_{2}^{3} \mathrm{He}+{ }_{2}^{4} \mathrm{He} \rightarrow{ }_{4}^{7} \mathrm{Be}+\gamma
$$

Por sua vez, 99,7\% do berílio assim formado, produz lítio por captura de elétrons:

$$
{ }_{4}^{7} \mathrm{Be}+e^{-} \rightarrow{ }_{3}^{7} \mathrm{Li}+\mathrm{v}_{e}
$$

Na sequência, o lítio capturando prótons produz dois núcleos de hélio-4:

$$
{ }_{3}^{7} \mathrm{Li}+{ }_{1}^{1} \mathrm{H} \rightarrow 2{ }_{2}^{4} \mathrm{He}
$$

O conjunto de reações denominado p-p II é dominante em temperaturas entre 14 e 23 milhões de kelvins. Resumindo o p-p II:

$$
\begin{gathered}
{ }_{2}^{3} \mathrm{He}+{ }_{2}^{4} \mathrm{He} \rightarrow{ }_{4}^{7} \mathrm{Be}+\gamma \\
{ }_{4}^{7} \mathrm{Be}+e^{-} \rightarrow{ }_{3}^{7} \mathrm{Li}+v_{e} \\
{ }_{3}^{7} \mathrm{Li}+{ }_{1}^{1} \mathrm{H} \rightarrow 2{ }_{2}^{4} \mathrm{He}
\end{gathered}
$$

Os neutrinos produzidos na segunda reação do processo acima têm energia com valores de $0,861 \mathrm{MeV}$ (90\% deles) e $0,383 \mathrm{MeV}$ (10\% deles). A diferença entre as energias 
assinaladas decorre do fato do lítio produzido encontrar-se, respectivamente, no estado fundamental ou no estado excitado.

\subsection{2 - A CADEIA P-P III:}

A última ramificação da cadeia p-p, chamada de p-p III, diz respeito aos 0,3\% do berílio produzido na reação:

$$
{ }_{2}^{3} \mathrm{He}+{ }_{2}^{4} \mathrm{He} \rightarrow{ }_{4}^{7} \mathrm{Be}+\gamma
$$

O berílio-7 capturando um próton forma o boro-8 com emissão de radiação gama. Este por sua vez decai no berílio-8 com emissão de um pósitron e um neutrino do elétron. Por fim, o berílio-8 decai em dois núcleos de hélio-4.

$$
\begin{gathered}
{ }_{4}^{7} \mathrm{Be}+{ }_{1}^{1} \mathrm{H} \rightarrow{ }_{5}^{8} \mathrm{~B}+\gamma \\
{ }_{5}^{8} \mathrm{~B} \rightarrow{ }_{4}^{8} \mathrm{Be}+e^{+}+v_{e} \\
{ }_{4}^{8} \mathrm{Be} \rightarrow 2{ }_{2}^{4} \mathrm{He}
\end{gathered}
$$

A cadeia p-p III tem pouca importância na produção da energia solar, respondendo por apenas $0,11 \%$ da energia produzida. Ela é dominante quando a temperatura ultrapassa 23 milhões de kelvins. A importância dessa cadeia será vista no tópico seguinte sobre o problema dos neutrinos solares.

Um outro conjunto de reações nucleares dominantes em estrelas com massa superior à massa solar e em estrelas com temperatura do núcleo superior a 17 milhões de kelvins é o chamado ciclo CNO, cujas reações estão adiante esquematizadas:

$$
\begin{aligned}
& { }_{6}^{12} \mathrm{C}+{ }_{1}^{1} \mathrm{H} \rightarrow{ }_{7}^{13} \mathrm{~N}+\gamma+1,95 \mathrm{MeV} \\
& { }_{7}^{13} \mathrm{~N} \rightarrow{ }_{6}^{13} \mathrm{C}+e^{+}+v_{e}+1,20 \mathrm{MeV} \\
& { }_{6}^{13} \mathrm{C}+{ }_{1}^{1} \mathrm{H} \rightarrow{ }_{7}^{14} \mathrm{~N}+\gamma+7,54 \mathrm{MeV}
\end{aligned}
$$




$$
\begin{aligned}
& { }_{7}^{14} \mathrm{~N}+{ }_{1}^{1} \mathrm{H} \rightarrow{ }_{8}^{15} \mathrm{O}+\gamma+7,35 \mathrm{MeV} \\
& { }_{8}^{15} \mathrm{O} \rightarrow{ }_{7}^{15} \mathrm{~N}+e^{+}+v_{e}+1,73 \mathrm{MeV} \\
& { }_{7}^{15} \mathrm{~N}+{ }_{1}^{1} \mathrm{H} \rightarrow{ }_{6}^{12} \mathrm{C}+{ }_{2}^{4} \mathrm{He}+4,96 \mathrm{MeV}
\end{aligned}
$$

Considerando a energia liberada pela aniquilação de dois pósitrons com dois elétrons $(2,04 \mathrm{MeV})$, o total de energia liberada pelo ciclo é 26,77 MeV. Esse ciclo foi originalmente chamado ciclo C-N (ciclo carbono-nitrogênio) e também de ciclo Bethe Weizsäcker. O oxigênio não foi originalmente incluído na designação por que o ciclo não formava um isótopo estável desse elemento.

Inicialmente, a partir de seus cálculos, Bethe julgou que esse ciclo constituía-se na fonte primária de energia solar pois se acreditava, então, que o Sol era composto de 10\% de nitrogênio. Hoje sabemos que o nitrogênio corresponde a menos de $0,5 \%$ da composição solar.

Note que o carbono que participa da reação inicial do ciclo é restituído ao final e atua como se fosse um "catalisador" para a transformação do hidrogênio em hélio. O ciclo CNO responde por apenas $1,7 \%$ do hélio-4 produzido no Sol.

\section{5 - O problema dos neutrinos solares}

Os neutrinos foram propostos teoricamente, em 1930, pelo físico austríaco Wolfgang Ernst Pauli (1900-1958) com a finalidade de manter a conservação da energia no decaimento beta. Tem-se estudado diversas fontes de neutrinos, entre elas, os solares, produzidos nas reações nucleares que dão origem à energia solar, os atmosféricos produzidos por raios cósmicos bloqueados pela atmosfera terrestre, os produzidos pelos decaimentos radioativos naturais nas rochas terrestres, chamados de geoneutrinos e os produzidos pelas reações nucleares que ocorrem nos reatores nucleares. 
Existem três tipos de neutrinos e há evidências que possuam massas extremamente pequenas. Os três tipos (ou sabores ${ }^{30}$ ) estão designados de acordo com os léptons que os acompanham na interação fraca: o neutrino do elétron $\left(v_{e}\right)$, o neutrino do múon $\left(v_{\mu}\right)$ e o neutrino do tau $\left(v_{\tau}\right)$.

Os neutrinos possuem esses nomes porque, por exemplo, o neutrino do elétron $\left(v_{\mathrm{e}}\right)$ só participa das interações entre partículas subatômicas em que o elétron participa também. O mesmo vale para os outros: o neutrino do múon $\left(v_{\mu}\right)$ só participa das reações onde o múon participa também, o mesmo acontecendo com o neutrino do tau $\left(v_{\tau}\right)$. $\mathrm{O}$ elétron, o múon e o tau são três partículas elementares que, juntamente com os três neutrinos, são classificadas como léptons ${ }^{31}$.

Os neutrinos provenientes do Sol são neutrinos do elétron $\left(v_{\mathrm{e}}\right)$. Quando se estuda o fluxo de neutrinos provenientes do Sol, nota-se que a sua quantidade é inferior ao valor esperado teoricamente. Em 1964, John Norris Bahcall (1934 -2005) astrofísico americano, predisse, a partir do modelo solar de produção de energia, um fluxo de $5 \times 10^{6}$ neutrinos $/ \mathrm{cm}^{2} / \mathrm{s}$. O modelo solar padrão nos leva a prever a quantidade de neutrinos que deve chegar a Terra. Experimentalmente, no entanto, a quantidade não confere. Um primeiro experimento consistiu em um grande tanque de percloroetileno ${ }^{32}$ enterrado bem abaixo da superfície da Terra. Foi denominado Telescópio Solar de Neutrinos.

Os neutrinos detectados correspondiam a apenas um terço da quantidade esperada a partir dos melhores modelos do interior solar. Experimentos mais recentes como o Super Kamiokande, o GALLEX ${ }^{33}$, o SAGE ${ }^{34}$, e o Sudbury Neutrino Observatory, todos juntos detectaram apenas a metade do fluxo esperado de neutrinos.

\footnotetext{
${ }^{30} \mathrm{O}$ "sabor" é um conjunto de números quânticos que caracterizam os diversos tipos de quarks e léptons.

${ }^{31}$ Os léptons são partículas que não participam da interação nuclear forte. Só participam das interações eletromagnética e fraca. Existem seis léptons: o elétron, o múon, a partícula tau e seus respectivos neutrinos.

${ }^{32}$ Percloroetileno, nome comercialmente usual do tetracloroeteno $\left(\mathrm{C}_{2} \mathrm{Cl}_{4}\right)$. É um composto químico fabricado e largamente usado para a limpeza a seco de produtos e desengraxe de metais.

${ }^{33}$ GALLEX (GALLium EXperiment) foi um experimento de radioquímica que detectou neutrinos utilizando o ${ }^{71} \mathrm{Ga}$ (gálio-71) como alvo. Está localizado no Laboratório Nacional de Gran Sasso (LNGS), Itália.

${ }^{34}$ SAGE (Soviet American Gallium Experiment), localizado na Rússia. Semelhante ao GALLEX, também detecta neutrinos através do gálio-71.
} 
O GALLEX consistiu em um tanque preenchido com 101 toneladas de tricloreto de gálio-ácido clorídrico $\left(\mathrm{GaCl}_{3}-\mathrm{HCl}\right)$. Os neutrinos são capturados através da seguinte equação:

$$
\nu_{e}+{ }_{31}^{71} G a \rightarrow{ }_{32}^{71} G e+e^{-}
$$

O gálio foi escolhido pois o limiar de energia para detecção de neutrinos por essa reação é de apenas 233,2 keV. Reações com outros elementos, como o cloro-37, por exemplo, não permitem detectar neutrinos de baixa energia. Temos, então, três possibilidades para explicar a diferença entre a quantidade prevista e a quantidade detectada:

a) o modelo solar padrão não está correto, prevendo um fluxo de neutrinos maior que o verdadeiro;

b) os experimentos fornecem valores que não correspondem aos valores reais;

c) no trajeto Sol-Terra uma certa quantidade deixa de ser detectável.

Das possibilidades exploradas recentemente, algumas envolvem a ideia de mudanças nos sabores dos neutrinos: os três tipos de neutrinos transformam-se espontaneamente uns nos outros, fenômeno conhecido por "oscilação de neutrinos". A possibilidade dos neutrinos mudarem de "sabor" e, então, não serem detectados pelos experimentos, foi estudada no novo Sudbury Neutrino Observatory. Experimentos mais recentes com o detector de neutrinos Super Kamiokande, no Japão, encontrou fortes evidências que apoiam essa oscilação dos neutrinos.

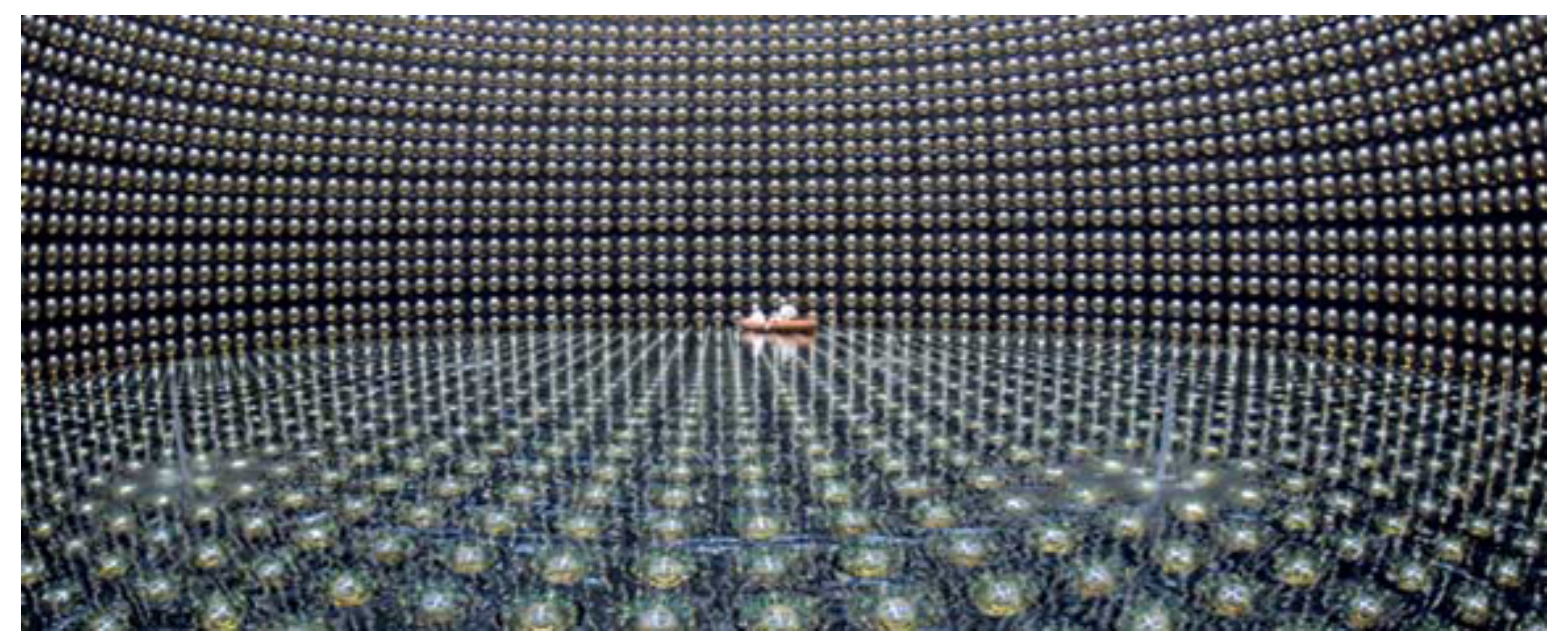

Fig. 7.2 - O Super-Kamiokande, detector de neutrinos instalado em Hida, Japão.

http://revistapesquisa.fapesp.br/2010/10/27/ao-sabor-dos-neutrinos/ 


\section{8 - A ESTRUTURA DO SOL}

\section{1 - A estrutura interna do Sol}

A estrutura interna do Sol foi deduzida a partir de um modelo desenvolvido com a utilização das equações da estrutura estelar (apêndice 5) nas quais se inseriram dados observacionais. As equações da estrutura estelar são utilizadas na forma diferencial e permitiram calcular a estrutura interna do Sol (e de outras estrelas) e fazer previsões detalhadas sobre a sua luminosidade, sobre a sua temperatura e sobre a sua evolução ao longo do tempo.

O modelo calculado para o Sol, o considera constituído pelas seguintes regiões: núcleo, zona de radiação, zona de convecção, fotosfera e atmosfera solar (cromosfera e coroa solar).

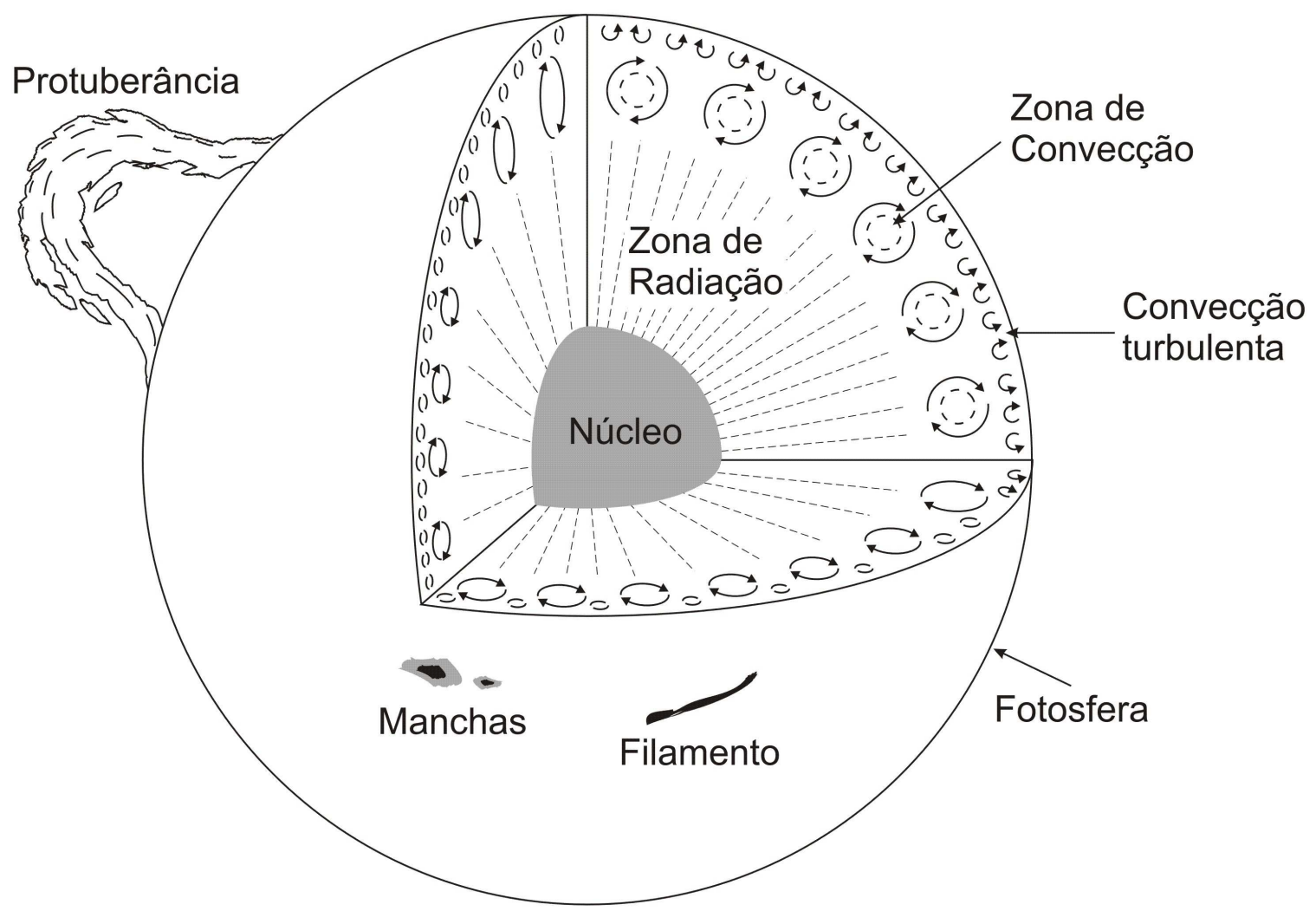

Fig. 8.1 - A estrutura interna do Sol e alguns fenômenos que ocorrem na fotosfera e na cromosfera. 
Observado por meio de projeção ou através de filtros e equipamentos especiais, o Sol apresenta-se como uma esfera, cuja "superfície" de coloração amarelada denominamos fotosfera (esfera de luz). Acima da fotosfera está a atmosfera solar constituída por duas camadas: a cromosfera e a coroa. A atmosfera solar é bastante transparente, o que nos permite observar a fotosfera. Esta, por sua vez, é opaca impedindo a observação do interior solar. Apesar disso, os astrônomos, através da interpretação dos resultados de cuidadosas observações, conseguiram estabelecer um modelo para descrever o interior do solar. $\mathrm{Na}$ tabela 4 estão resumidos os tamanhos e as temperaturas de cada região.

\section{TABELA 4 - ESTRUTURA DO SOL}

\begin{tabular}{lcc}
\hline REGIÕES & DIMENSÕES & TEMPERATURAS \\
\hline \hline Núcleo & até 0,20 a $0,25 \mathrm{R}_{\odot}$ & cerca de 15,7 milhões $\mathrm{K}$ \\
Zona de Radiação & de $0,25 \mathrm{R} \odot$ a $0,7 \mathrm{R} \odot$ & de 7 a 2 milhões $\mathrm{K}$ \\
Zona de Convecção & de $0,7 \mathrm{R} \odot$ a $0,999 \mathrm{R}_{\odot}$ & de $2 \times 10^{6}$ a $15.000 \mathrm{~K}$ \\
Fotosfera & Espessura de $\sim 400 \mathrm{~km}$ & $5.770 \mathrm{~K}$ \\
Cromosfera & Espessura de $\sim 10.000 \mathrm{~km}$ & de 4.000 a $20.000 \mathrm{~K}$ \\
Coroa & Extensão de milhões de km & $1,5 \times 10^{6} \mathrm{~K}$ \\
\hline
\end{tabular}

\subsection{1 - O núcleo solar}

É a região central correspondendo de $20 \%$ a $25 \%$ do raio solar, com temperatura de cerca de $15,7 \times 10^{6} \mathrm{~K}$, pressão da ordem de $24,8 \times 10^{15} \mathrm{~Pa}\left(\sim 2,5 \times 10^{11}\right.$ atm $)$ e densidade ao redor de $1,60 \times 10^{5} \mathrm{~kg} / \mathrm{m}^{3}\left(160 \mathrm{~g} / \mathrm{cm}^{3}\right)$ na região correspondente ao centro do $\mathrm{Sol}^{35}$. Até cerca de $0,2 \mathrm{R}_{\odot}$ encontra-se $35 \%$ de toda a massa do Sol, embora, em volume, essa região represente apenas 0,8 \% do volume solar. Ao redor de $175.000 \mathrm{~km}$ do centro do Sol (cerca de $0,25 \mathrm{R}_{\odot}$ ), a temperatura cai para $7 \times 10^{6} \mathrm{~K}$ e a densidade para, aproximadamente, $2 \mathrm{~g} / \mathrm{cm}^{3}$.

O núcleo solar é constituído por gás muito quente no estado de plasma, isto é, formado por íons e elétrons. Nas condições reinantes no núcleo, os átomos estão, por assim dizer, "esmagados" uns contra os outros e ocorrem reações de fusão nuclear que transformam o hidrogênio em hélio liberando imensas quantidades de energia.

\footnotetext{
${ }^{35}$ Sun Fact Sheet - https://nssdc.gsfc.nasa.gov/planetary/factsheet/sunfact.html
} 
Mário Schenberg e S. Chandrasekhar, em 1942, estimaram que o limite superior, em massa, da quantidade de hidrogênio que pode ser exaurida do núcleo, na transformação em hélio, é de 10\% para as chamadas estrelas da sequência principal. As reações nucleares predominantes constituem o chamado CICLO PRÓTON-PRÓTON (ciclo P-P), que foi descrito em detalhes no capítulo 7. Para o Sol, nas regiões externas à região central, o transporte de energia se faz por radiação e por convecção.

\subsection{2 - A zona de radiação}

Região correspondente a $40 \%$ do raio solar, que recebe a radiação proveniente do núcleo e a transmite na forma de radiação eletromagnética (fótons). A matéria na zona de radiação é densa e os fótons podem se deslocar apenas por distâncias muito curtas sendo logo absorvidos ou espalhados (livre caminho médio ${ }^{36}$ muito pequeno). Os fótons de raios gama produzidos no núcleo são absorvidos e re-emitidos pelos átomos da zona de radiação e gradualmente vão tendo seus comprimentos de onda aumentados. Além disso, quando são re-emitidos o são em direções aleatórias (trajetórias em "zig-zag") podendo, inclusive, serem re-emitidos em direção ao núcleo, de onde vieram.

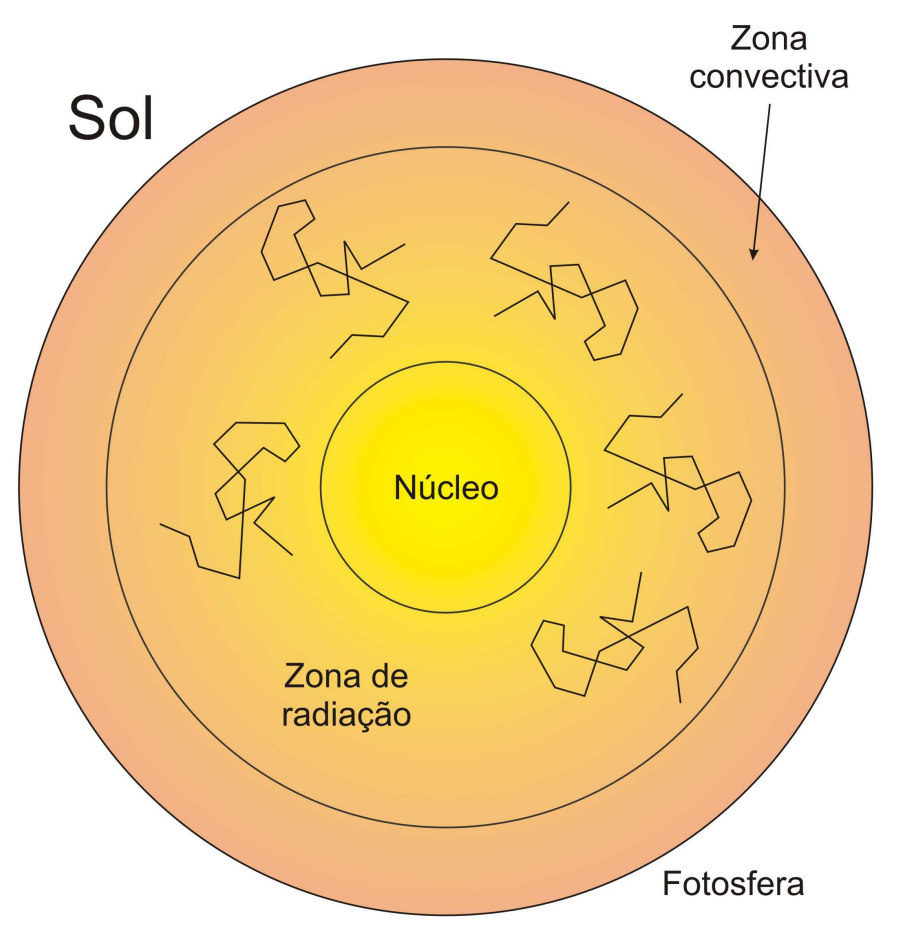

Fig.8.2- Trajetórias aleatórias de fótons na zona de radiação.

\footnotetext{
${ }^{36} \mathrm{O}$ livre caminho médio é a distância média que um fóton pode percorrer antes ser absorvido ou espalhado.
} 
Nesse processo de absorção e re-emissão, os fótons acabam levando um tempo muito longo para atingir a camada seguinte. Alguns astrônomos estimam que um fóton produzido no núcleo demore, em média, ao redor de 170 mil anos para atravessar a zona de radiação e chegar à zona convectiva.

\subsection{3 - A tacoclina}

Entre a zona de radiação e a zona seguinte (a de convecção) há uma camada de pequena espessura (menor que 1\% do raio solar) chamada tacoclina. Nessa fina camada há uma enorme variação de velocidade no fluxo de escoamento de plasmas. Na base da camada (junto à zona radiativa) praticamente não há fluxos de matéria. Porém, após atravessá-la, os fluxos aumentam e se igualam, em velocidade, aos movimentos da zona convectiva. Acredita-se que seja na tacoclina que surge o campo magnético do Sol, em função das súbitas velocidades que os plasma adquire.

\subsection{4 - A zona de convecção ou zona convectiva}

Região que, como seu nome indica, a energia é transportada por convecção da camada anterior até a superfície, onde é liberada para o espaço. A zona de convecção corresponde a $29,9 \%$ do raio do Sol. Na zona convectiva, há um movimento do plasma, formando uma convecção circular, com o plasma quente ascendendo e o plasma mais frio descendendo. A convecção ocorre devido à baixa temperatura que favorece a formação do íon $\mathrm{H}^{-}$(átomo de hidrogênio com dois elétrons). Esse íon torna o meio mais opaco e enfraquece o transporte radiativo.

\subsection{5 - A fotosfera}

É a região do Sol que podemos observar todos os dias e corresponde ao disco solar ou a sua superfície. É uma camada de espessura inferior a $0,1 \%$ do raio solar (ao redor de $400 \mathrm{~km}$ de espessura) e bastante opaca impedindo a observação das camadas internas.

A fotosfera apresenta temperaturas entre $4.500 \mathrm{~K}$ e $6.000 \mathrm{~K}$ (a temperatura efetiva, como vimos no capítulo 6, é de $5.770 \mathrm{~K}$ ). Ela é composta por células de convecção, 
denominadas granulações, com aproximadamente $1.000 \mathrm{~km}$ de extensão, com plasma quente ascendente em sua região central e plasma mais frio descendente em suas bordas: a região central das granulações tem temperatura ao redor de $100 \mathrm{~K}$ mais alta que as bordas.

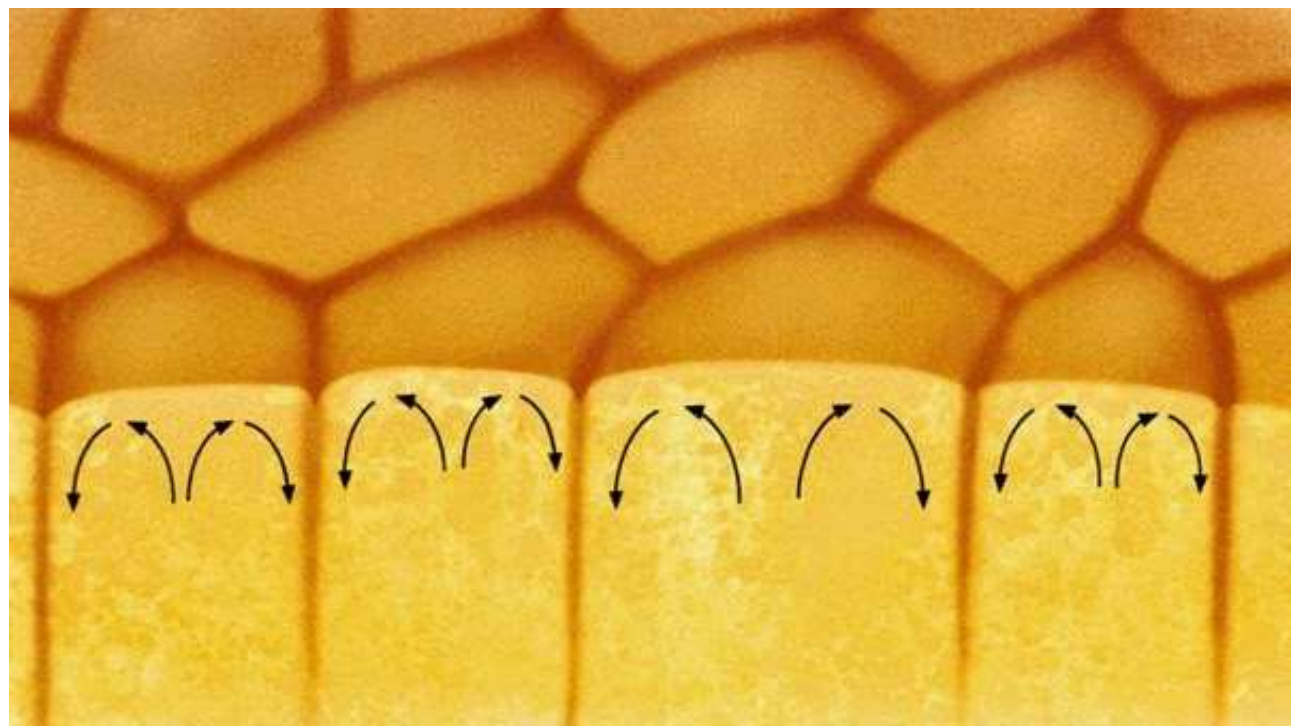

Fig. 8.3 - Células convectivas e granulações da fotosfera. Fonte:https://astrojurnalul.blogspot.com.br/p/soarele_21.html

A duração média das granulações é ao redor de oito minutos (duram entre 5 e 10 minutos). Algumas formações maiores reunindo várias granulações - as chamadas supergranulações - podem se estender por até 30 mil quilômetros e durar até 24 horas. As granulações são os topos das células de convecção da zona convectiva (figura 8.3).

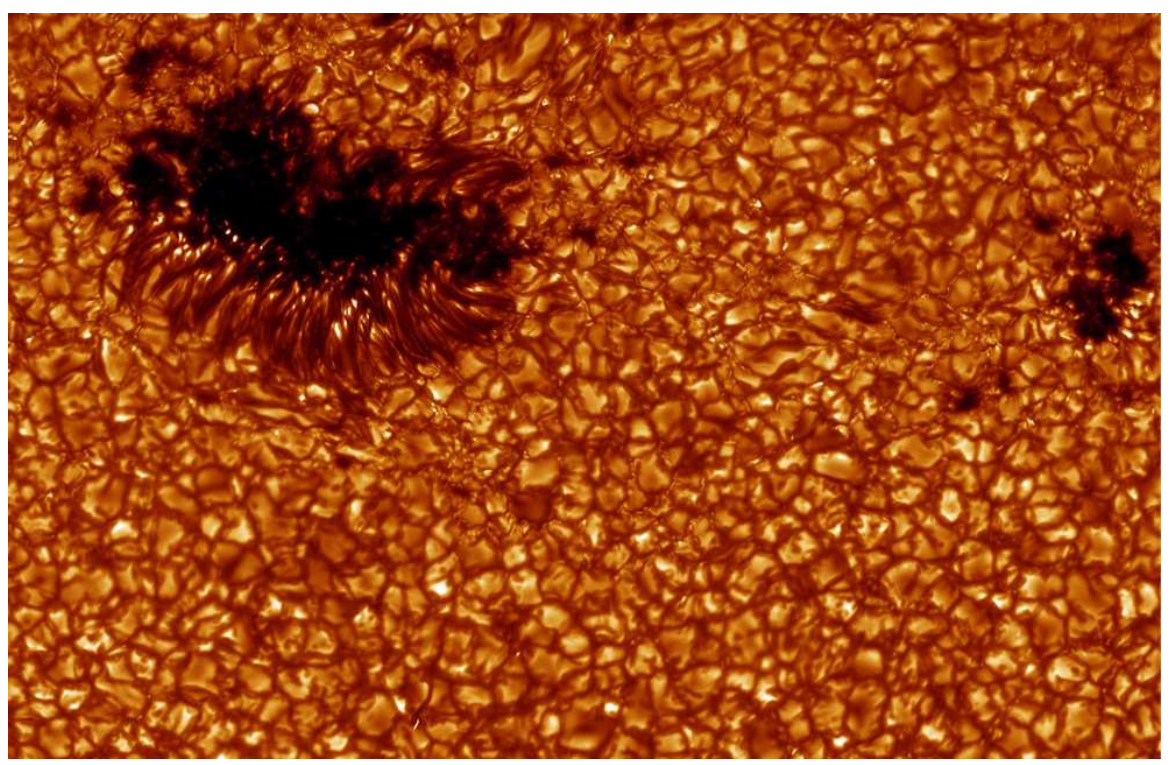

Fig. 8.4 - Imagem da fotosfera solar com granulações. Vêem-se, também, algumas manchas solares. Fonte:https://astrojurnalul.blogspot.com.br/p/soarele_21.html 
$\mathrm{Na}$ fotosfera ocorrem, ainda, as manchas solares e as fáculas. As manchas solares são regiões que aparecem escuras contrastando com as regiões mais brilhantes que estão ao seu redor. Essas áreas mais escuras têm temperatura inferior causada pela concentração do fluxo do campo magnético que inibe a convecção. As temperaturas típicas das manchas são ao redor de $4.200 \mathrm{~K}$, cerca de $1.500 \mathrm{~K}$ inferior à região fotosférica circundante.

As fáculas são regiões brilhantes da fotosfera que se formam entre as granulações solares. Elas são regiões magnéticas como as manchas, porém, nelas, o campo magnético está concentrado em feixes muito mais finos que nas manchas solares.

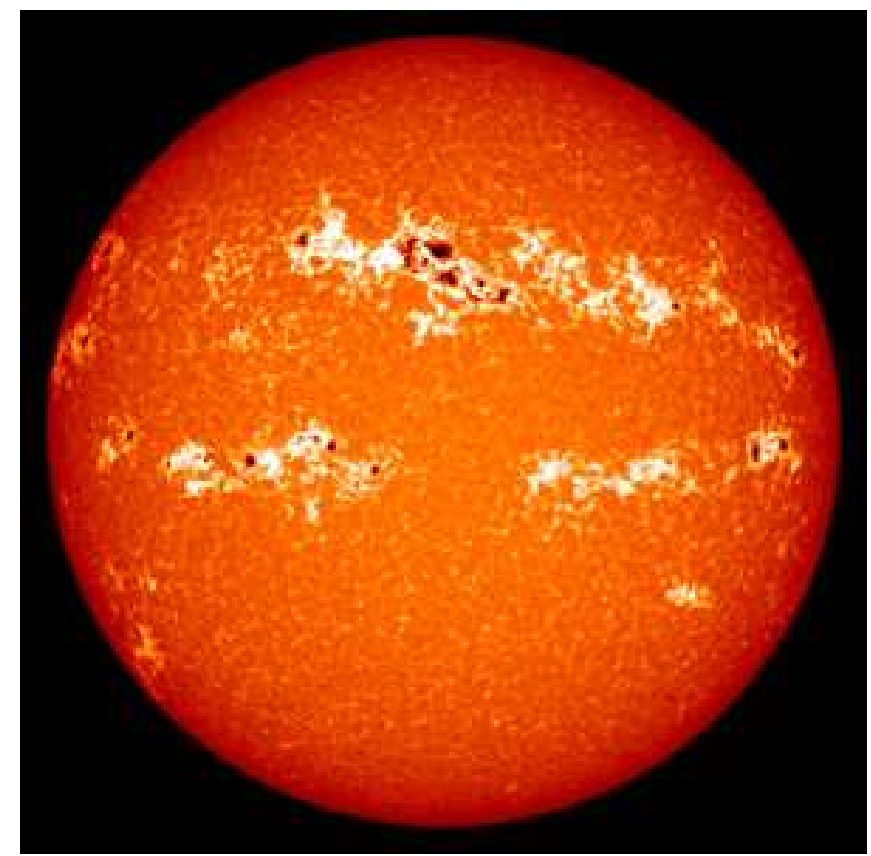

8.5 - Imagem da fotosfera solar com regiões de fáculas. Fonte: http:/lasp.colorado.edu/home/science/solarinfluences/sun-and-climate/

O brilho da fotosfera não é uniforme, decrescendo do centro para as bordas do Sol. $\mathrm{Na}$ figura 8.6, pode-se observar claramente esse fato. Esse fenômeno, chamado obscurecimento da borda ou obscurecimento do limbo, é causado pelo fato de haver variação de temperatura dentro da fotosfera.

A partir da base da fotosfera (que está no limite com a zona de convecção) a temperatura vai diminuindo e só volta a subir quando se aproxima da primeira camada da atmosfera, chamada cromosfera. 


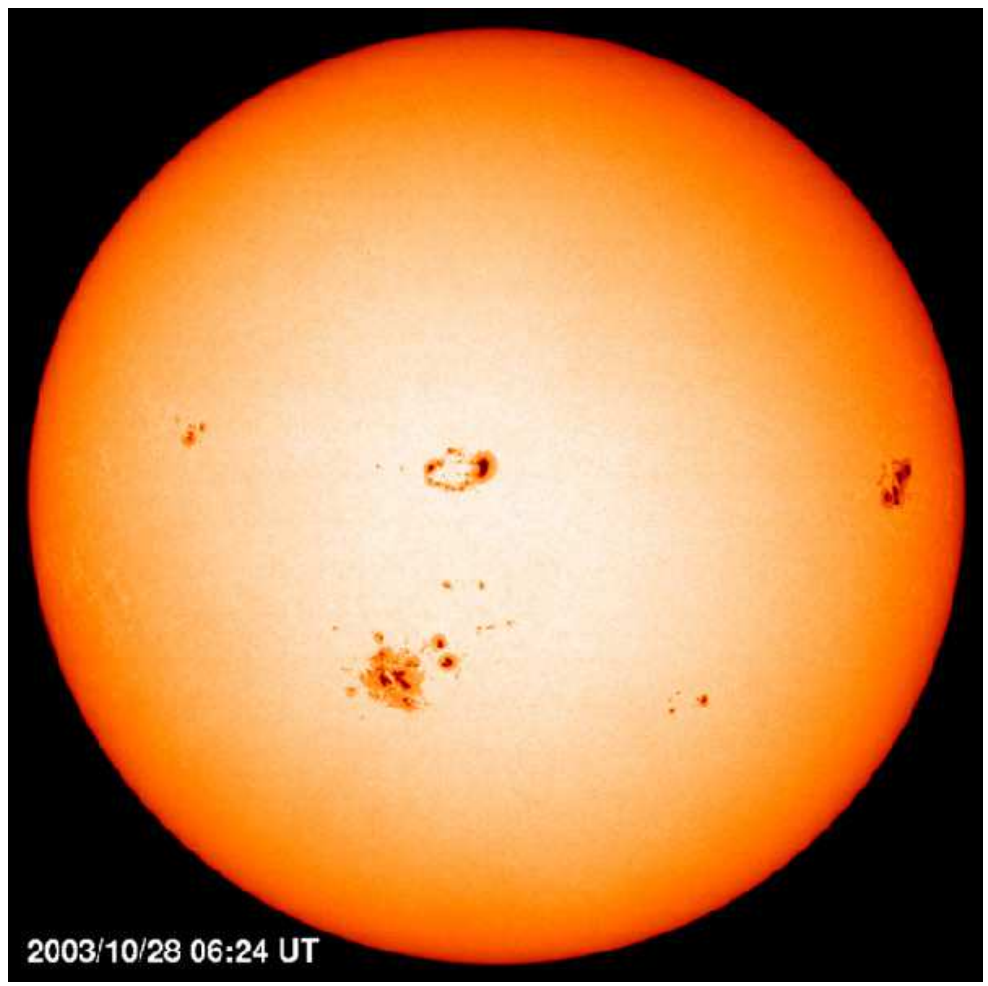

Fig.8.6 - Imagem do SOHO mostrando a presença de manchas solares e a diferença de brilho da fotosfera entre a região central, mais clara, e as bordas do Sol mais escuras. Fonte: NASA SOHO

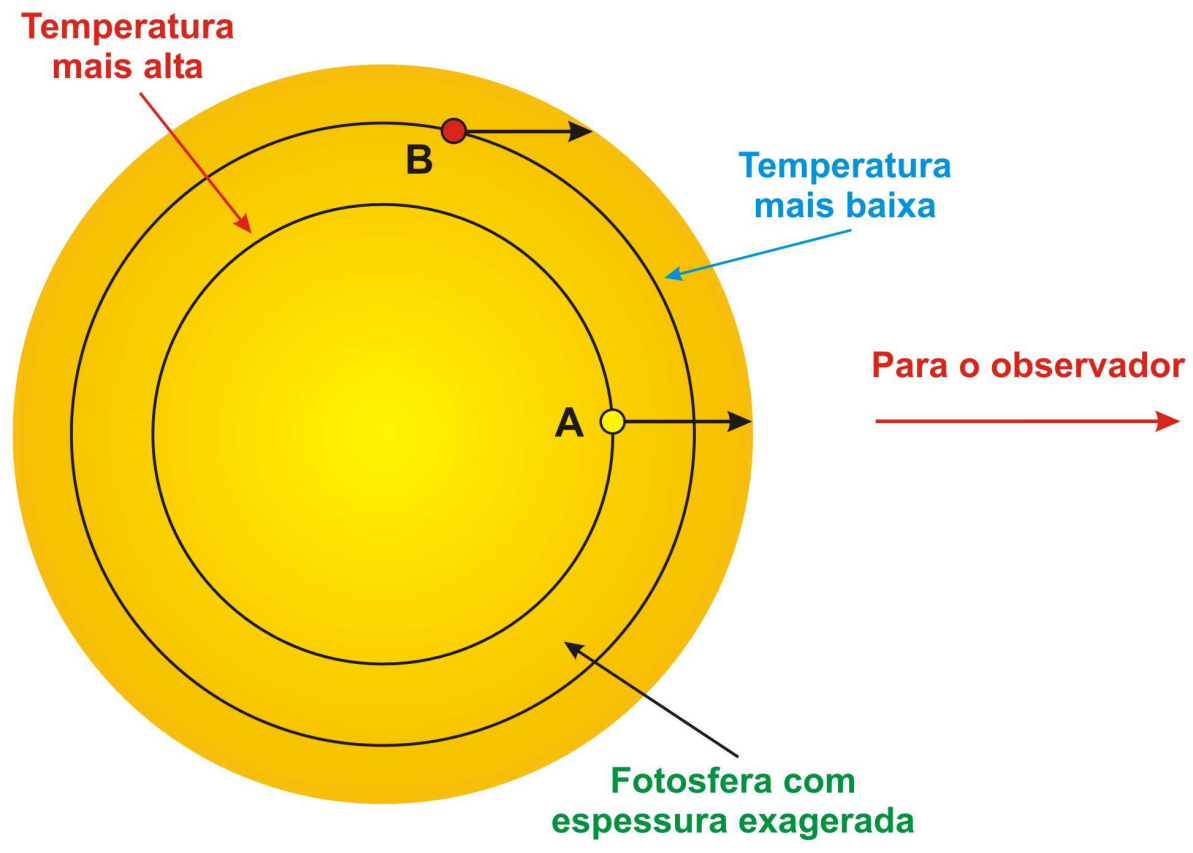

Fig. 8.7 - Obscurecimento da borda do disco solar. Para uma mesma trajetória da luz em direção ao observador, a luz proveniente do centro (ponto A) se origina em uma região mais quente (mais brilhante) que a luz proveniente da borda (ponto $\mathrm{B}$ ), menos brilhante e mais fria. 
A variação de temperatura provoca variação do brilho, de modo que na região do centro do disco o brilho observado corresponde às contribuições de temperaturas mais altas do que nas bordas em que, por efeito da geometria da observação, observamos contribuições de temperaturas menores e, portanto, de menor brilho (figura 8.7).

\subsection{6 - A atmosfera solar}

Acima da fotosfera encontra-se uma camada transparente denominada atmosfera solar composta pela cromosfera e pela coroa. A cromosfera está localizada imediatamente acima da fotosfera e é de coloração avermelhada. Pode ser observada durante a fase central dos eclipses totais do Sol. Possui espessura de cerca de $10.000 \mathrm{~km}$ e é composta principalmente por hidrogênio, hélio e cálcio. A temperatura da cromosfera vai de $6.000 \mathrm{~K}$ - junto à fotosfera - até $20.000 \mathrm{~K}$ nas regiões mais altas. Nessa temperatura o hidrogênio emite luz de coloração avermelhada (emissão H $\alpha$, de comprimento de onda de 656,3 nm) que dá coloração à camada e também seu nome - esfera de cor (figura 8.8). Sem equipamentos especiais, a cromosfera não pode ser observada por causa do brilho da fotosfera.

Quando se observa o Sol com um espectrógrafo ou um filtro que deixa passar apenas a emissão $\mathrm{H} \alpha$, podem ser observados vários fenômenos cromosféricos, entre eles as protuberâncias, os filamentos, a rede cromosférica, as praias ao redor das manchas solares e os espículos.

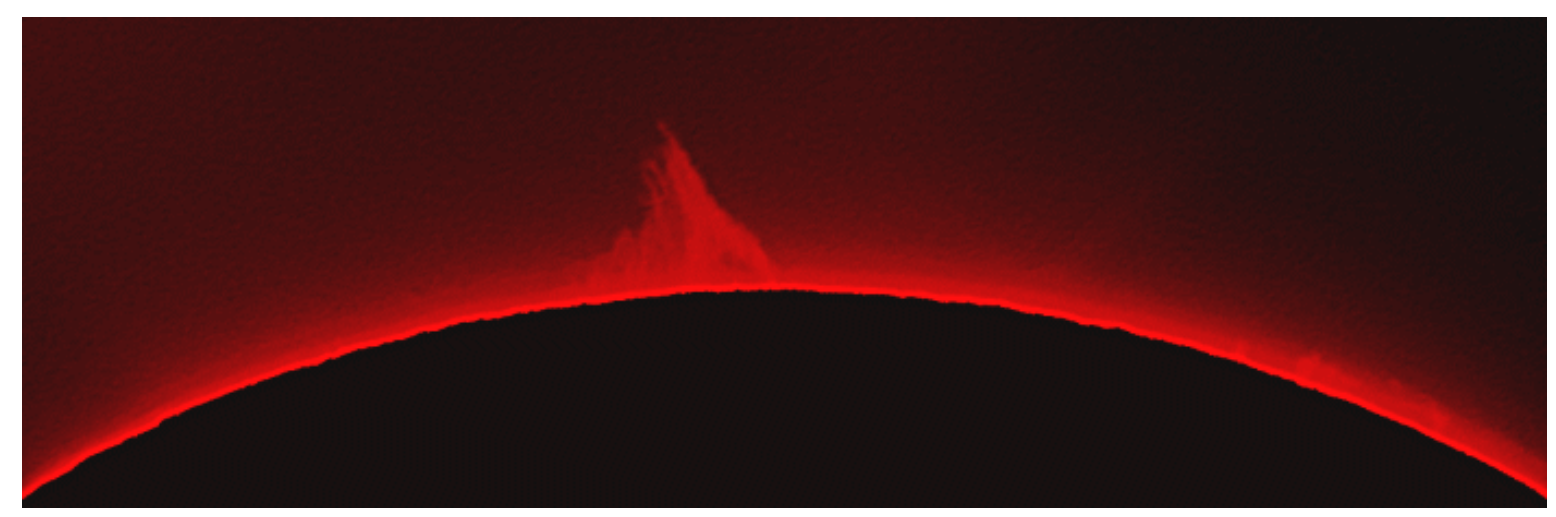

Fig. 8.8 - Imagem da cromosfera solar em $\mathrm{H} \alpha$, durante um eclipse total do Sol. Fonte: http://petermulroy.squarespace.com/the-sun/ 
As protuberâncias são enormes e densas nuvens gasosas suspensas acima da superfície solar por loops (laços) do campo magnético solar. Podem ser observadas no limbo solar ou projetadas sobre o disco solar. Nesse último caso são vistas como estruturas escuras, por serem constituídas de gases em menor temperaturas, chamadas de filamentos. Tanto as protuberâncias como os filamentos podem durar de dias até semanas.

As protuberâncias e os filamentos podem permanecer no estado estável por vários dias e até umas poucas semanas. No entanto, como os loops magnéticos que dão sustentação ao fenômeno mudam, as protuberâncias e os filamentos podem entrar em erupção e se modificar em horas ou até em minutos.

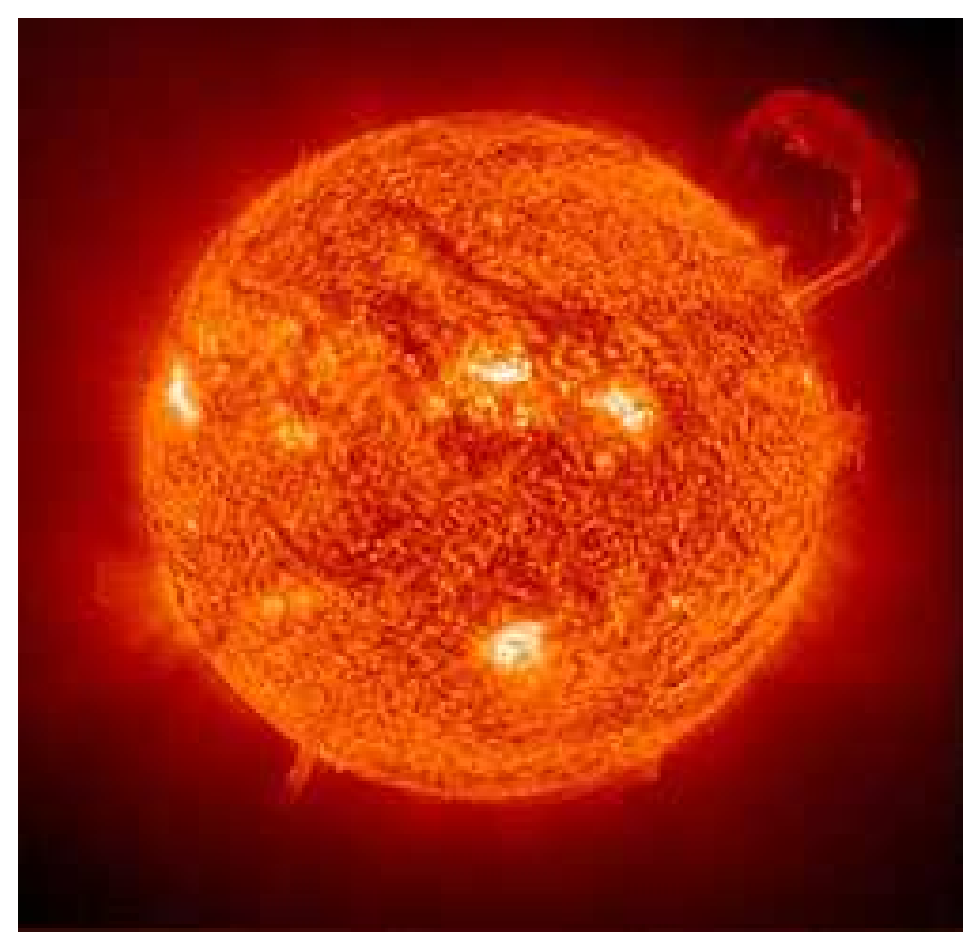

Fig. 8.9 - Protuberância solar observada e fotografada em 14 de setembro de 1999 - Fonte: https://sunearthday.nasa.gov/2007/locations/ttt_prominences.php 


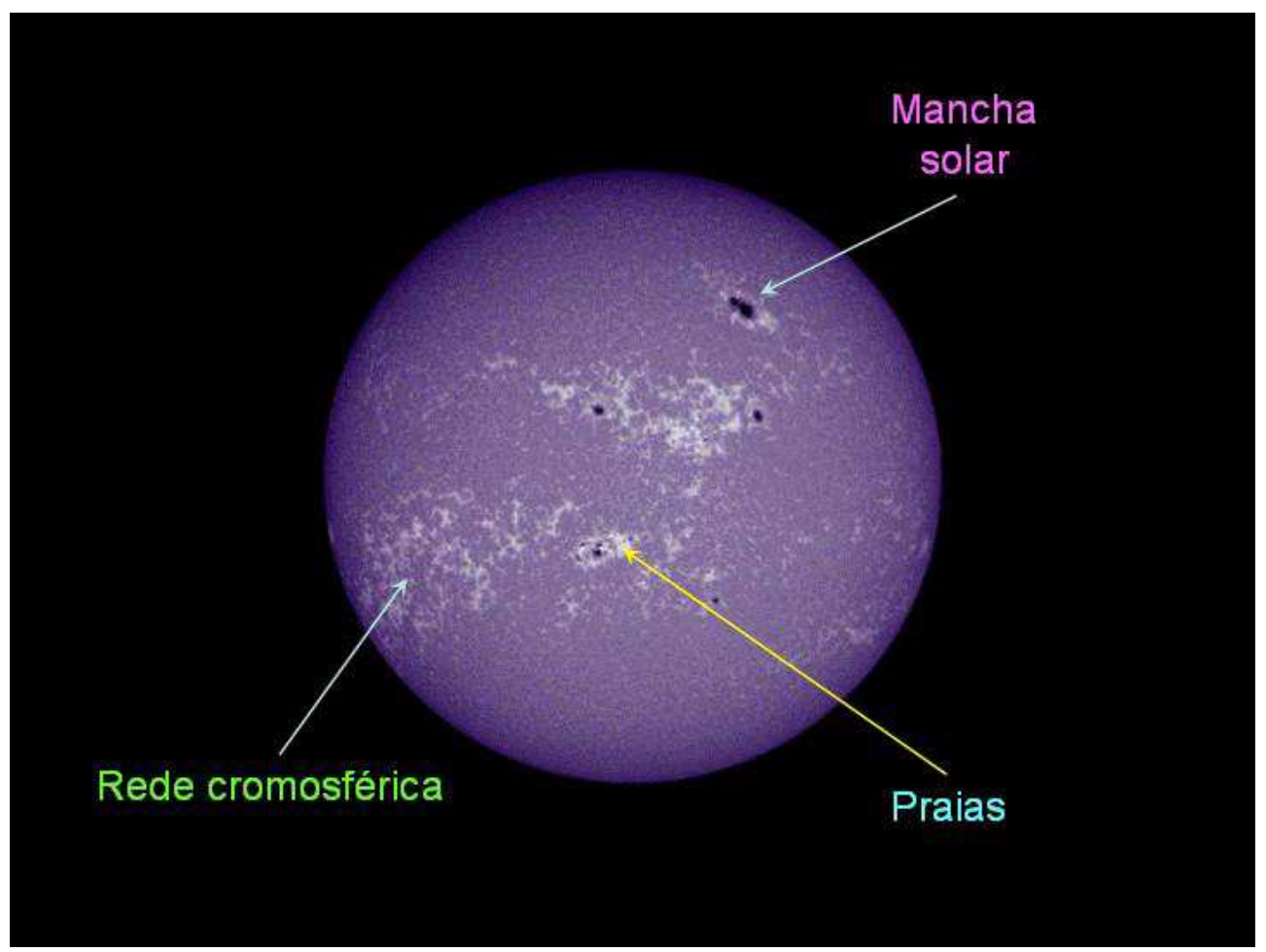

Fig. 8.10 - Rede cromosférica observada no violeta, (comprimento de onda de 393,37 nm do CaII). Na imagem aparecem, também, praias e manchas solares. Imagem editada pelo autor, a partir de imagem da NASA. Fonte: https://solarscience.msfc.nasa.gov/chromos.shtml

A rede cromosférica do campo magnético é um padrão de rede facilmente observado na luz vermelha da emissão $\mathrm{H} \alpha$ do hidrogênio e no violeta correspondendo à linha de emissão K do cálcio uma vez ionizado (CaII), no comprimento de onda de 393,37 nm. A rede está distribuída ao redor das supergranulações e é devida à presença de feixes de linhas de campo magnético que são concentrados lá pelos movimentos de fluido nas supergranulações.

As praias são regiões cromosféricas quentes e brilhantes que são observadas frequentemente acima das regiões das manchas solares e estão associadas a concentrações de campos magnéticos. Fazem parte da rede de emissões brilhantes da cromosfera e são melhor observadas na luz vermelha correspondendo à emissão $\mathrm{H} \alpha$ do hidrogênio. Podem ser vistas, também, no comprimento de onda de 393,37 nm do CaII.

Os espículos são pequenos jatos de matéria que ocorrem em toda a superfície solar e que se elevam pela cromosfera movendo-se com velocidades de $20 \mathrm{~km} / \mathrm{s}$ e atingem milhares de quilômetros de altura antes de colapsarem e desaparecerem. São formações 
também associadas ao campo magnético, em particular nas regiões onde há alto fluxo magnético. São algumas vezes chamados de tubos de fluxo solar. Foram descobertos, em 1877, pelo Pe. Ângelo Secchi.

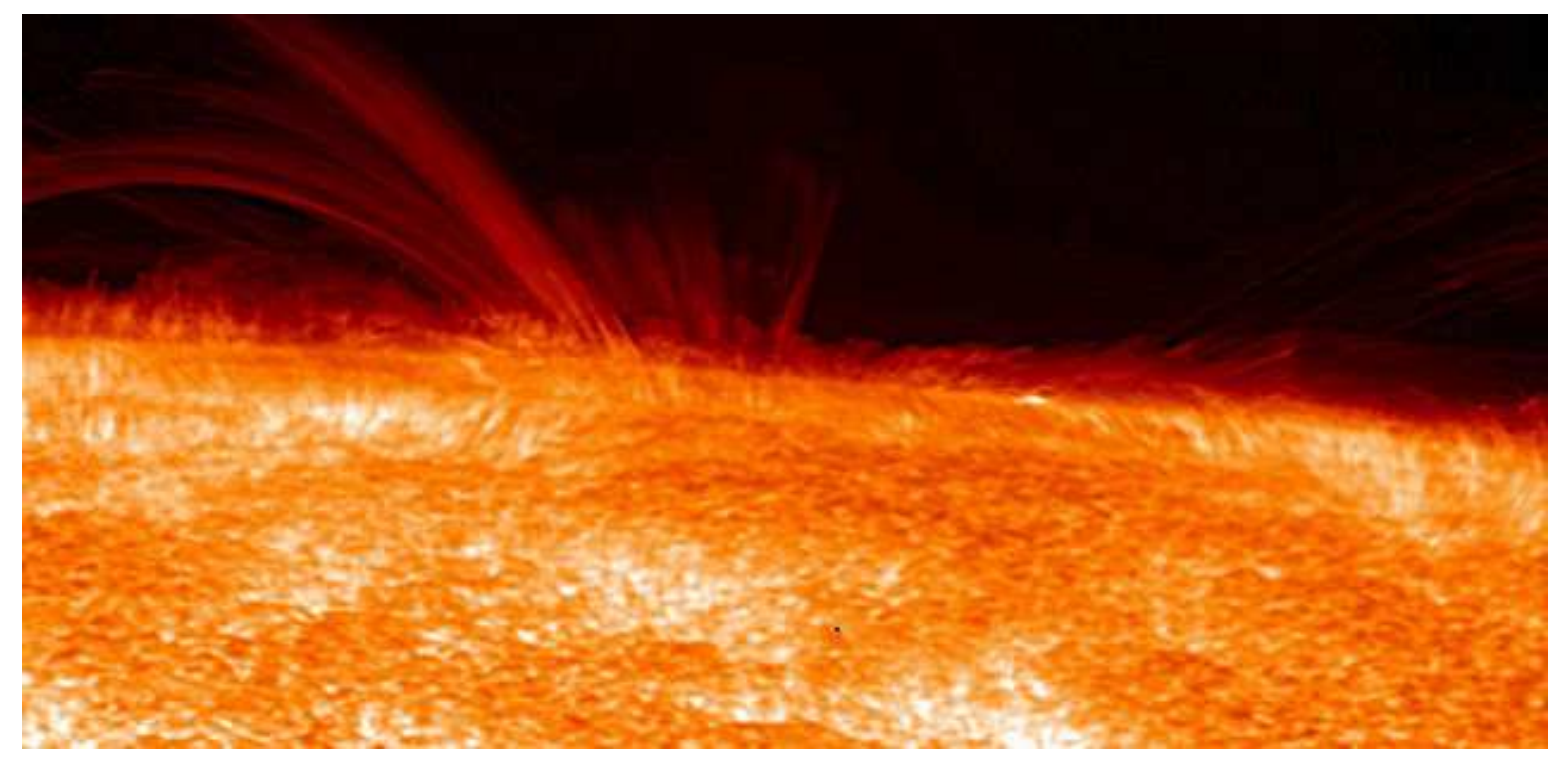

Fig. 8.11 - Espículos. Fonte: http://sciexplorer.blogspot.com.br/2013/03/the-sun-part-6-photosphere-and.html

Acima da cromosfera está a coroa solar que se estende a grandes distâncias do Sol - cerca de 13 milhões de quilômetros a partir da fotosfera - apresentando forma variável de acordo com a atividade solar (capítulo 9). Pode ser observada durante os eclipses totais do Sol ou com o emprego do coronógrafo ${ }^{37}$. A coroa é constituída por plasma a 1,5 milhões de kelvins, o que se constitui, ainda, em um problema ainda não totalmente esclarecido pela física solar. No espectro da coroa encontram-se linhas de emissão do Ferro XIV (átomo de ferro que perdeu 13 dos seus 26 elétrons) o que é um indicativo da temperatura acima citada. Além disso, o hidrogênio não se apresenta mais como unidade atômica pois seu elétron está destacado do próton. A coroa é constituída de partículas carregadas (plasma) e é um fluido condutor de eletricidade que interage com o campo magnético.

\footnotetext{
${ }^{37}$ O coronógrafo é um instrumento inventado, em 1931, pelo astrônomo francês Bernard Lyot (1897-1952). O equipamento é acoplado a um telescópio e simula um eclipse total do Sol permitindo que seja observada a coroa solar (de onde deriva seu nome).
} 
A coroa, pela sua temperatura, não é aquecida pela radiação proveniente da fotosfera. Acredita-se que o seu aquecimento seja produzido por ondas de Alfvén ${ }^{38}$ (ondas magnetohidrodinâmicas ou ondas MHD), que transportam energia da turbulência da zona convectiva.

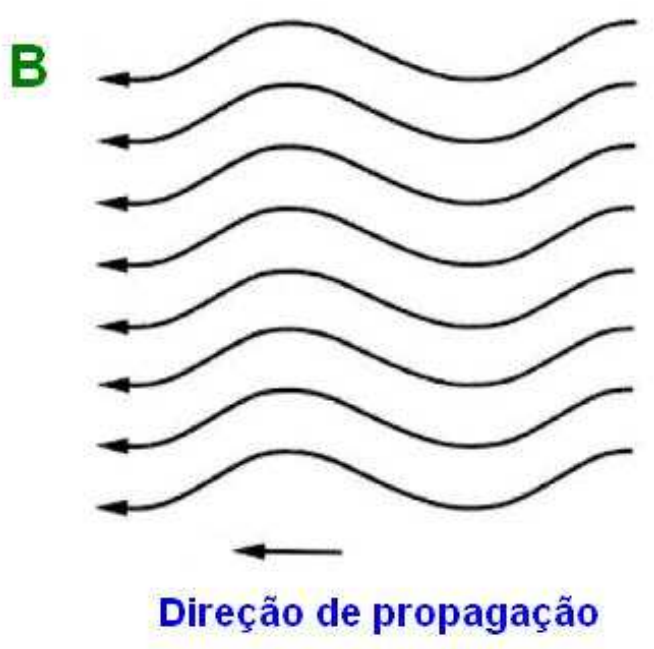

Figura 8.12 - Configuração das linhas do campo magnético na presença de ondas de Alfvén. B é o campo magnético.

Nos plasmas, as ondas de Alfvén são ondas transversais, de baixa de frequência e que se propagam na direção do campo magnético através da oscilação de íons. Quando um fluido condutor está imerso em um campo magnético e é posto a oscilar, as linhas do campo também oscilam (figura 8.12). Alguns astrônomos acreditam que o aquecimento da coroa solar pode ser ocasionado pela ocorrência de microflares ou de nanoflares.

A coroa é composta por três (ou quatro) componentes que se distinguem pelo mecanismo de produção de luz: a coroa K (do termo alemão Kontinuerlich que significa continuo), a coroa F (de Fraunhofer) e a coroa E (de emissão). As três componentes são formadas por mecanismos diferentes e apresentam propriedades diferentes. A coroa $\mathbf{K}$ mostra um espectro contínuo originado no espalhamento da luz fotosférica por elétrons livres. A luz da coroa K é fortemente polarizada.

\footnotetext{
${ }^{38}$ Assim designadas em homenagem ao físico sueco Hannes Olof Gosta Alfvén (1908-1995) ganhador do Premio Nobel de Física em 1970 por seus estudos e descobertas em física de plasmas.
} 
A coroa $\mathbf{F}$ recebe esse nome porque seu espectro mostra a presença de linhas de absorção que Fraunhofer encontrou no espectro do disco solar. A luz proveniente da fotosfera é espalhada por partículas de poeira situadas no plano da eclíptica (partículas situadas entre as órbitas de Mercúrio e Terra) e pode ser considerada como a luz zodiacal interna. Desta forma, a coroa F, na realidade, apenas reflete a luz brilhante da fotosfera, não se constituindo em uma radiação originada na coroa propriamente.

A coroa $\mathbf{E}$ representa a única componente que realmente emite radiação a partir do gás nela situado. Consiste na emissão de linhas espectrais isoladas produzidas pelos íons coronais de alta temperatura.

Por fim, alguns astrônomos consideram a chamada coroa $\mathbf{T}$ (de térmica), cuja emissão, predominantemente no infravermelho, origina-se na emissão térmica da poeira interplanetária - a mesma poeira que produz a luz da coroa $\mathrm{F}$.

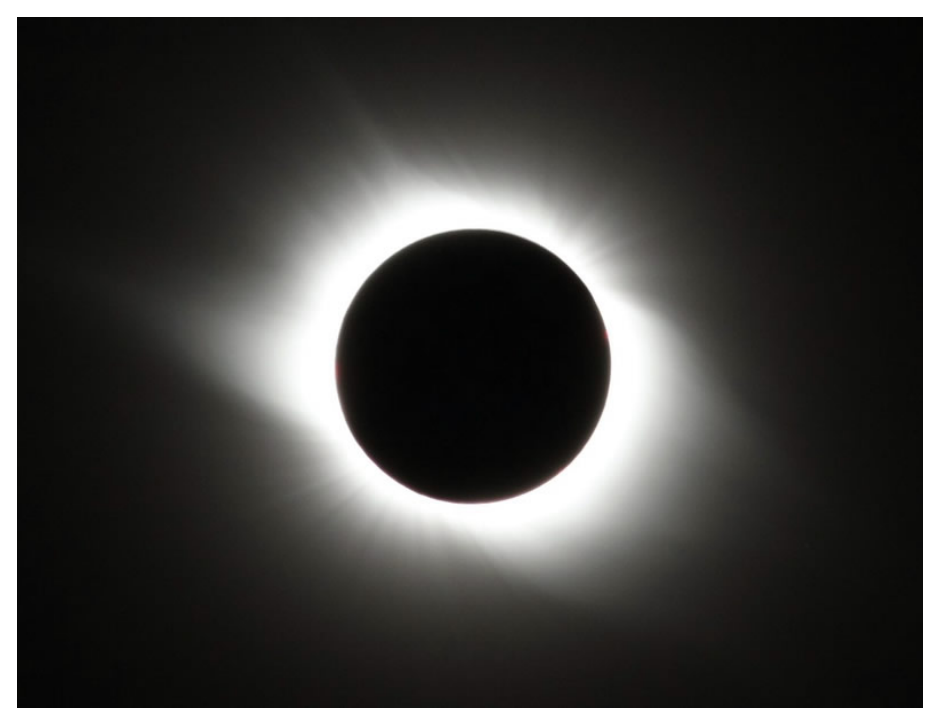

Figure 8.13 - Coroa solar visível durante o eclipse total do Sol em 01 de agosto de 2008. Fonte: (http://www.kcvs.ca/martin/astro/au/unit3/71/chp7_1.html) - Foto:NASA

Entre os fenômenos importantes que ocorrem na coroa, podemos destacar os loops coronais, os buracos coronais e a ejeção de massa coronal (que será tratada no próximo capítulo). 


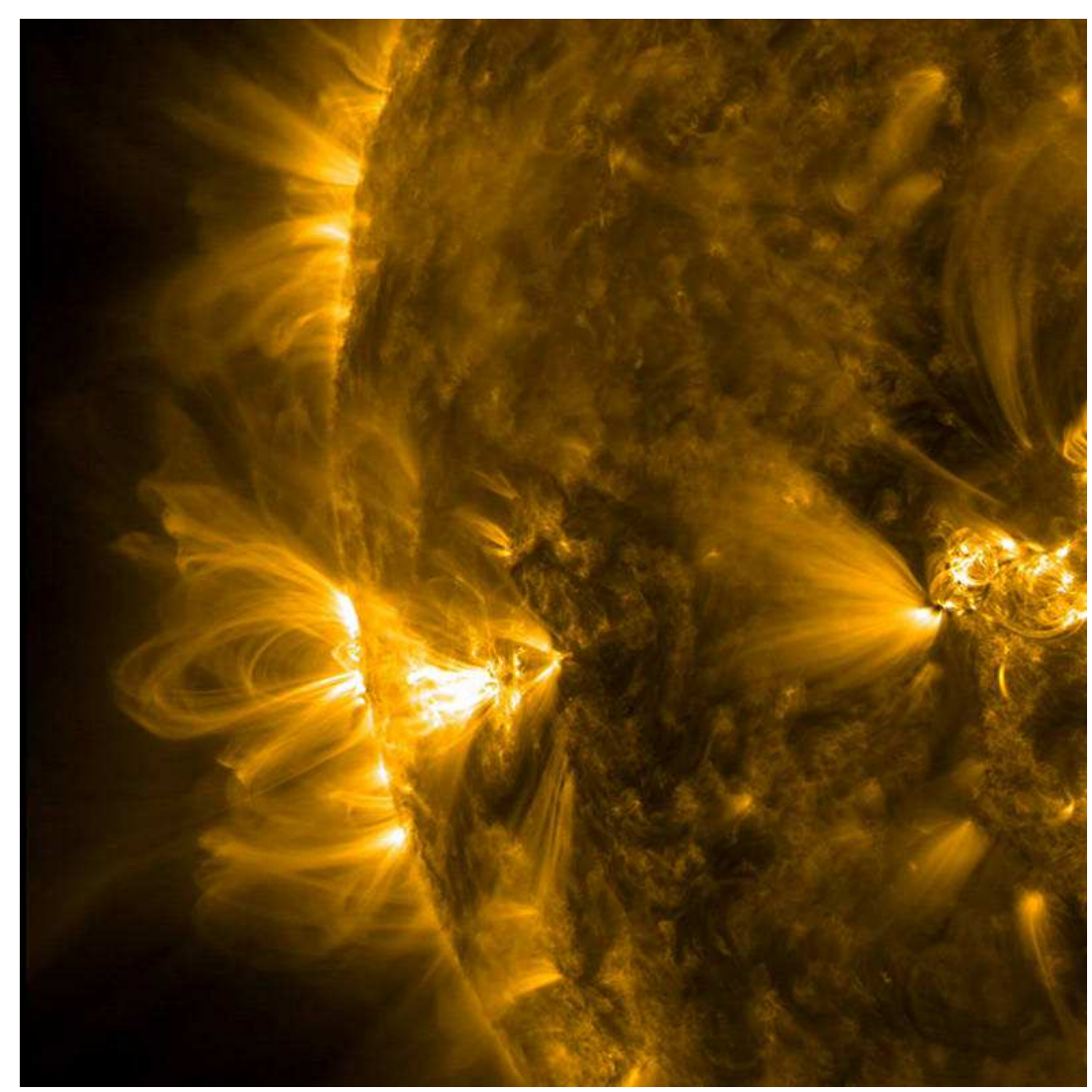

Fig. 8.14 - Loops coronais observados em regiões solares ativas nos dias 8 e 10 de fevereiro de 2014. A imagem foi obtida em ultravioleta extremo (EUV). Créditos: NASA/Solar Dynamics Observatory https://www.nasa.gov/content/coronal-loops-in-an-active-region-of-the-sun

Os loops (ou laços) coronais são estruturas que estão associadas às linhas de campo magnético fechadas que conectam regiões magnéticas na superfície solar (figura 8.14). São encontrados em torno de manchas solares e em regiões ativas. Muitos loops coronais duram dias ou semanas, mas a maioria se altera muito rapidamente.

Buracos coronais são regiões na corona onde a densidade do plasma a essa temperatura é muito baixa em comparação com o entorno (cerca de 100 vezes menor do que a média) e, assim, elas se apresentam como regiões escuras. Os buracos coronais foram encontrados quando o telescópio de raios-X do Skylab fotografou a estrutura da coroa solar. 


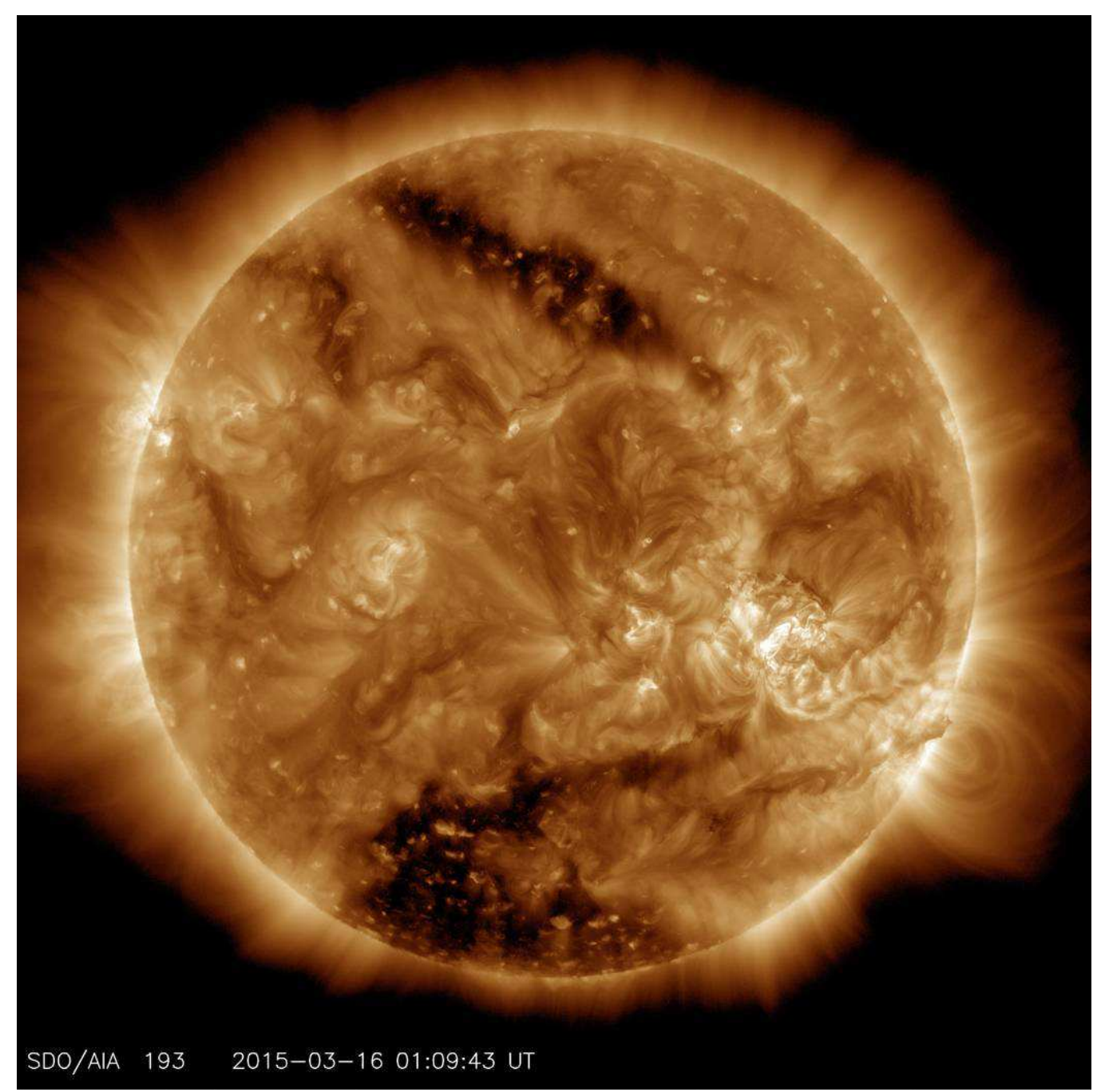

Fig. 8.15 - Grande buraco coronal observado no ultravioleta extremo (EUV), no dia 16 de março de 2015. Fonte: https://www.nasa.gov/content/goddard/sdo/two-coronal-holes-on-the-sun

Eles estão vinculados aos campos magnéticos unipolares (linhas de campo magnético abertas) que se estendem no espaço indefinidamente. Assim sendo, estas regiões permitem a saída de material da coroa solar para o espaço e são a fonte do vento solar de alta velocidade (que será descrito no próximo capítulo) podendo criar distúrbios geomagnéticos.

\subsection{7 - Sobre as cores das imagens do Sol}

Em várias imagens apresentadas ao longo deste capítulo (e em outros, também), o Sol foi mostrado com diversas colorações. As imagens correspondentes aos comprimentos 
de onda da região do visível no espectro são cores reais. Há, no entanto, imagens que estão com falsas cores pois correspondem às regiões do espectro que não são visíveis e, obviamente, não apresentam cores. São os casos das imagens do Sol no ultravioleta e em raios-X. Essas imagens foram colorizadas para permitir a sua visualização, realçar detalhes e produzir contrastes que se desejavam destacar. 


\section{9 - A ATIVIDADE SOLAR}

Sob o nome de atividade solar reúne-se um conjunto de diversos fenômenos que ocorrem no Sol, tais como: manchas solares, flares, ejeções de massas coronais, vento solar, partículas energéticas provenientes do Sol, etc. Toda a atividade solar é originada no campo magnético solar e nas suas variações. O Sol é uma estrela variável magnética que apresenta flutuações temporais numa escala que vai da fração de segundo até milhares de anos.

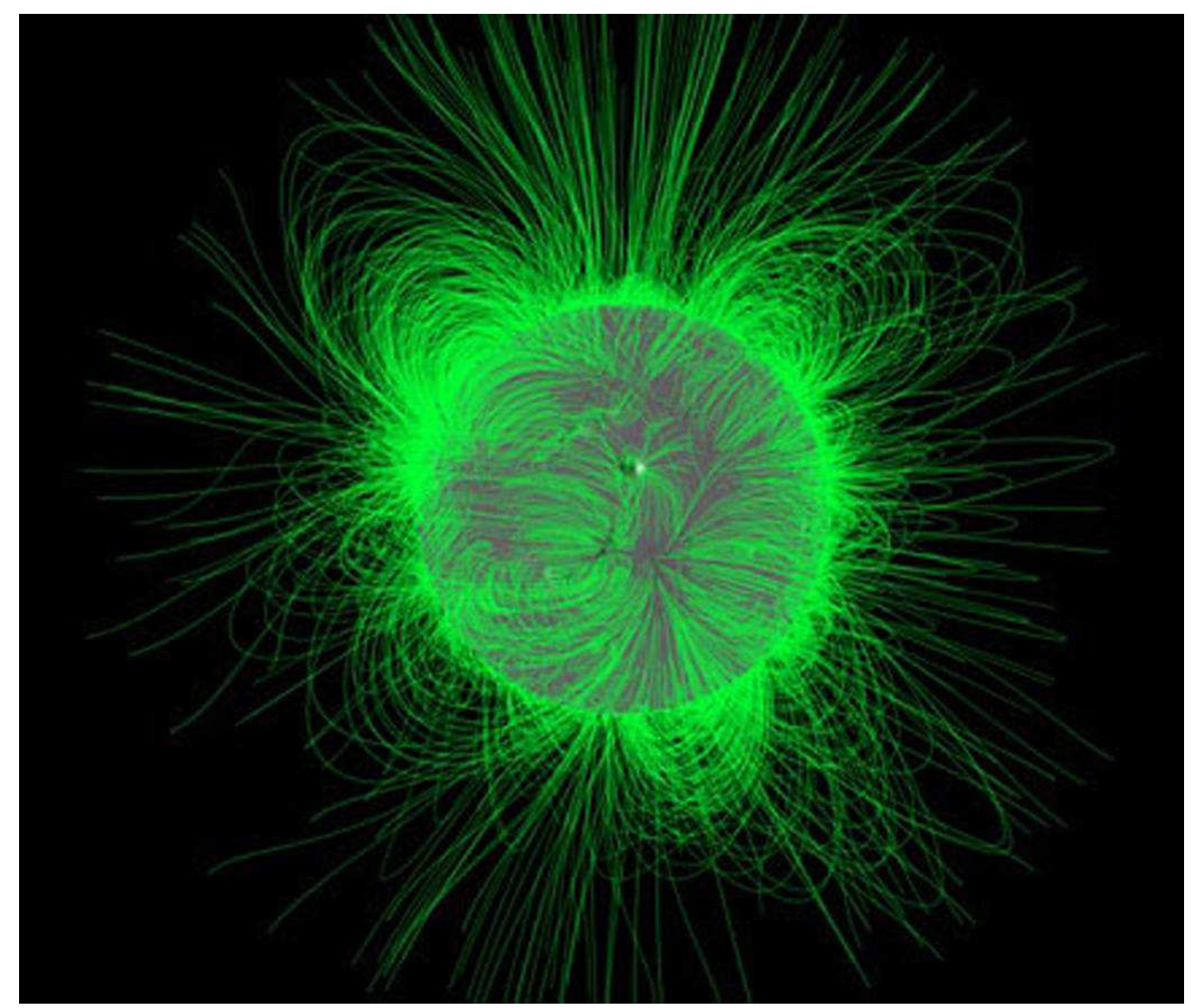

Fig.9.1 - O Sol e seu complexo campo magnético, ilustrado por linhas em verde. Imagem: NASA (https://www.nasa.gov/content/goddard/what-is-solar-activity)

O campo magnético solar tem sua origem na tacoclina que, como vimos, é a região de transição entre a zona de radiação e a zona de convecção. Seu valor médio é de 0,01 T. Apesar desse valor, ele é cerca de cem vezes mais intenso que o campo magnético da Terra. O chamado modelo de dínamo proposto para explicar a origem do campo magnético 
solar (CMS) admite que ele seja gerado por fluxos de gases eletricamente carregados. $\mathrm{O}$ movimento do plasma no interior solar é que impulsiona o dínamo. Na tacoclina há uma enorme ruptura nas velocidades de rotação do Sol. Na zona radiativa (interior solar) a velocidade de rotação solar é uniforme. Após a tacoclina as velocidades de rotação se alteram passando a existir velocidades diferentes: maior no equador e menores nas altas latitudes heliográficas. As variações de velocidade originam as correntes nas diversas regiões da camada convectiva. Cabe ressaltar que a velocidade de rotação no equador é maior do que nas regiões abaixo da tacoclina ao passo que nas altas latitudes a velocidade de rotação é menor que no interior do Sol.

\section{1 - As manchas solares}

As manchas solares são regiões da fotosfera que aparecem escuras em contraste com as regiões circundantes. São áreas de temperatura reduzida - ao redor de $1.500 \mathrm{~K}$ abaixo da temperatura geral da fotosfera - podendo em alguns casos atingir $2.000 \mathrm{~K}$ a menos nas regiões centrais das manchas (temperatura na região central da mancha em torno de $3.700 \mathrm{~K})$. As baixas temperaturas são causadas pela concentração de fluxo do campo magnético que inibe a convecção. As manchas solares aparecem comumente aos pares e apresentam polaridades magnéticas opostas.

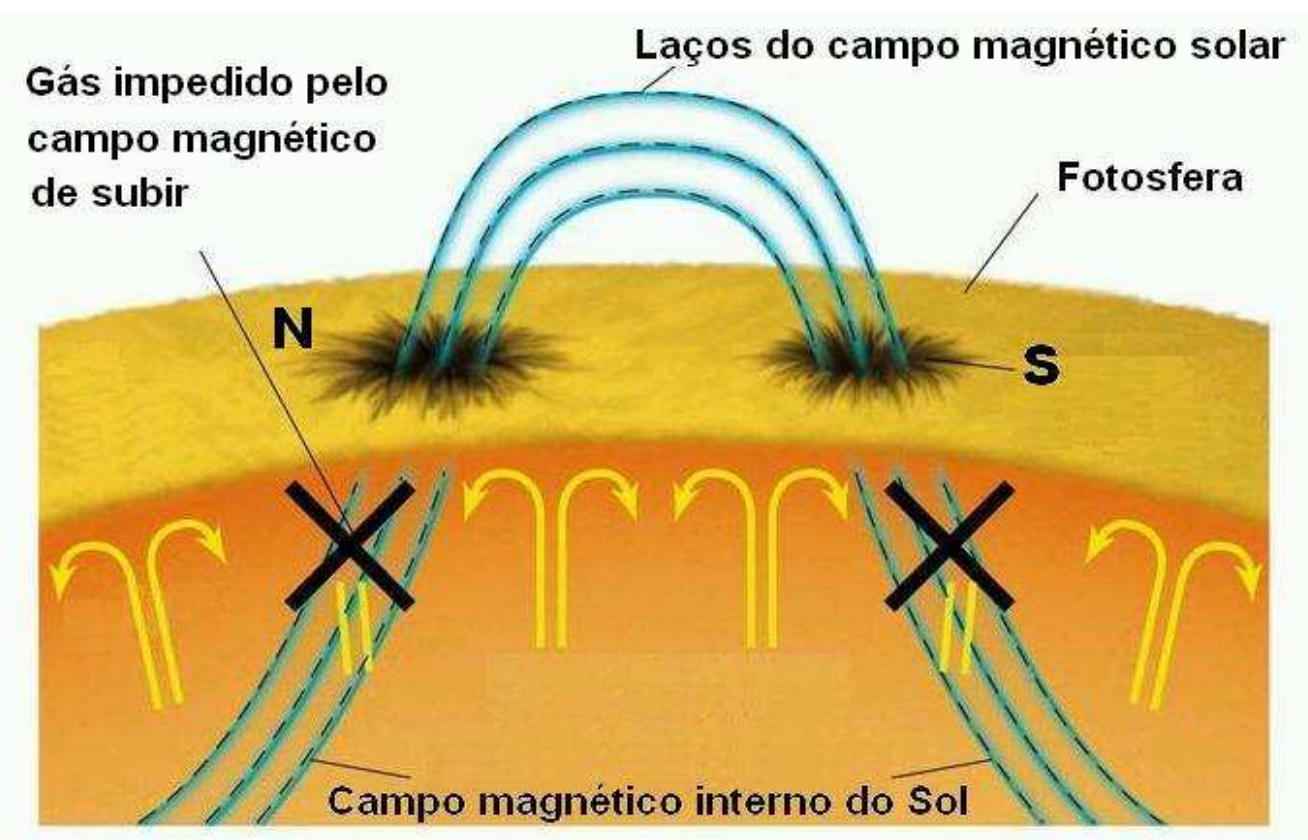

Fig. 9.2 - Polaridade das manchas solares. Figura editada pelo autor a partir de ilustração original de http://www.oswego.edu/ kanbur/a100/lecture10.html 
Foi o astrônomo americano George Ellery Hale $\left(1868\right.$ - 1938) que descobriu ${ }^{38}$ que as manchas solares possuíam um intenso campo magnético (da ordem de décimos de teslas). Em 1908, utilizando um espectroheliógrafo (de sua própria invenção) obteve o espectro de manchas solares e observou o efeito Zeeman ${ }^{39}$, estabelecendo, portanto, que as manchas solares possuíam campos magnéticos. Mais tarde demonstrou que as manchas apresentavam polaridades com simetria em relação ao equador solar e que essa polaridade se alternava de um ciclo de 11 anos para o seguinte.

Manchas individuais podem permanecer visíveis por dias e até mesmo por semanas, desaparecendo em seguida. Seus tamanhos variam entre algumas dezenas de quilômetros até 160.000 quilômetros de extensão. Na figura 9.3 está ilustrada uma grande mancha solar observada em 2010 e sua estrutura,. A região mais escura chama-se umbra e a mais clara ao seu redor, denomina-se penumbra. É na região da umbra que encontramos as temperaturas mais baixas em relação à fotosfera.

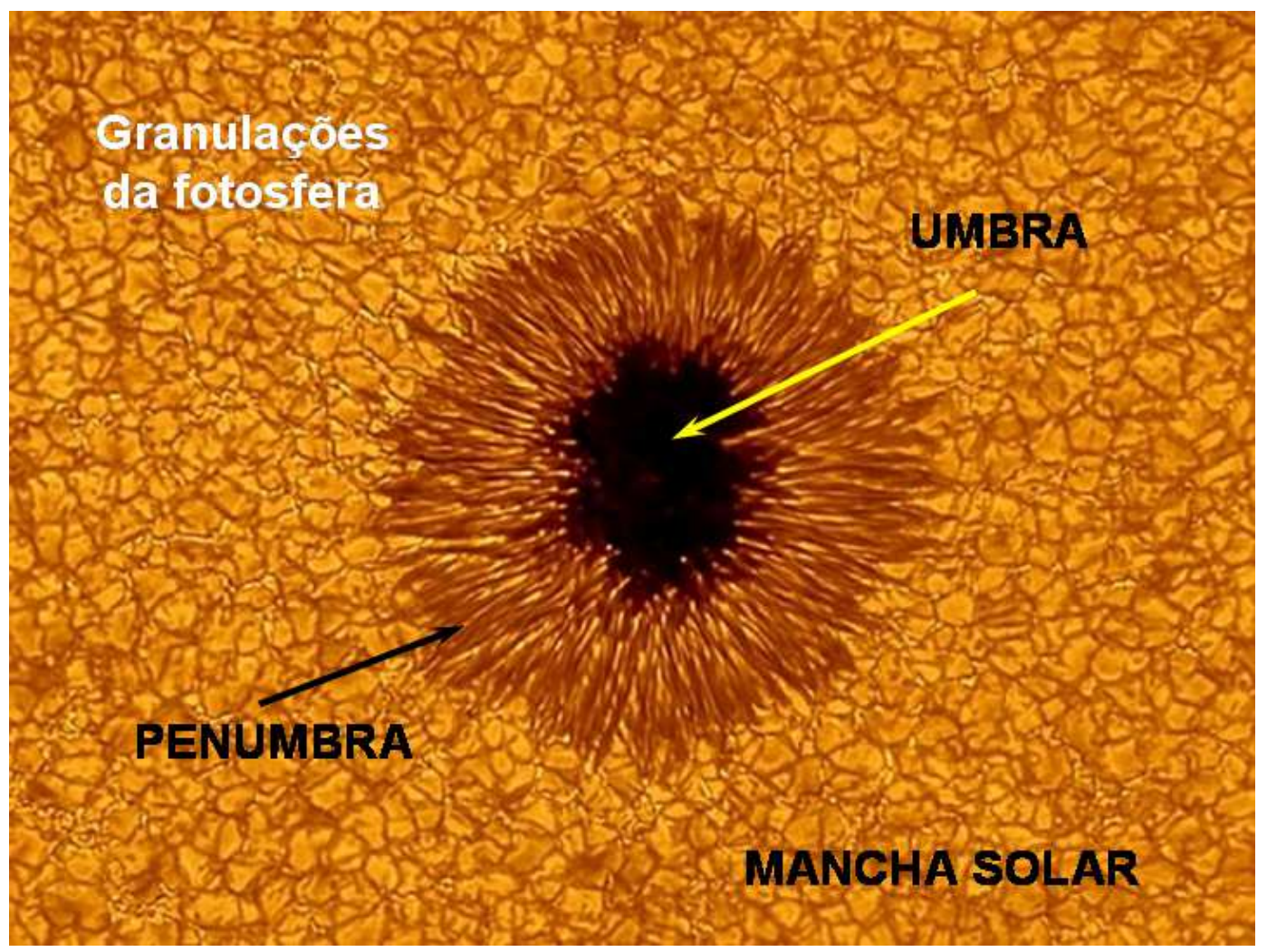

Fig. 9.3 - Imagem ilustrando uma grande mancha solar e sua estrutura - a umbra e a penumbra. As granulações da fotosfera são, também, facilmente perceptíveis. Editada pelo autor a partir da imagem publicada em: http://spacefellowship.com/wp-content/uploads/2010/08/011-03410-01high-610x457.jpg

\footnotetext{
${ }^{38}$ Hale, G.E. - On the Probable Existence of a Magnetic Field in Sun-Spots. Ap.J, 28, 315, 1908.

${ }^{39} \mathrm{O}$ efeito Zeeman consiste no desdobramento das linhas espectrais quando a radiação atravessa um campo magnético.
} 
A existência de uma atividade no Sol foi constatada após as primeiras observações do Sol com instrumentos ópticos (princípio do século XVII). Galileu Galilei (1564-1642) efetuou grande quantidade de observações do Sol entre 03 de maio e 21 de agosto de 1612. Suas observações permitiam notar que a quantidade de manchas era variável, cobrindo áreas variáveis da superfície solar e surgiam em diversas posições (em variadas latitudes heliográficas).

O astrônomo alemão e padre jesuíta, Christoph Scheiner (1573/75? - 1650), também realizou centenas de observações do Sol no período de 21 de outubro de 1611 a junho de 1627. No entanto, Pe. Scheiner achava que as manchas não eram fenômenos solares mas a passagem de pequenos planetas entre o Sol e a Terra.

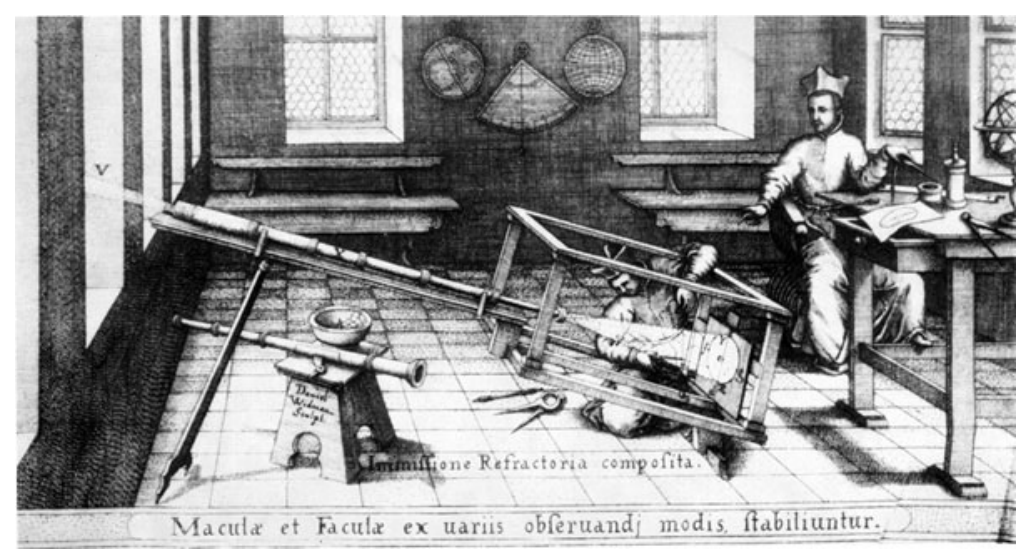

Fig. 9.4 - Padre Christoph Scheiner realizando observações do Sol pelo método de projeções (gravura do século XVII).

A presença das manchas solares em maior ou menor quantidade ensejou a sua contagem diária e permitiu, ao longo dos anos, a descoberta de uma periodicidade média de 11,2 anos em suas quantidades. A ideia de se estabelecer a contagem através de um número específico foi do astrônomo suíço Johann Rudolf Wolf (1816-1893), em 1848. O chamado número de Wolf (ou Número Internacional de Manchas, Número Relativo de Manchas ou, ainda, Número de Zürich), designado por R, é calculado por:

$$
\mathrm{R}=\mathrm{k}(10 \mathrm{~g}+\mathrm{f})
$$

onde g é o número de grupos de manchas, f é o número total de manchas (individuais ou em grupos) e k é uma constante que depende do instrumento utilizado - instrumentos com 
objetivas de tamanhos diferentes permitem observar quantidades diferentes de manchas. $\mathrm{O}$ valor de $\mathbf{k}$ foi tomado igual a um para o telescópio refrator de Zürich cuja objetiva tinha 8 cm de diâmetro. Para telescópios com objetivas maiores, o fator k é menor do que um. A figura 9.5 ilustra a contagem diária de manchas solares para o período de 1750 a 2000.

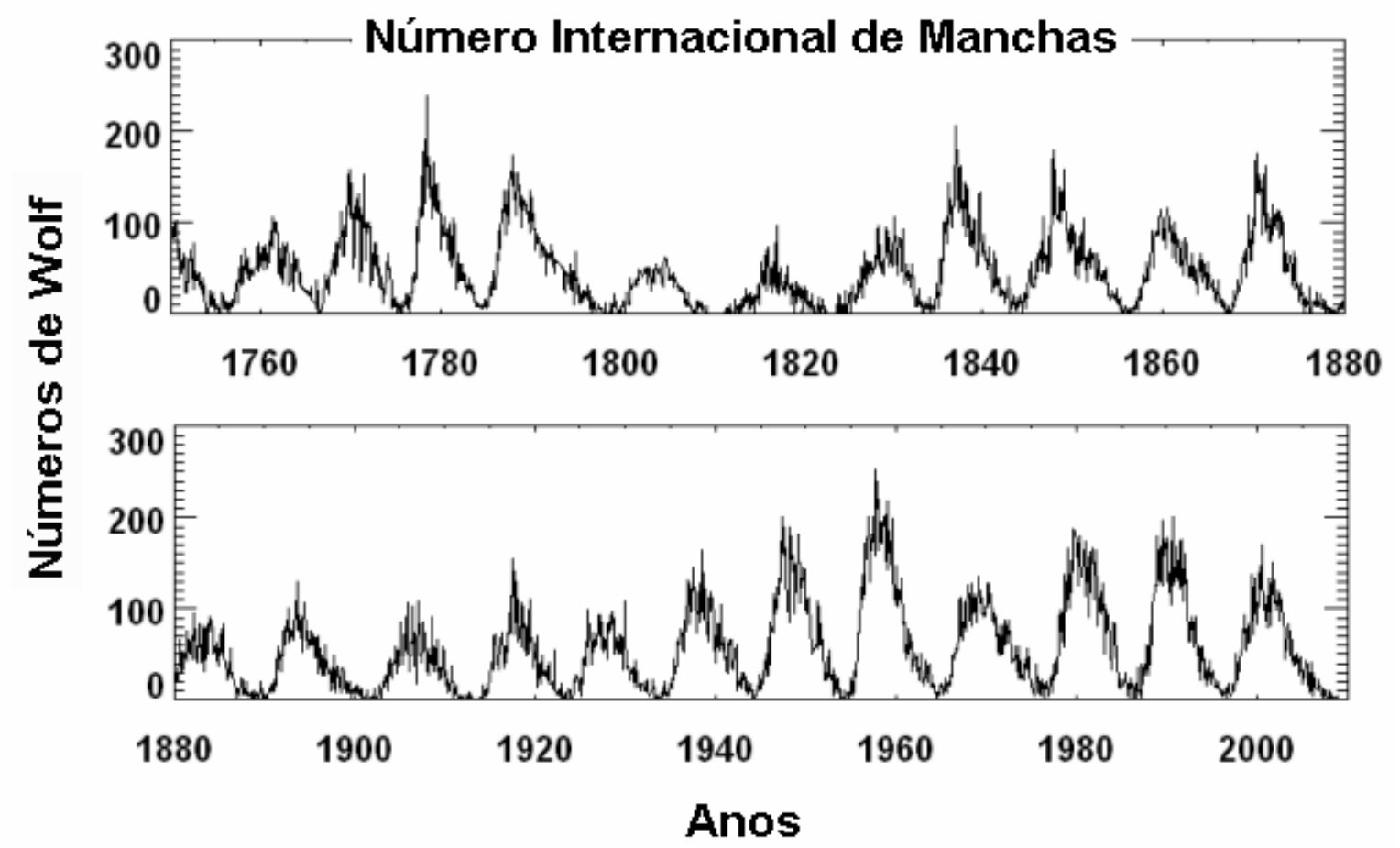

Fig. 9.5 - Gráfico do número diário (média para vários observatórios) de manchas solares para o período de 1750 a setembro de 2000. Fonte: http://spaceweather.com/glossary/sunspotnumber.html

Em 1843, o astrônomo alemão Samuel Heinrich Schwabe (1789-1875), após 17 anos de quase continuas observações de manchas solares e, estudando registros de contagem de manchas do passado, concluiu que havia uma periodicidade de cerca de 10 anos na quantidade de manchas visíveis no disco solar. Publicou seus resultados no "Astronomische Nachrichten" famoso periódico de Astronomia da Alemanha. No entanto, seu artigo pouca atenção atraiu. Somente em 1851, quando seus dados observacionais foram incluídos por Alexander Von Humboldt (1769-1859) no volume III de sua obra Kosmos, suas conclusões passaram a ser levadas em consideração.

Em 1904, o astrônomo inglês Edward Walter Maunder (1851-1928) reuniu anos de observações suas, de sua esposa Annie Maunder e de outros observadores sobre as quantidades, áreas e posições (latitudes e longitudes heliográficas) e elaborou um gráfico 
com essas informações. Obteve-se um diagrama, hoje chamado de "diagrama em borboleta". As manchas, no início de um ciclo de 11,2 anos aparecem inicialmente em altas latitudes heliográficas - cerca de $40^{\circ}$ ao norte e ao sul do equador solar.

Com o passar dos meses, vão surgindo cada vez mais manchas agora mais concentradas nas regiões próximas do equador solar (figura 9.6).

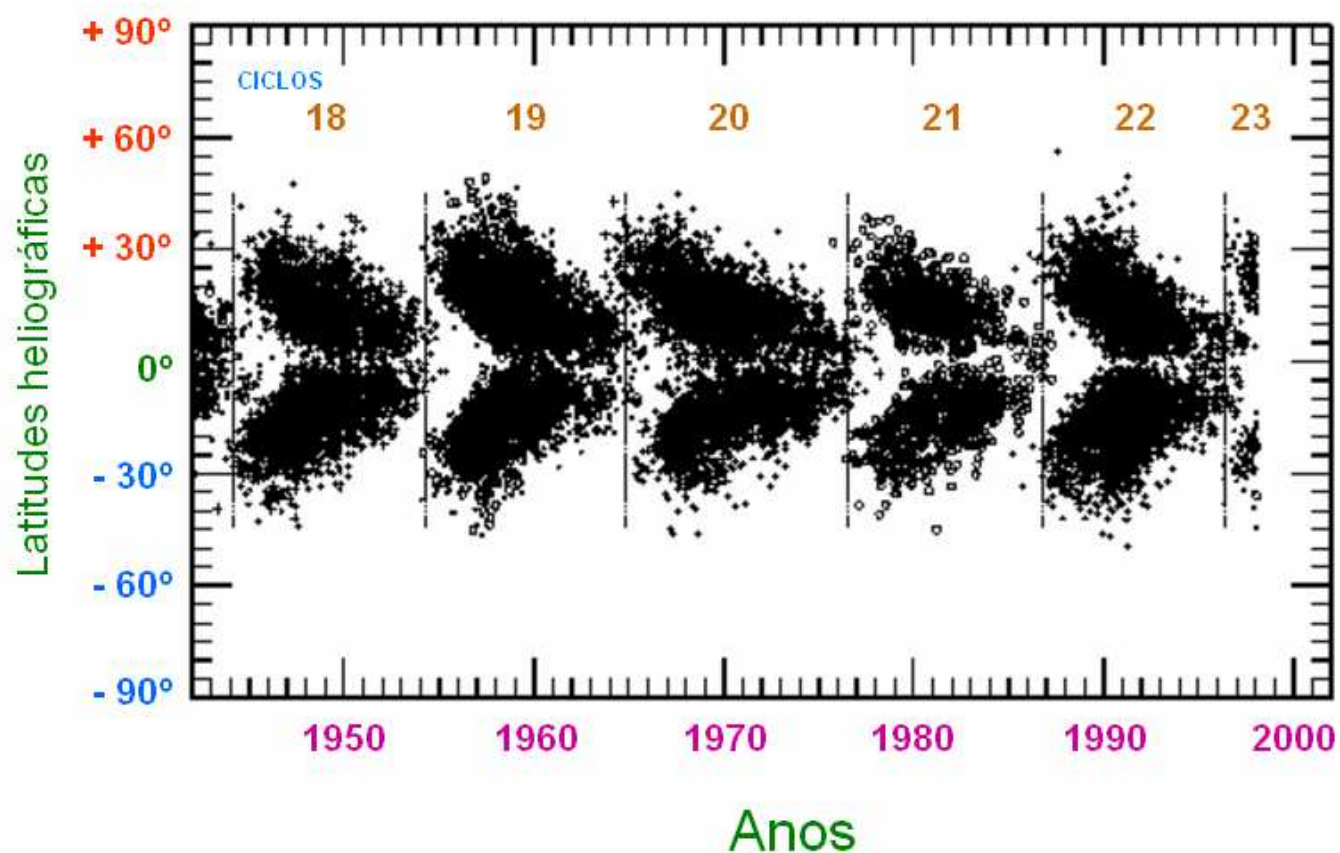

Fig. 9.6 - Diagrama de Maunder ou em borboleta para o período de 1942 a 2000 descrevendo as latitudes das manchas e suas áreas e evidenciando o ciclo de 11,2 anos (numerados dentro da figura). Gráfico editado pelo autor a partir de diagrama reproduzido em http://www.milliganphysics.com/Astronomy/Sunspots.htm.

\section{2 - A rotação solar}

A presença de manchas duradouras na fotosfera solar permitiu que se descobrisse que o Sol possui um lento movimento de rotação que se processa, na região do equador, com velocidade de $2,04 \mathrm{~km} / \mathrm{s}$, correspondendo a um período de rotação de 25,38 dias (609,12 horas). Foram também as manchas duradouras que são observadas em altas latitudes no início dos ciclos, que permitiram descobrir que o Sol não gira ao redor de seu eixo como um corpo rígido: na latitude de $30^{\circ}$, seu período de rotação é de 26,5 dias e na latitude de $45^{\circ}$ chega a 27 dias. Esse fato é chamado de rotação diferencial do Sol. 


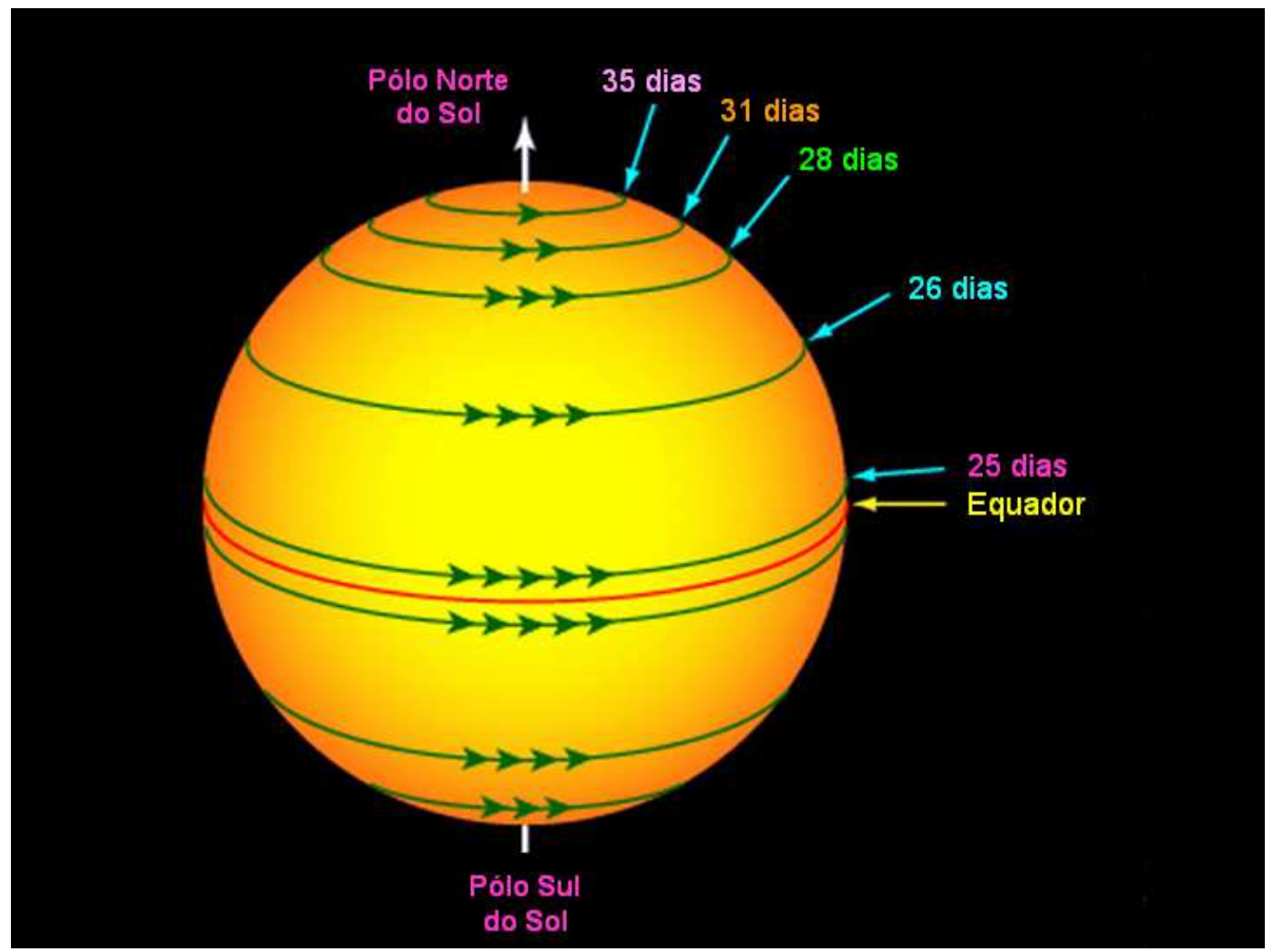

Fig. 9.7 - Rotação diferencial do Sol. Legendada pelo autor a partir da ilustração da NASA obtida em: https://www.nasa.gov/mission_pages/sunearth/science/solar-rotation.html

O eixo de rotação do Sol encontra-se inclinado de $7^{\circ} 1^{\prime}$ em relação a uma perpendicular ao plano da órbita da Terra ( $82^{\circ} 45^{\prime}$ em relação ao plano da órbita terrestre). Estudando os deslocamentos de grupos de manchas, R.A. Zappalá e F. Zuccarello estabeleceram uma relação que expressa a velocidade angular de rotação do $\operatorname{Sol} \xi(\theta)$ em função da latitude heliográfica $(\theta)^{40}$ :

$$
\xi(\theta)=14,643^{\circ} \pm\left(0,015^{\circ}\right)-2,2407^{\circ} \pm\left(0,16^{\circ}\right) \sin ^{2} \theta
$$

a velocidade angular de rotação $\xi(\theta)$ está expressa em graus por dia, e é válida para as latitudes heliográficas $(\theta)$ até $\pm 30^{\circ}$. Os períodos de rotação, em cada latitude heliográfica, podem ser obtidos por: $\mathrm{T}(\xi)=360 / \xi(\theta)$ em dias.

${ }^{40}$ Zappalá, R.A. e Zuccarello, F. Angular Velocity of Sunspot-Groups and Solar Photospheric Rotation. Astronomy and Astrophysics, 242, 480-487 (1991). 
A rotação diferencial do Sol levou o astrônomo americano Horace Welcome Babcock $^{41}$ (1912-2003) a propor um modelo para explicar os campos magnéticos das manchas solares. Considerando a situação inicial (figura 9.8) em que as linhas do campo magnético estão dispostas quase perpendicularmente ao equador solar, a cada rotação elas vão sofrendo "alongamento" na região do equador solar onde a rotação é mais rápida. Como o plasma solar tem alta condutividade elétrica, as linhas do campo magnético acompanham o movimento do plasma parecendo estar "congeladas" nele. Elas vão sendo torcidas ao longo de várias rotações. Essas linhas estão localizadas abaixo da fotosfera na base da região convectiva chamada tacoclina. Os campos magnéticos são carregados pelas correntes de convecção e, quando chegam à fotosfera, algumas linhas atravessam a superfície solar. Nesse local surgem as manchas. O modelo de Babcock esclarece o porquê das manchas aparecem aos pares: uma com polaridade positiva e outra com polaridade negativa (figura 9.8).

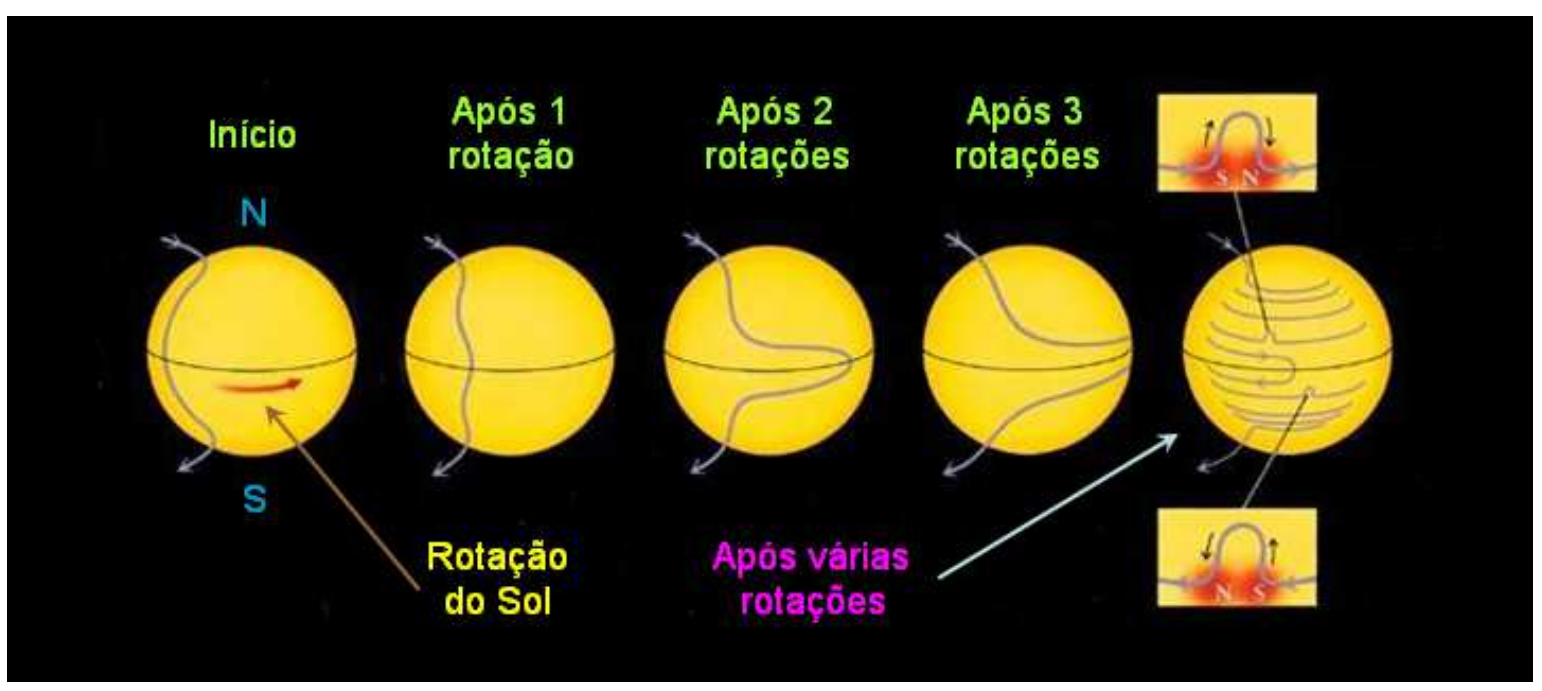

Fig. 9.8 - Modelo de Babcock para o campo magnético das manchas solares. Figura editada pelo autor do gráfico contido em http://www.astro-photography.net/Space-Weather.html

\section{3 - Flares}

Em 01 de setembro de 1859 o astrônomo inglês Richard Christopher Carrington (1826-1875), em seu rotineiro trabalho de observação de manchas solares, estava acompanhando, desde 28 de agosto, um enorme grupo de manchas que havia

\footnotetext{
41 Horace Welcome Babcock era filho do famoso astrônomo Harold Delos Babcock (1882-1968) que realizou estudos sobre o magnetismo estelar.
} 
surgido na região leste do Sol. Inesperadamente, notou, por volta das 11:20 da manhã, o aparecimento de duas regiões muito brilhantes exatamente no local da grande mancha que ele estava desenhando. Surpreso, registrou o fenômeno que durou cerca de 5 minutos.

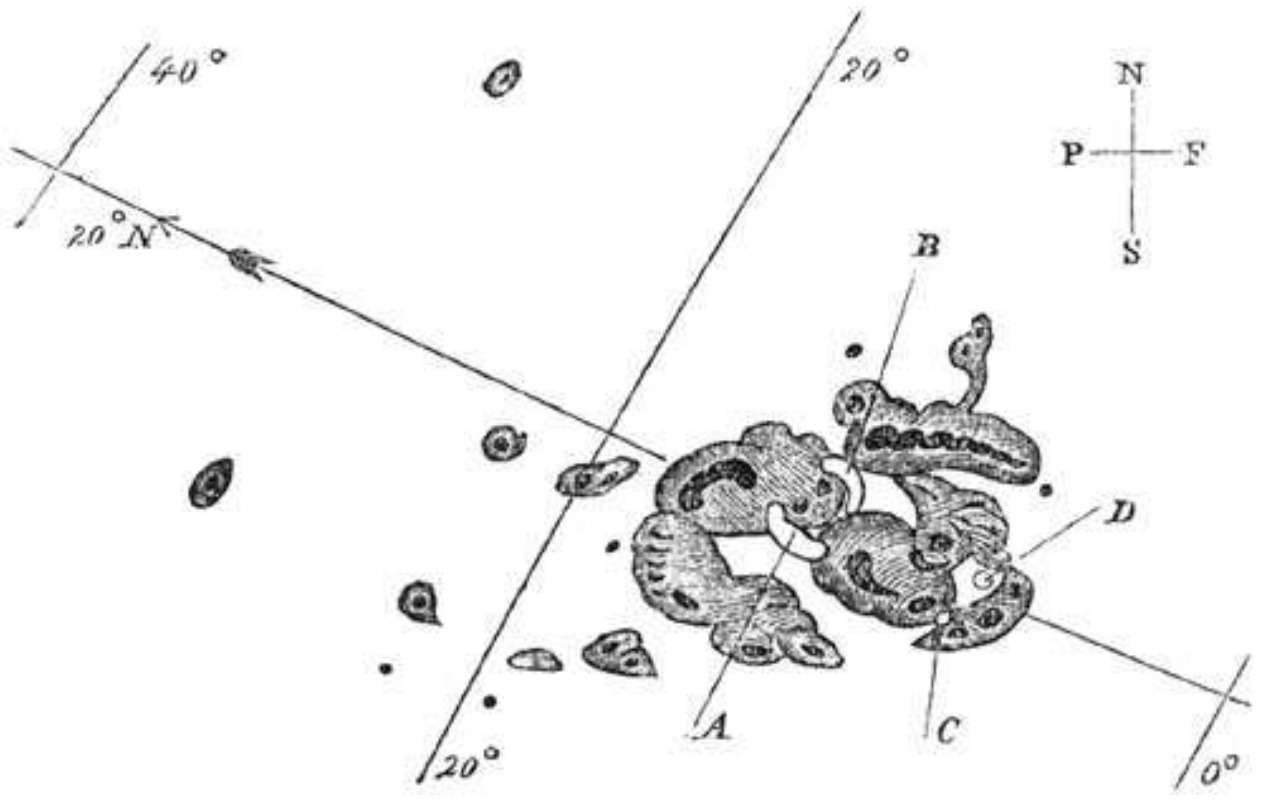

Fig. 9.9 - Desenho elaborado por Richard Carrington em 01 de setembro de 1859 mostrando a grande mancha solar e as regiões muito brilhantes (flares) assinaladas por A e B. Em cinco minutos o brilho deslocou-se para as regiões C e D. Fonte: Carrington, R. C., "Description of a Singular Appearance seen in the Sun on September 1,1859". Monthly Notices of the Royal Astronomical Society. 20:13 (1859).

Carrington tomou conhecimento que outro astrônomo inglês - Richard Hodgson (1804-1872) - também havia observado o mesmo fenômeno. No dia seguinte, uma quantidade enorme de auroras (boreais e austrais) foi observada e registrada em vários locais do mundo, algumas sendo observadas em latitudes próximas aos trópicos. Além disso, distúrbios magnéticos também foram percebidos em diversos locais e foram descritos como perturbações nas direções das agulhas das bússolas. Há, ainda, vários relatos sobre a paralisação do funcionamento de telégrafos. Não precisou muito para que os astrônomos - entre eles Carrington - associassem esses fenômenos com a súbita aparição das regiões brilhantes no Sol.

Por sugestão de Carrington, os dois astrônomos (ambos membros da Royal Astronomical Society - RAS) resolveram apresentar o resultado de suas observações na reunião da Sociedade em 11 de novembro de 1859. Os relatórios apresentados na reunião 
foram publicados, posteriormente, no Monthly Notices of the Royal Astronomical Society ${ }^{42}$. Esse súbito aparecimento de um intenso brilho no Sol foi batizado de flare.

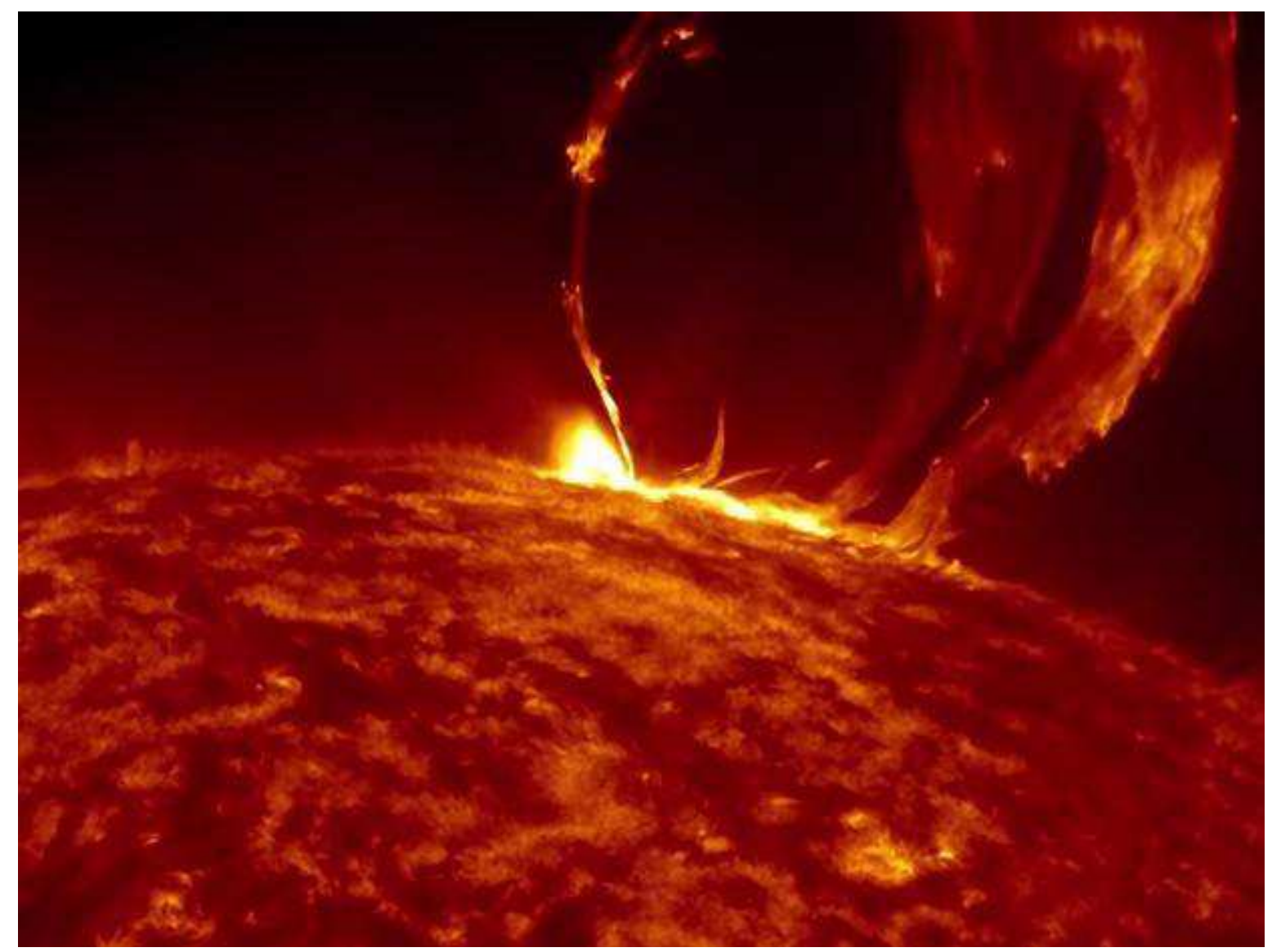

Fig. 9.10 - Flare (explosão) capturada pela NASA.

Fonte:http://www.independent.co.uk/news/science/exploding-solar-flare-is-captured-by-nasa-video10357383.html

Os flares são, enfim, súbitos aumentos de brilho (explosões) que ocorrem próximos à superfície do Sol. Apresentam um espectro muito amplo de emissões (em vários comprimentos de onda) e liberam energia da ordem de $10^{20}$ joules. Muitas vezes os flares são acompanhados por ejeções de massas coronais. Eles ejetam nuvens de elétrons, íons e átomos através da coroa solar para o espaço. Em geral, um ou dois dias após a ocorrência do fenômeno, a nuvem de partículas atinge a Terra (figura 9.10).

Os flares ocorrem em regiões ao redor de manchas solares onde campos magnéticos intensos conectam a coroa com o interior solar. Suas durações são da ordem de alguns

\footnotetext{
${ }^{42}$ Carrington, R. C., "Description of a Singular Appearance seen in the Sun on September 1, 1859". Monthly Notices of the Royal Astronomical Society. 20:13 (1859) e Hodgson, R., "On a curious Appearance seen in the Sun". Monthly Notices of the Royal Astronomical Society. 20: 15. (1859)
} 
minutos, chegando até dezenas de minutos. As emissões de radiação ultravioleta e de raios$\mathrm{X}$ dos flares afetam a ionosfera interrompendo comunicações via rádio, prejudicando o funcionamento de radares e colocam em risco os astronautas no espaço.

Em 2012, uma tempestade solar semelhante em intensidade àquela observada por Carrington, com forte ejeção de massa coronal, teve lugar em 23 de julho. A região que produziu a explosão não estava dirigida para a Terra naquele momento.

\section{4 - Ejeções de massas coronais}

As ejeções de massas da coroa solar são enormes explosões associadas ao campo magnético do Sol e ao plasma da coroa solar. São também chamadas de tempestades solares. Quando essas massas atingem a Terra e interagem com a magnetosfera terrestre, ocorrem tempestades geomagnéticas e surgem muitas auroras. As ejeções têm origem em estruturas chamadas "cordas de fluxo" onde as linhas do campo magnético encontram-se altamente torcidas.

Protuberâncias e filamentos também se originam em regiões onde as linhas do campo encontram-se, também, torcidas. Porém o campo magnético é de menor intensidade. Quando as "cordas de fluxo" surgem nas regiões ativas no Sol (regiões associadas a manchas solares e campos magnéticos muito fortes), são muitas vezes acompanhadas por grandes flares.

As massas coronais são lançadas a velocidades típicas de $300 \mathrm{~km} / \mathrm{s}$, podendo apresentar velocidades entre $100 \mathrm{~km} / \mathrm{s}$ e atingir até $3.000 \mathrm{~km} / \mathrm{s}$. As ejeções mais rápidas originam-se nas regiões ativas com muitas manchas solares onde intensos campos magnéticos estão concentrados. Essas ejeções podem atingir rapidamente a Terra, em cerca de 14 a 17 horas. As ejeções mais lentas, associadas às regiões onde se tem erupções de filamentos e protuberâncias, podem demorar vários dias para chegar à Terra. 


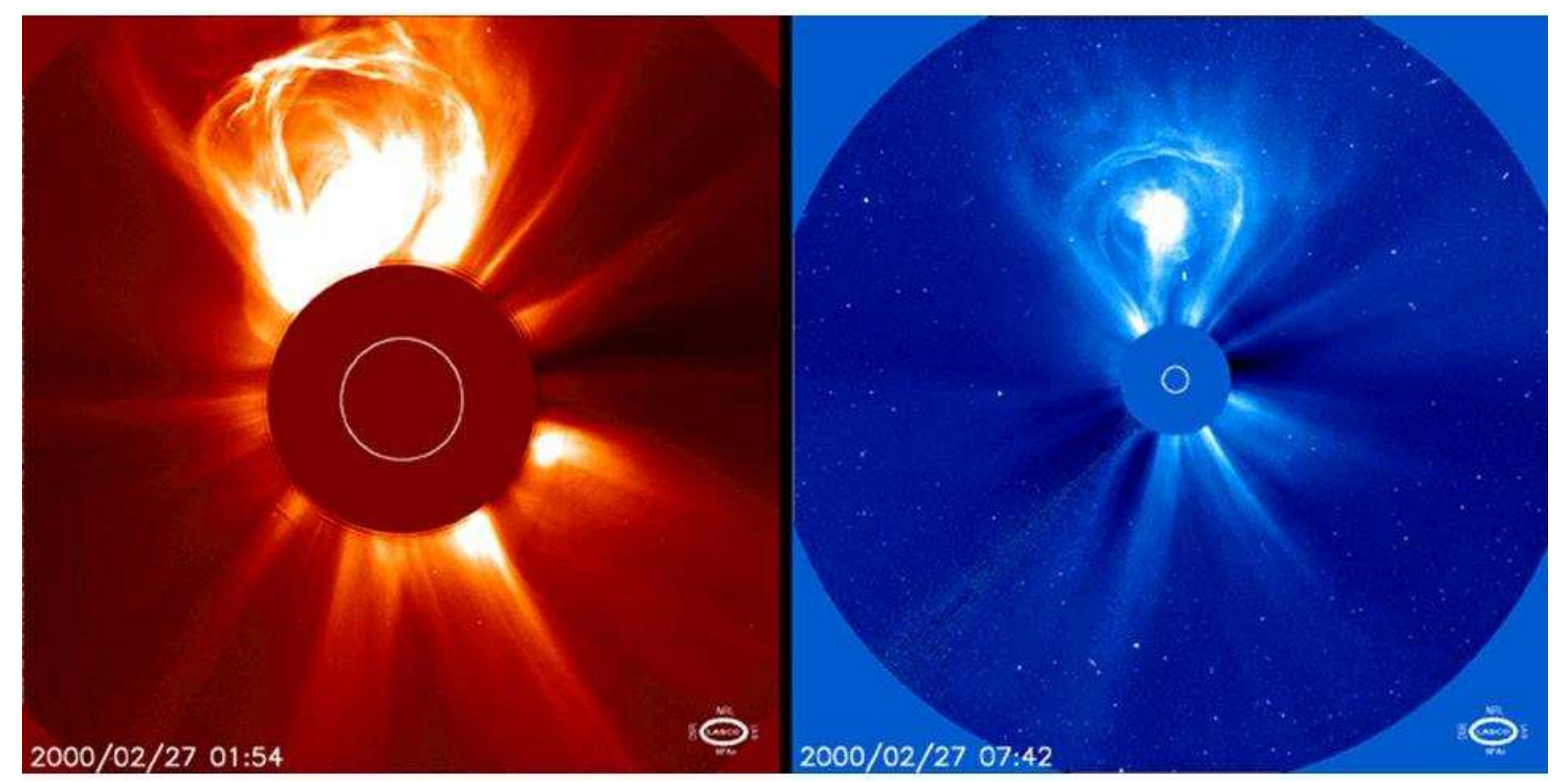

Figura 9.11 - Ejeção de massa coronal. O coronógrafo a bordo do SOHO produz um "eclipse" do Sol, permitindo que seja fotografada a coroa solar. Imagens: NASA/ESA missão SOHO.

\section{5 - O vento solar}

O vento solar é um fluxo de plasma e partículas carregadas (principalmente prótons e elétrons) provenientes da coroa solar e que se propaga em todas as direções no meio interplanetário. São partículas altamente energéticas, com energias variando entre $1,5 \mathrm{keV}$ e $10 \mathrm{keV}^{43}$. Viajam a velocidades supersônicas, entre $250 \mathrm{~km} / \mathrm{s}$ e $750 \mathrm{~km} / \mathrm{s}$. Como veremos adiante, a velocidade do vento solar passa de supersônica para infra-sônica quando ele atinge o termination shock, região da heliosfera situada a cerca de 93 unidades astronômicas do Sol.

A origem do vento solar é a coroa do Sol onde reina uma temperatura muito alta. A energia cinética das partículas nessa temperatura é tão grande que elas escapam à gravidade solar. Há dois tipos de vento solar: o vento solar lento ou de baixa velocidade e o vento solar rápido ou de alta velocidade.

\footnotetext{
${ }^{43} \mathrm{keV}$ é abreviatura de quilo elétron-Volt.
} 
Na região próxima da Terra, o vento solar lento tem velocidades entre $300 \mathrm{~km} / \mathrm{s}$ e $500 \mathrm{~km} / \mathrm{s}$ (velocidade típica de $400 \mathrm{~km} / \mathrm{s}$ ) e composição correspondente à baixa coroa solar. Já o vento solar rápido, originado nos buracos coronais, possui velocidade de 750 $\mathrm{km} / \mathrm{s}$ e sua composição é semelhante à composição da fotosfera. Observações solares efetuadas durante cinco anos (entre 1996 e 2001) permitiram concluir que o vento solar lento origina-se nas latitudes heliográficas entre $30^{\circ}$ e $35^{\circ}$ durante o período de mínima atividade solar e vai se expandindo até os pólos do Sol à medida que o máximo de atividade vai se aproximando.

Os ventos solares de baixas e altas velocidades interagem com a magnetosfera terrestre produzindo tempestades. O campo magnético da Terra serve, por assim dizer, como um escudo espalhando o material que chega ao redor do planeta para que ele flua para além dele. A pressão do vento solar alonga o campo magnético terrestre de modo que ele é arredondado na região entre a Terra e o Sol e esticado no lado oposto (correspondente à noite). Se o material transportado pelo vento solar atingisse a superfície da Terra, sua radiação causaria severos danos a qualquer forma de vida que existisse.

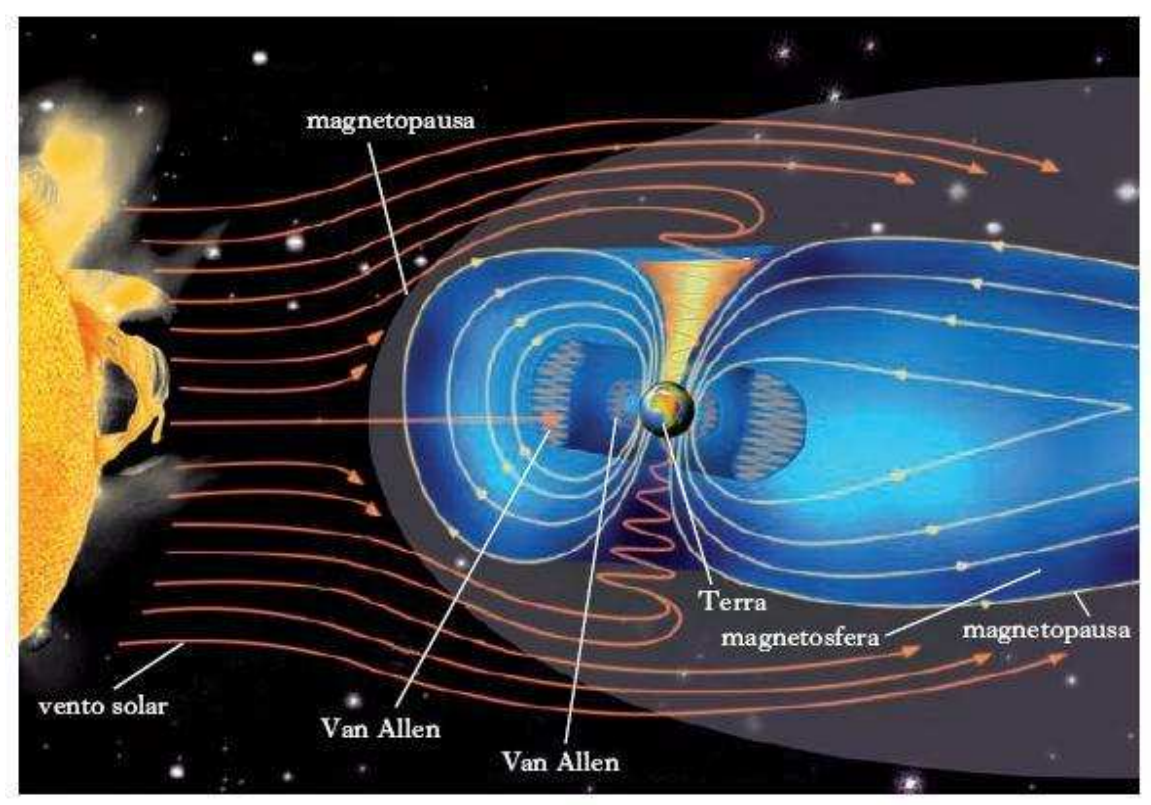

Fig. 9.12 - A magnetosfera terrestre desviando as partículas do vento solar e protegendo o planeta. Fonte da ilustração: https://thoth3126.com.br/campo-magnetico-da-terra-esta-mais-instavel/

Alguns corpos do Sistema Solar estão protegidos por um campo magnético, porém, outros não possuem essa proteção. Nosso satélite natural, a Lua, não tem um campo 
magnético para protegê-la e o vento solar incide sobre a sua superfície com bastante intensidade. Mercúrio, o planeta mais próximo do Sol, possui um campo magnético que o protege do vento solar regular, mas seria necessário um campo mais intenso para protegêlo do vento de maior intensidade. Por outro lado, planetas com magnetosferas tênues, ou mesmo inexistentes, estão sujeitos à lenta remoção de sua atmosfera pelo vento solar.

O vento solar e a pressão da radiação solar atuam de maneira intensa sobre as caudas dos cometas fazendo com que estas estejam sempre dirigidas para o lado oposto ao Sol. Os cometas apresentam dois tipos de caudas: a cauda de poeira originada pela ação da pressão da radiação sobre a poeira que se encontra na coma do cometa (uma espécie de "atmosfera" que envolve o núcleo cometário quando este se encontra próximo do Sol) e cauda iônica, composta por gases e íons criados pela ação da luz solar sobre os gases da coma. Os íons são suscetíveis à ação do campo magnético solar e do vento solar e são arrancados dos gases que envolvem o núcleo do cometa. Origina-se, então, uma longa e quase retilínea cauda em direção oposta ao Sol. A cauda iônica é produzida, então, pela ação do vento solar.

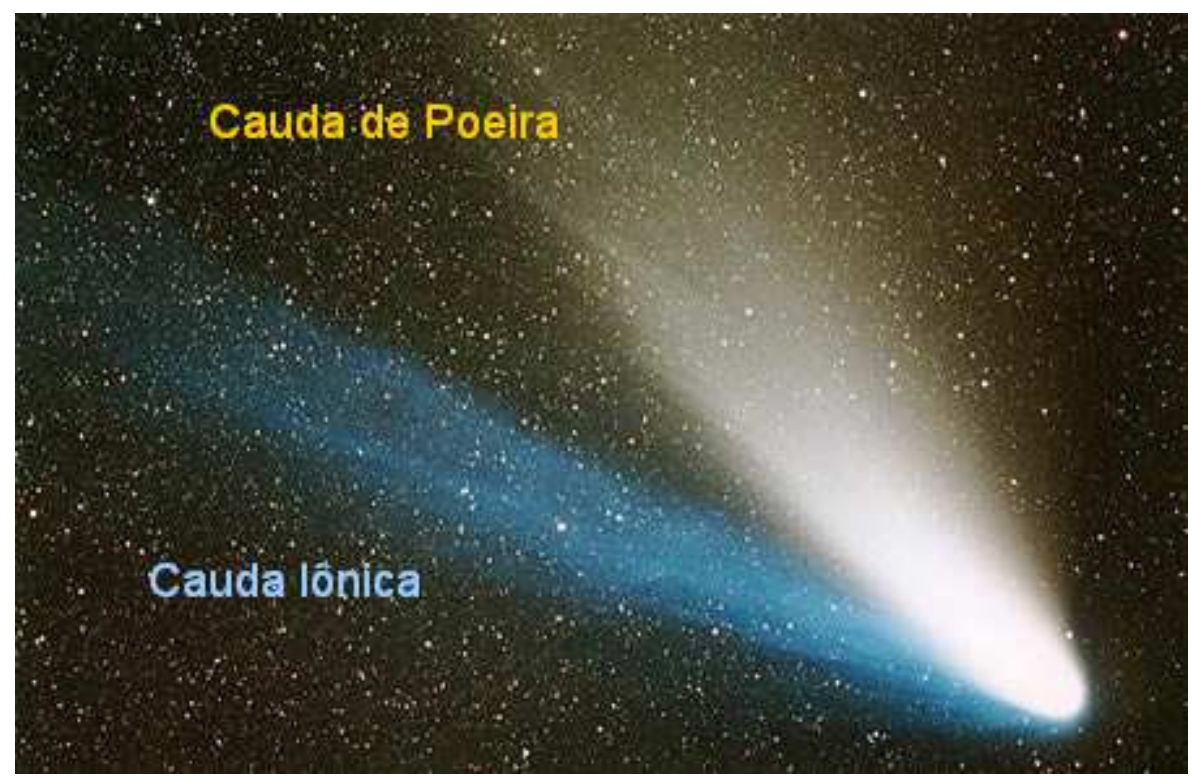

Fig. 9.13 - O cometa Hale-Bopp observado em 1996/1997. Destaque para as duas caudas bem visíveis: a azulada (cauda iônica) e a esbranquiçada (cauda de poeira). Figura legendada pelo autor a partir da fotografia publicada em http://www.lpl.arizona.edu/ hubbard/PtyS206/Lectures4/Apr10.htm

Pelo fato do íon mais comum ser o $\mathrm{CO}^{+}$, que espalha mais a luz azul do que a vermelha, a cauda iônica nos aparece mais azulada. Já a cauda de poeira aparece mais 
esbranquiçada (ou ligeiramente rosada) porque a poeira reflete mais os comprimentos de onda longos da luz solar do que os curtos.

A missão Ulysses da NASA, lançada em 6 de outubro de 1990, estudou o Sol em várias latitudes heliográficas e mediu as várias propriedades do vento solar ao longo de mais de uma década. O satélite ACE (Advanced Composition Explorer), lançado em 1997, orbita o Sol no ponto $\mathrm{L}_{1}$ de Lagrange ${ }^{44}$, mantendo uma órbita estável e fornecendo, em tempo real, medidas do fluxo de partículas.

O SOHO (Solar and Heliospheric Observatory ou Observatório Solar e Heliosférico), uma sonda da Agência Espacial Européia (ESA) e da NASA, lançado em dezembro de 1995, foi projetado para estudar a estrutura interna do sol, sua ampla atmosfera externa e a origem do vento solar. Continua enviando para a Terra informações sobre a atividade solar a despeito do seu tempo de vida ter sido há muito ultrapassado.

\section{6 - Auroras boreais e austrais}

As auroras são um fenômeno observado nos céus noturnos nas regiões próximas aos polos terrestres e decorrem do impacto de partículas do vento solar com a alta atmosfera da Terra. Essas partículas são dirigidas pelo campo magnético da Terra para as regiões dos polos magnéticos terrestres. Eles estão localizados (2015) nas seguintes posições: polo magnético norte em $80,37^{\circ}$ de latitude norte e $72,62^{\circ}$ de longitude oeste (localizado na ilha Ellesmere, no arquipélago ártico do Canadá) e o polo magnético sul a $64,28^{\circ}$ de latitude sul e $136,59^{\circ}$ de longitude leste, externamente ao círculo polar antártico. Sua distância ao polo geográfico sul é de aproximadamente $2.860 \mathrm{~km}$. O campo magnético terrestre é relativamente fraco e na superfície da Terra sua intensidade varia entre $25 \mu \mathrm{T}$ e $65 \mu \mathrm{T}$ (microteslas). Cabe, ainda, destacar que os referidos polos costumam ser designados como polos geomagnéticos. O polo geomagnético norte é, de fato o polo magnético sul do campo magnético da Terra e o polo geomagnético sul é o polo norte do campo.

\footnotetext{
${ }^{44}$ Para um sistema constituído por dois corpos, os pontos de Lagrange são cinco pontos em que um terceiro corpo, de massa desprezível, pode co-orbitar o astro de grande massa. No caso do sistema Terra-Sol, o ACE co-orbita o Sol juntamente com a Terra em uma órbita pouco perturbada.
} 
As auroras polares são causadas por elétrons com energias entre 1 e $15 \mathrm{keV}$, além de prótons e partículas alfa, sendo que a luz é produzida quando as partículas colidem com os átomos das camadas mais altas da atmosfera terrestre (entre 80 e $150 \mathrm{~km}$ de altitude), predominantemente o nitrogênio e o oxigênio. As partículas carregadas provenientes do Sol são desviadas pelo campo magnético terrestre. Porém, uma parte delas é capturada e atinge a alta atmosfera nas regiões correspondentes aos pólos magnéticos (figura 9.12). Ocorrem então colisões entre essas partículas e os átomos da atmosfera terrestre, especialmente com o oxigênio e com o nitrogênio. No processo colisional, parte da energia é transferida da partícula para o átomo que sofreu a colisão e podem ocorrer os seguintes fenômenos: ionização, dissociação ou excitação. Ocorrendo a ionização, o elétron (ou elétrons) arrancado(s) do átomo acaba provocando outras ionizações em outros átomos. A excitação leva os elétrons dos átomos a estados excitados que, em seguida, emitem luz em frequências bem determinadas.

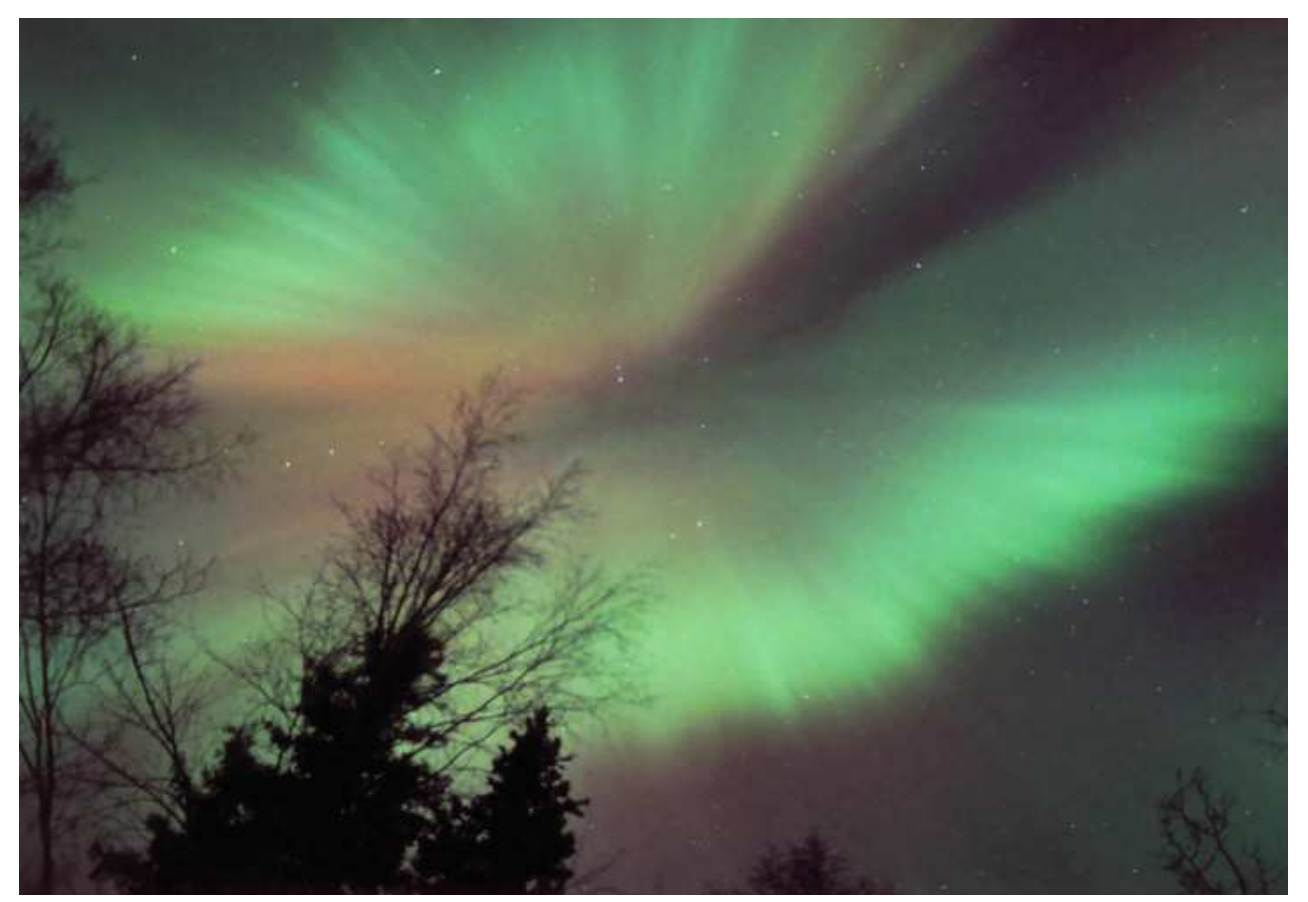

Fig. 9.14 - Aurora boreal. Fonte: https://stereo.gsfc.nasa.gov/spaceweather/spaceweather.shtml

As colorações esverdeadas, muito frequentes, são devidas à emissão por parte dos átomos de oxigênio que se encontram nas altas camadas da atmosfera. Nas tempestades mais intensas as partículas provenientes do Sol podem atingir camadas mais baixas da nossa atmosfera e, então, aparecem colorações avermelhadas emitidas por moléculas de 
nitrogênio (predominantemente) e oxigênio. Átomos de oxigênio emitem cores bastante variadas, mas as predominantes são o verde $(558 \mathrm{~nm})$ e o vermelho $(630 \mathrm{~nm})$.

Historicamente, foi o astrônomo inglês Edmond Halley (1656-1742) um dos primeiros a suspeitar que o campo magnético terrestre estivesse relacionado com o aparecimento das auroras. Os astrônomos suecos Anders Celsius (1701-1744) e Olof Petrus Hiorter (1696-1750) foram os primeiros a relatar evidências de anomalias magnéticas quando as auroras eram observadas.

Mas, somente há alguns anos, os astrônomos conseguiram compreender que o Sol é o responsável pelo aparecimento dessas misteriosas e maravilhosas luzes. A teoria do vento solar supersônico apareceu, em 1957, em um trabalho do astrofísico americano Eugene Newman Parker (1927-). No ano seguinte, foi lançado o satélite Explorer 1 (que marca a entrada dos Estados Unidos da América na corrida espacial) e os instrumentos que estavam a bordo do satélite comprovaram as ideias de Parker. O programa espacial permitiu que se sondasse e observasse a alta atmosfera, o que nos trouxe um conhecimento mais completo do fenômeno. As observações mostraram que as ejeções de massas coronais e o constante fluxo de partículas solares (vento solar) capturadas pelo campo magnético terrestre são os responsáveis pelos belos aparecimentos no céu.

\section{7 - Avaliando a atividade solar: o índice F10.7}

Talvez o melhor índice disponível para avaliar a atividade solar, cobrindo pelo menos seis décadas, seja o fluxo solar no comprimento de onda de $10,7 \mathrm{~cm}$ (frequência de 2,8 GHz). Esse índice é uma medida integrada da emissão de todas as fontes presentes no disco solar e tem sido medido diariamente pelo Conselho Nacional de Pesquisa do Canadá (National Research Council of Canada) por cerca de 65 anos e atualmente é utilizado no mundo inteiro como um índice básico para a atividade solar. Passou a ser designado atualmente de índice F10.7.

O fluxo solar no comprimento de onda de $10,7 \mathrm{~cm}$, daqui em diante, representado

por $\mathrm{F}_{10.7}$, é expresso em unidades de fluxo solar (ufs) que correspondem a $10^{-22} \mathrm{~W} \cdot \mathrm{m}^{-2} \cdot \mathrm{Hz}^{-1}$. As principais vantagens do $\mathrm{F}_{10.7}$ é que ele pode ser medido sob quaisquer condições de 
tempo e não necessita da presença de um observador ou de sua interpretação. Nas condições denominadas de Sol calmo, o valor de $\mathrm{F}_{10.7}$ é de 64 ufs, ocasionado pela emissão térmica livre-livre (free-free) da coroa solar.

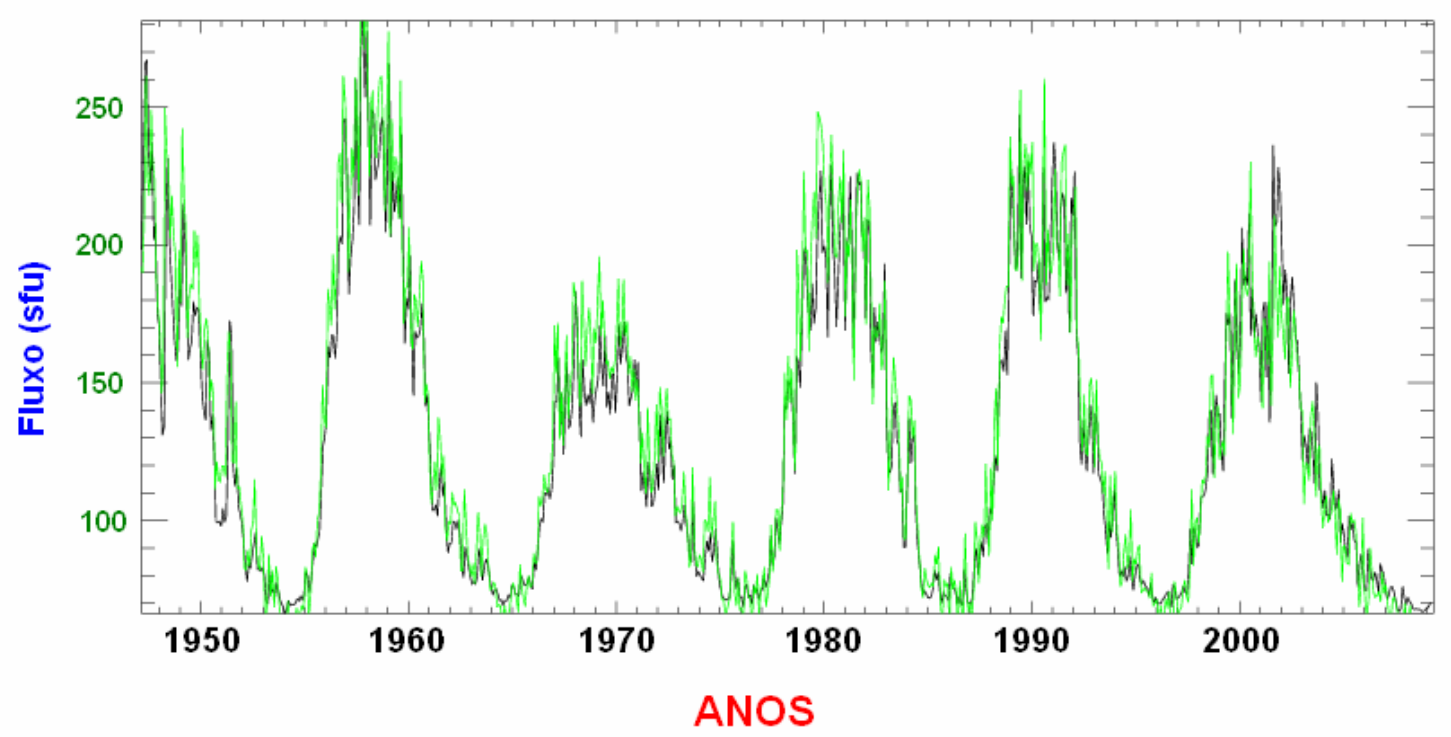

Fig. 9.15 - Valores mensais do fluxo solar em $\lambda=10,7 \mathrm{~cm}(2,8 \mathrm{GHz})$, para o período 1947 a 2009 . O fluxo é dado em unidades de fluxo solar (s.f.u. = solar flux unit). 1 s.f.u. $=10^{-22} \mathrm{~W} \cdot \mathrm{m}^{-2} \cdot \mathrm{Hz}^{-1}$. A linha verde mostra o número médio mensal de manchas solares $\left(\mathrm{R}_{\mathrm{m}}\right)$, acrescido de 60 , para maior destaque e comparação com os valores do fluxo (em preto). Fonte: Inspire Hep (http://inspirehep.net/record/882879/plots).

A emissão $F_{10.7}$ origina-se nas regiões mais altas da cromosfera e nas baixas regiões da coroa solar (figura 9.15). Ela tem muito boa correlação com a quantidade de manchas solares e com os registros de irradiação solar no ultravioleta e no visível. Tem sido medido com muita regularidade desde 1947. O índice $F_{10.7}$ varia, durante um ciclo solar, de 50 s.f.u. a cerca de 300 s.f.u.

$\mathrm{O}$ índice $\mathrm{F}_{10.7}$ mostrou-se, também, muito útil no estudo de outras emissões originadas nessa região. As emissões no extremo ultravioleta (EUV) que produzem influências na ionosfera terrestre e produzem modificações na atmosfera superior da Terra são bem acompanhadas com a utilização desse índice. Muitas emissões no ultravioleta que afetam a atmosfera e a camada de ozônio também estão correlacionadas com esse índice. 


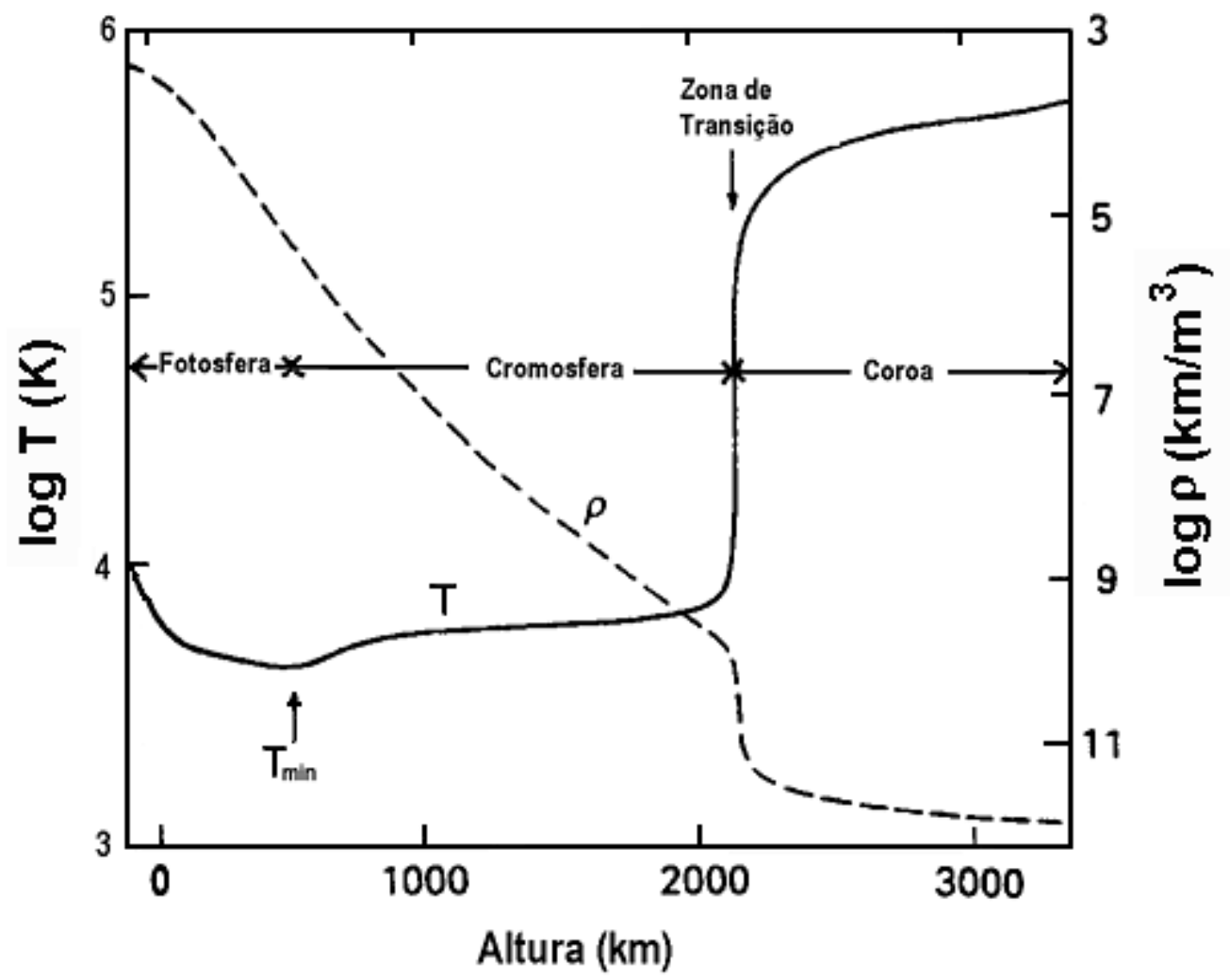

Fig. 9.16 - Temperaturas (T) e densidades $(\rho)$ (em escala logarítmica) nas diversas camadas da atmosfera solar. Diagrama de Kepler de Souza Oliveira e Maria de Fátima O. Saraiva - http://www.astro.ufrgs.br

\section{8 - A heliosfera}

A heliosfera é a região do espaço na qual a ejeção de massa solar (incluindo o vento solar) e o campo magnético do Sol predominam sobre o meio interestelar e o campo magnético galáctico. A heliosfera se estende muito além dos planetas-anões mais distantes conhecidos no Sistema Solar. Ela funciona como uma "bolha" que se opõe à pressão do meio interestelar, formado pelo hidrogênio e o hélio que permeiam a Galáxia. Sua forma não é perfeitamente esférica e é controlada pelo meio interestelar. O limite exterior da heliosfera é chamado de heliopausa. 


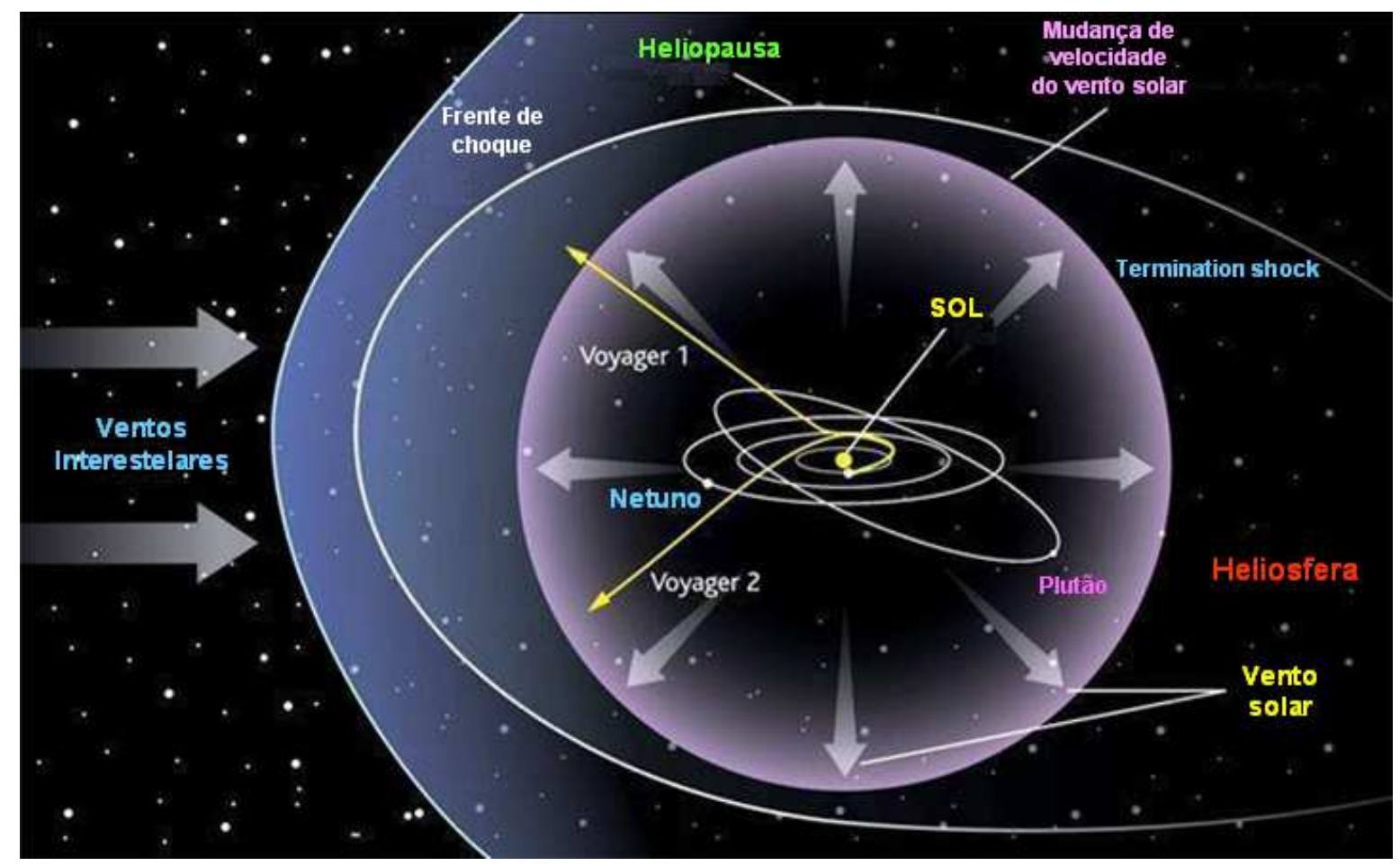

Fig. 9.17 - Concepção artística da heliosfera e das posições das sondas espaciais Voyager 1 e Voyager 2. Figura extraída de http://slideplayer.com/slide/8215372/ e modificada pelo autor.

Estudos da heliosfera e seu limite com o meio interestelar foram feitos pelas duas sondas Voyager que sobrevoaram os planetas Júpiter, Saturno, Urano e Netuno no período de 1979 a 1989. Em 16 de dezembro de 2004, a sonda Voyager 1 cruzou o que chamamos de termination shock, região situada a 93 unidades astronômicas do Sol, onde a velocidade do vento solar passa de supersônica para infra-sônica (figura 9.17). A Voyager 2 cruzou a mesma região em 30 de agosto de 2007. Essa é a região onde o vento solar colide pela primeira vez com o meio interestelar. Ela surge porque o vento solar é emitido pelo Sol com velocidade de $400 \mathrm{~km} / \mathrm{s}$ enquanto que a velocidade do som no meio interestelar é ao redor de $100 \mathrm{~km} / \mathrm{s}^{45}$. O meio interestelar, embora de baixa densidade tem, no entanto, uma pressão constante associada a ele. Já a pressão do vento solar diminui com o quadrado da distância ao Sol. À medida que o vento solar se afasta o suficiente do Sol, a sua pressão cai e já não mantém mais um fluxo supersônico contra a pressão do meio interestelar. A velocidade do vento solar diminui para valores inferiores à velocidade do som causando uma onda de choque. A passagem da Voyager 1 pelo termination shock produziu um considerável aumento na densidade e na contagem das partículas do vento solar. Esse

45 O valor exato da velocidade do som no meio interestelar depende de sua densidade que flutua consideravelmente. 
aumento foi causado pela brusca diminuição da velocidade do vento solar produzindo um aumento na densidade de partículas.

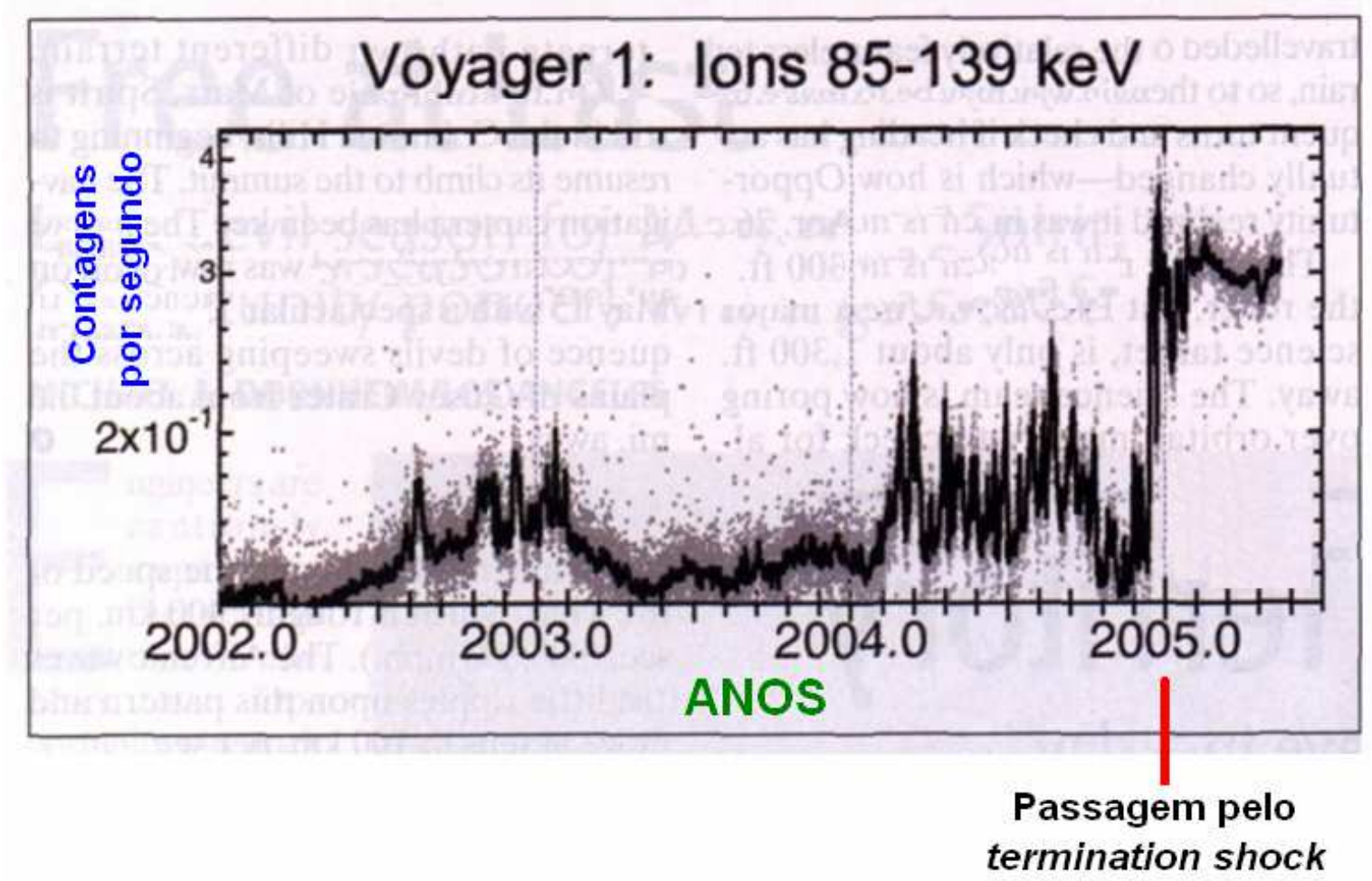

Fig. 9.18 - Aumento na quantidade de partículas do vento solar registrado pelos equipamentos da sonda Voyager 1 na sua passagem pelo termination shock. Figura extraída de http://slideplayer.com/slide/8215372/ e modificada pelo autor.

A região externa da heliosfera, onde o vento solar é comprimido pela pressão do meio interestelar e se torna turbulento, é chamada de heliosheath. ${ }^{46}$ A seguir vem a heliopausa onde o vento solar e o interestelar estão em equilíbrio e, por fim, acredita-se na existência de uma frente de choque (bow shock) causada pelo heliosfera na direção em que o Sol (e o Sistema Solar) se desloca.

Em 25 de agosto de 2012 a Voyager 1 deixou a heliosfera e notou-se que, subitamente, as medidas na quantidade de partículas por segundo diminuíram drasticamente (figura 9.19) e a quantidade de raios cósmicos aumentou significativamente (figura 9.20).

\footnotetext{
${ }^{46}$ Não há uma nomenclatura em português para as regiões da heliosfera, exceto para a heliopausa;
} 


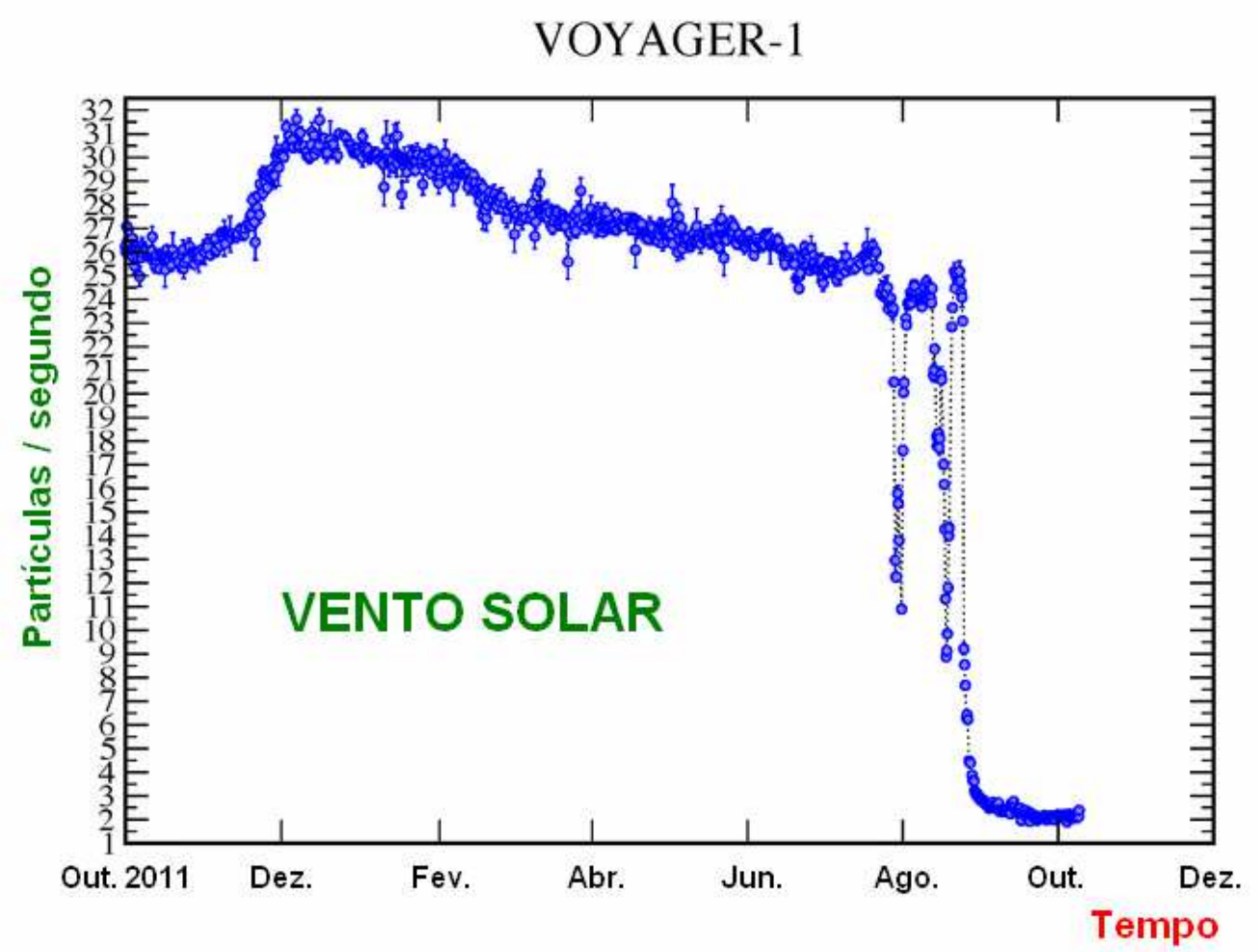

Fig. 9.19 - Drástica diminuição na contagem de partículas registrada pelos equipamentos da Voyager 1 no período de outubro de 2011 a outubro de 2012. Adaptada pelo autor do gráfico publicado em https://en.wikipedia.org/wiki/Voyager_1

Registrou-se, ainda, que a densidade de plasma aumentou ao redor de 40 vezes. Considerando que a heliosfera marca o limite entre o vento solar e o meio interestelar, costuma-se considerar que a Voyager 1 atingiu o espaço interestelar. ${ }^{47}$

Em setembro de 2012, a Voyager 1 encontrava-se a 16,89 horas-luz ${ }^{48}$ distante do Sol, correspondendo à cerca de 121 unidades astronômicas ou 18,2 bilhões de quilômetros. A magnitude aparente do Sol, na distância em que se encontrava a Voyager 1, correspondia a -16,3 (muito brilhante) - cerca de 30 vezes mais brilhante do que a Lua Cheia. A Voyager 1 desloca-se em direção à constelação de Ophiuchus.

\footnotetext{
${ }^{47}$ Alguns astrônomos utilizam a heliopausa para estabelecer um limite para o Sistema Solar.

${ }^{48}$ A hora-luz é uma unidade de distância que corresponde à distância percorrida pela luz em uma hora. Seu valor, em quilômetros, é aproximadamente igual a $1,079 \times 10^{9} \mathrm{~km}$.
} 


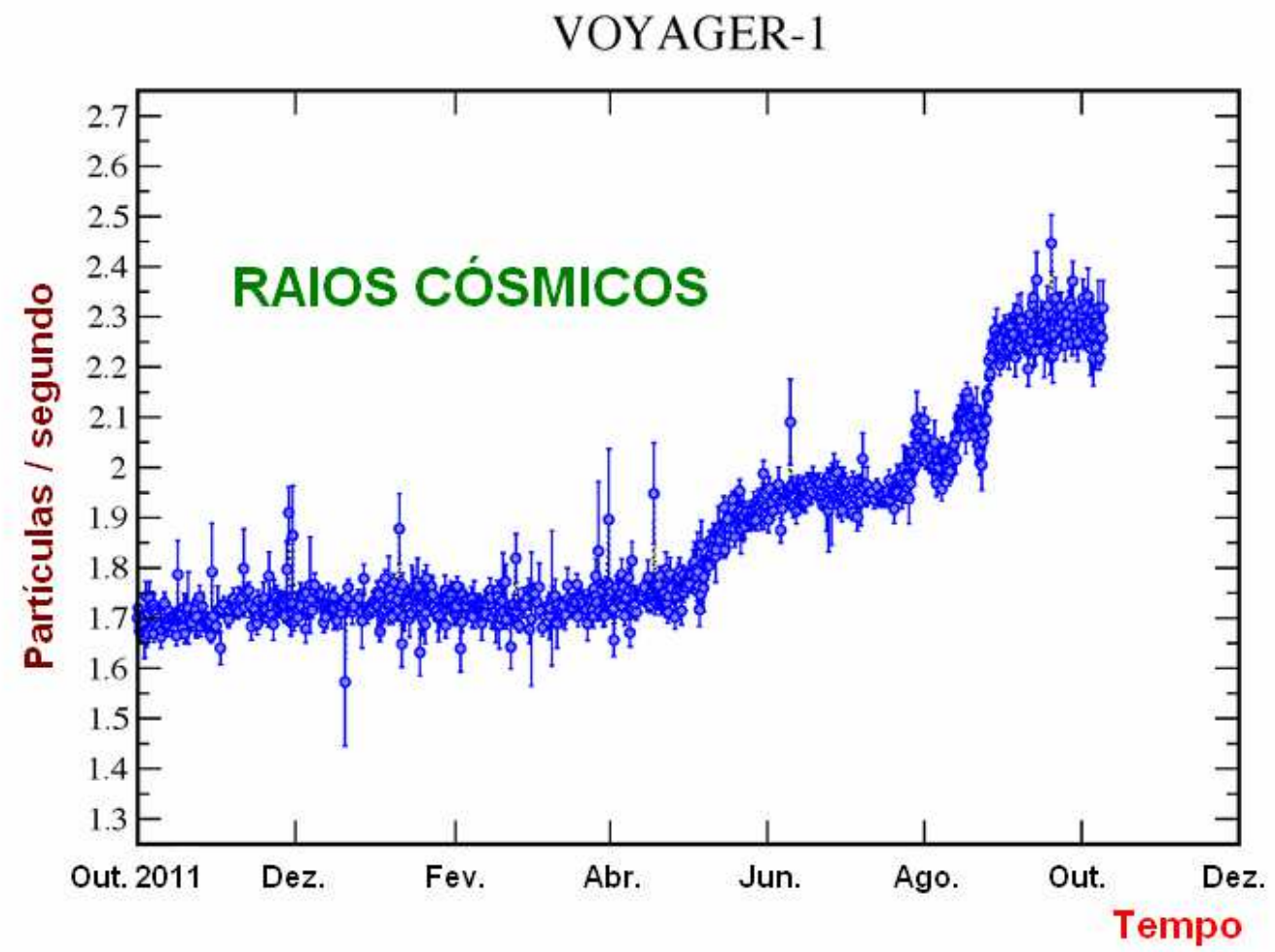

Fig. 9.20 - Aumento significativo na contagem de raios cósmicos registrados pelos equipamentos da Voyager1 no período de outubro de 2011 a outubro de 2012. Adaptada pelo autor do gráfico publicado em https://en.wikipedia.org/wiki/Voyager_1 


\section{0 - A HELIOSISMOLOGIA}

\section{1 - Oscilações estelares}

Excetuando-se as repentinas aparições de estrelas novas e supernovas registradas desde a antiguidade até o século XVI, as estrelas eram consideradas imutáveis. Em 1596, no entanto, um pároco da Frísia ${ }^{70}$ chamado David Fabricius (1564-1617) notou que uma estrela da constelação de Cetus (Baleia) permanecia brilhando durante umas poucas semanas e permanecia invisível durante alguns meses. Foi designada por Omicron Ceti, em 1603, por Johann Bayer em sua Uranometria e, posteriormente, por Mira (que significa Maravilhosa, em latim), por Johannes Hevelius em sua Historiola Mirae Stellae (1662).

A partir dessa descoberta outras estrelas de brilho variável foram observadas. Algumas tinham seu brilho alterado pela presença de uma estrela companheira que periodicamente a eclipsava e outras por fenômenos intrínsecos a elas. Nessa última categoria estavam as estrelas Mira, a $\delta$ Cephei, descoberta por John Goodricke em 1784 e várias outras estrelas acessíveis sem o uso de telescópios. O mecanismo de variabilidade dessas estrelas era, basicamente, uma pulsação. Foi essa a conclusão que chegou o astrônomo russo Aristarkh Apollonovich Belopolskii (1854-1934), em 1894, que notou deslocamentos nas linhas espectrais da estrela $\delta$ Cephei e deduziu que a atmosfera da estrela estava aumentando e diminuindo de raio periodicamente (oscilações radiais). As pulsações para algumas estrelas ocorriam em curtos intervalos de tempo (de alguns dias) e, em outras, em intervalos mais longos (de semanas a meses).

A teoria das oscilações radiais das estrelas foi desenvolvida pelo astrônomo inglês Sir Arthur Stanley Eddington (1882-1944) em 1917. Na teoria desenvolvida por Eddington, ele considerou uma estrela gasosa com pulsações radiais adiabáticas obtendo uma relação entre o período de pulsação e a densidade média da estrela.

\footnotetext{
${ }^{70}$ A Frísia corresponde, hoje, à região situada no noroeste da Alemanha e nordeste da Holanda.
} 
Ele propôs que a mudança de transparência na atmosfera causa as pulsações: a atmosfera opaca retém o calor e causa a expansão, que por sua vez causa a redução da opacidade permitindo que a luz escape, esfriando a atmosfera e causando a contração (colapso). Em 1960, o astrônomo americano John Paul Cox (1926-1984) descobriu que a ionização parcial do hélio era a fonte de opacidade que fazia as Cefeidas pulsarem.

\section{2 - Oscilações solares}

A existência de estrelas que apresentavam pulsações certamente levantou a questão sobre a possibilidade de nossa estrela - o Sol - apresentar, também, algum tipo de variabilidade, algum tipo de oscilação ou, mesmo, uma pulsação.

Em 1960 foram detectadas por Robert Leighton, Robert Noyes e George Simon, oscilações no Sol, com período de cinco minutos, por meio de medidas de deslocamento Doppler das linhas de Fraunhofer em vários pontos do disco solar distantes das regiões ativas. As oscilações eram rítmicas correspondendo a ascensão e a queda de regiões da fotosfera e da baixa cromosfera com milhares de quilômetros de extensão.

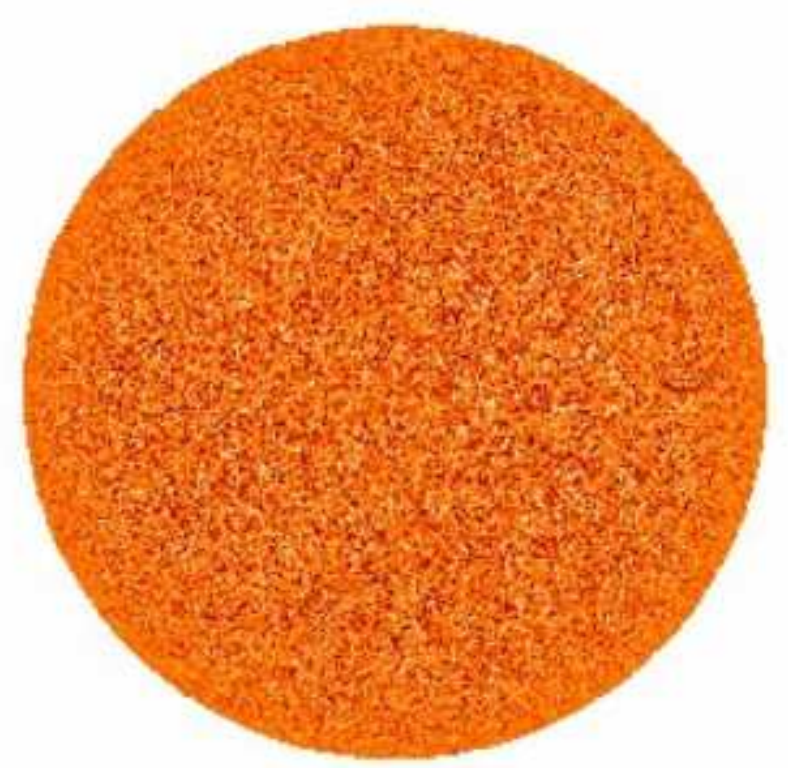

Fig. 10.1 - Oscilações observadas com períodos de cerca de 5 minutos no disco solar. Imagens desse tipo são chamadas de "Dopplergramas". As cores mais escuras indicam movimentos na direção do observador (aproximação) e as cores claras indicam movimentos de afastamento em relação ao observador. Fonte: http://nisp.nso.edu/solar_interior_contd 
Essas oscilações, com períodos de cerca de 300 s (5 minutos), persistiam em cada região por menos de meia hora e atingiam a velocidade máxima de $0,5 \mathrm{~km} / \mathrm{s}$. Acredita-se que essas oscilações sejam produzidas por ondas sonoras de baixa frequência geradas pela turbulência na zona convectiva e que se dirigem para fora dela em direção à fotosfera. $\mathrm{Na}$ figura 8.1, página 73 , pode-se notar a presença de uma região chamada de zona convectiva turbulenta bem próxima à fotosfera. A análise da ocorrência global dessas oscilações, em um extenso intervalo de tempo, permite elaborar um imageamento do interior solar.

\section{3 - Heliosismologia}

Além das oscilações com período de 5 minutos descobertas em 1960, em janeiro de 1976, dois artigos foram publicados na revista Nature relatando observações de oscilações solares com período de 160 minutos (2h 40min): Observations of solar pulsations, no volume 259, January 15, pp. 87-89 de autoria de A. B. Severny, V. A. Kotov and T. T. Tsap e Observation of free oscillations of the sun, no volume 259, January 15, pp. 92-95, de autoria de J. R. Brookes, G. R. Isaak e H. B van der Raay.

Com isso, o estudo das oscilações solares passou a ser objeto de pesquisa específica e nasceu um novo campo da física solar: a heliosismologia. O termo vem das seguintes palavras em grego: helios (Sol), seismos (abalo) e logos (estudo).

A heliosismologia é um ramo da física solar que estuda o interior do Sol a partir das oscilações observadas em sua superfície. Nesse sentido, a heliosismologia é análoga à sismologia (a geo-sismologia) que estuda o que está abaixo da superfície da Terra através das ondas que se propagam no interior de nosso planeta. As ondas que se propagam no interior do Sol nos dão informações sobre as suas camadas internas.

O interior solar é bastante opaco à propagação da radiação produzida no núcleo pelas reações nucleares. No entanto, é muito transparente aos neutrinos e às ondas acústicas. A análise da propagação das ondas acústicas no interior solar é muito semelhante ao processo do ultrassom que permite produzir imagens do interior do corpo humano. 
Instrumentos utilizados nas observações das oscilações solares são: espectrógrafos com redes de difração, filtros de interferência de banda estreita, imageadores e tacômetro de Fourier. Esses equipamentos monitoram mais de 60.000 pontos do disco solar simultaneamente. Há extensos programas de monitoramento como por exemplo o Global Oscillations Network Group (GONG) e o continuo monitoramento heliosismológico realizado pelo $\mathrm{SOHO}$.

\section{4 - Modos de oscilação}

As oscilações solares são divididas em três tipos, baseados na força restauradora ${ }^{71}$ : $\mathrm{p}, \mathrm{g}$ e f. As ondas sonoras (p) produzem oscilações que são detectadas na fotosfera e podem ser utilizadas para determinar as propriedades internas do Sol até a profundidade de $0,2 \mathrm{R}_{\odot}$. As ondas de gravidade ( $\mathrm{g}$ ) nunca atingem a fotosfera e são refletidas para o interior do Sol atingindo o núcleo. As ondas de gravidade superficial (f) são também ondas de gravidade mas ocorrem na fotosfera ou próximo a ela.

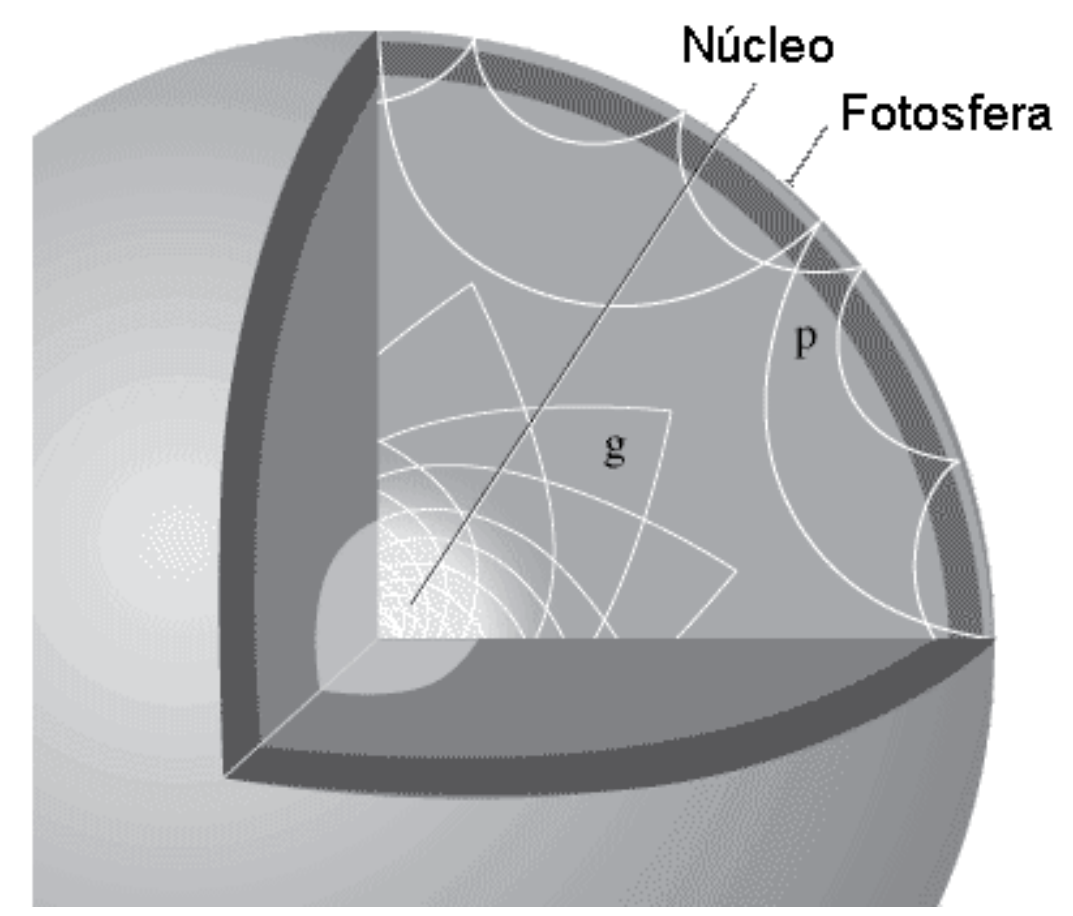

Fig. 10.2 - Trajetórias de ondas sonoras (modo-p) e ondas de gravidade (modo-g) no interior solar. Diagrama obtido em https://ase.tufts.edu/cosmos/print_images.asp?id=25 (modificado pelo autor).

\footnotetext{
${ }^{71}$ Recordando ao leitor, a força restauradora é a força que atua em movimentos periódicos restituindo o movimento do sistema.
} 
Modo-p: são ondas acústicas em que a força restauradora é a força que causa a pressão, daí o seu nome. Esse modo é determinado pela variação de velocidade do som no interior solar. Oscilações do modo-p têm frequências superiores a $1 \mathrm{MHz}$ e são bastante intensas no intervalo que vai de 2 a $4 \mathrm{MHz}$.

As oscilações se assemelham às produzidas em ressonadores acústicos esféricos, isto é, grandes esferas ocas com um pequeno orifício em sua superfície. Se colocarmos um diapasão a vibrar nas proximidades do orifício, isto excitará a massa de gás no interior da esfera. Se a frequência do diapasão coincidir com alguma das frequências de oscilação da massa de gás, observaremos a amplificação do som. Os modos-p na superfície solar têm amplitudes de centenas de quilômetros e são detectados com facilidade pelo efeito Doppler.

Modo-g: são ondas que têm a gravidade como força restauradora, daí seu nome de modog. As oscilações do modo-g são de baixa frequência (até $0,4 \mathrm{MHz}$ ) e estão confinadas no interior do Sol, abaixo da zona de convecção. Praticamente não podem ser observadas na superfície solar. Como a variação de temperatura não é muito pronunciada na zona de radiação, quando uma pequena porção de gás se move para cima, ele ficará mais frio e mais denso do que o gás ao seu redor e será trazido de volta à sua posição original pela força da gravidade.

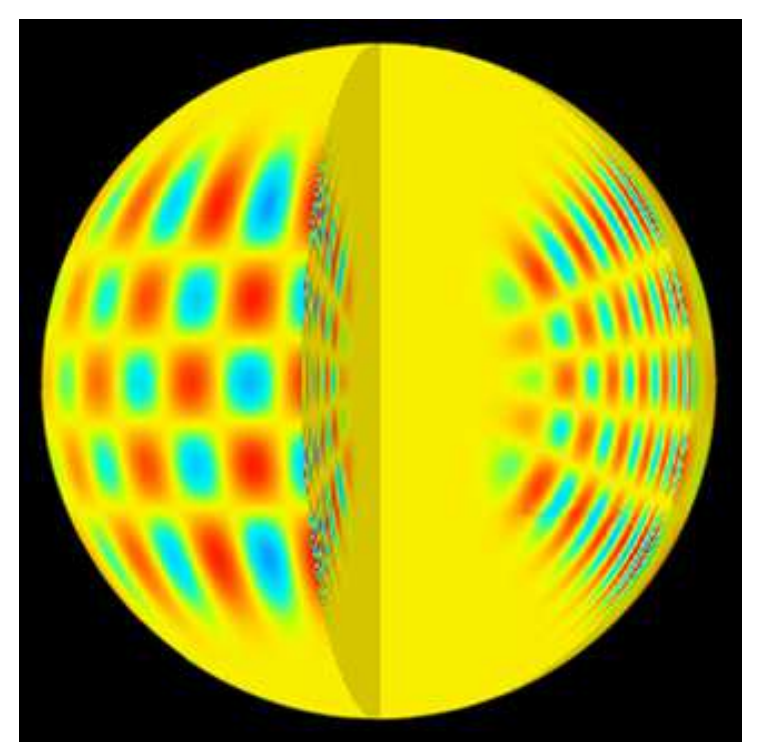

Fig. 10.3 - Oscilações no modo-p observadas no Sol. Imagem gerada por computador. As regiões em azul se aproximam do observador enquanto as regiões avermelhadas se afastam. Fonte: https://pt.wikipedia.org/wiki/Heliosismologia 
Modo-f: modo de gravidade na superfície, como ondas no oceano, só que na superfície de uma estrela.

As estrelas e o Sol têm comportamento mais complexo que os ressonadores acústicos esféricos pois o gás que as compõe não apresenta densidade constante e nem são homogêneos em suas composições.

Nas estrelas do tipo solar os modos-p são dominantes já que o modo-g está confinado no interior pela zona de convecção. Modos-g, no entanto, têm sido observados em estrelas anãs brancas pulsantes.

\section{5 - Modos de oscilação: como se estudam}

Os diversos modos de oscilação do modo-p (predominante no Sol) são estudados matematicamente com uma técnica que não está ao nível deste curso. Vamos fazer uma breve apresentação de como esse estudo é feito. Na física, e em vários outros ramos de estudos, é comum se considerar um sistema de coordenadas esféricas, como mostrado na figura 10.4:

A posição de um ponto $\mathrm{P}$ fica determinada por três valores: sua distância $\mathbf{r}$ até o ponto $\mathrm{O}$, origem do sistema de coordenadas (centro da esfera), pelo ângulo $\boldsymbol{\theta}$, chamado colatitude e pelo ângulo $\phi$, denominado ângulo azimutal. Quando se utiliza um sistema de coordenadas com centro no Sol e eixo $\mathrm{Z}$ coincidente com o eixo de rotação solar, as coordenadas $\boldsymbol{\theta}$ e $\phi$ estão relacionadas à coordenadas heliográficas. 


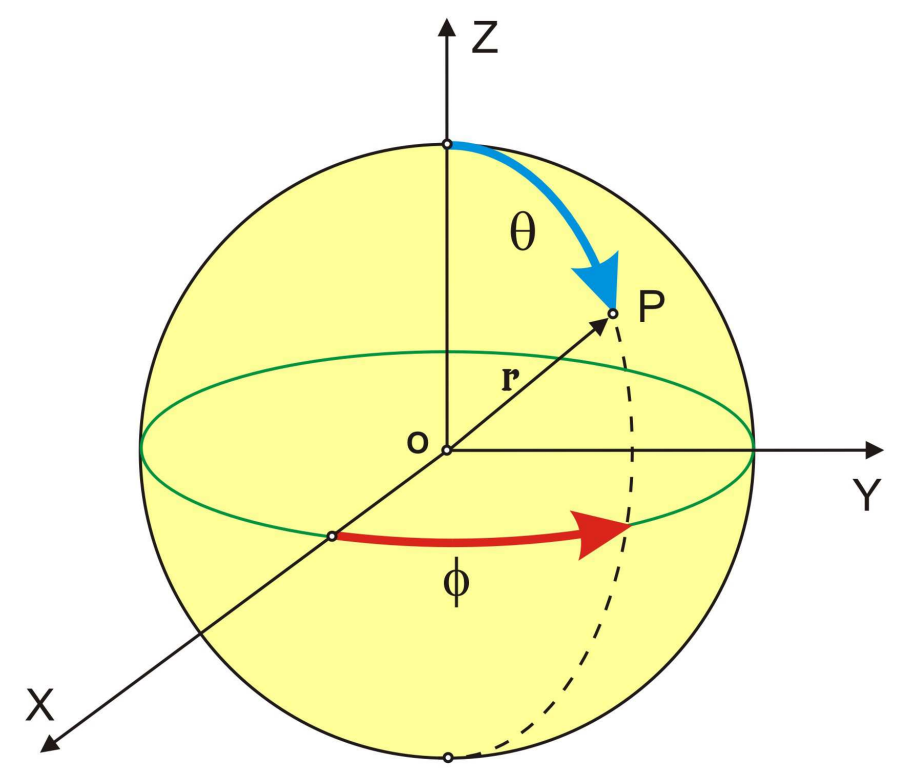

Fig. 10.4 - Sistema de coordenadas esféricas.

As oscilações observadas na superfície e no interior do Sol são descritas pelos chamados harmônicos esféricos que utilizam esse sistema de coordenadas. Assim, as oscilações são proporcionais à expressão:

$$
\mathrm{R}_{\mathrm{n}}(\mathrm{r}) . \mathrm{Y}_{\ell, \mathrm{m}}(\theta, \phi)
$$

$\mathrm{O}$ termo $R_{n}(r)$ descreve as oscilações radiais, enquanto que $Y_{\ell, m}(\theta, \phi)$ descreve a parte angular das oscilações. Cada modo de oscilação é caracterizado por um conjunto de valores para $n, \ell$ e m. Na figura 10.3, as oscilações representadas correspondem à: $n=14, \ell$ $=20$ e $\mathrm{m}=16$. O número $\mathbf{n}$ indica a quantidade de zeros da função $R_{n}(r) ; \boldsymbol{l}$ a quantidade de zeros da função $\mathrm{Y}_{\ell, m}$ e $\mathbf{m}$ um número associado à rotação do astro. $\mathrm{O}$ número m apresenta valores que obedecem à relação: $|\mathrm{m}|<\boldsymbol{\ell}$. Nas figuras adiante, estão ilustrados outros modos de oscilação para diversos valores de $\ell$ e m: 

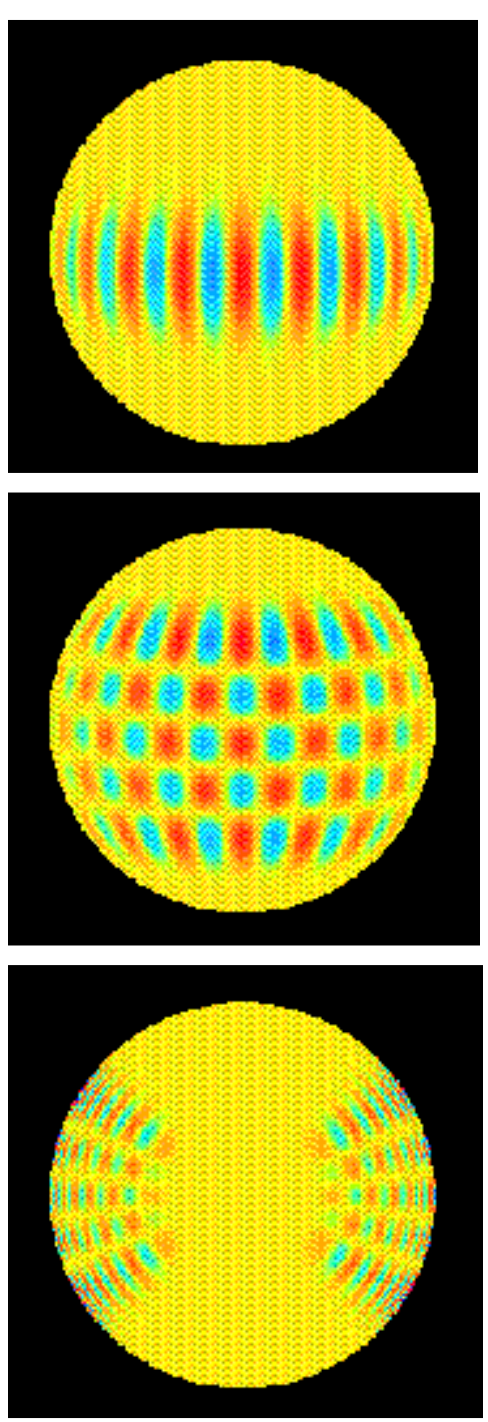

Estão aqui representadas as oscilações na superfície com $\ell=19$ e $\mathrm{m}=19$. Há 19 círculos passando pelos pólos do Sol e cruzando o equador solar. Neste modo-p a superfície se movimenta em direção ao observador (regiões em azul) e nas adjacentes (em vermelho) se afastando do observador.

Nesta simulação feita em computador, mostram-se as oscilações para $l=19$ e $\mathrm{m}=15$. Temos, agora, 15 meridianos e 4 linhas nodais paralelas ao equador solar.

Aqui temos um corte do Sol mostrando as oscilações para $n=11, \ell=19$ e $m=15$. Há 11 zeros na função $R_{n}(r)$ e estão destacadas as 11 reversões nas camadas entre a superfície e o núcleo.

Fig. 10.5 - Diversos modos-p de oscilação para diferentes valores de $n, \quad l$ m. Fonte: http://soi.stanford.edu/press/ssu8-97/pmodes.html

\section{6 - O que nos trouxe a heliosismologia}

Com a heliosismologia novos conhecimentos sobre o Sol e seu interior, assim como dos interiores estelares, foram adquiridos. Entre eles, destacamos:

1. A rotação com diferentes velocidades na zona convectiva e na zona radiativa, o que gera o campo magnético do Sol na camada que separa estas duas zonas - a tacoclina; 
2. Como a velocidade interna de rotação é uniforme (ou praticamente uniforme), isto indica que o interior solar não perde momento angular. Por outro lado, os ventos solares e as ejeções de matéria por parte da atmosfera solar, contribuem para a perda de momento angular total do Sol.

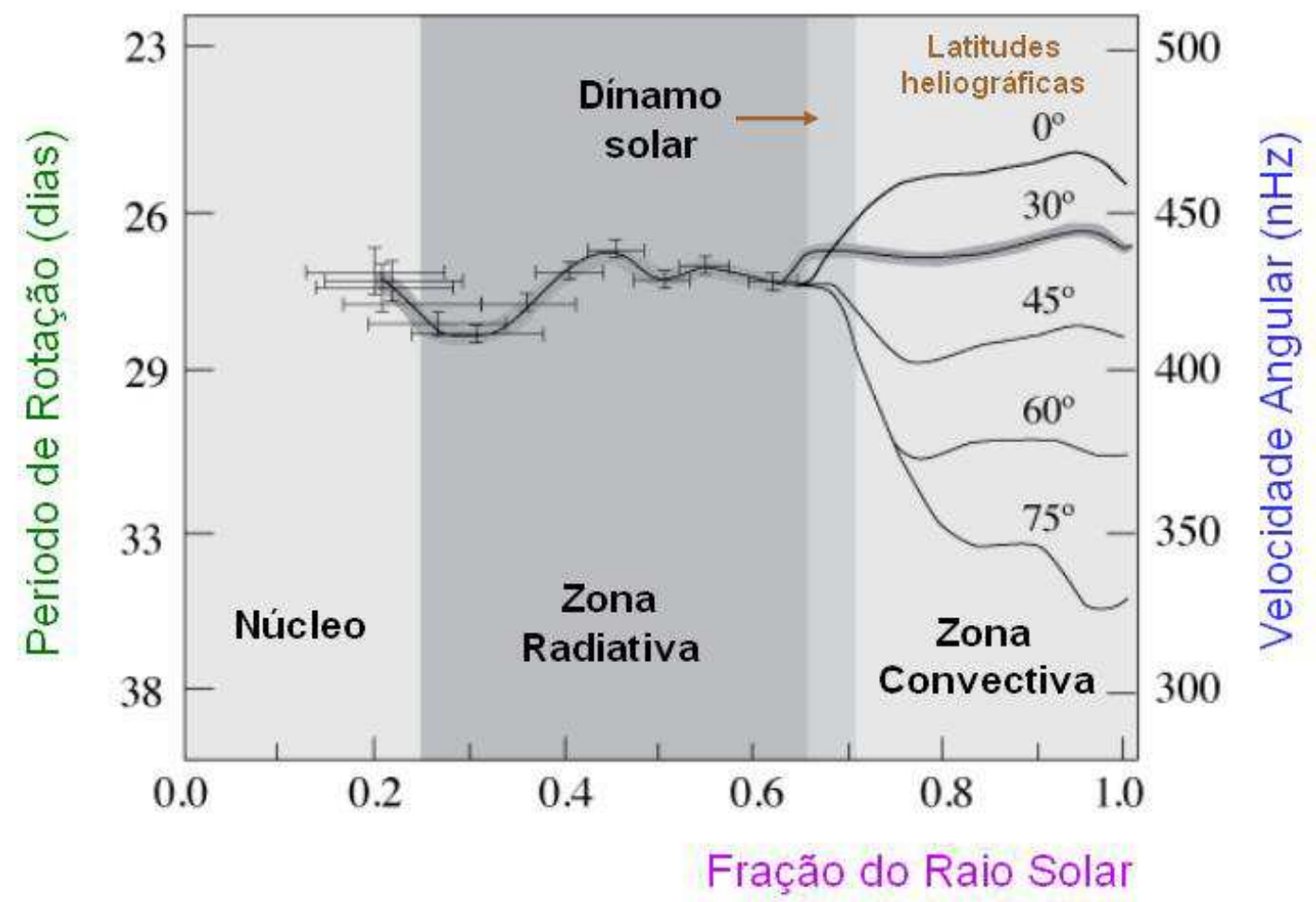

Fig. 10.6 - As diferentes velocidades de rotação solar em suas diferentes camadas. Figura editada pelo autor a partir de gráfico publicado em: http://www.sunorbit.net/new_facts.htm

A heliosismologia nos trouxe, enfim, respostas para uma série de questões, algumas das quais com uma precisão inesperada. Aprendemos como a velocidade do som e a densidade da matéria variam ao longo de quase toda a matéria solar, o que nos parecia impossível conhecer. Aprendemos como o Sol executa seu movimento de rotação e como a matéria flui no interior solar e na região das manchas solares. Também aprendemos sobre transporte de energia do centro para a superfície, a distribuição do momento angular em suas diversas camadas e, ainda, sobre o dínamo solar.

O que acabamos de ver neste breve capítulo nos remete à necessidade da elaboração de um trabalho específico e circunscrito à heliosismologia que, no entanto, ultrapassa o escopo desta dissertação pela necessidade de conceitos físicos e ferramentas matemáticas. 


\section{CONCLUSÕES}

Os capítulos aqui apresentados fizeram parte de diversos cursos da Escola Municipal de Astrofísica dirigidos ao público em geral e aos professores da rede municipal de ensino durante alguns anos. Os tópicos permitiram - e permitem - cobrir os principais temas da Física Solar de forma atualizada. Reunidos em um conjunto constituem-se em um material que pode ser utilizado tanto no aperfeiçoamento de professores como para estudantes dos cursos de licenciatura em ciências. Os assuntos escolhidos permitem ilustrar capítulos da física tradicional abordados no ensino médio e na física superior atendendo a necessidade de se expor exemplos onde os tópicos estudados se aplicam. 


\title{
Apêndice 1
}

\section{TABELA A1.1 - DADOS NUMÉRICOS DO SOL}

\author{
01 Diâmetro \\ 02 Diâmetro (Terra $=1)$ \\ 03 Diâmetro aparente à distância de 1 UA \\ 04 Diâmetro aparente máximo \\ 05 Diâmetro aparente mínimo \\ 06 Massa \\ $07 \quad$ Massa $($ Terra $=1)$ \\ 08 Massa $($ Terra + Lua $=1)$ \\ 09 Volume \\ 10 Volume $($ Terra $=1)$ \\ 11 Densidade média \\ 12 Densidade média $($ Terra $=1)$ \\ 13 Densidade central \\ 14 Área da superfície \\ 15 Área da superfície $($ Terra $=1)$ \\ 16 Achatamento \\ 18 Aceleração da gravidade na superfície $($ Terra $=1)$ \\ 19 Velocidade de escape na superfície \\ 20 Momento de Inércia $\left(1 / \mathrm{MR}^{2}\right)$ \\ 21 Temperatura efetiva na superfície \\ 22 Temperatura no centro \\ 23 Pressão na superfície \\ 24 Pressão no centro \\ 25 Velocidade de rotação no equador \\ 26 Inclinação do equador solar com a Eclíptica \\ 27 Longitude do nodo asc. do equador com a Eclíptica \\ 28 Período de rotação sideral no equador \\ 29 Período de rotação sinódica no equador \\ 30 Período de rotação no paralelo de $30^{\circ}$ de latitude
}

$1,39198 \times 10^{6} \mathrm{~km}$

109,3

$31^{\prime} 59,26 "$

32 ' 32"

$31^{\prime} 28 "$

$1,9891 \times 10^{30} \mathrm{~kg}$

$332.946,0$

$328.900,5$

$1,4138 \times 10^{27} \mathrm{~m}^{3}$

1.305 .240

$1,408 \times 10^{3} \mathrm{~kg} / \mathrm{m}^{3}$

0,245

$1,622 \times 10^{5} \mathrm{~kg} / \mathrm{m}^{3}$

$6,092 \times 10^{18} \mathrm{~m}^{2}$

11.950

0

$273,98 \pm 0,04 \mathrm{~m} / \mathrm{s}^{2}$

27,9

$617,7 \mathrm{~km} / \mathrm{s}$

0,070

$5.770 \mathrm{~K}$

$1,5 \times 10^{7} \mathrm{~K}$

$0,001 \mathrm{~atm}$

$10^{10} \mathrm{~atm}$

$2,04 \mathrm{~km} / \mathrm{s}$

$7^{\circ} 1^{\prime}$

74을 22' (2000.0)

25,38 dias $=609,12$ horas

27,275 dias

26,5 dias 
31 Período de rotação no paralelo de $45^{\circ}$ de latitude

32 Luminosidade $(\mathrm{L})$

33 Fluxo superficial $\left(L / 4 \pi R^{2}\right)$

34 Fluxo à distância de $1 \mathrm{UA}\left(\mathrm{L} / 4 \pi \mathrm{a}^{2}\right)$ (Constante Solar)

35 Magnitude aparente visual (V)

$36 \quad$ Magnitude aparente bolométrica $\left(\mathrm{m}_{\text {bol }}\right)$

37 Magnitude absoluta visual $\left(\mathrm{M}_{\mathrm{V}}\right)$

38 Magnitude absoluta bolométrica $\left(\mathrm{M}_{\text {bol }}\right)$

39 Índice de cor (B - V)

40 Índice de cor (U - B)

41 Distância à Terra $(1 \mathrm{UA}=1 \mathrm{~A})$

42 Paralaxe (IAU - 1976)

43 Tempo que leva a luz do Sol à Terra

44 Valor de 1" à distância média do Sol

45 Classe espectral

46 Ápex - Ascensão Reta e Declinação

47 Ápex - Longitude e Latitude galácticas

48 Velocidade do Sistema Solar para o Ápex

49 Distância do Sol ao centro da Galáxia

50 Velocidade em torno do centro da Galáxia

51 Período de revolução em torno do centro galáctico

52 Idade do Sol

53 Tempo de permanência na Seqüência Principal

54 Duração média de um ciclo de manchas solares
27 dias

$3,846 \times 10^{26} \mathrm{~W}$

$6,34 \times 10^{7} \mathrm{~W} / \mathrm{m}^{2}$

$1,3676 \times 10^{3} \mathrm{~W} / \mathrm{m}^{2}$

$-26,72$

$-26,82$

$+4,85$

$+4,75$

$+0,65$

$+0,13$

$1,49597870 \times 10^{8} \mathrm{~km}$

$8,794148 "$

$499,004782 \mathrm{~s}=8 \mathrm{~min} 19,0 \mathrm{~s}$

$725,27 \mathrm{~km}$

G2 V

$\mathrm{AR}=18 \mathrm{~h} 04 \mathrm{~m} / \mathrm{Dec}=+30^{\circ}$

$\ell^{\prime \prime}=57^{\circ} / b^{\prime \prime}=+22^{\circ}$

$(19,7 \pm 0,5) \mathrm{km} / \mathrm{s}$

$8,5 \mathrm{kpc}$

$220 \mathrm{~km} / \mathrm{s}$

$2,2 \times 10^{8}$ anos

$5 \times 10^{9}$ anos

$10^{10}$ anos

11,2 anos

TABELA A1.2 - ABUNDÂNCIAS DE ELEMENTOS QUÍMICOS NO SOL

\section{ELEMENTO}

ABUNDÂNCIA

POR ÁTOMOS

\begin{tabular}{lcc}
\hline \hline Hidrogênio $(\mathrm{H})$ & $90,9 \%$ & $71,0 \%$ \\
\hline Hélio $(\mathrm{He})$ & $8,9 \%$ & $27,1 \%$ \\
\hline $\mathrm{O}, \mathrm{C}, \mathrm{N}, \mathrm{Si}, \mathrm{Mn}, \mathrm{Ne}, \ldots$ & $0,2 \%$ & $1,9 \%$ \\
\hline
\end{tabular}

ABUNDÂNCIA
EM MASSA 


\section{Apêndice 2: O TEOREMA DO VIRIAL}

O físico alemão Rudolf Julius Emanuel Clausius (1822-1888), inspirado nos trabalhos sobre o calor desenvolvidos pelo engenheiro francês N. L. Sadi Carnot (17961832), começou a desenvolver estudos sobre a natureza mecânica do calor em 1851. Seus estudos, que se desenvolveram por mais de vinte anos, levaram à formulação do que hoje chamamos de teorema do virial.

Em 13 de junho de 1870, em uma apresentação na Associação de Ciências Naturais e Médicas do Baixo Reno, intitulada "On a Mechanical Theorem Applicable to Heat", ele apresenta o teorema: "A vis viva média de um sistema é igual ao seu virial". Naquela época era comum utilizar-se de expressões latinas para designar algumas grandezas físicas associadas a um sistema. Os estudantes de física superior sabem que a vis viva é a energia cinética total de um sistema. Clausius utilizava a expressão latina virias (plural de vis), que significa forças, para designar a expressão utilizada no teorema.

A quantidade escalar que ele chamava de virial pode ser representada, em termos das forças $\vec{F}_{i}$ que atuam no sistema, por:

$$
\frac{1}{2} \sum \vec{F}_{i} \cdot \vec{r}_{i}
$$

e pode-se mostrar que ela corresponde à metade da energia potencial do sistema.

Em um sistema de partículas interagindo gravitacionalmente, se a energia cinética média do sistema $E_{C}$ e a energia potencial média do sistema $E_{P}$ não variarem significativamente no tempo, então:

$$
E_{C}=-\frac{1}{2} E_{P}
$$

Se considerarmos uma partícula de massa $m$ em órbita circular de raio $\mathrm{R}$ ao redor de um corpo de massa $M$, teremos: 


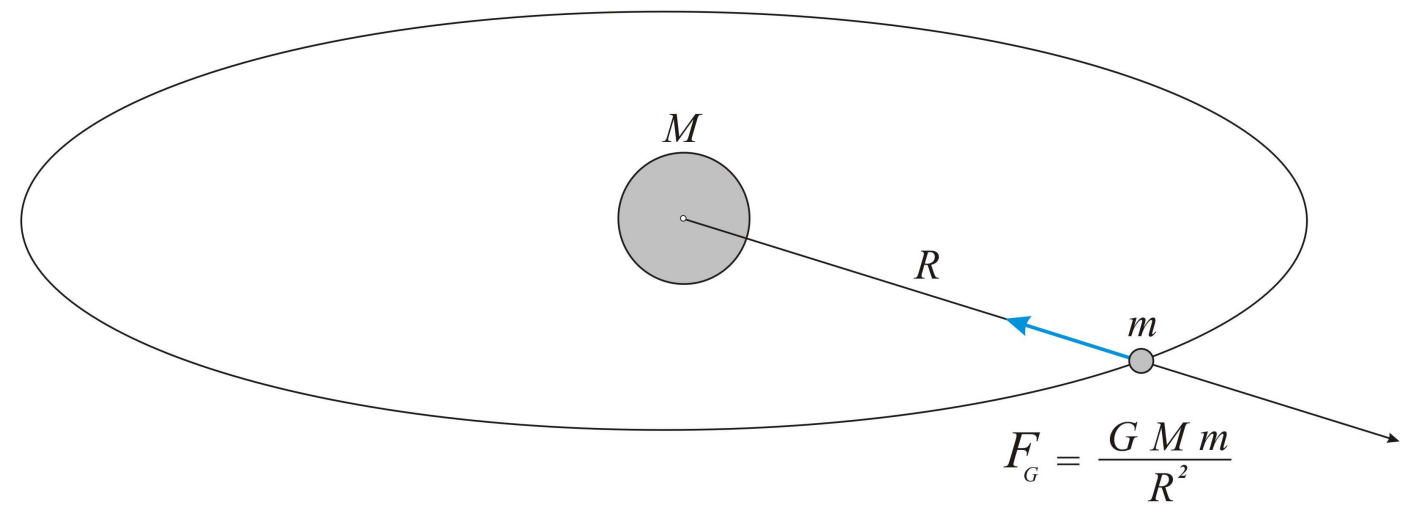

Fig.A2.1 - Sistema composto por dois corpos de massas M e m, onde o corpo de massa m realiza um movimento circular ao redor do outro, com órbita de raio R.

a) A energia potencial da partícula de massa $\boldsymbol{m}$ será:

$$
E_{P}=-\frac{G m M}{R}
$$

b) A força de atração gravitacional que $M$ exerce sobre $\boldsymbol{m}$ é dada por:

$$
F_{G}=-\frac{G m M}{R^{2}}
$$

A força de atração gravitacional sobre $m$ é a força centrípeta:

$$
F_{C}=-\frac{m V^{2}}{R}
$$

de maneira que, igualando $F_{G} \operatorname{com} F_{C}$, teremos:

$$
\frac{G m M}{R^{2}}=\frac{m V^{2}}{R}
$$

tirando dessa relação o valor de $\mathrm{V}^{2}: \quad V^{2}=\frac{G M}{R}$ 
e, substituindo o valor de $V^{2}$ na expressão da energia cinética da partícula, teremos:

$$
E_{C}=\frac{m V^{2}}{2}=\frac{m G M}{2 R}
$$

o que permite concluir que $\quad E_{C}=-\frac{E_{P}}{2}$

O teorema do virial não é somente aplicável aos sistemas dinâmicos e termodinâmicos mas, também, pode ser formulado para ser aplicado aos sistemas relativísticos (relatividade restrita) e, ainda, aos sistemas com velocidades dependentes de forças, sistemas viscosos, sistemas com campos magnéticos e sistemas que mostram movimentos macroscópicos como rotação, por exemplo.

$\mathrm{Na}$ astrofísica, o teorema do virial tem inúmeras aplicações. Ele pode ser aplicado, por exemplo, aos aglomerados de estrelas em fase de evolução avançada, às galáxias elípticas, aos aglomerados de galáxias em fase de evolução avançada. O teorema não se aplica, no entanto, para as seguintes situações: aglomerados de estrelas jovens, às galáxias em colisão e aos aglomerados de galáxias em fase de formação. 


\section{Apêndice 3}

\section{CENTRO DE MASSA DO SISTEMA SOLAR}

Para determinar a posição do centro de massa do Sistema Solar, vamos utilizar um sistema de coordenadas heliocêntricas retangulares, adiante descrito.

\section{A3.1 - Coordenadas esféricas eclípticas heliocêntricas}

As posições dos astros do Sistema Solar ficam determinadas pelas suas coordenadas esféricas heliocêntricas, isto é, referidas ao centro do Sol. Adota-se como plano fundamental o plano da órbita da Terra ou plano da eclíptica.

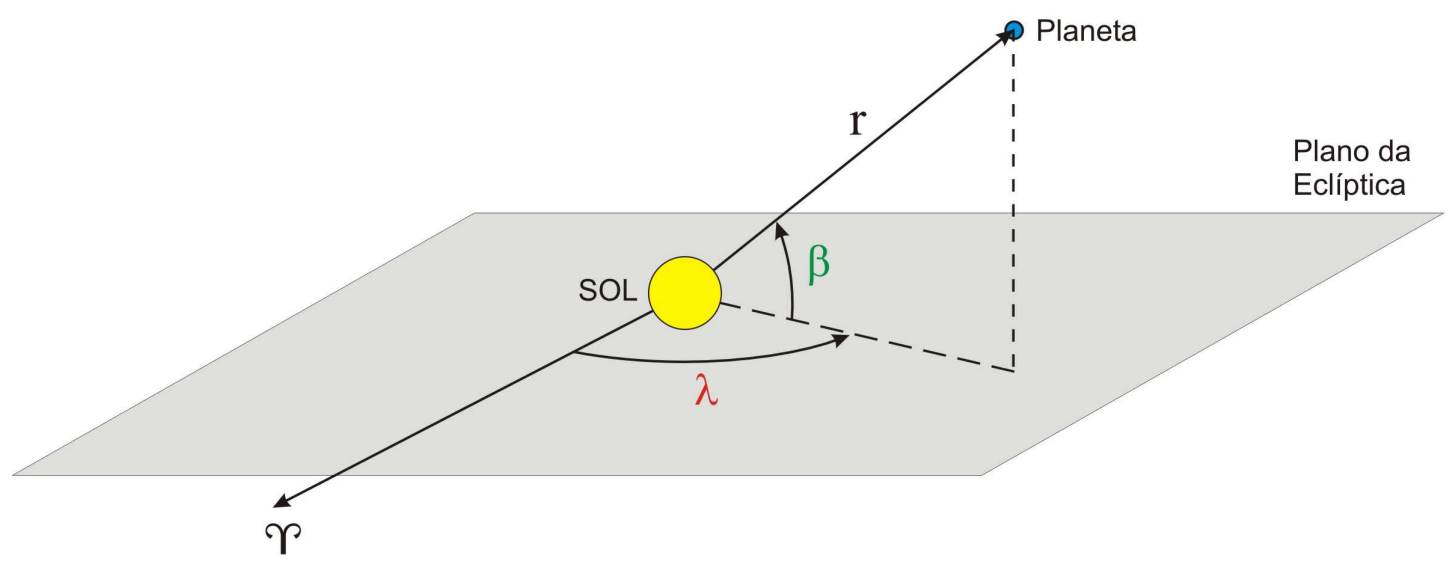

Fig. A3.1 - Sistema de coordenadas esféricas eclípticas heliocêntricas. A posição de um planeta fica determinada pela sua latitude celeste $(\beta)$, pela sua longitude celeste $(\lambda)$ e pela sua distância ao Sol (r).

A posição de um planeta, por exemplo, fica determinada por três valores:

r - distância do centro do Sol ao centro do planeta; 
$\beta$ - latitude celeste heliocêntrica - indica o afastamento angular de um astro em relação ao plano da eclíptica, contado positivamente para o norte e negativamente para o sul da eclíptica;

$\lambda$ - longitude celeste heliocêntrica - ângulo entre a direção do ponto vernal $(\Upsilon)$ e a projeção de $\mathbf{r}$ sobre o plano da eclíptica, contado no sentido da regra da mão direita.

\section{A3.2 - Coordenadas heliocêntricas retangulares}

Utiliza-se um sistema cartesiano tri-ortogonal convencional, com origem no centro do Sol, com o eixo $\mathrm{X}$ coincidindo com a direção do ponto vernal e o eixo $\mathrm{Z}$ perpendicular ao plano da Eclíptica. O eixo Y encontra-se, evidentemente, no plano da Eclíptica e situado a $90^{\circ}$ do eixo X, obedecendo a chamada "regra da mão direita".

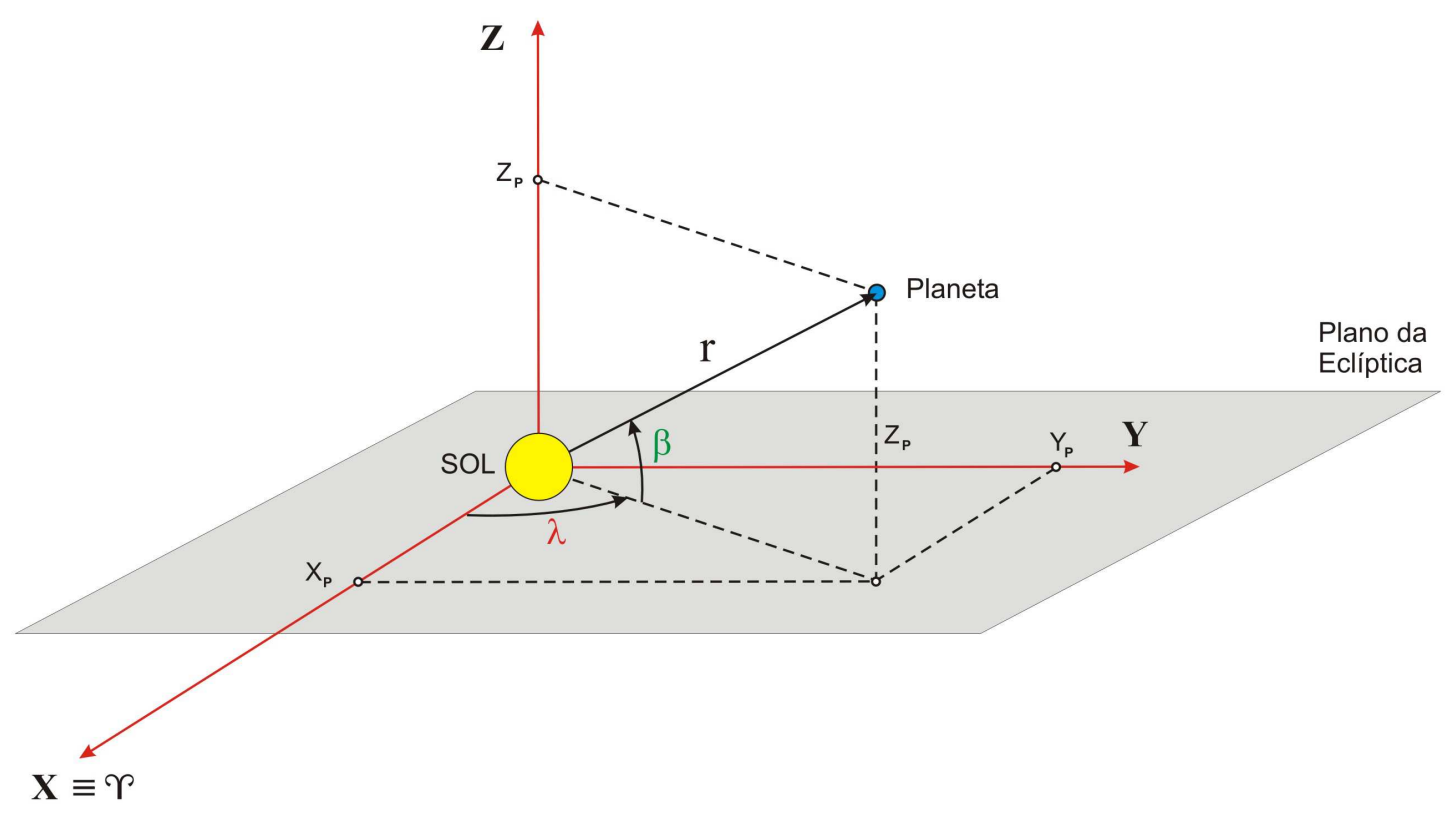

Fig. A3.2 - Sistema de coordenadas heliocêntricas retangulares.

As coordenadas dos astros neste sistema relacionam-se com as suas coordenadas no sistema anterior pelas fórmulas: 


$$
X=r \cos \beta \cos \lambda \quad Y=r \cos \beta \sin \lambda \quad Z=r \sin \beta
$$

\section{A3.3 - Posição do Centro de Massa do Sistema Solar}

Para se determinar a posição do centro de massa CM, em um determinado instante, devemos conhecer as massas $m_{i}$ dos corpos que levaremos em consideração (em geral os planetas, que são os astros de maior massa) e as suas posições, no instante considerado, dadas pelas suas coordenadas esféricas eclípticas $(\mathrm{r}, \beta, \lambda)$. Uma vez de posse desses valores procedemos da seguinte maneira:

- Calculamos as coordenadas retangulares heliocêntricas dos planetas, utilizando, como vimos, as relações:

$$
\mathrm{X}_{\mathrm{P}}=\mathrm{r} \cos \beta \cos \lambda \quad \mathrm{Y}_{\mathrm{P}}=\mathrm{r} \cos \beta \sin \lambda \quad \mathrm{Z}_{\mathrm{P}}=\mathrm{r} \sin \beta
$$

- Determinamos, em seguida, a posição do centro de massa em coordenadas heliocêntricas retangulares $\left(\mathrm{X}_{\mathrm{CM}}, \mathrm{Y}_{\mathrm{CM}}\right.$ e $\left.\mathrm{Z}_{\mathrm{CM}}\right)$ pelas expressões:

$$
X_{C M}=\frac{\sum X_{i} m_{i}}{\sum m_{i}} \quad Y_{C M}=\frac{\sum Y_{i} m_{i}}{\sum m_{i}} \quad Z_{C M}=\frac{\sum Z_{i} m_{i}}{\sum m_{i}}
$$

- A distância do baricentro ao centro do Sol fica determinada por:

$$
R_{C M}=\sqrt{X_{C M}^{2}+Y_{C M}^{2}+Z_{C M}^{2}}
$$

- A latitude e a longitude heliocêntricas do centro de massa ( $\beta_{\mathrm{CM}}$ e $\lambda_{\mathrm{CM}}$ ) ficam conhecidas pelas expressões:

$$
\beta_{C M}=\arctan \left(\frac{Z_{C M}}{\sqrt{X_{C M}^{2}+Y_{C M}^{2}}}\right) \quad \text { e } \quad \lambda_{C M}=\arctan \left(\frac{Y_{C M}}{X_{C M}}\right)
$$


- Em geral, $\mathbf{r}$ é dado, nas efemérides astronômicas, em Unidades Astronômicas e, portanto, os valores de $\mathrm{X}, \mathrm{Y}, \mathrm{Z}, \mathrm{X}_{\mathrm{CM}}, \mathrm{Y}_{\mathrm{CM}}, \mathrm{Z}_{\mathrm{CM}}$ e $\mathrm{R}_{\mathrm{CM}}$ também estarão expressos nessa unidade. Para converter o valor de $\mathrm{R}_{\mathrm{CM}}$ para raios solares utilize a seguinte relação:

$$
1 \mathrm{R} \odot=0,0046524 \mathrm{UA} \quad \text { (adotando-se } \mathrm{R} \odot=695.990 \mathrm{~km} \text { ) }
$$

- O maior valor possível para $\mathrm{R}_{\mathrm{CM}}$ é 2,26 $\mathrm{R} \odot$, que ocorreria na situação hipotética de todos os planetas estarem com a mesma longitude heliocêntrica e, ainda, todos no afélio, isto é, com suas máximas distâncias ao Sol. Tal situação não pode acontecer pois os afélios dos planetas apresentam diferentes longitudes heliocêntricas;

- Se considerarmos, no entanto, todos os planetas com as mesmas longitudes heliocêntricas e situados em suas distâncias médias do Sol, obtemos $\mathrm{R}_{\mathrm{CM}}=2,17 \mathrm{R} \odot$;

Recentemente, o menor valor para $\mathrm{R}_{\mathrm{CM}}$ ocorreu em abril de 1990, quando o centro de massa esteve localizado a apenas $0,066 \mathrm{R} \odot$ do centro do Sol. 


\section{Apêndice 4: VELOCIDADE DE ESCAPE}

Considere um corpo de massa $\mathbf{m}$ situado na superfície de um astro (planeta ou estrela) de massa $\mathbb{M}$. O trabalho realizado pela força gravitacional quando o corpo é transferido da superfície do astro e levado ao infinito é a energia potencial gravitacional $\left(E_{\mathrm{P}}\right)$ do corpo de massa $\mathbf{m}$ e vale $E_{\mathrm{P}}=-\mathrm{G} \mathbf{M} \mathrm{m} / \mathrm{R}$

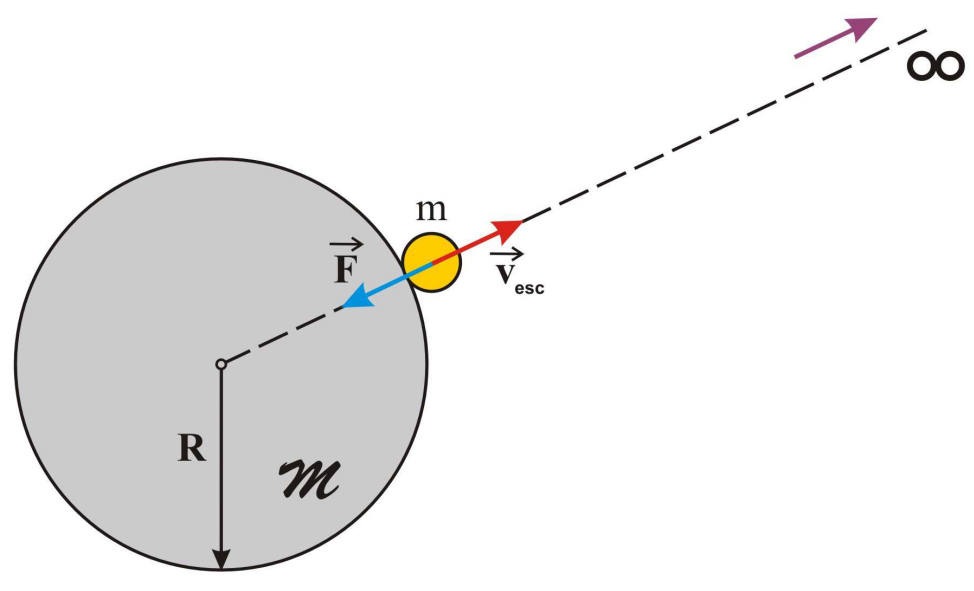

Fig. A4.1 - Velocidade de escape de um corpo.

A velocidade mínima que um corpo deve ter para ser lançado da superfície de um astro, sem ser acelerado, e não considerando a existência de atmosfera no corpo de massa $\boldsymbol{M}$, chama-se velocidade de escape $\left(\mathrm{V}_{\text {esc }}\right)$. À medida que o corpo de massa $\mathbf{m}$ vai se afastando da superfície do astro de massa $\mathbb{M}$, sua velocidade vai diminuindo (a força de atração produz uma aceleração negativa no corpo) e a sua energia potencial vai aumentando. Quando o corpo atingir o infinito, sua velocidade será nula e sua energia potencial também. Pelo teorema da conservação da energia, a energia total (ET) no lançamento deve ser igual à energia total quando o corpo chegar ao infinito. Desta forma,

$$
\mathrm{ET}_{\text {início }}=\mathrm{ET}_{\text {final }} \rightarrow-\frac{G m m}{R}+\frac{m V_{e s c}^{2}}{2}=0+0 \rightarrow V_{e s c}=\sqrt{\frac{2 G m}{R}}
$$

A velocidade de escape para o planeta Terra é de $11,2 \mathrm{~km} / \mathrm{s}$. Um foguete que partisse da superfície terrestre com essa velocidade (desconsiderando a atmosfera) não mais retornaria ao nosso planeta. 


\section{Apêndice 5:}

\section{A ESTRUTURA INTERNA DAS ESTRELAS}

Com a finalidade de dar uma ideia simplificada para os futuros professores (e para os professores de física que estão em contato pela primeira vez com a astrofísica) do procedimento para se calcular um modelo para o interior estelar, vamos apresentar as equações da estrutura estelar, utilizando para a apresentação algumas ideias acessíveis à física do ensino médio.

De início devemos lembrar que um dos problemas mais complexos da Astrofísica é a determinação da estrutura interna de uma estrela. Para o estudo das superfícies estelares dispomos de dados observacionais e o problema é relativamente menos complexo: podemos determinar a luminosidade, temperatura, composição química da atmosfera, ...

Para o estudo dos interiores estelares, não havendo meios diretos de se obter a informação ${ }^{1}$, devemos fazer algumas hipóteses. Assim, vamos considerar o seguinte problema: dada uma certa distribuição de matéria, cuja massa é igual à massa da estrela em estudo e conhecida a composição química dessa massa, quais devem ser:
a) a distribuição de massa $\mathbb{M}(r)$;
b) a pressão $\mathrm{P}(\mathrm{r})$;
c) a luminosidade $\mathrm{L}(\mathrm{r})$;
d) a temperatura $\mathrm{T}(\mathrm{r})$,

em cada ponto interno a essa distribuição, se soubermos que ela está em equilíbrio, ocupa um determinado volume e irradia uma certa quantidade de energia?

Hipóteses: Para responder a essas questões, vamos partir das seguintes suposições:

\footnotetext{
${ }^{1}$ No último capítulo veremos como a Heliosismologia contribuiu para o conhecimento do interior solar
} 
1. As leis da Física que governam o interior das estrelas são as mesmas descobertas aqui na Terra;

2. A estrela está em equilíbrio termodinâmico local, isto é, a quantidade de energia produzida em seu interior é igual à quantidade de energia irradiada pela sua superfície;

3. A estrela é estável, isto é, não está explodindo e nem entrando em colapso;

4. A estrela é esférica e não apresenta movimento de rotação;

5. O material constituinte da estrela obedece à equação dos gases perfeitos, mesmo no interior mais profundo;

Para poder estudar os interiores estelares, os astrofísicos elaboram modelos que são baseados em equações da Física. Há quatro equações importantes no estudo da estrutura estelar e na descrição de seus interiores: duas representando como a massa e pressão variam com a distância ao centro da estrela (como variam com o seu raio) e as outras duas descrevem como a luminosidade e a temperatura variam com o raio da estrela, ou com a distância ao seu centro.

Adiante apresentaremos essas equações, deduzindo algumas e apenas comentando aquelas cuja dedução requer conhecimentos mais avançados de Física e que não fazem parte do curso de Licenciatura em Física. A nossa abordagem permite ilustrar algumas dessas equações utilizando conceitos e conhecimentos acessíveis com a Física do ensino médio.

A5.1) Equação de Conservação da Massa: Considere, no interior de uma estrela, uma casca esférica de espessura $\Delta r$, situada entre duas esferas de raios respectivamente iguais a $\mathrm{r}$ e $\mathrm{r}+\Delta \mathrm{r}$. (figura A5.1). Os volumes $\mathrm{V}$ e $\mathrm{V}^{\prime}$ das esferas de raios respectivamente iguais a $\mathrm{r}$ e $\mathrm{r}+\Delta \mathrm{r}$, serão:

$$
V=\frac{4}{3} \pi r^{3} \quad e \quad V^{\prime}=\frac{4}{3} \pi(r+\Delta r)^{3}
$$




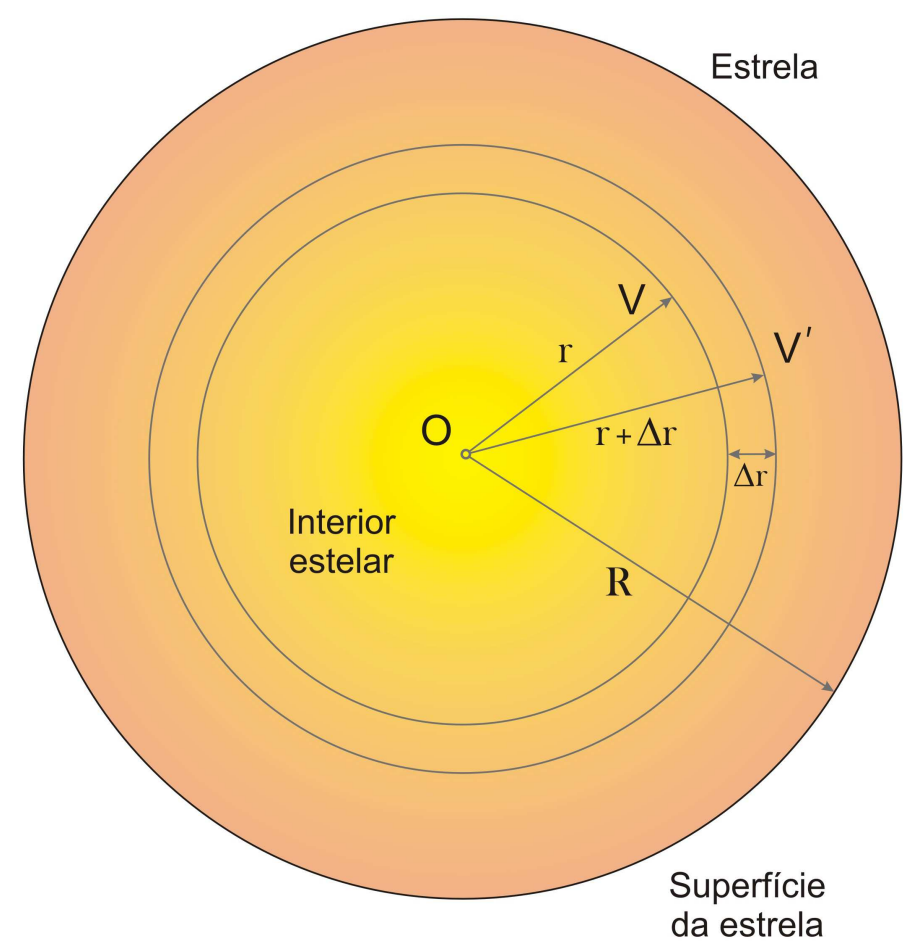

Fig. A5.1 - Casca esférica de espessura $\Delta r$, situada no interior de uma estrela esférica de raio R.

O volume da casca esférica será a diferença entre os volumes das duas esferas consideradas:

$$
\begin{gathered}
\Delta V=V^{\prime}-V=\frac{4}{3} \pi\left[(r+\Delta r)^{3}-r^{3}\right]=\frac{4}{3} \pi\left[r^{3}+3 r^{2} \Delta r+3 r \Delta r^{2}+\Delta r^{3}-r^{3}\right] \\
\Delta V=\frac{4}{3} \pi\left[3 r^{2} \Delta r+3 r \Delta r^{2}+\Delta r^{3}\right]
\end{gathered}
$$

Se escolhermos $\Delta r$ bem pequeno, podemos desprezar os termos que contém $\Delta r^{2} \mathrm{e}$ $\Delta r^{3}$ por serem muito pequenos. O volume $\Delta V$ será, então, calculado por:

$$
\Delta V=\frac{4}{3} \pi \times 3 r^{2} \times \Delta r=4 \pi r^{2} \Delta r
$$

Considerando $\mathbb{M}$ e $\mathfrak{M}$ ' respectivamente as massas nas esferas de raios $r$ e $r+\Delta r$, temos:

$$
\Delta m=m^{\prime}-m=m(r+\Delta r)-m(r)
$$


Se a espessura da camada $(\Delta r)$ for muito pequena, podemos admitir que a densidade na camada seja constante e igual à densidade na esfera de raio r. Assim, teremos:

$$
\rho(r)=\frac{\Delta \mathbb{M}}{\Delta V} \quad \rightarrow \quad \Delta \mathbb{M}=\rho(r) \times \Delta \mathrm{V}=4 \pi \mathrm{r}^{2} \Delta r \rho(r)
$$

A equação da massa pode ser escrita como: $\frac{\Delta \mathscr{M}(r)}{\Delta r}=4 \pi r^{2} \rho(r)$

ou, na forma diferencial,

$$
\frac{d \mathscr{M}(r)}{d r}=4 \pi r^{2} \rho(r)
$$

Se integrarmos a equação da massa para r variando de 0 (zero) a R (raio da estrela), teremos a massa total da estrela, ou seja, a massa total é a "soma" das massas das várias camadas:

$$
M=\int d M(r)=\int 4 \pi r^{2} \rho(r) d r \quad(\text { com r variando de } 0 \text { a } \mathrm{R})
$$

Para efetuarmos a integração precisamos conhecer como a densidade se modifica (diminui) ao longo das camadas à medida que nos dirigimos do centro para a superfície. Precisamos conhecer, portanto, a função $\rho(\mathrm{r})$.

\section{A5.2) Equação do Equilíbrio Hidrostático ou equação do gradiente de pressão:}

Vamos iniciar a apresentação dessa equação recordando um conteúdo que é ministrado no ensino médio. Consideremos um reservatório, como ilustrado na figura A5.2, contendo um líquido, por exemplo água, com altura h em relação ao fundo do recipiente. 


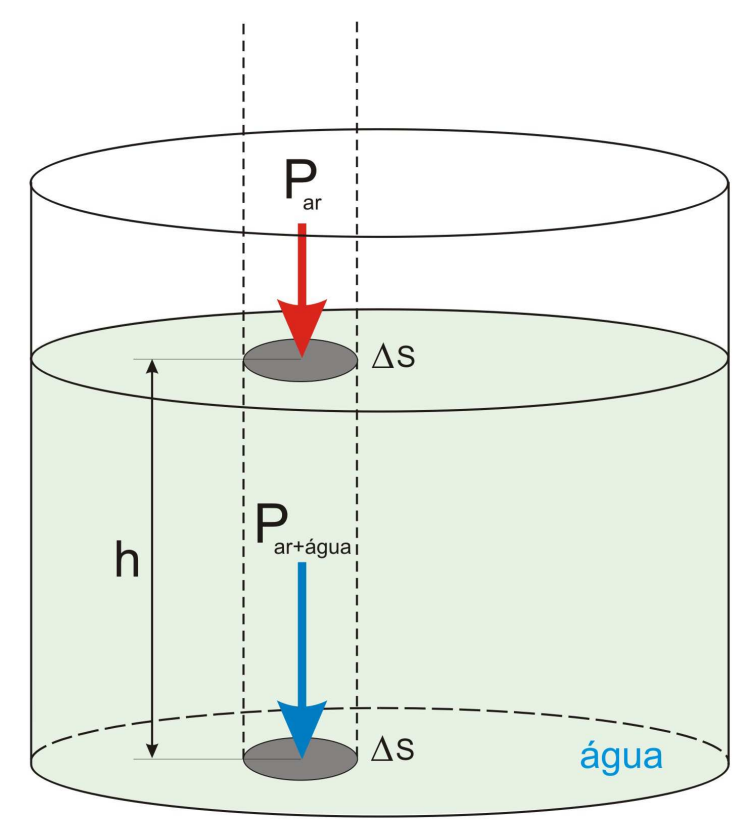

Fig. A5.2 - Diferença de pressão entre a superfície e o fundo de um recipiente contendo água.

A coluna de ar exerce uma pressão $\mathrm{P}_{\mathrm{ar}}$ sobre a área $\Delta \mathrm{S}$ localizada na superfície da água. A pressão exercida sobre a área $\Delta \mathrm{S}$ na superfície da água é a pressão atmosférica, isto é, o peso da coluna de ar que se encontra sobre ela dividido pela área $\Delta \mathrm{S}$. Já no fundo do recipiente a pressão será maior pois é o resultado do peso da coluna de ar adicionado ao peso de uma coluna de água de altura $\mathrm{h}\left(\mathrm{P}_{\text {ar+água }}\right)$, dividido pela área $\Delta \mathrm{S}$.Teremos para a pressão total $\mathrm{P}_{\text {total }}$ no fundo do recipiente:

$$
P_{\text {total }}=\frac{\text { Peso da coluna de ar }}{\Delta S}+\frac{\text { Peso da coluna de água }}{\Delta S}
$$

Considerando $\mathrm{P}_{\mathrm{ar}}$ o peso da coluna de ar, podemos escrever:

$$
P_{a r}=m_{a r} \cdot g=\rho_{\mathrm{ar}} \cdot V_{a r} \cdot g=\rho_{\mathrm{ar}} \cdot \Delta S \cdot H_{a r} \cdot g
$$

onde $\mathrm{m}_{\mathrm{ar}}$ é a massa da coluna de ar sobre a área $\Delta \mathrm{S}$ que está na superfície da água, $\mathrm{V}_{\mathrm{ar}}$ é o seu volume, $\mathrm{H}_{\mathrm{ar}}$ a sua altura, $\rho_{\mathrm{ar}}$ a densidade do ar e $\mathrm{g}$ a aceleração da gravidade.

A coluna de água, que se encontra sobre a área $\Delta \mathrm{S}$ situada no fundo do recipiente, exercerá a seguinte pressão: 


$$
P_{\text {água }}=m_{\text {água }} \cdot g=\rho_{\text {água }} \cdot V_{\text {água }} \cdot g=\rho_{\text {água }} \cdot \Delta S \cdot h_{\text {água }} \cdot g
$$

e a pressão total será:

$$
\begin{gathered}
P_{\text {total }}=\frac{\rho_{a r} \cdot \Delta S \cdot H_{a r} \cdot g}{\Delta S}+\frac{\rho_{\text {agua }} \cdot \Delta S \cdot h_{\text {agua }} \cdot g}{\Delta S} \\
P_{\text {total }}=\rho_{\text {ar }} \cdot H_{a r} \cdot g+\rho_{\text {agua }} \cdot h_{\text {agua }} \cdot g=P_{\text {atm }}+\rho_{\text {agua }} \cdot h_{\text {agua }} \cdot g \\
\Delta P=P_{\text {total }}-P_{\text {atm }}=\rho_{\text {agua }} \cdot h_{\text {agua }} \cdot g
\end{gathered}
$$

Assim,

Consideremos agora, no interior de uma estrela, uma camada (casca) de raio interno $\mathrm{r}_{1}$ e raio externo $\mathrm{r}_{2}$, conforme a fig. A5.3.

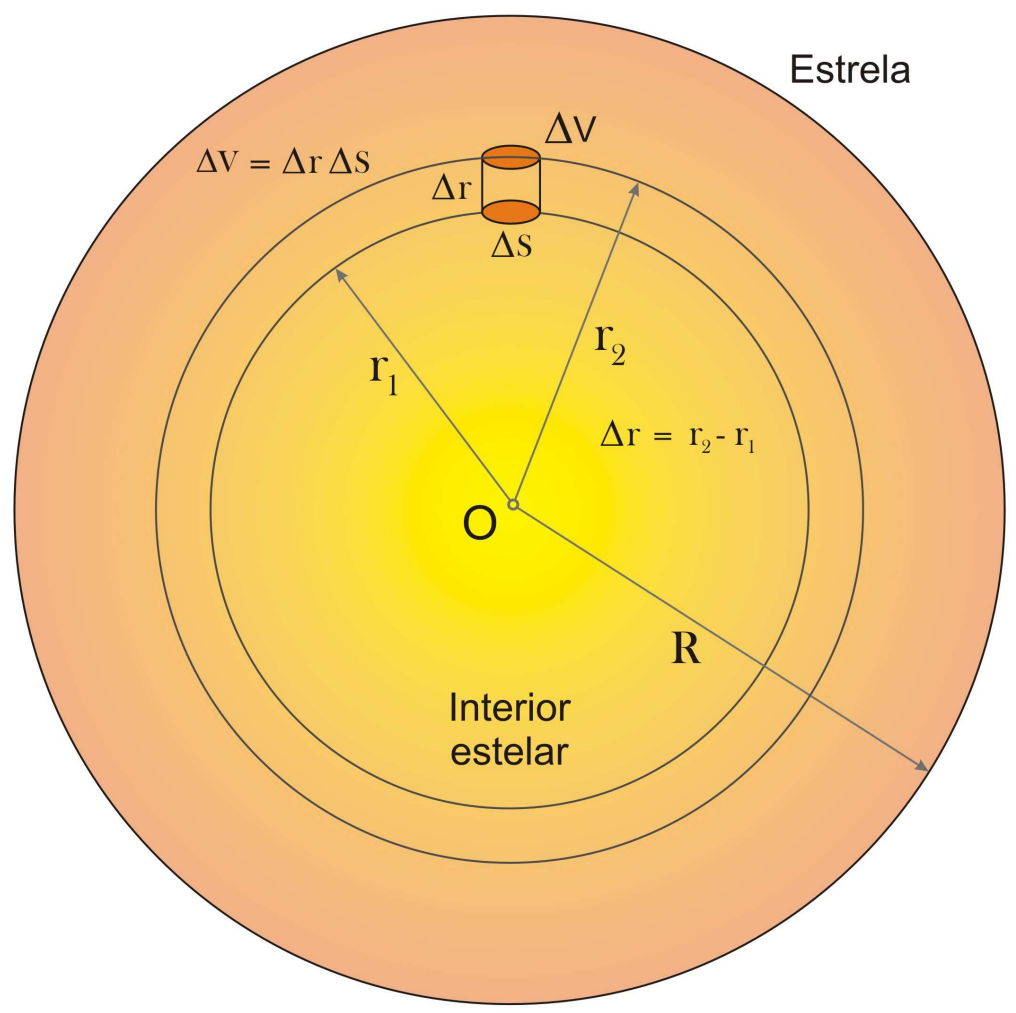

Fig. A5.3 - Gradiente de pressão no interior de uma estrela.

Vamos calcular como varia a pressão entre os limites da camada considerada. Para tanto, vamos considerar um elemento de volume com bases nas camadas. 
$\mathrm{O}$ pequeno volume tem bases com áreas $\Delta \mathrm{S}$ e altura $\Delta \mathrm{r}$. As pressões serão: $\mathrm{P}_{1}$ na base situada na camada de raio $\mathrm{r}_{1}$ (base inferior) e $\mathrm{P}_{2}$ na base localizada na camada de raio $\mathrm{r}_{2}$ (base superior).

Quando passamos da camada de raio $r_{1}$ para a camada de raio $r_{2}\left(r_{2}>r_{1}\right)$, a pressão diminui, de modo que:

$$
\Delta P=P_{2}-P_{1}=-\rho \cdot g \cdot \Delta r \quad\left(\Delta \mathrm{r}=\mathrm{r}_{2}-\mathrm{r}_{1}\right)
$$

Sendo $g=G \mathbb{M}(r) / r^{2}$, onde $\mathbb{M}(r)$ é a massa contida na esfera de raio $\underline{r}$, podemos então escrever:

$$
\frac{\Delta P}{\Delta r}=-\rho(r) \frac{G M(r)}{r^{2}}
$$

Na forma diferencial, teremos: $\quad \frac{d P}{d r}=-\rho(r) \frac{G m(r)}{r^{2}}$

A equação descreve o equilíbrio entre o gradiente de pressão e a força de gravidade, isto é, o peso das camadas externas, para cada valor da distância $\underline{r}$ ao centro da estrela. À medida que a distância ao centro da estrela aumenta, a pressão decresce.

A5.3) Equação da Conservação da Energia: Também chamada de equação da produção de energia, descreve como a quantidade de energia liberada em uma camada de raio $r$ é transferida para uma outra de raio $r+\Delta r$.

Vamos considerar no interior de uma estrela uma camada de espessura $\Delta \mathrm{r}$, compreendida entre duas esferas de raios respectivamente iguais a $r$ e $r+\Delta r$. Como já vimos anteriormente, o volume dessa camada é:

$$
\Delta V=4 \pi r^{2} \Delta r
$$


Se considerarmos $\varepsilon$ a quantidade de energia produzida por unidade de tempo e por unidade de massa, a partir da transformação de massa em energia, teremos:

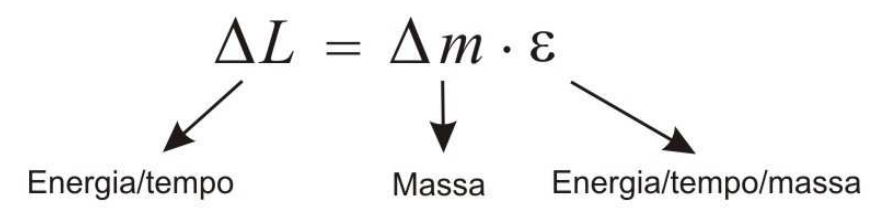

Fig. A5.4 - Produção de energia a partir da transformação de massa.

Como $\Delta m=\rho . \Delta V$, teremos:

$$
\begin{gathered}
\Delta L=\rho \cdot \Delta \mathrm{V} \cdot \varepsilon \\
\Delta L=4 \cdot \pi \cdot r^{2} \cdot \rho \cdot \Delta r \cdot \varepsilon \\
\frac{\Delta L}{\Delta r}=4 \pi r^{2} \rho \varepsilon
\end{gathered}
$$

A quantidade de energia transferida depende, portanto, da taxa de produção de energia $\varepsilon$, na camada de raio $r$. Se considerarmos agora, na notação diferencial, $d L(r)$ a quantidade de energia produzida pelas reações nucleares, na camada de raio $r$ a partir da quantidade de massa $d \boldsymbol{M}(\mathrm{r})$, teremos:

$$
d L(r)=\varepsilon(r) d m(r) \quad \rightarrow \quad \frac{d L(r)}{d \mathscr{M}(r)}=\varepsilon(r)
$$

onde $\varepsilon(r)$ é a quantidade de energia produzida por unidade de massa, na camada de raio $r$ :

Como

$$
d m(r)=4 \pi r^{2} \rho(r) d r
$$

segue-se que

$$
d L(r)=\varepsilon(r) 4 \pi r^{2} \rho(r) d r
$$

e, portanto,

$$
\frac{d L(r)}{d r}=4 \pi r^{2} \rho(r) \varepsilon(r)
$$


A5.4) Equação do Transporte Energia: Descreve como a energia é transportada das camadas interiores para as camadas mais externas. Se a energia é transportada por radiação, a relação entre o gradiente de temperatura e o fluxo de radiação será:

Como

$$
\begin{gathered}
\frac{d T(r)}{d r}=-\frac{3}{4 a c} \frac{k(r) \rho(r)}{T^{3}(r)} F_{r a d} \\
F_{r a d}=\frac{L(r)}{4 \pi r^{2}}
\end{gathered}
$$

Teremos

$$
\frac{d T(r)}{d r}=-\frac{3}{4 a c} \frac{k(r) \rho(r)}{T^{3}(r)} \frac{L(r)}{4 \pi r^{2}}
$$

$\frac{d T(r)}{d r}$ é o gradiente de temperatura, que descreve como a temperatura se altera ao longo da distância ao centro do Sol (ao longo do raio), $k(r)$ é a opacidade do material onde a energia é transportada, a é a constante de radiação, cujo valor é a $=7,564 \times 10^{-16} \mathrm{~J} \cdot \mathrm{m}^{-3} \cdot \mathrm{K}^{4}$

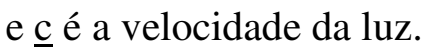

Se o gradiente de temperatura for muito grande, ocorrem processos convectivos e, então, a relação será:

$$
\frac{d T}{d r}=\frac{\gamma-1}{\gamma} \frac{T}{P} \frac{d P}{d r}
$$

onde $\gamma=c_{p} / c_{v}$ é o chamado índice adiabático. É a relação entre o calor específico à pressão constante $\left(\mathrm{c}_{\mathrm{p}}\right)$ e o calor específico a volume constante $\left(\mathrm{c}_{\mathrm{v}}\right)$, para o material que transporta a energia por convecção. Para um gás ideal altamente ionizado, $\gamma=5 / 3$.

A equação anterior se aplica quando temos um gás monoatômico e quando o processo de convecção é adiabático, isto é, quando bolhas de gás não trocam calor com a região ao seu redor. Quando o processo convectivo não é adiabático, o gradiente de 
temperatura não pode ser calculado pela equação anterior. O cálculo da estrutura interna de uma estrela torna-se, portanto, bem mais complexo.

Finalmente, quando se resolvem as equações da estrutura estelar, as seguintes condições de contorno são utilizadas para os parâmetros que tem valores no núcleo $(r=0)$ e na superfície $(r=R)$ :

a) $\mathbb{M}(r=0)=0$, ou seja, não há massa no centro solar; condição necessária para termos valores finitos de densidade;

b) $\mathbb{M}(\mathrm{r}=\mathrm{R})=\mathbb{M}$, a massa total da estrela;

c) $\mathrm{P}(\mathrm{r}=\mathrm{R})=0$, isto é, a pressão na superfície da estrela é nula, e

d) $\mathrm{T}(\mathrm{r}=\mathrm{R})=\mathrm{T}_{\text {eff }}$, isto é, a temperatura na superfície da estrela é a sua temperatura efetiva.

Uma última quantidade deve se juntar às equações anteriores: a composição química da estrela. Em geral, representa-se por $\mathrm{X}, \mathrm{Y}$ e $\mathrm{Z}$ as frações em massa iniciais, respectivamente, para o hidrogênio, para o hélio e para os elementos mais pesados. De início pode-se assumir uma composição mais homogênea e construir modelos. No caso do Sol escolhe-se como modelo adequado aquele em que, para a idade calculada do Sol, se ajusta melhor à sua luminosidade. 


\section{BIBLIOGRAFIA}

- ABOTT, C. G., The Sun. New York and London: D. Appleton and Company, 1929, $433 \mathrm{p}$.

- ABETTI, G., El Sol. Buenos Aires: Editora Universitária de Buenos Aires (EUDEBA), 1962, 316p.

- ANTIA, H. M., BHATNAGAR, A., ULMSCHNEIDER, P. (eds.). Lectures on Solar Physics. Berlim: Springer-Verlag, 2003, 290p.

- AROCA, S. C., Ensino de Física Solar em um Espaço não Formal de Educação. Tese de Doutoramento. Instituto de Física de São Carlos. Universidade de São Paulo. São Carlos, 2008. 173p.

- ASHBROOK, Joseph, Richard Carrington and a "singular appearance" on the Sun. in The Astronomical Scrapbook, Cambridge, Massachusetts: Sky Publishing Corporation, pp. 340-344, 1984.

- BARLOW, C.W.C., BRYAN, G.H., Elementary Mathematical Astronomy. University Tutorial Press. $2^{\mathrm{a}}$ ed., London, 1900, 442p.

- BHATNAGAR, A., LIVINGStONE, W., Fundamentals of Solar Astronomy. World Scientific Series in Astronomy and Astrophysics. World Scientific Publishing Co., Cingapura, 2005.

- CARRIngton, R. C., Description of a Singular Appearance seen in the Sun on September 1, 1859. London: Monthly Notices of the Royal Astronomical Society. 20: 13, 1859.

- CHAPMAN, D. M. F., The Sun in Observer's Handbook 2014. Toronto: The Royal Astronomical Society of Canada, 2013, 352p.

- CHEN, C. Julian., Physics of Solar Energy. John Wiley \& Sons, Inc., Hoboken, New Jersey, 2011, 311p.

- CHRISTEnSEN-DAlSGAARD, J., Helioseismology. Rev. Mod. Phys. 74, 1073 (2002).

- EMILIO, M., Variações do Limbo Solar. São Paulo: Tese de Doutoramento. Instituto Astronômico e Geofísico. Universidade de São Paulo. 2001. 112p. 
- EMILIO, M., Estudo das Variações do Semi Diâmetro Solar. São Paulo: Dissertação de Mestrado. Instituto Astronômico e Geofísico. Universidade de São Paulo. 1997. 88p.

- $\quad$ EMILIO, M., KUHN, J. R., BUSH, R. I., and SCHOLL, I. F., Measuring the Solar Radius from Space During the 2003 and 2006 Mercury Transits. The Astrophysical Journal, 750: 135.

- GAMOW, G., Nascimento e Morte do Sol. Coleção Catavento, Editora Globo, 1961, 208p.

- GAMOW, G., Uma Estrella Llamada Sol. Madrid: Espasa-Calpe, 1967, 261p.

- GOLUB, L., PASACHOFF, J. M., Nearest star: the surprising science of our sun. Csmbridge, Massachusetts: Harvard University Press., 2001, 267p.

- HEATH, T., Aristarchus of Samos, The Ancient Copernicus. Oxford: Oxford At The Clarendon Press., 1913, 425p.

- HODGSON, R., On a curious Appearance seen in the Sun. London: Monthly Notices of the Royal Astronomical Society. 20: 15, 1859.

- HORVATH, J. E., Fundamentos da Evolução Estelar, Supernovas e Objetos Compactos. São Paulo: Editora Livraria da Física, 2011.

- JENKINS, J. L., The Sun and How to Observe It. New York: Springer Science+Business Media, 2009, 213p.

- JOSE, P. D., Sun's Motion and Sunspots. Chicago: The Astronomical Journal, vol.70, nº1, 1965, American Astronomical Society, pp 193-200.

- KITCHIN, C., Solar Observing Techniques. Patrick Moore's Practical Astronomy Series. New York: Springer, 218p.

- $\quad$ LANG, K. R., Sun, Earth and Sky. Berlin: Springer-Verlag, 1995, 282p.

- LANGLEY, S. P., The Bolometer. New York: American Metrological Society, $1881,18 \mathrm{p}$

- LEISTER, N. V., M. EMILIO, P. BENEVIDES-SOARES, Measuring the Solar Diameter. In Astrometry in Latin America. ADeLA Publications Series $\mathrm{n}^{0} 1$. Universidade de São Paulo. 2002, 233p.

- LeISTER, N. V., Conceitos Básicos. Notas de aula do Curso MPA 5001 (Conceitos Básicos no Ensino de Astronomia); MPEA-IAG-USP, São Paulo, 2013; 
- LEISTER, N. V., Curso de Extensão Universitária. Apostila. IAG-USP, São Paulo, 2011;

- LEISter, N. V., Determinação do Diâmetro Solar com o Astrolábio Danjon. Comunicação Pessoal, São Paulo, 2017;

- MASIEVICH, A. Estructura Del Sol. Moscou: Ediciones en Lengua Extranjeras, sd. 122p.

- MENZEL, D. H., Our Sun. The Harvard Books on Astronomy. PhiladelphiaToronto: The Blakiston Company, 1949, 326p.

- MOCHÉ, D.L., Astronomy: A Self-Teaching Guide. John Wiley \& Sons, Inc., Hoboken, New Jersey, $7^{\text {th }}$ ed., 2009, 372p.

- NELSON, O. R., Uma abordagem didática da natureza dos processos de aquecimento da atmosfera estelar. São Paulo: Revista Brasileira de Ensino de Física, v. 35, n. 3, 3317, 2013.

- NOGUEIRA, S., Ao sabor dos neutrinos. Pesquisa Fapesp, n 176, outubro de 2010, p.50-51.

- OliVEIRA, K., SARAIVA, M. F., Astronomia e Astrofísica. São Paulo: Editora Livraria da Física. $3^{\text {a }}$ ed. 2014, 780p.

- PALEN, S. E., Theory and Problems of Astronomy. Schaum's Outline Series, McGRAW-HILL, 2002, 234p.

- PICAZZIO, E., Sol: Uma estrela típica da Seqüência Principal. Apostila para a disciplina AGA 210 - Introdução à Astronomia. IAG-USP, São Paulo, s/d.

- RAPONI, A., The Measurement of Solar Diameter and Limb Darkening Function With the Eclipse Observations. Master Thesis, Università di Roma, Roma, 2011, atualizada em 2013, 69p.

- REIS NETO, E., Observações solares: Estudo das variações do diâmetro e suas correlações. Rio de Janeiro: Tese de Mestrado. Observatório Nacional. 2002. 93p.

- REIS NETO, E., O Desenvolvimento do Heliômetro do Observatório Nacional e aplicação ao estudo do Sistema Sol-Terra. Rio de Janeiro: Tese de Doutoramento. Observatório Nacional. 2009. 240p.

- ROCAS-CORTÉS, T., Las Oscilaciones Solares. Madrid: Investigación y Ciencia, $n^{\circ} 68$, mayo 1982, pp. 6-15; 
- ROZELOT, J. P., Alexander G. Kosovichev, Ali Kilcik, A Brief History of the Solar Diameter Measurements: a critical quality assessment of the existing data. https://arxiv.org/ftp/arxiv/papers/1609/1609.02710.pdf

- ROZELOT, J.P., Damiani C., Rights and wrongs of the temporal solar radius variability. European Physical Journal H., 2012, Volume 37, pp 709-743.

- SCHÖNBERG, M., CHANDRASEKHAR, S., On the Evolution of the MainSequence Stars. Ap.J. 96, 2. pp161-172, September, 1942

- SILVA, A.V. R., Nossa Estrela: o Sol. São Paulo: Editora Livraria da Física, $1^{\mathrm{a}}$ ed. 2006, 166p.

- SONETT, C. P., GIAMPAPA, M. S., MATTHEWS, M.S. (eds), The Sun in Time. Tucson: The University of Arizona.1991.990p.

- Struve, O., ZEBERGS, V., Astronomy of the $20^{\text {th }}$ Century. New York: MacMillan, 1962. 544p.

- TEIXEIRA, R, N.V. LEISTER, V.A.F. MARTIN, P. BENEVIDES-SOARES (eds), Astrometry in Latin America. ADeLA Publications Series $n^{\circ} 1$. Universidade de São Paulo. 2002, 233p.

- VAldivieSso, G.A. e GUZZO, M.M, Compreendendo a Oscilação dos Neutrinos. São Paulo: Revista Brasileira de Ensino de Física, v.27, nº, p.507-515, 2005.

- VAQUERO, J. M., The Sun Recorded Through History. New York: Springer Science+Business Media, 2009, 307p.

- VARElla, I. G., A Observação do Sol. São Paulo: Boletim do Centro de Estudos Astronômicos de São Paulo, no 12, 1973.

- VARElla, I. G., Determinação de Distâncias em Astronomia. São Paulo: Monografia de Especialização em Astronomia. Núcleo de Astrofísica Teórica. Universidade Cruzeiro do Sul, 2010, 105p.

- VITA-FINZI, C., The Sun: A User's Manual. Springer Science+Business Media, 2008, 163p.

- ZAPPALÁ, R.A. e ZUCCARELlO, F., Angular Velocity of Sunspot-Groups and Solar Photospheric Rotation. Astronomy and Astrophysics, 242, 480-487,1991. 


\section{WEBGRAFIA}

IAU:

Sun - Página Principal

http://astroedu.iau.org/collections/sun/

1. Build a Safe Sun Viewer

http://astroedu.iau.org/activities/safe-sun-viewer/

2. Meet Our Neighbours: Sun

http://astroedu.iau.org/activities/meet-our-neighbours-sun/

3. Measure the Solar Diameter

http://astroedu.iau.org/activities/measure-the-solar-diameter/

4. Counting Sunspots

http://astroedu.iau.org/activities/counting-sunspots/

SOLAR FILTER SAFETY - Sky and telescope

http://www.skyandtelescope.com/observing/celestial-objects-to-watch/solar-filter-safety/

Consultada em 30.11.2015

HOW TO SAFELY ENJOY THE OCTOBER 23 PARTIAL SOLAR ECLIPSE

http://www.universetoday.com/115200/how-to-safely-enjoy-the-october-23-partial-solareclipse/

MECÂNICA

http://efisica.if.usp.br/mecanica/ensinomedio/energia/experimento/

CIÊNCIAS NO SÉCULO XXI

https://cienciasnoseculoxxi.wordpress.com/tag/lentes-convergentes/

ASTRONOMY MAGAZINE

http://cs.astronomy.com/asy/b/astronomy/archive/2014/08/08/25-tips-for-the-august-21-

2017-total-solar-eclipse.aspx 
SOLAR OBSERVING - Peter Meadows

http://www.petermeadows.com/indexsolar.html

Consultada várias vezes. Última consulta em 30.11.2015

FOTO DE HANS A. BETHE

http://kids.britannica.com/comptons/art-59239/Hans-Albrecht-Bethe?

Consultada em 10.01.2017

HELIÓMETRO DE PARALAJE - S. Paolantonio

https://historiadelaastronomia.wordpress.com/2014/12/18/heliometro-de-paralaje/ Consultado 26 de novembro de 2016

NASA - MARSHALL SPACE FLIGHT CENTER - Solar Physics

https://solarscience.msfc.nasa.gov/whysolar.shtml (consultada em 01.09.2017)

https://solarscience.msfc.nasa.gov/SolarWind.shtml (consultada em 09.09.2017) 